\title{
Explotación de las TICs en la gestión del ruido, y su influencia sobre la percepción ciudadana del ruido
}

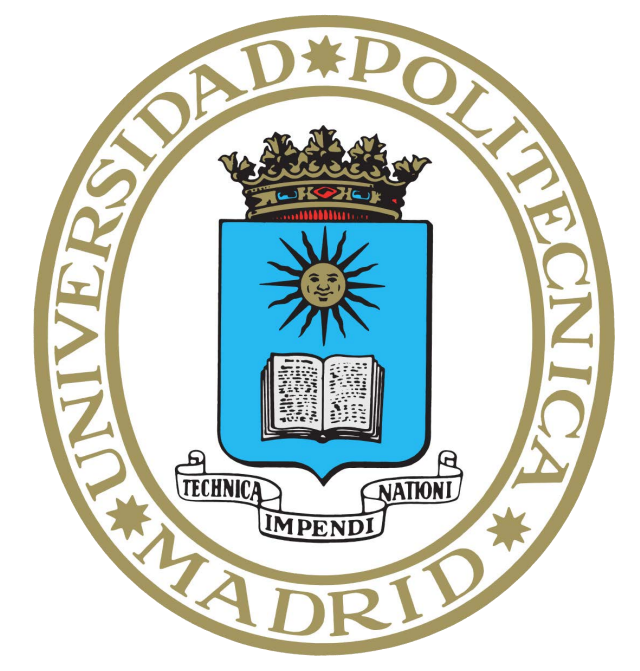

\section{TESIS DOCTORAL}

\section{Luis Gascó Sánchez}

Departamento de Ingeniería Mecánica

Escuela Técnica Superior de Ingenieros Industriales

Universidad Politécnica de Madrid 
Documento maquetado con $\mathrm{T}_{\mathrm{E}} \mathrm{XIS}$ v.1.0+.

Este documento está preparado para ser imprimido a doble cara. 


\title{
Explotación de las TICs en la gestión del ruido, y su influencia sobre la percepción ciudadana del ruido
}

\author{
Memoria que presenta para optar al titulo de Doctor \\ Luis Gascó Sánchez
}

Dirigida por los Doctores

César Asensio Rivera

Guillermo de Arcas Castro

Departamento de Ingeniería Mecánica

Escuela Técnica Superior de Ingenieros Industriales

Universidad Politécnica de Madrid 



\section{TRIBUNAL}

Tribunal nombrado por el Mafgco. y Excmo. Sr. Rector de la Universidad Politécnica de Madrid, el día

Presidente: Dr.

Vocales: Dr.

Dr.

Dr.

Secretario: Dr.

Suplentes: Dr.

Dr.

Realizado el acto de lectura y defensa de la Tesis Doctoral el de de En la Escuela Técnica Superior de Ingenieros Industriales de la Universidad Politécnica de Madrid.

Calificación:

EL PRESIDENTE LOS VOCALES

EL SECRETARIO 

A mi madre, por haber luchado y haber salido $y$ a mi padre y hermanas. 



\section{Agradecimientos}

Nunca pensé al comienzo de mi formación universitaria en el año 2009, que diez años más tarde estaría tan cerca de obtener el último grado académico conferido por una universidad. Sin duda alguna César Asensio, mi director de TFG, TFM y Tesis doctoral, es el causante de esto y el mayor responsable de mi evolución personal y profesional. Gracias por darme la oportunidad de comenzar mi andadura en la investigación, por haberme formado y por haberme aconsejado en cada una de las etapas que he ido superando durante este periodo.

Gracias a Guillermo de Arcas, por haber entendido mis inquietudes personales y profesionales, por posibilitarme llevarlas a cabo en un excelente entorno de trabajo y ayudarme en la consecución de mis objetivos de futuro.

Gracias a los supervisores de mis estancias de investigación. A la profesora Chloé Clavel, por haberme acogido en Télécom ParisTech; y a Daniele Quercia, Luca Aiello y Rossano Schifanella, por darme la oportunidad de realizar mi segunda estancia de investigación en un entorno tan excepcional como son los Nokia Bell Labs de Cambridge.

Una mención especial a Pablo, por todos estos años compartiendo inquietudes relacionadas con nuestras tesis doctorales. Has sido un apoyo constante desde que comenzó nuestra amistad en el instituto, y especialmente en mis años de doctorando, ayudándome y dándome opiniones sinceras tanto a nivel personal como profesional. Gracias.

A Berta, por haberme escuchado sin tregua desde el comienzo de mi doctorado y haberme ayudado de forma continuada con los aspectos de forma de esta tesis doctoral. Lo hemos conseguido.

A Julio, que incluso antes de comenzar su doctorado ya aportaba su visión crítica en mi trabajo. Eres el siguiente.

Una mención especial a mis amigos del EIT Digital Doctoral School: Juan Manuel, Ahmad, Paolo, Raúl, Iñigo, Roberto, Carmen, Joaquín y a las dos Susanas. Nos hemos apoyado mutuamente, hemos establecido sinergias y hemos creado un vínculo que difícilmente se romperá en el futuro. Gracias.

A todos mis compañeros del Grupo de Instrumentación y Acústica Aplicada, Labenac y Lacainac. Gracias por crear un ambiente de trabajo distendido y ayudarme a relativizar los problemas del día a día. Mención especial a Nacho, por ayudarme con todos los trámites administrativos durante estos años, por aportar ideas a mi investigación y por enseñarme a valorar mi investigación de forma adecuada.

A todos mis amigos de Guadalajara, a los de siempre y a los nuevos, porque sin su ayuda para desconectar durante los fines de semana no hubiera sido posible finalizar este trabajo.

A mis amigos de Paris, por haberme hecho sentir como en casa durante mi estancia en la ciudad. Especialmente gracias a Chloe y Alejandro, por escucharme en uno de los momentos más complicados que he vivido, cuando no tenía a nadie más para atenderme.

A la gente de Cambridge: Jose, Alessandro, Alexander, Katrin, Marios, Matheus, Mélanie, Milan, Sanja y Yongsoung, amigos internacionales y excelentes profesionales. Especialmente gracias a Amanda, por ayudarme a valorar mis logros y por aportar tu visión 
crítica para mejorar mi trabajo.

Y desde luego gracias a toda mi familia, que siempre muestran un apoyo incondicional a las decisiones que tomo, aunque sean arriesgadas. Especialmente a mi madre que pasó por una grave enfermedad durante estos años como doctorando y pudo salir de ella. Gracias papá, Adriana y Arri por haber comprendido las dificultades de esta etapa de mi vida, y no juzgarme por haber estado ausente en momentos importantes por tener que trabajar. 


\section{Resumen}

La Organización Mundial de la Salud identifica la contaminación acústica como la segunda causa medioambiental que más afecta a la salud de la población urbana tras la contaminación atmosférica. La exposición a altos niveles de ruido puede propiciar la aparición de enfermedades en el sistema nervioso y circulatorio, además de generar molestias a la población, siendo esta la respuesta más inmediata de la ciudadanía.

La molestia hacia el ruido tiene un marcado carácter subjetivo, ya que además de depender de factores objetivos, como la intensidad del sonido, está relacionada con otros agentes de naturaleza no acústica que dependen de la percepción individual de cada persona. Por este motivo es esencial considerar la participación ciudadana en las acciones de mitigación del ruido, puesto que esto permite identificar a los gestores urbanos los orígenes de ruido más molestos para la población y priorizar las acciones hacia estos, aumentando la eficacia y el impacto de las actuaciones.

Por otra parte, la evolución de las TICs (Tecnologías de la Información y las Comunicaciones) ha favorecido un cambio en los modelos de gestión urbana en los que, con la llegada de Internet, se ha transformado el paradigma de la gestión tradicional hacia sistemas más completos que contemplan la participación ciudadana. Esta evolución tecnológica ha fomentado la transparencia institucional, lo que ha propiciado que el ciudadano tenga más información sobre la situación municipal y medioambiental en su región de residencia que en cualquier otro momento de la historia.

Además, con la llegada de la Era de la Información y del Internet social, la ciudadanía ha modificado sus hábitos de comunicación y puede expresar su opinión en plataformas sociales, en las que establece vínculos con otros usuarios y opina de forma activa sobre diversos temas incluyendo cuestiones medioambientales. Esta opinión, a pesar de no estar expresada en los medios oficiales, puede proporcionar información de interés a los gestores urbanos sobre las acciones a llevar a cabo para mejorar la calidad de vida de la ciudadanía.

En esta tesis doctoral se pretende incorporar las TICs a los modelos tradicionales de gestión de la contaminación acústica en ciudades. Se quiere incorporar la opinión ciudadana a la gestión de este contaminante mediante el uso de tecnologías web, además de medir el efecto que la transparencia y la comunicación de información sobre contaminación acústica tienen sobre la molestia de la población.

Adicionalmente, con el fin de desarrollar sistemas de gestión inclusiva en los que se tenga en cuenta la opinión de un alto porcentaje de población residente en una ciudad, se adaptarán las técnicas de inteligencia artificial y de procesado de lenguaje natural a la problemática de la contaminación acústica. Esto permitirá extraer, clasificar y analizar de forma automatizada la opinión que la ciudadanía expresa en medios sociales online en relación a actividades ruidosas en ciudades.

Asimismo, se pretende explorar el uso de otro tipo de datos provenientes de medios sociales, como el contenido multimedia, para estimar la presencia de fuentes sonoras específicas en una ciudad. Esa información se utilizará, junto a otros datos de carácter público, para mejorar el conocimiento de los efectos del ruido urbano en la población de una ciudad. Los gestores podrán identificar las áreas de la ciudad en las que el ruido afecta más a la 
salud de los residentes y llevar a cabo acciones de gestión sonora en las áreas en las que la contaminación acústica perjudica a más porcentaje de población.

PALABRAS CLAVE: Ruido en ciudades, análisis de texto, aprendizaje automático, ciencia de datos, ciudad, computación social, contaminación acústico, efectos del ruido, factores no acústicos, internet, medios sociales, molestia, procesado de lenguaje natural, redes sociales, respuesta comunitaria, ruido ambiental, twitter, datos abiertos. 


\section{Abstract}

The World Health Organization identifies noise pollution as the second leading environmental factor affecting the health of the urban population after air pollution. Exposure to high noise levels can lead to the appearance of diseases in the circulatory and nervous system, in addition to causing annoyance to the population, which is the most immediate reaction among citizens.

Noise annoyance has a strong subjective nature since besides depending on objective features, such as sound intensity, it is also related to other non-acoustic factors that depend on the distinct perception of each person. For this reason, it is essential to consider citizen participation in noise mitigation actions, as this allows city managers to identify the most annoying noise sources for the population and prioritize actions towards them, increasing the effectiveness and the impact of the interventions.

On the other hand, the evolution of ICTs (Information and Communication Technologies) has led to a change in urban management models in which, with the rise of the Internet, the paradigm of traditional management has shifted into complex systems that consider citizen participation. This technological evolution has fostered institutional transparency, which has given citizens more information about the municipal and environmental situation in their region of residence than at any other time in history.

Furthermore, with the arrival of the Information Age and the social internet, citizens have modified their communication habits and can express their opinions on social platforms. Here, they establish links with other users and actively comment on different topics, which include environmental issues. This opinion, despite not being expressed in any official media, can provide useful information for urban managers to improve their actions.

This doctoral thesis aims to incorporate ICTs into traditional noise pollution management models in cities. Public opinion is intended to be taken into account in the management of this pollutant through the use of web technologies. Moreover, the effect that transparency and communication of noise pollution has on the annoyance of the population will be measured.

To develop inclusive management systems that consider the opinions of a high percentage of the population living in a city, artificial intelligence and natural language processing techniques will be adapted to the problem of noise pollution. This will allow for extracting, classifying, and analyzing in an automated way the opinion that citizens express on social media in relation to noisy activities in cities.

It also aims to explore the use of other types of data from social media, such as multimedia content, to estimate the presence of specific sound sources in a city. This information will be used, together with other public data, to improve knowledge of the effects of urban noise on the population of a city. Managers will be able to identify the areas of the city where noise most affects residents'health to carry out sound management actions in areas where noise pollution harms a greater percentage of the population. 
KEYWORDS: Urban noise, text analytics, machine learning, data science, city, social computing, noise pollution, noise effects, natural language processing, online social networks, community response, environmental noise, twitter, open data. 


\section{Índice}

\begin{tabular}{|l|l}
\hline Agradecimientos & IX
\end{tabular}

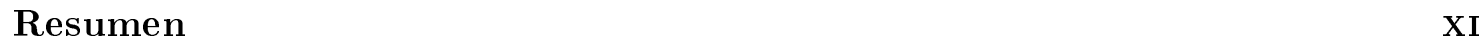

\begin{tabular}{lll}
\hline Abstract & XIII \\
\hline
\end{tabular}

1. Introducción 1

1.1. La contaminación acústica, las ciudades y las infraestructuras del transporte 1

1.1.1. La contaminación acústica: un problema de salud pública . . . . . 1

1.1.2. La evolución de las ciudades, las infraestructuras del transporte y el

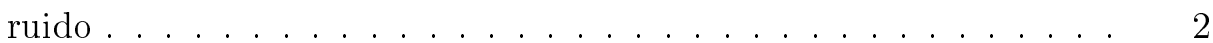

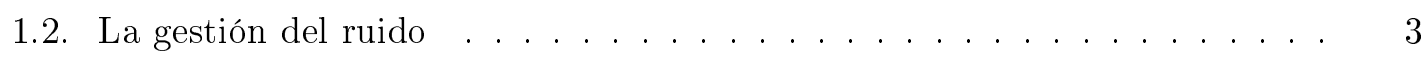

1.2.1. La gestión del ruido tradicional . . . . . . . . . . . . . . 3

1.2.2. El papel de la tecnología en la gestión del ruido . . . . . . . . . . . 4

1.3. La percepción del ruido y la aceptación de actividades ruidosas . . . . . . 7

1.3.1. Molestias por ruido: Factores acústicos y no acústicos . . . . . . . 8

1.3.2. Acciones de participación comunitaria y su efecto en la aceptación

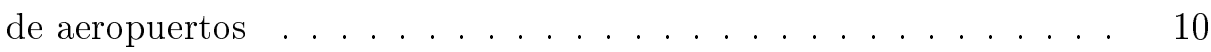

1.4. La comunicación de la información acústica . . . . . . . . . . . . . . . 13

1.4.1. Métricas para la medida de la contaminación acústica . . . . . . . 13

1.4.2. Comunicación de la información de ruido . . . . . . . . . . . 17

1.5. Retos, oportunidades y justificación de la investigación . . . . . . . . . . . 29

1.6. Hipótesis y objetivos de la investigación . . . . . . . . . . . . . . . 31

1.7. Estructura del documento . . . . . . . . . . . . . . . . . . . 32

2. Efecto de la comunicación en la percepción del ruido de ocio 33

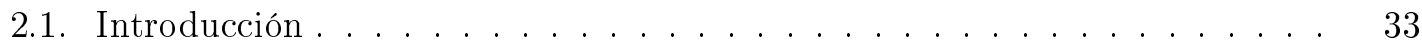

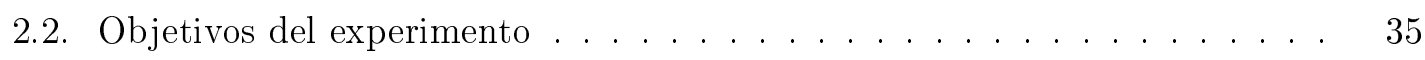

2.3. Málaga y el problema del ruido de ocio . . . . . . . . . . . . . . . . . . . . . . . . . . . 35

2.4. El proyecto ETIC-GIRU . . . . . . . . . . . . . . . . . . 36

2.5. Metodología . . . . . . . . . . . . . . . . . 37

2.5.1. Primera fase. . . . . . . . . . . . . . . . . 37

2.5.2. Segunda fase . . . . . . . . . . . . . . . 43

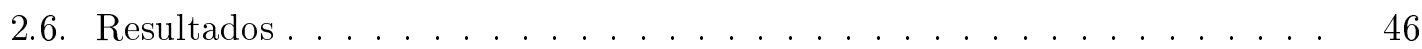

2.6.1. Difusión pública . . . . . . . . . . . . . . . . 46

2.6.2. Participación en las encuestas . . . . . . . . . . . . . . . 47

2.6.3. Resultados de las encuestas . . . . . . . . . . . . . . 47

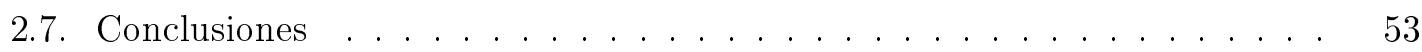


3. Detección de la opinión ciudadana sobre actividades ruidosas presente $\begin{array}{ll}\text { en medios sociales online } & 55\end{array}$

3.1. Introducción. . . . . . . . . . . . . . . . . . . . . . . 55

3.2. Hipótesis y objetivos . . . . . . . . . . . . . . . . . . . 57

3.3. Metodología . . . . . . . . . . . . . . . . . . . . 57

3.3.1. Obtención de los datos . . . . . . . . . . . . . . . . . 58

3.3.2. Preparación de los datos . . . . . . . . . . . . . . . . 60

3.3.3. Detección de quejas sobre ruido . . . . . . . . . . . . . . . . . . . . 64

3.3.4. Detección de la fuente sonora . . . . . . . . . . . . . . . . 66

3.4. Evaluación de la metodología . . . . . . . . . . . . . . . . . . . . . . . . 68

3.4.1. Evaluación del modelo de detección de quejas sobre ruido . . . . . 69

3.4.2. Evaluación del modelo de detección de fuentes sonoras . . . . . . . 70

3.5. Caso de estudio: Sistema de detección de eventos sonoros. . . . . . . . . . 71

3.6. Conclusiones ......................... 75

\begin{tabular}{|lllll}
\hline 4. Uso de datos públicos para estudiar los efectos del ruido en la salud & 77
\end{tabular}

4.1. Introducción. . . . . . . . . . . . . . . . . . . 77

4.2. Objetivos del experimento . . . . . . . . . . . . . . . . . . . . 78

4.3. Datos .......................... . . 79

4.4. Metodología . . . . . . . . . . . . . . . . . . . . 81

4.4.1. Tasa de prevalencia de hipertensión. . . . . . . . . . . . . . . . . . 81

4.4.2. Exposición al ruido . . . . . . . . . . . . . . . . . . . 82

4.4.3. Presencia de fuentes sonoras . . . . . . . . . . . . . . . . 84

4.4.4. Análisis ....................... 86

4.5. Resultados . . . . . . . . . . . . . . . . . . . . . . 88

4.5.1. Subareas de clase baja . . . . . . . . . . . . . . . 88

4.5.2. Subareas de clase media . . . . . . . . . . . . . . . 90

4.5.3. Subareas de clase alta . . . . . . . . . . . . . . . . 92

4.6. Conclusiones ......................... . . 94

4.6.1. Limitaciones del experimento . . . . . . . . . . . . . . 95

\begin{tabular}{|rr}
\hline 5. Conclusiones y aportaciones & 97
\end{tabular}

5.1. Conclusiones ......................... 98

5.2. Aportaciones ....................... 101

5.3. Publicaciones . . . . . . . . . . . . . . . . . . . . 103

5.3.1. Artículos científicos publicados . . . . . . . . . . . 103

5.3.2. Artículos en congresos . . . . . . . . . . . . . . . . . . 103

5.3.3. Divulgación científica, posters y participación en sesiones técnicas. 103

5.4. Líneas futuras de investigación . . . . . . . . . . . . . . . . . . . . . . 104

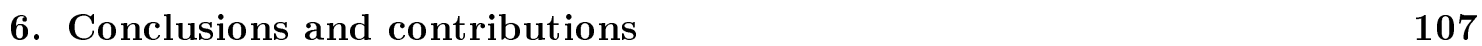

6.1. Conclusions ........................ . 108

6.2. Contributions .......................... 111

6.3. Publications . . . . . . . . . . . . . . . . . . . . . 112

6.3.1. Papers in scientific journals . . . . . . . . . . . . . . 112

6.3.2. Papers in conferences. . . . . . . . . . . . . . . . . . 112

6.3.3. Scientific dissemination, posters and participation in technical sessions 13

6.4. Future research ........................ 113 
\begin{tabular}{ll}
\hline Bibliografía & 117
\end{tabular}

\begin{tabular}{ll}
\hline Lista de acrónimos & 138
\end{tabular}

\begin{tabular}{ll}
\hline A. Encuesta inicial & 143
\end{tabular}

\begin{tabular}{ll}
\hline B. Invitación a la encuesta & 155
\end{tabular}

\begin{tabular}{lr}
\hline C. Encuesta final & 157
\end{tabular}

D. Descriptivos de las encuestas $\quad 173$ 



\section{Índice de figuras}

1.1. Evolución del número de pasajeros en transporte aéreo y ferroviario en Europa, y evolución del número del número total de autovías . . . . . . . 3

1.2. Esquema del modelo de Policy Making 3.0 . . . . . . . . . . . . . 5

\begin{tabular}{llll}
\hline 1.3. & Ejemplo de uso de nuevas tecnologías en la elaboración de mapas de ruido & 7
\end{tabular}

1.4. Adaptación del Policy Making 3.0 para la contaminación acústica . . . . . 8

1.5. Esquema de la rueda de la participación (Wheel of participation) . . . . . 11

1.6. Representación gráfica del índice Harmonica . . . . . . . . . . . . . . . . . . . . . 17

1.7. Métodos de visualización de los mapas de ruido . . . . . . . . . . . . . . . 18

1.8. Diagrama esquemático sobre la visualización de los sistemas NOMS. . . . 21

1.9. Captura de la aplicación Site Rumeur 2.0. desarrollada por Bruitparif . . 22

1.10. Capturas de las aplicaciones de visualización de datos de ruido en ciudades 23

1.11. Diagrama usado para representar el uso de pistas de aeropuertos . . . . . 23

1.12. Visualizaciones utilizadas para mostrar la dispersión de sobrevuelos en un

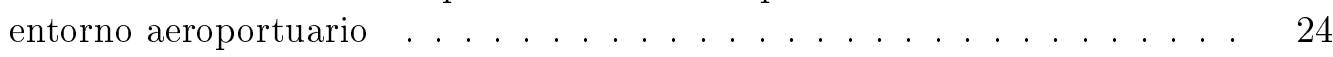

1.13. Tipos de representación de quejas de ruido de aviones cartográficamente . 25

1.14. Gráficos de barras utilizados en informes sobre ruido aeroportuario . . . . 27

2.1. Interfaz gráfica de la aplicación de visualización de datos de ruido . . . . . 37

2.2. Captura del cuestionario online implementado . . . . . . . . . . . . . . 39

2.3. Delimitación de las calles consideradas en el estudio. . . . . . . . . . . . . 41

2.4. Diagrama lógico de la encuesta POST . . . . . . . . . . . . . . . . . . . . . . . . 44

2.5. Página de inicio de la web del proyecto. . . . . . . . . . . . . . 45

2.6. Estadísticas de acceso a la web del proyecto . . . . . . . . . . . . . . 46

3.1. Metodología de análisis de RSO (Redes Sociales Online , Online Social Networks) para la detección y clasificación de quejas sobre ruido.

3.2. Captura de la aplicación web desarrollada para el etiquetado de textos cortos. 62

3.3. Flujo de pre-procesado de texto aplicado a los tweets. . . . . . . . . 63

3.4. Taxonomía de ruido desarrollada en el proyecto Chatty maps . . . . . . . 66

3.5. Ejemplo de la expansión léxica de la taxonomía con WordNet y DBPedia. 67

3.6. Curva ROC para el modelo de detección de quejas . . . . . . . . . . . 69

3.7. Series temporales de las quejas sobre ruido detectadas cada día para cada

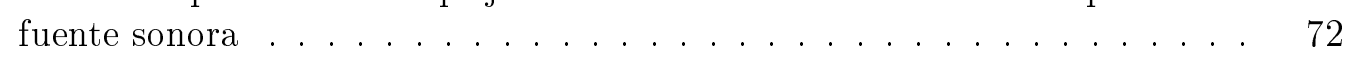

3.8. Palabras más utilizadas en los días anómalos para cada fuente de ruido. . 73

3.9. Evolución del número de quejas que contienen las palabras más usadas de

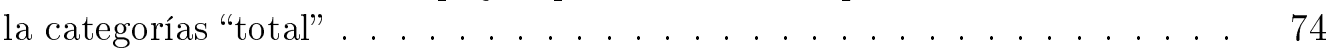

4.1. Representaciones gráficas de la variable $H T_{\text {prescripctions }}$. . . . . . . . . . . 82

4.2. Porcentaje de población expuesta estimada en los MSOAs de Londres . . 83 
4.3. Índice de eficiencia energético medio de las viviendas de cada MSOA . . . 84

4.4. Fuente sonora predominante para cada MSOA, calculada a partir de datos de medios sociales. . . . . . . . . . . . . . 85

4.5. Clasificación de los MSOAs de Londres en función de su clase social. . . . 87

4.6. Distribución de la fuente sonoras predominantes para los MSOAs de cada clase social de Londres. . . . . . . . . . . . . . . . . . . 88

4.7. Importancia relativa de las variables de los modelos calculados para la clase

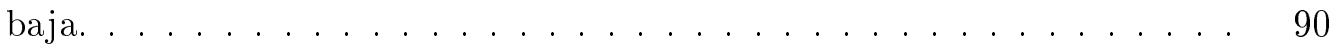

4.8. Importancia relativa de las variables de los modelos calculados para la clase media-baja y media-alta. . . . . . . . . . . . . . . 99 92

4.9. Importancia de las variables de los modelos calculados para la clase alta. . 93 


\section{Índice de Tablas}

1.1. Factores no acústicos que afectan a la aceptación de actividades ruidosas . 9

1.2. Resumen de indicadores de ruido utilizados en acústica ambiental. . . . . 16

2.1. Listado de preguntas realizadas en los cuestionarios . . . . . . . . . . . . . 40

2.2. Cálculos de muestra de las encuestas . . . . . . . . . . . . . . . . 42

2.3. Contrastes de homogeneidad realizados para las variables mostradas entre los grupos PRE y POST. . . . . . . . . . . . . . . . . . 48

2.4. Tabla de contingencia entre la pregunta $T M R 2$ y $R R 3$. . . . . . . . . . . 49

2.5. Contrastes de homogeneidad realizados para las variables mostradas entre los grupos PRE y POST tras filtrar a los participantes que no conocían la red de monitorado de ruido desplegada en Málaga. . . . . . . . . . . . . 50

2.6. Contrastes de homogeneidad realizados para las variables mostradas entre los grupos PRE y POST tras filtrar a los participantes que no accedieron a la aplicación web de datos de ruido. . . . . . . . . . . . . . 50

2.7. Contrastes de homogeneidad realizados para las variables mostradas entre los participantes que formaban parte de una asociación del ruido y los que

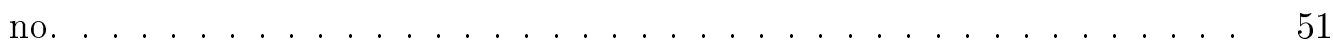

2.8. Modelo de molestia asociada al ruido de ocio. . . . . . . . . . . . . 52

3.1. Distribución del tipo de tweets de la base de datos original obtenida entre el 1 de junio y el 1 de septiembre del 2017. . . . . . . . . . . . . . . 59

3.2. $\quad$ Estadísticas de la base de datos de tweets originales obtenidos entre el 1 de junio y el 1 de septiembre del 2017. . . . . . . . . . . . . . . . 60

3.3. Resultados de las pruebas de "inter-annotator agreement" para cada combinación de categorías. . . . . . . . . . . . . . . . . 62

3.4. Estadísticas de los tweets de clase 0 y clase 1. . . . . . . . . . . . . . . 63

3.5. Resumen de los pasos llevados a cabo para la implementación de la meto-

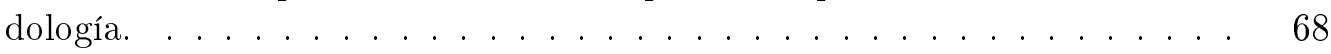

3.6. Ejemplos de predicciones realizadas por el detector de quejas sobre ruido. 70

4.1. Lista de variables consideradas para generar los modelos de regresión mul-

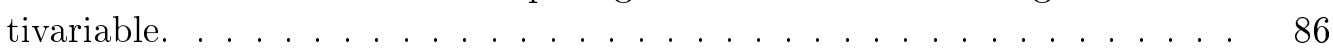

4.2. Modelos calculados para los MSOAs de clase baja de Londres. . . . . . . . 89

4.3. Modelos calculados para los MSOAs de clase media-baja de Londres. . . . 91

4.4. Modelos calculados para los MSOAs de clase media-alta de Londres. . . . 91

4.5. Modelos calculados para los MSOAs de clase alta de Londres. . . . . . . . 93 



\section{Capítulo 1}

\section{Introducción}

Think before you speak. Read before you think.

Fran Lebowitz

\subsection{La contaminación acústica, las ciudades y las infraes- tructuras del transporte}

\subsubsection{La contaminación acústica: un problema de salud pública}

La contaminación acústica, también referida cómo ruido ambiental o contaminación sonora, es el conjunto de sonidos no deseados generados por actividades humanas que pueden producir efectos nocivos sobre la salud de la población expuesta. La OMS (Organización Mundial de la Salud) reconoce a la contaminación acústica como la segunda causa medioambiental que más afecta a la salud de las personas tras la contaminación del aire (European Environment Agency, 2014). De hecho, en Europa se estima que el $25 \%$ de la ciudadanía está expuesta a niveles de ruido excesivos, una circunstancia que provoca pérdidas en la calidad de vida y en la salud de la población de las grandes ciudades, principalmente como consecuencia de la falta de descanso y del estrés generado por los altos niveles sonoros (WHO Regional Office for Europe, 2009, 2011).

El ruido ambiental propicia la aparición de enfermedades en el sistema circulatorio y nervioso. Se han llevado a cabo estudios epidemiológicos en los que se observa una correlación entre la exposición al ruido y la prevalencia de enfermedades cardiovasculares en la población. La mayor parte de estas investigaciones están centradas en estudiar el efecto de los niveles de ruido sobre la hipertensión arterial, incluyendo experimentos específicos sobre el ruido aeroportuario, ferroviario y tráfico rodado (Barregard et al., 2009, Belojević et al. 2008, Bodin et al. 2009, Dratva et al., 2011, Leon Bluhm et al., 2007, Sørensen et al., 2011). Además, la exposición al ruido genera molestia en la población, lo que incrementa su estrés, que favorece la aparición de ansiedad (Beutel et al. 2016, Standing y Stace, 1980). Adicionalmente, si el ruido se produce en franjas horarias nocturnas puede influir en la aparición de alteraciones en el sueño como el insomnio (Evandt et al. 2017, Halonen et al. 2012, Kageyama et al., 1997), con los procesos que la falta de descanso desencadena en la salud.

Además de sus efectos sobre la salud, la molestia es la respuesta al ruido ambiental más estudiada y documentada. La molestia hacia el ruido se puede definir como "el sentimiento de desagrado, incomodidad, desasosiego, insatisfacción o agravio que ocurre cuando el ruido interfiere con los pensamientos, sentimientos o actividades realizadas por un individuo" (Passchier-Vermeer, 1993). La molestia tiene una componente objetiva, basada en las 
características físicas del sonido como son su espectro frecuencial o su nivel de presión sonora; pero también una componente subjetiva, no relacionada con factores necesariamente acústicos, que se ha comenzado a estudiar recientemente (Maris et al., 2007, Sánchez et al. 2015, Vader, 2007). Entre estos factores se encuentran, entre otros, la confianza en los órganos de gestión, la transparencia, la concienciación sobre la problemática del ruido, el acceso y comprensión de la información proporcionada por las autoridades o el desagrado con las actuaciones ejecutadas para reducir el ruido (Maris et al., 2007; Sánchez et al. 2015, Vader, 2007).

La contaminación acústica es un problema de difícil gestión que puede producir efectos negativos en la población. Por una parte, a diferencia de la contaminación del aire, el ruido no se acumula o mantiene en el tiempo, lo que dificulta la concienciación sobre su importancia y peligrosidad en la ciudadanía. Por otra parte, la contaminación acústica está íntimamente relacionada con actividades de alta importancia económica esenciales para el crecimiento y desarrollo de la sociedad como son el transporte, el turismo, las actividades recreativas o la industria; esto provoca que haya un gran número de partes con intereses contrapuestos, lo que dificulta y alarga los procesos de análisis, gestión y reducción de estas actividades ruidosas (European Aviation Safety Agency, 2016, European Commission, 2011, National Economic Council, 2014).

\subsubsection{La evolución de las ciudades, las infraestructuras del transporte y el ruido}

El advenimiento de la revolución industrial trajo consigo un proceso de éxodo rural en el que los habitantes de zonas agrícolas se trasladaron a espacios urbanos. Este proceso se extendió a lo largo del siglo XX y sigue produciéndose en la actualidad. Hoy en día, el $55 \%$ de la población mundial vive en áreas urbanas, pero las NU (Naciones Unidas) estiman que será al menos el $70 \%$ en el 2050 (United Nations, 2018). Una parte significativa de este crecimiento demográfico urbano se está llevando a cabo en las denominadas global cities o ciudades globales. Una ciudad global es un área metropolitana que actúa como nodo en la red económica global, generando importantes ventajas para el desarrollo profesional y social de sus habitantes (Sassen, 1991). El crecimiento de las ciudades globales ha generado importantes retos a los responsables y gestores urbanos: han aparecido importantes problemas de gentrificación asociados al incremento de los precios de alquiler de las viviendas, provocados parcialmente por la proliferación de alquileres de corta duración en las grandes ciudades (Ardura et al. 2019, Wachsmuth y Weisler, 2018) y por el incremento de los precios de venta de las viviendas en barrios céntricos (Andersson y Turner, 2014 Florida, 2017); la congestión del tráfico se ha convertido en un inconveniente dado que el crecimiento poblacional requiere una rápida adaptación del planeamiento urbano y de los medios de transporte públicos (Barthelemy, 2016; Wallsten, 2015). El incremento del número de vehículos privados, en detrimento de los sistemas de transporte colectivo, y la mayor afluencia de personas a las grandes ciudades ha incrementado la polución ambiental de éstas, siendo el ruido uno de los principales contaminantes que afecta a la población.

Por otra parte, las mejoras tecnológicas y la paulatina incorporación de las sociedades avanzadas al mundo globalizado ha producido un cambio en las dinámicas de transporte de los habitantes de las diferentes regiones. Dado que las infraestructuras de transporte determinan la capacidad de una región en integrarse en la red económica global, se han efectuado grandes inversiones para su desarrollo que han favorecido la creación de riqueza y trabajo, además de incrementar los intercambios económicos y la movilidad de la población. Según datos de Eurostat, mostrados en la Figura 1.1. el número de usuarios de transportes colectivos se ha incrementado de forma continuada desde hace más de 5 años, siendo especialmente destacado el crecimiento del número de pasajeros de transporte aéreo, 
probablemente por la irrupción de aerolíneas de bajo coste que han democratizado este modo de transporte (Eurocontrol, 2016, Vidović et al. 2006). Además, se ha incrementado significativamente el número de kilómetros de autovías europeas, permitiendo que los ciudadanos puedan viajar entre puntos cercanos del territorio invirtiendo menor tiempo. El rápido crecimiento de estas infraestructuras ha creado riqueza en Europa y no es previsible que se reduzca, pero debería ser medioambientalmente sostenible, minimizando el impacto sobre el entorno y sobre las personas.

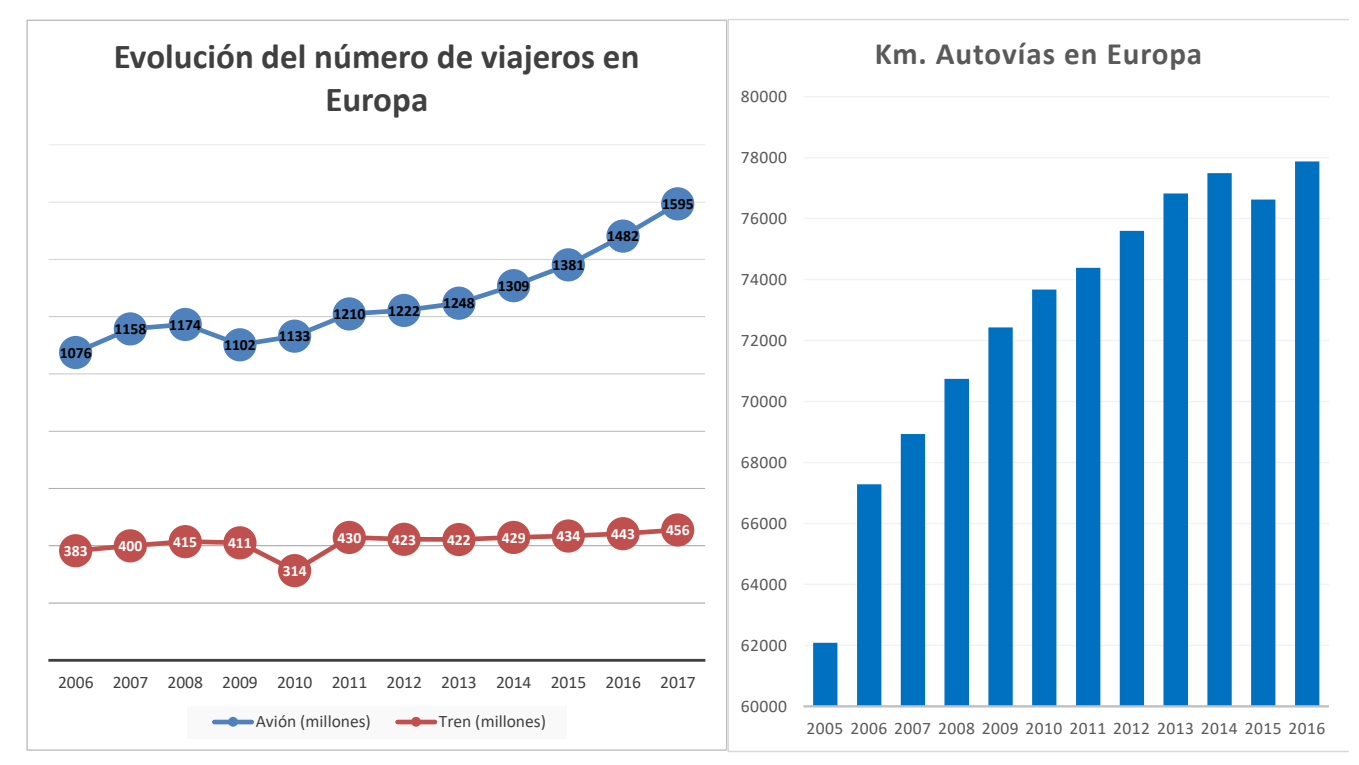

Figura 1.1: Evolución del número de pasajeros en transporte aéreo y ferroviario en Europa, y evolución del número del número total de kilómetros de autovías. Fuente: (European Commission, 2018).

Concretamente, en el caso de la contaminación acústica, el incremento del número de vuelos genera mayor molestia a la población residente cercana a los aeropuertos (Babisch et al. 2009, Le Masurier et al. 2007, 2008). Además, el incremento de las actividades turísticas puede producir un mayor trasiego de personas en las ciudades, extendiéndose en algunos casos hasta altas horas de la noche, lo que generado situaciones crónicas de molestia por ruido, principalmente asociado al ocio y especialmente en los países del Sur de Europa (Ballesteros et al. 2015, Fiamini y Luzzi, 2015, Ottoz et al., 2015, 2016). La importancia y dependencia económica de estas actividades provoca que la contaminación acústica sea un problema para todas las partes: por una parte la población expuesta se siente afectada y padece los síntomas de la exposición al ruido; por otra parte, los gestores no pueden paralizar esas actividades de forma inmediata por el interés económico y social que generan. Adicionalmente, existe desinformación sobre el problema y sobre los efectos del ruido, algo que dificulta la ejecución de acciones efectivas para reducirlo, ya sea a través de métodos tradicionales o alternativos.

\subsection{La gestión del ruido}

\subsubsection{La gestión del ruido tradicional}

Desde sus inicios, la gestión de la contaminación acústica ha estado íntimamente relacionada con el ruido aeroportuario, debido principalmente a las molestias que este genera a la población residente en las inmediaciones de los aeropuertos. Una de las primeras regulaciones para reducir los niveles sonoros de aeropuertos fue el Noise Control Act aprobado 
en 1972 en los Estados Unidos de América, en él se establece que es necesario proveer de información a la población sobre los niveles de ruido producidos por estas infraestructuras (U.S. Congress, 1972). Algo más tarde, en el año 1979, se comienzan a aprobar regulaciones similares en Europa, empezando con The Noise Nuisance Act (Wer geluidhinder) en Holanda, en el que se asientan las bases de la participación ciudadana en la gestión del ruido (States General of the Netherlands, 1979). En 1985 el gobierno francés aprueba la Loi $n^{\circ}$ 85-696, siendo esta la primera regulación que establece la necesidad de elaborar mapas de ruido en aeropuertos y comunicarlos a la población (République Française, 1985). Durante los años venideros aparecieron leyes similares en otros países europeos hasta que en 1996, la UE (Unión Europea) comienza un proceso de armonización de la gestión del ruido con la publicación del Libro Verde. Este documento aborda, por primera vez, el ruido desde una perspectiva medioambiental, y establece que la lucha contra el ruido debe llevarse a cabo mediante dos focos diferenciados: la reducción de las emisiones acústicas en la fuente y la generación de políticas generales para la lucha contra el ruido (European Commission, 1996).

El Libro Verde sirvió como base de trabajo para desarrollar la Directiva 2002/49/CE sobre evaluación y gestión del ruido ambiental, que fue publicada y adoptada en el año 2002 como marco regulador común en materia de contaminación acústica para los países de la UE. Esta directiva establece la obligación de realizar mapas estratégicos de ruido de forma periódica en grandes ciudades, grandes ejes viarios, grandes ejes ferroviarios y grandes aeropuertos (European Parliament, 2002). Además, define unas guías básicas para comunicar a la ciudadanía la información de los mapas de ruido y las acciones pertinentes para su reducción, aunque no es hasta el año siguiente cuando se publica la Directiva 2003/4/CE sobre el acceso público a la información medioambiental, en la que se establece la obligación de ofrecer públicamente toda la información ambiental recopilada por los órganos gestores a la ciudadanía (European Parliament, 2003).

Sin embargo, los mapas de ruido presentan algunas limitaciones. En primer lugar, al ser resultado de una simulación, la ciudadanía los percibe como artefactos que no representan la situación real que sufren. En segundo lugar, al representar el nivel sonoro por un tipo de fuente de ruido específica a lo largo de un periodo temporal largo, no son una herramienta que pueda ser utilizada para mostrar la situación acústica en un periodo temporal reducido, algo que suscita una falta de confianza hacia este tipo de herramientas por parte de la población. En tercer lugar, los indicadores utilizados para representar los niveles de ruido son demasiado técnicos y de difícil comprensión para la ciudadanía. Intentando mitigar esos problemas, las gestores urbanos suelen desplegar monitores de ruido en un intento de mostrar el ambiente acústico en puntos específicos de la ciudad. Estos sistemas son eficientes tanto para la gestión del ruido, como para informar,concienciar y conseguir la participación de los residentes, siendo ésta una de las tendencias que se están explotando en la actualidad.

\subsubsection{El papel de la tecnología en la gestión del ruido}

La evolución de las TICs (Tecnologías de la Información y las Comunicaciones) ha propiciado un cambio en los modelos de gestión y creación de políticas (referidas en este texto indistintamente como tal o policymaking). Antes de la llegada de Internet, este proceso se caracterizaba por ser un sistema representativo en el que la participación ciudadana estaba acotada a la elección de sus portavoces políticos y a consultas realizadas con relativa poca frecuencia, debido a los costes asociados que conllevaban. Con la expansión de las tecnologías y la aparición de plataformas de comunicación digitales como las redes sociales, la ciudadanía ha comenzado a valorar las políticas actuales y los problemas que padecen en su día a día a través de estos mecanismos virtuales. Esto ha favorecido la transformación 
de los modelos de gestión de políticas, que están incorporando progresivamente sistemas de participación pretendiendo fomentar la opinión de la población. Uno de estos modelos es conocido cómo PM 3.0 (Policy Making 3.0, Creación de políticas 3.0), introducido por Franco Accordino en el año 2013 (Accordino, 2013). En el PM 3.0 la toma de decisiones la realizan los gestores políticos, utilizando para ello su propio criterio, datos medidos de forma objetiva y la opinión ciudadana. El proceso se divide en cinco pasos representados en la Figura 1.2 .

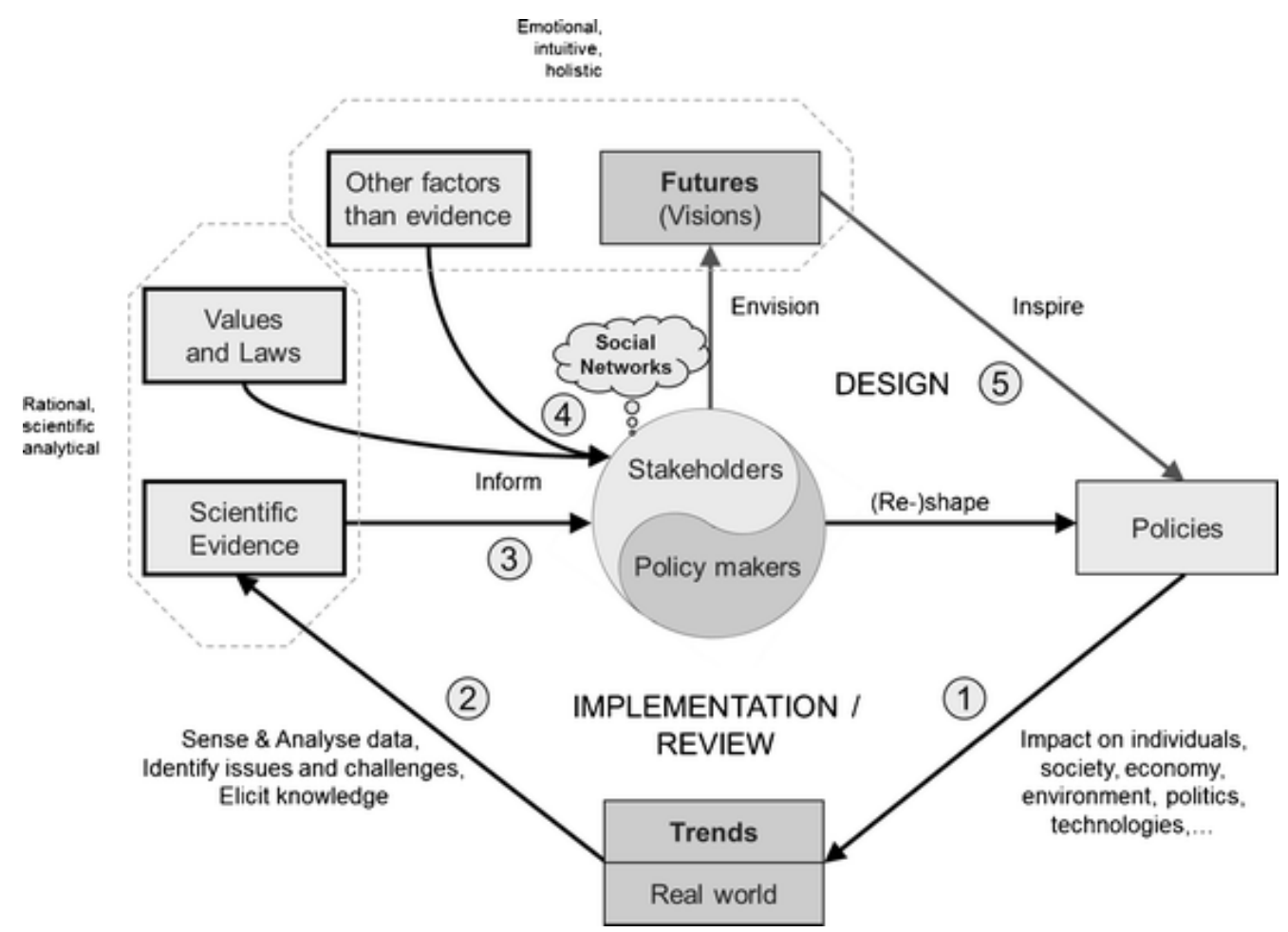

Figura 1.2: Esquema del modelo de Policy making 3.0. Fuente: (Accordino, 2013).

1. En primer lugar, todas las partes interesadas definen los objetivos a conseguir en un futuro próximo.

2. Una vez definidos los objetivos, los políticos y el resto de las partes interesadas desarrollan conjuntamente políticas para llevarlos a cabo, que tendrán un impacto en la población.

3. A continuación, mediante sensorización y análisis de datos se mide el efecto de estas políticas y se detectan nuevos problemas desde un punto de vista objetivo, basado en datos.

4. Estas evidencias objetivas pueden y deben ser utilizados por los gestores y partes interesadas para reajustar y mejorar las políticas.

5. Además, los agentes involucrados pueden interactuar con la ciudadanía mediante redes sociales, para conocer la opinión de esta e incorporarla en el proceso de creación de nuevas políticas o la definición de nuevos objetivos.

Esta nueva tipología de modelo de gestión está relacionada con la expansión de las TICs, favorecida por la Revolución Digital experimentada en la segunda mitad del siglo XX y la entrada en la Era de la Información en el siglo XXI, y de la colaboración de la 
ciudadanía, que ha cambiado su manera de actuar e interaccionar gracias a la creación de las plataformas digitales surgidas al comienzo de la Era de la Información. De hecho, la concepción de sistema participativo del PM 3.0 se basa en la metáfora del collective brain y está íntimamente relacionado con el concepto de inteligencia colectiva, una de las áreas de la Computación Social (Social Computing), que precisamente busca obtener información de la población a través de entornos virtuales (Khosrow-Pour. 2015).

En el caso de los sistemas de participación ciudadana en ciudades, los ayuntamientos de las grandes ciudades del mundo han intentado empoderar a la población a través de plataformas propias en la que los ciudadanos son llamados a opinar sobre diferentes problemas y sugerir otros que hayan identificado en la ciudad Ajuntament de Barcelona, 2018a, Ayuntamiento de Madrid, 2018b, Ayuntamiento de Zaragoza, 2018b, Mairie de Paris, 2018). La opinión de la ciudadanía está basada en su percepción subjetiva frente a problemas específicos y a los datos públicos a los que pueden acceder mediante las plataformas de datos abiertos que los ayuntamientos han creado para este fin (Ajuntament de Barcelona, 2018b, Ayuntamiento de Madrid, 2018a; Ayuntamiento de Zaragoza, 2018a; Mayor of London, 2018a). No obstante estos datos no son ofrecidos de una forma amigable, lo que dificulta su comprensión y uso. Además, existen indicios del posible sesgo de estas plataformas por ser utilizadas mayoritariamente por individuos involucrados en la lucha por los cambios políticos, población normalmente conocida por el término "activista", que a pesar de defender ideales lícitos no representan necesariamente al conjunto de la sociedad (Martí, 2012, Moreno et al., 2016).

Sin embargo, debido a la casuística del ruido y a las dificultades de su gestión, asociadas al gran número de actores que se benefician de las actividades que lo generan como el turismo y el transporte; a su naturaleza efímera, que lo convierten en un contaminante difícil de comprender para los que no lo padecen; y a la componente subjetiva y personal en su percepción, lo que dificulta el proceso de evaluación del problema por parte de las autoridades competentes; la implementación de este tipo de políticas participativas no es trivial.

Desde el punto de vista de infraestructuras y tecnologías de medida se han implantado mejoras en el proceso de sensorización, facilitados en parte por la llegada del IoT (Internet of Things, Internet de las Cosas), por la aparición de protocolos de comunicación más eficientes y seguros (LoRa Alliance, 2018, Zigbee Alliance, 2018), por el decremento de precios en la computación informática de forma paralela a un aumento en la velocidad de cálculo y por la reducción de costes en la producción de sensores de calidad. Esas mejoras tecnológicas han permitido que se comiencen a actualizar los métodos de gestión tradicionales como:

- Mapas de ruido: Han aparecido dos corrientes de investigación que tienen la pretensión de corregir las limitaciones de los mapas de ruido introducidas en la sección 1.2.1. La primera de ellas, motivada por la expansión y avances técnicos de los dispositivos de telefonía móvil, comenzó a finales de la década de los 2000 con el proyecto NoiseTube, en el que se desarrolló la primera aplicación para realizar mediciones de ruido colaborativas a través de smartphones que permitía mapear los niveles de ruido en distintas áreas de una ciudad (Maisonneuve et al. 2010, Sony Computer Science Laboratory Paris, 2019). Esta investigación fue prolongada en el proyecto Cart_ASUR (Lavandier et al., 2013), en el que se han ido incorporando mejoras en los algoritmos de agregación de los datos y en la precisión de las medidas (Aumond et al. 2017, 2018, De Coensel et al. 2015, Guillaume et al., 2016). Por otra parte surge el proyecto DYNAMAP (Dynamap 2019), en el que se ha ideado y desarrollado un sistema para producir mapas de ruido calculados mediante simulación, pero que se actualizan a tiempo real con datos provenientes de monitores de ruido distribuidos por la ciudad, permitiendo de este modo que sean percibidos en menor medida como 
artefactos que no representan la realidad (Belluci et al. 2019, Benocci y Roman H, 2019: Peruzzi et al. 2017, Socoró et al. 2017, Zambon et al. 2017). Algunos ejemplos de los mapas elaborados en estos proyectos se pueden ver en la Figura 1.3

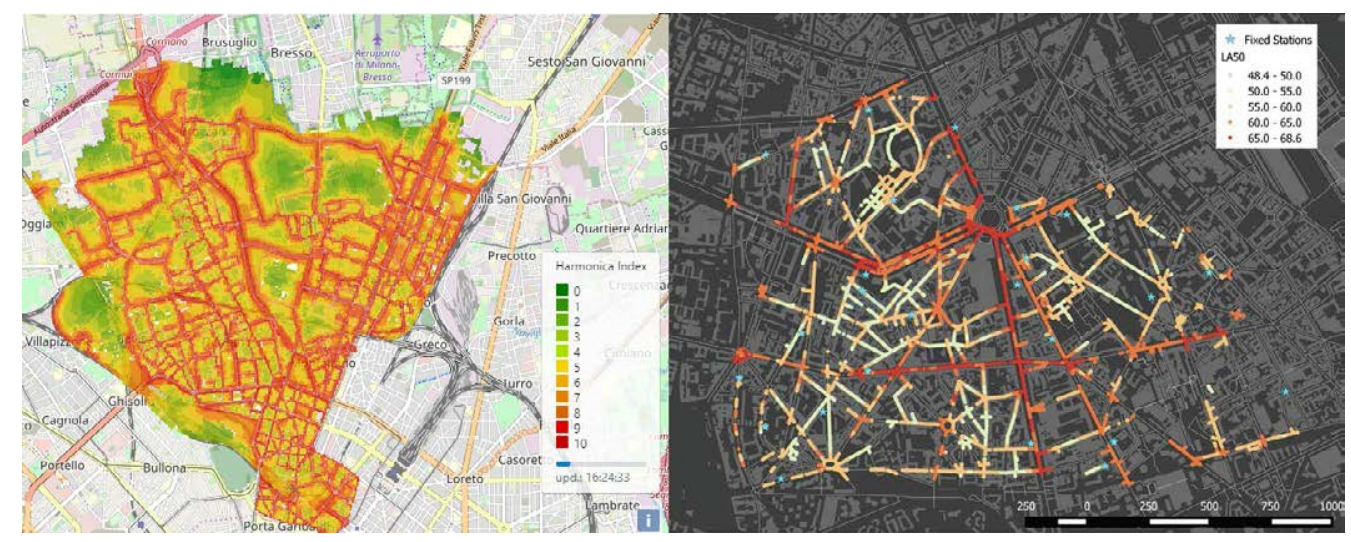

Figura 1.3: Izquierda: Mapa de ruido dinámico piloto desarrollado en un área de Milán en el proyecto DYNAMAP (Dynamap, 2019). Derecha: Resultado de mapa de ruido realizado mediante mediciones móviles en una continuación del proyecto Cart_ASUR (Aumond et al. 2017).

- Redes de sensores de ruido: Aunque las redes de monitores de ruido ambiental existen en las ciudades desde hace más tiempo, la explosión del concepto de la ciudad inteligente, comúnmente conocida como smartcity, llevó a cabo un proceso de sensorización de muchos parámetros en las ciudades, incluyendo el ruido. Uno de los proyectos más destacados fue SmartSantander que implementó la primera red de sensores de bajo coste en el ámbito del ruido (SmartSantander, 2019). Esta red sería posteriormente explotada en el proyecto EAR-IT para detectar cierto tipo de actividades en las ciudades (Cordis Europe, 2019b). Actualmente, la utilización de sensores de ruido de bajo coste que son capaces de detectar eventos sonoros en el entorno urbano está siendo extensamente investigado en el proyecto SONYC de la New York University (New York University, 2019), en el que han implantado una red de monitorado de bajo coste en la ciudad de Nueva York para medir ruido (Bello et al. 2019, Mydlarz et al., 2017), que además es capaz de detectar fuentes sonoras mediante técnicas de reconocimiento de audio y describir así el ambiente acústico de forma automática (Salamon y Bello, 2017).

Sin embargo, esos avances tecnológicos no han contemplado la participación ciudadana en la gestión del ruido como una necesidad. Eso cambia en el año 2015, cuando investigadores de la Universidad Politécnica de Madrid proponen la adaptación del modelo de Policy Making 3.0 a la gestión de la contaminación acústica (Asensio et al. 2015). El modelo propuesto, mostrado en la Figura 1.4 se centra en mejorar la comunicación de forma reiterada a través de procesos de participación ciudadana, además de considerar las plataformas digitales como un área esencial a tener en cuenta para conseguir ese objetivo.

\subsection{La percepción del ruido y la aceptación de actividades ruidosas}

En los últimos años se han intensificado las lineas de investigación basadas en modificar algunos factores que afectan a la percepción del sonido y que podrían modificar la 


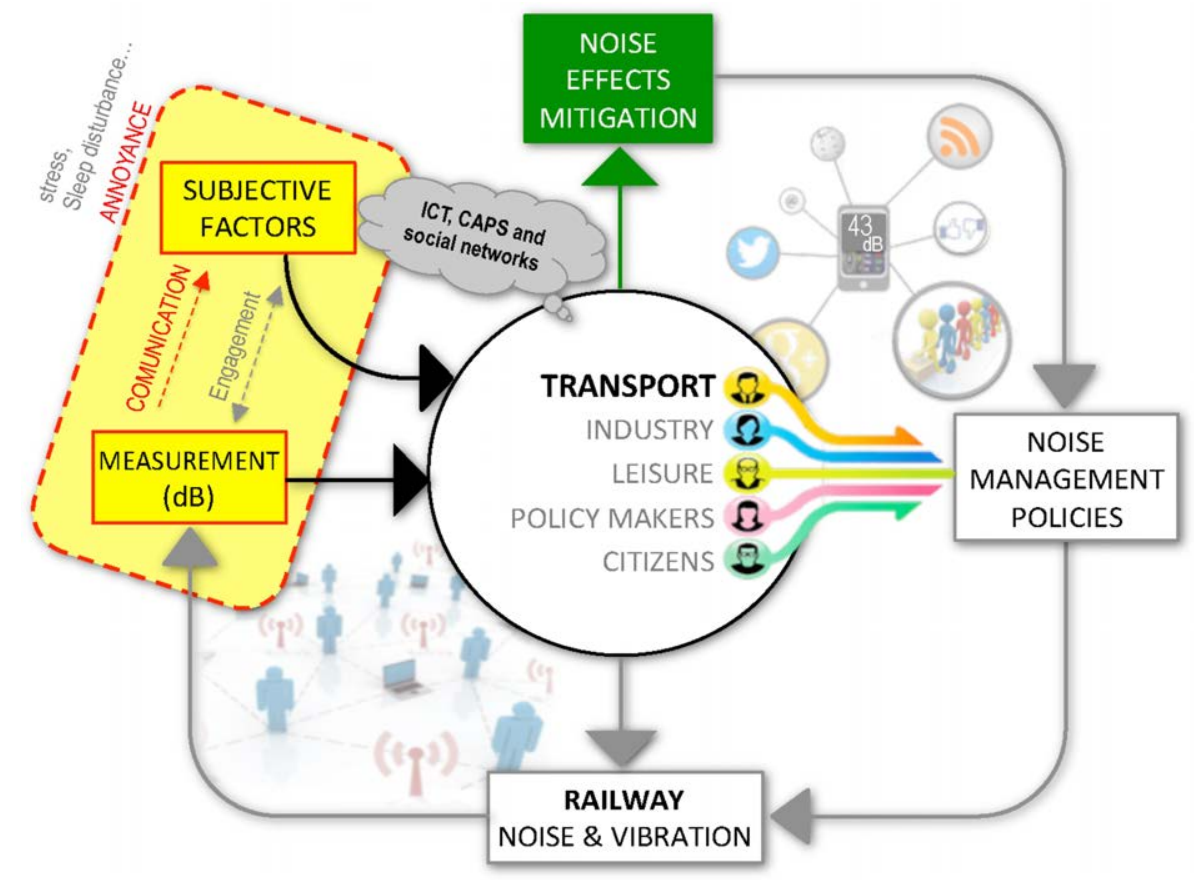

Figura 1.4: Esquema del modelo de Policy Making 3.0 para la contaminación acústica Fuente: (Asensio et al. 2015).

aceptación de una actividad ruidosa. Algunos de estos factores están relacionados con la comunicación de la información y la involucración de la ciudadanía en los procesos de gestión presentados en la sección 1.2.2 por lo que en este apartado se presentan los estudios realizados en torno a esta linea y las actividades de gestión participativa implementadas por algunas infraestructuras para mejorar la aceptación de los ciudadanos.

\subsubsection{Molestias por ruido: Factores acústicos y no acústicos}

Las investigaciones sobre la percepción de la molestia por ruido han estado tradicionalmente ligadas a las grandes infraestructuras de transporte, por ser esenciales para el crecimiento próspero de las ciudades, ser los principales focos de contaminación acústica y el principal motivo por el que los residentes rechazan el crecimiento de estas (Asensio, 2014 ICAO, 2016 Lawton y Fujiwara, 2016). Especialmente en los aeropuertos esto es crítico; su importancia económica es innegable porque facilitan los intercambios comerciales y generan multitud de puestos de trabajo en una región, pero el ruido generado por estas infraestructuras impide su crecimiento sostenible y es el causante de la mayoría de las protestas y quejas de la ciudadanía que vive en sus inmediaciones (Brooker, 2009; Fidell et al. 2002, May y Hill, 2006). Por ese motivo, tratando de incrementar la capacidad operativa de estas infraestructuras, se han desarrollado investigaciones sobre la percepción de la molestia con intención de cuantificarla y modificarla.

El primer estudio sobre la molestia por ruido se realizó en Nueva York en 1929, en el que se relacionaron el número de protestas realizadas por ciudadanos con los niveles de ruido registrados (Galt, 1930). No es hasta 1943 cuando se realiza la primera encuesta formal de valoración de actividades ruidosas en Inglaterra, conocida como la British Home Noise Survey, centrada en los ruidos provenientes de vecinos y del propio hogar (Fields, 1999). Con la evolución del sector aeronáutico se incrementó el número de operaciones aéreas a nivel mundial, lo que conllevó a un incremento de los niveles de ruido en las inmediaciones de los aeropuertos, algo que impedía su crecimiento. A partir de la década 
de 1970 se comenzó a estudiar de manera intensiva las molestias por el ruido proveniente de estas infraestructuras. De estas investigaciones es especialmente relevante el estudio de Schultz, que establece la relación existente entre molestia y nivel de ruido, conocida como la relación dosis-efecto (Schultz, 1978). Durante la década de 1990 se volvieron a replicar los estudios de Schultz concluyendo que, ante el mismo nivel sonoro producido por diferentes medios de transporte, el ruido procedente de aeronaves generaba más desagrado que el de otros medios de transporte como el tráfico rodado o los trenes, lo que abría una puerta a la existencia de otros factores adicionales a los niveles de ruido que produjeran cambios en la molestia percibida (Fidell et al., 1991, Fields, 1994 Finegold et al. 1994 Miedema y Vos, 1998,1999 .

Tras la publicación de la Guía para el Ruido Comunitario (Guidelines for Community Noise), publicada por la OMS en 1999 (World Health Organization, 1999), se llevaron varios proyectos que descubrieron que el ruido, caracterizado por varias métricas físicas como su intensidad, frecuencia o timbre; solo describe una parte de la sensación subjetiva de molestia generada en un individuo o comunidad (Gille et al. 2017; Guski et al., 1999; Hume et al. 2004). Es decir que una parte de la molestia estaba explicada por factores de naturaleza no acústica, no directamente relacionados con la naturaleza física del sonido.

En relación a esos parámetros, Vader publicó en 2007 un conjunto de 31 factores no acústicos que clasificó según su influencia en la molestia percibida y la capacidad de ser modificados (Maris et al., 2007, Sánchez et al., 2015, Vader, 2007). La Tabla 1.1 muestra los factores identificados, que podrían afectar a la molestia asociada al ruido aeroportuario.

Tabla 1.1: Factores no acústicos que afectan a la aceptación de actividades ruidosas. Fuente: (Vader, 2007).

\begin{tabular}{|c|c|c|c|}
\hline & Fuerte & Intermedio & Debil \\
\hline Factor modificable & $\begin{array}{l}\text {-Influencia } \\
\text {-Percepción de control } \\
\text {-Reconocimiento del problema } \\
\text {-Confianza } \\
\text {-Satisfacción con el aislamiento } \\
\text {-Compensación económica personal } \\
\text {-Equidad } \\
\text { - Actitud hacia el aeropuerto } \\
\text {-Factores temporales } \\
\text {-Interferencia con las actividades } \\
\text {-Satisfacción con el vecindario }\end{array}$ & $\begin{array}{l}\text {-Evasión } \\
\text { - Compensación económica grupal } \\
\text { •Expectativas sobre el futuro de la } \\
\text { fuente } \\
\text {-Información (accesibilidad y transpa- } \\
\text { rencia) } \\
\text { - Previsibilidad de la situación de ruido } \\
\text { - Métricas de ruido } \\
\text {-Concienciación ambiental }\end{array}$ & $\begin{array}{l}\text { - Cobertura de los medios de comunica- } \\
\text { ción } \\
\text { •Estatus social }\end{array}$ \\
\hline Factor no modificable & $\begin{array}{l}\text {-Edad (por debajo de los } 55 \text { años) } \\
\text {-Ingresos } \\
\text { • Sensibilidad individual al ruido } \\
\text { • Experiencias pasadas con la fuente so- } \\
\text { nora }\end{array}$ & $\begin{array}{l}\text { - Tiempo de residencia en la cercanía } \\
\text { del aeropuerto } \\
\text { - Miedo relacionado con el ruido } \\
\text {-Ser propietario de la vivienda } \\
\text { - Uso de los servicios del aeropuerto } \\
\text { - Aviones visibles desde el domicilio } \\
\text { - Grado de urbanización }\end{array}$ & $\begin{array}{l}\text {-Edad (por encima de los } 55 \text { años) } \\
\text { - Género } \\
\text { •Concieciación de las consecuencias ne- } \\
\text { gativas } \\
\text {-Niños } \\
\text {-Nivel educativo } \\
\text { - Nivel cultural }\end{array}$ \\
\hline En duda & $\begin{array}{l}\text {-Convicción de que el ruido podría ser } \\
\text { reducido por otros }\end{array}$ & $\begin{array}{l}\text {-Beneficios del aeropuerto } \\
\text {-Diferencias socioculturales } \\
\text {-País de origen }\end{array}$ & \\
\hline
\end{tabular}


Muchos de los factores no acústicos mostrados en la Tabla 1.1 hacen referencia a problemas similares, por lo que se puede considerar que existen relaciones entre ellos. Por ejemplo, la falta de transparencia se traduce en una falta de confianza por parte de la ciudadanía hacia los gestores, que a su vez puede aumentar el rechazo hacia el ruido de aviones. La actitud hacia el aeropuerto también ha sido identificada como uno de los factores más influyentes en la molestia, estando a su vez relacionado con el reconocimiento del problema del ruido por los órganos gestores y la percepción de imparcialidad en los procesos de gestión de la infraestructura (Sánchez et al. 2015, Schreckenberg y Meis, 2007). Adicionalmente y en relacción a estos factores no acústicos, Marís y su equipo demostraron que el conocimiento sobre la aparición de la fuente sonora puede tener un efecto positivo en la reducción de la molestia (Maris et al. 2007).

También se encuentran relaciones entre el factor temporal del ruido, que se refiere al momento del día en el que se produce el ruido (Hoeger et al., 2002, Porter et al. 2000. Schreckenberg y Meis, 2006, Vader, 2007); y la interferencia con las actividades personales llevadas a cabo por los residentes (Bartels, S and Marki, F and Muller, U, 2015, CANSO, 2015 Sánchez et al. 2015 Sustainable Aviation 2014 Vader 2007). A su vez, ambos factores pueden relacionarse con otros factores sociológicos como por ejemplo la edad o la actividad profesional de los residentes; ya que por ejemplo, a esos grupos no les molestarán en igual medida los sobrevuelos efectuados a las 10 de la mañana de un domingo.

Las campañas de aislamiento acústico implementadas en los edificios próximos a los aeropuertos también pueden modificar la sensación de molestia hacia el ruido Asensio et al. 2014). De hecho, la percepción de la calidad del tratamiento acústico llevado a cabo en las viviendas puede modificar la molestia aunque la exposición en el interior no sea significativamente distinta (Davidson, 1998, Knowles y Porter, 2016). Los gestores aeroportuarios conocen esta situación y algunos aeropuertos, como los de Londres, indican que los programas de aislamiento acústico son una manera de mejorar la relación con los residentes de las inmediaciones de los aeropuertos (London City Airport, 2010).

\subsubsection{Acciones de participación comunitaria y su efecto en la aceptación de aeropuertos}

Debido a las necesidades de crecimiento de los aeropuertos, los gestores aeroportuarios han llevado a cabo estrategias para involucrar a la ciudadanía en los procesos de gestión con la intención de aumentar la aceptación de sus infraestructuras y disminuir de este modo la molestia. Estas acciones se conocen como las actividades de participación comunitaria o community engagement, y se definen como los intentos que llevan a cabo los órganos gestores para establecer vínculos con la población con intención de conocer sus inquietudes, incrementar la confianza mutua y mejorar la coexistencia de ambas partes mediante una comunicación bidireccional y sostenible. Siendo estos, tres de los factores no acústicos identificados en la Tabla 1.1.

Las acciones de community engagement son simplificadas por Davidson utilizando un esquema similar al de la Figura 1.5 conocida como la rueda de la participación (Davidson, 1998). Davidson establece que cualquier proceso participativo se sostiene sobre cuatro pilares:

- Información: Proporcionar al público información clara y objetiva que le ayude a entender los problemas y las soluciones existentes. Este proceso de comunicación unidireccional se puede llevar a cabo a través de sitios web, folletos, etc.

- Consulta: Obtener retroalimentación del público relativa a la información proporcionada previamente mediante el uso de encuestas, entrevistas cara a cara, etc. 
- Participación: Proceso que por una parte busca la participación pública, para conocer y entender los problemas y preocupaciones de los residentes antes de llevar a cabo una acción, y por otra parte busca su colaboración para la toma de decisiones.

- Empoderamiento: Dejar en manos de los residentes la toma de decisiones. En el caso del ruido no se aplica.

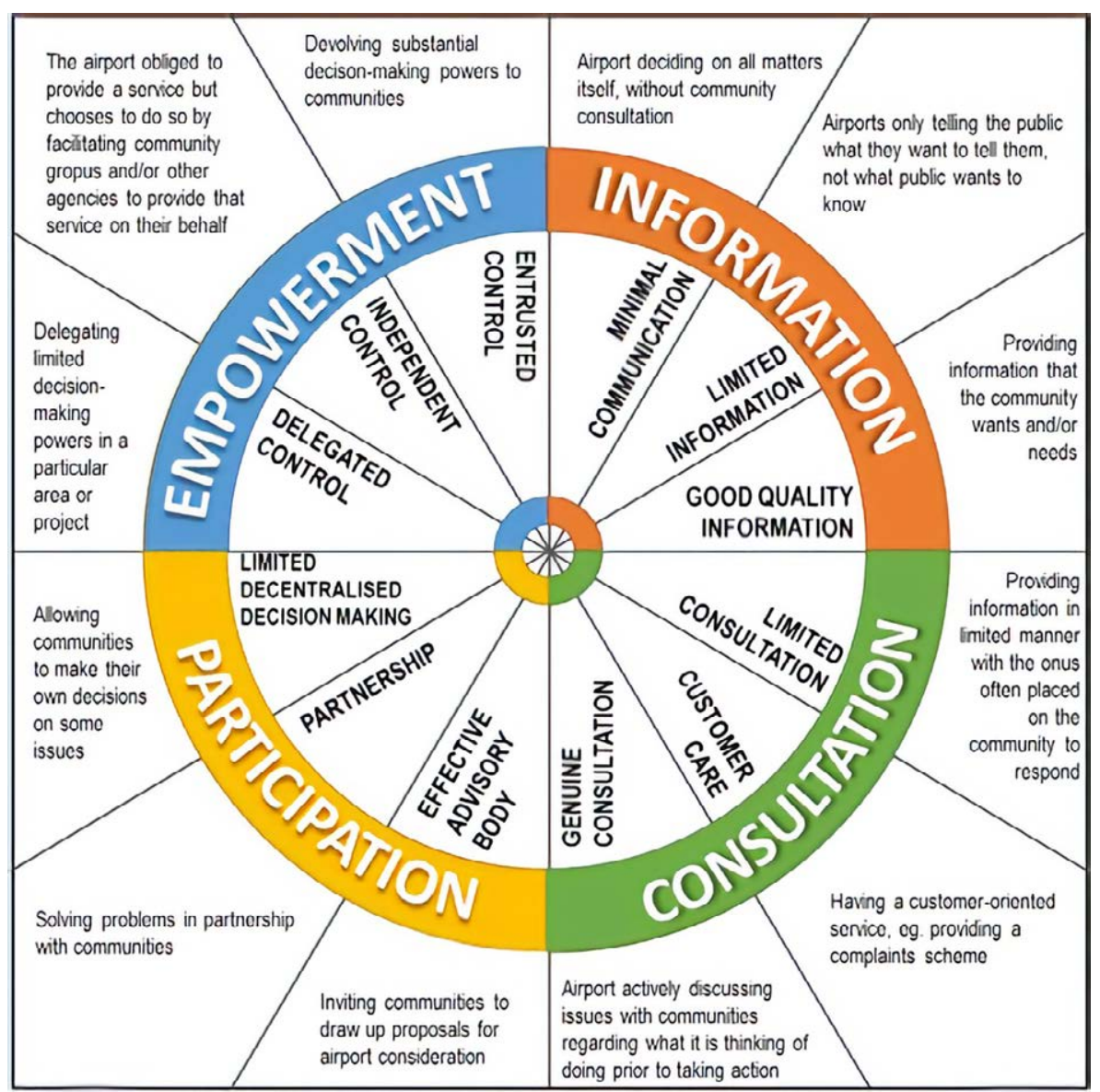

Figura 1.5: Esquema de la rueda de la participación (Wheel of participation) propuesto por Davidson. Fuente: (Davidson, 1998).

Varias organizaciones internacionales como EUROCONTROL, ICAO (International Civil Aviation Organization), ACI (Airport Council International) o FAA (Federal Aviation Administration) han abordado la temática de la participación estableciendo una serie de recomendaciones que faciliten a los aeropuertos tener buenas relaciones con los habitantes de sus inmediaciones (CANSO, 2015, Eurocontrol, 2013, Federal Aviation Administration, 2016 ICAO, 2017; Woodward et al. 2009). Estas estrategias están íntimamente relacionadas con algunos de los factores no acústicos mostrados en la Tabla 1.1 y las herramientas participativas de gestión del ruido mostradas en la sección 1.2.2 ya que buscan involucrar a la ciudadanía en procesos participativos para mejorar su confianza hacia los órganos gestores, incrementar la transparencia institucional, reconocer el problema de ruido que sufren los residentes o aumentar la voz de la ciudadanía en la toma de decisiones.

A continuación se muestran algunas de las recomendaciones en relación a los bloques de comunicación, consulta y participación definidos por Davidson (Davidson, 1998). 


\subsubsection{Comunicación}

La comunicación de la información de ruido transmitida de forma simple y clara mejora la confianza de los afectados. Para ello, es necesario que las herramientas de comunicación estén adaptadas al nivel de conocimientos del público general. Woodward indica que los enfoques tradiciones de comunicación, que tienen como objetivo educar a los residentes desde los intereses del aeropuerto, no son efectivos por ser unidireccionales y no permitir establecer relaciones igualitarias. La implementación de sistemas de comunicación bidireccionales puede modificar algunos factores no acústicos como: incrementar la sensación de influencia en la toma de decisiones de la ciudadanía, aumentar la sensación de control sobre el problema o reforzar la confianza en los órganos gestores; permitiendo construir de ese modo una relación de mayor calidad y confianza entre las partes (Woodward et al. 2009).

Aunque la información proporcionada por los aeropuertos es tratada en profundidad en la sección 1.4.2 investigaciones recientes han demostrado que los datos comunicados son percibidos como excesivamente técnicos, de difícil comprensión y opuestos a la sensación de molestia que los residentes sufren en sus domicilios (Griefahn et al. 2013, Hooper y Flindell, 2013). El estudio realizado por Hooper en el año 2009 concluyó que desde un punto de vista de métricas de ruido, los índices agregados como el $L_{d e n}$ no son útiles para los residentes por no representar las situaciones acústicas más adversas (Hooper et al., 2009). Además, los afectados no entienden esos índices acumulados y prefieren otros suplementarios, que combinan información del ruido y la periodicidad de este, por comprenderse mejor sin tener conocimientos técnicos (Eagan, 2007; Goldschagg, 2013).

Continuando con la comunicación y la aceptación de actividades aeroportuarias, un estudio realizado por Phun demostró que la tolerancia hacia este tipo de actividades puede modificarse cuando se proporciona a los residentes información sobre el impacto acústico que tendrá la infraestructura en el futuro, junto a los beneficios de los posibles incrementos operacionales de un aeropuerto. Además, su trabajo demostró que la información acerca de la situación acústica en diferentes lugares de los alrededores del aeropuerto era más relevante para los residentes sin conocimientos sobre contaminación acústica y podían aumentar la tolerabilidad hacia los propios niveles de ruidos (Phun et al. 2016).

Recientemente, se han realizado experimentos aplicando nuevas tecnologías para incrementar la comprensión de los indicadores, y por lo tanto la aceptación de las infraestructuras y la disminución de la molestia. Para ello se han utilizado herramientas de realidad virtual, tanto visual como auditiva, con el objetivo de ayudar a los ciudadanos a comprender el efecto de las medidas de reducción de ruido llevadas a cabo por los gestores del aeropuerto (Arntzen y Simons, 2014, Netherlands Aerospace Centre, 2016, Sahai et al. 2016).

\subsubsection{Consulta y participación}

Desde el punto de vista de la consulta y la participación, la ICAO sugiere que para que las acciones de participación comunitaria sean efectivas, tienen que estar bien planeadas, ambas partes deben ser proactivas y se tiene que actuar con relativa celeridad (ICAO, 2016). Además, el proceso no debe limitarse al corto plazo, sino que debe ser continuado una vez que los cambios en la infraestructura hayan sido ejecutados para obtener información continua de la población y actuar a tenor de la retroalimentación recibida.

El "Manual de Participación Comunitaria" publicado por la FAA en 2016 pretende ser una guía para planificar proyectos de temática aeroportuaria teniendo en cuenta la opinión de la población residente en las inmediaciones de la infraestrutura (Federal Aviation Administration, 2016). La FAA estructura estos proyectos en cinco fases, desde la planificación previa hasta el cierre, pero insiste en que en todas es necesario hacer un 
esfuerzo en involucrar a la comunidad. La planificación previa tiene como objetivo identificar cualquier preocupación que pueda surgir acerca del proyecto y encontrar formas de involucrar a la comunidad. En la segunda fase es necesario poner en marcha medidas de participación, con el fin de sensibilizar a las partes interesadas sobre los resultados del proyecto y recibir así la respuesta de la comunidad. La tercera fase, planificación, es la que mayor nivel de compromiso comunitario necesita, ya que es la fase en la que la FAA decide como implementar el proyecto y es el momento de tomar decisiones que no perjudiquen a ninguna de las partes. En esta etapa se deben evaluar tanto el impacto ambiental del proyecto como las preocupaciones de la comunidad para tenerlas en cuenta en el proyecto. En caso de implantar el proyecto, es necesario mantener a la población informada sobre la ejecución de este y contestar las dudas que puedan surgir durante el proceso. En la fase de cierre también se necesitan implementar acciones para mantener la participación de los residentes en el futuro.

Un ejemplo de implantación de políticas de participación es el caso del Aeropuerto de Viena. En 1998 el Aeropuerto de Viena publicó un plan de ampliación para el año 2015 (Forum Mediation, 2005). Este hecho provocó una serie de protestas ciudadanas para mostrar su rechazo a la ampliación e intentar revertir ese plan de extensión. Con la intención de solucionar el problema, los gestores aeroportuarios comenzaron un proceso de mediación. Después de reuniones entre los representantes de todas las partes durante 5 años, en el 2003 se aprobó un pre-acuerdo en el que el aeropuerto se comprometía a reducir la exposición al ruido en su vecindad mediante la prohibición de operaciones nocturnas y regular el número de operaciones anuales. Más tarde, en el año 2005, se firmó y publicó el acuerdo final en el que se definían todos los posibles escenarios de operación futuros teniendo en cuenta los aspectos económicos, sociales y ambientales. Gracias al éxito de esta iniciativa los gestores del aeropuerto crearon una institución para continuar el diálogo con los residentes y poder gestionar los futuros problemas con la misma efectividad.

En esta sección se han mostrado las principales investigaciones sobre factores no acústicos de la molestia. La mayoría de los proyectos en esta temática están relacionados con el ruido aeroportuario, no existiendo investigaciones sobre la temática en entornos urbanos. El estudio de estos factores en ciudades podría ser una solución parcial a los problemas de gestión del ruido existentes, ya que podrían mejorar la aceptación de actividades ruidosas y reducir así el malestar de la población.

\subsection{La comunicación de la información acústica}

La comunicación de la contaminación acústica es uno de los grandes retos de las autoridades encargadas de la gestión ambiental en ciudades e infraestructuras del transporte porque, por una parte, es necesario que la ciudadanía comprenda la problemática del ruido de forma correcta para fomentar su participación y, por otra parte, como se mostró en la sección 1.3 las labores de comunicación de la información pueden mejorar la aceptación de las actividades ruidosas y de ese modo reducir la sensación de molestia que estas producen. En este apartado se analizan tanto las métricas utilizadas para describir el ruido producido en ciudades y aeropuertos, como las herramientas de visualización utilizadas para una mejor interpretación de la contaminación acústica.

\subsubsection{Métricas para la medida de la contaminación acústica}

Debido al impacto acústico de los aeropuertos, la evolución de las métricas utilizadas para evaluar la contaminación acústica ha estado íntimamente relacionada con esta fuente de ruido. Cuando comenzó la evaluación del impacto acústico de aeropuertos, los índices utilizados estaban centrados en evaluar el ruido producido por aeronaves individuales. Sin 
embargo, estas métricas presentaban carencias cuando se usaban para la gestión de la contaminación acústica dado que no representaban la situación acústica global de las inmediaciones de la infraestructura. Este hecho promovió un marco de desarrollo de nuevas métricas acumulativas que permitieran estimar el impacto de los aeropuertos en la población y el medio ambiente. En los años 60 se desarrolla el Noise and Number Index (NNI), que es considerada la primera métrica acumulativa (Wilson, 1963). No es hasta la década de 1980 cuando el uso de métricas basadas en el nivel de presión sonora equivalente, $L_{e q}$, se implanta en los aeropuertos de forma generalizada (Brooker et al., 1985). Estos indicadores permiten evaluar el efecto de un conjunto de eventos sonoros durante un periodo de referencia (Brooker et al. 1985; Critchley y Ollerhead, 1990). La FAA, la UE, la OMS, el gobierno australiano y la mayoría de organizaciones de gestión aeronáutica utilizan estos indicadores acumulados porque son los que mejor relacionan los niveles de ruido con la molestia producida por éste y con sus efectos sobre la salud(Critchley y Ollerhead, 1990).

El nivel de presión continuo equivalente evaluado en un periodo de tiempo, $L_{A e q, T}$, es una métrica estandarizada por la ISO (International Organization for Standardization, Organización Internacional de Normalización) en las normativas ISO 1996 y ISO 20906, que se utiliza para medir el nivel de presión sonora promedio en un periodo de tiempo T (International Organization for Standardization, 2009, 2016). El cálculo del nivel de presión sonora equivalente ponderado A se realiza mediante la Ecuación 1.1 .

$$
L_{A e q, T}=10 \log \left[\frac{1}{T} \int_{T} \frac{p_{A}^{2}(t)}{p_{0}^{2}(t)} d t\right] d B
$$

dónde $p_{A}(t)$ es la presión sonora instantánea ponderada A y medida con una constante temporal de integración $t$; y $p_{0}$ es la presión sonora de referencia, $20 \mu P a$.

A pesar de que el intervalo $\mathrm{T}$ puede tomar cualquier valor, se definen periodos estandarizados a lo largo de un día de medida. En el momento que se definen esos periodos estandarizados la métrica deja de verse como un promedio del nivel de ruido y se interpreta como un nivel de ruido acumulado. Generalmente encontramos dos o tres periodos de tiempo normalizados: día y noche, utilizados principalmente en los Estados Unidos de América; o día, tarde y noche, comúnmente utilizados en Europa. Cuando se utilizan estos intervalos temporales de referencia, los indicadores toman una denominación específica: nivel de presión sonora equivalente en el periodo diurno $\left(L_{d}\right)$, nivel de presión sonora equivalente en el periodo vespertino $\left(L_{e}\right)$ y nivel de presión sonora equivalente en el periodo nocturno $\left(L_{n}\right)$. Basándose en estas definiciones, la norma ISO 1996 define los indicadores combinados de nivel de presión sonora día-noche $\left(L_{d n}\right)$ y nivel de presión sonora díatarde-noche $\left(L_{d e n}\right)$, también conocido como Community Noise Equivalent Level (CNEL). La peculiaridad de estos indicadores combinados es que penalizan los periodos vespertinos y nocturno, debido a que las molestias producidas por el ruido en estos periodos suelen ser mayores. La expresión matemática de estas métricas se presenta en las Ecuaciones 1.2 y 1.3

$$
\begin{gathered}
L_{d e n} / C N E L=10 \log \frac{1}{24}\left(N_{d} * 10^{\frac{L_{d}}{10}}+N_{e} * 10^{\frac{L_{e}+5}{10}}+N_{n} * 10^{\frac{L_{n}+10}{10}}\right) d B(A) \\
L_{d n}=10 \log \frac{1}{24}\left(15 * 10^{\frac{L_{d}}{10}}+9 * 10^{\frac{L_{n}+10}{10}}\right) d B(A)
\end{gathered}
$$

donde $N_{d}, N_{e}$ y $N_{n}$ corresponden al número de horas del periodo diurno, vespertino y nocturno, respectivamente. La diferencia entre $L_{\text {den }}$ y el CNEL está en el uso de diferentes intervalos temporales para el periodo vespertino (de 19:00 a 22:00 en CNEL y de 19:00 a 23:00 en $L_{d e n}$ ) y nocturno (de 22:00 a 07:00 en CNEL y de 23:00 a 07:00 en $L_{d e n}$ ), aunque 
el $L_{\text {den }}$ también permite ajustar los periodos los periodos para adaptarse a la situación sociocultural de cada país Europeo.

Estudios recientes han demostrado que esos indicadores, cuando se utilizan para comunicar datos de contaminación al público, tienen el grave inconveniente de ser demasiado técnicos para los no expertos y de no satisfacer las expectativas de los ciudadanos (Hooper et al. 2009). Por ese motivo, los gestores aeroportuarios han incorporado métricas de más fácil compresión sin tener conocimientos técnicos previos como:

- Number Above: Éste índice indica el número de operaciones de aeronaves que superan un umbral de nivel de ruido específico en una zona determinada (Southgate. 2000).

- Time Above: Éste indicador expresa el tiempo total, o porcentaje del tiempo, en el que en nivel de presión sonora producido por los aviones excede un determinado valor (Woodward et al. 2009).

- Person-Events Index (PEI): El PEI se calcula, sumando sobre la población expuesta, el número total de ocasiones en el que una persona está expuesta al nivel sonoro de una aeronave por encima de un umbral de ruido específico (Jones y Cadoux, 2009).

- Average Individual Exposure (AIE): Esta métrica representa el número medio de operaciones aeroportuarias por encima de un nivel de ruido específico que afecta a una persona expuesta durante un periodo temporal. Se calcula como el PEI dividido por el número de residentes expuestos por encima del nivel de ruido especificado (Jones y Cadoux, 2009).

Esos índices permiten comunicar la información acústica relativa a los aeropuertos de forma más clara. Sin embargo, en el caso de los entornos urbanos, donde se presentan de forma simultánea multitud de fuentes sonoras distintas, es complicado separar eventos sonoros específicos y dar métricas de ruido sobre cada fuente independientemente. Por ello, y en parte gracias a las actividades de concienciación hacia el ruido llevadas a cabo desde la mitad de la década de los 2000 (Vader, 2007), se han ejecutado proyectos para mejorar las métricas utilizadas para comunicar los niveles de ruido al público general.

De estos, el proyecto más destacado ha sido HARMONICA, que buscaba definir un nuevo indicador de fácil comprensión por la ciudadanía (Mietlicki et al. 2015). El índice Harmonica está compuesto por dos elementos que representan el nivel de ruido de fondo y los sucesos eventuales que ocurren en un periodo de tiempo. El nivel de ruido de fondo se representa con un gráfico de barras, como se muestra en la Figura 1.6 mientras que el nivel relacionado con los eventos sonoros es presentado utilizado un triángulo encima de cada barra. En lugar de utilizar decibelios, que son una unidad de difícil comprensión para la mayoría de la población (Vincent y Lambert, 2006), el índice Harmonica utiliza una escala de 0-10 obtenida tras una transformación de las medidas de nivel realizadas cada segundo. Como se muestra en la Figura 1.6 la representación gráfica del índice incorpora una escala de colores que complementa la información: verde para niveles de ruido aceptables, naranja para niveles de ruido altos y rojo para niveles de ruido muy altos (Bruitparif, 2016, Mietlicki et al. 2014).

La Tabla 1.2 resume las distintas métricas indicadas hasta el momento, así como otras comúnmente utilizadas en acústica y sus descripciones. 
Tabla 1.2: Resumen de indicadores de ruido utilizados en acústica ambiental.

\begin{tabular}{|c|c|c|c|}
\hline & Concepto & Métrica & Descripción/referencia \\
\hline \multirow[t]{2}{*}{ Métricas para eventos sonoros } & Nivel de ruido máximo & $\begin{array}{l}L_{A \max } \\
L_{A F \max } \\
L_{A S \max } \\
L_{e q 1 s, \max }\end{array}$ & $\begin{array}{l}\text { Mayor nivel de presión sonora re- } \\
\text { gistrado durante un periodo de me- } \\
\text { dida. Definido en normativas inter- } \\
\text { nacionales como ISO 1996-1 (Inter- } \\
\begin{array}{|l|}\text { national Organization for Standar- } \\
\text { dization, 2016). }\end{array}\end{array}$ \\
\hline & Dosis de ruido por evento sonoro & $\begin{array}{l}L_{E} \\
L_{A E}\end{array}$ & $\begin{array}{l}\text { Nivel sonoro de un evento sono- } \\
\text { ro comprimiendo toda su energía } \\
\text { en un intervalo de tiempo estanda- } \\
\text { rizado (International Organization } \\
\text { for Standardization, 2007b). }\end{array}$ \\
\hline \multirow[t]{2}{*}{ Metricas de ruido acumulativas } & Nivel de ruido equivalente & $\begin{array}{l}L_{A e q T} \\
L_{d} \\
L_{e} \\
L_{n}\end{array}$ & 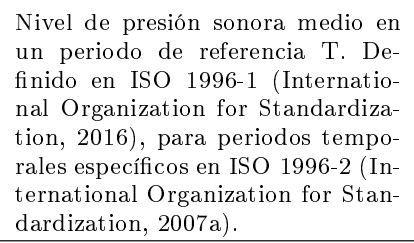 \\
\hline & Nivel de ruido combinado & $\begin{array}{l}L_{d e n^{-}} \text {CNEL } \\
L_{d n} \text { (DNL) }\end{array}$ & $\begin{array}{l}\text { Indicadores combinados basados } \\
\text { en el nivel de ruido equivalente que } \\
\text { representan el nivel de presión so- } \\
\text { nora medio durante un día, pe- } \\
\text { ro penalizando el periodo nocturno } \\
\text { o el vespertino y nocturno depen- } \\
\text { diendo de la métrica usada. Defi- } \\
\text { nidos en la Directiva 2002/49/CE } \\
\text { European Parliament, 2002) y en } \\
\text { la AC 150/5020-1 Federal Avia- } \\
\text { tion Administration, 1983. }\end{array}$ \\
\hline \multirow[t]{6}{*}{ Otras métricas de ruido } & Number Above a specified level & NA & $\begin{array}{l}\text { Número de eventos sonoros que ex- } \\
\text { ceden un límite de ruido durante } \\
\text { un periodo de tiempo determinado } \\
\text { (Haveloc y Jones, 2011). }\end{array}$ \\
\hline & Time Above a specified level & TA & $\begin{array}{l}\text { Este índice muestra el tiempo en el } \\
\text { que el nivel de ruido es mayor que } \\
\text { un valor establecido por ley. Gene- } \\
\text { ralmente el resultado se expresa en } \\
\text { segundos o minutos (Airbus, 2003). }\end{array}$ \\
\hline & Niveles percentiles & $\begin{array}{l}L_{90} \\
L_{50} \\
L_{10}\end{array}$ & $\begin{array}{l}\text { Nivel de ruido excedido por el } \\
\mathrm{N} \% \text { de medidas durante el tiempo } \\
\text { de medida (International Organi- } \\
\text { zation for Standardization, } 2016 \text {. }\end{array}$ \\
\hline & Person-Events Index & PEI (Noise Level) & $\begin{array}{l}\text { Este es el número de veces que una } \\
\text { persona está expuesta a eventos de } \\
\text { ruido de aeronaves sobre un límite } \\
\text { establecido en un periodo temporal } \\
\text { (Haveloc y Jones, 2011). }\end{array}$ \\
\hline & Average Individual Exposure & AIE & $\begin{array}{l}\text { Esta métrica muestra el promedio } \\
\text { de eventos de ruido por encima de } \\
\text { un umbral a los que una perso- } \\
\text { na está expuesta (Haveloc y Jones, } \\
\text { 2011). }\end{array}$ \\
\hline & Îndice Harmonica & & $\begin{array}{l}\text { Índice de ruido basado en una es- } \\
\text { cala de } 0 \text { a } 10 \text { que tiene en cuenta } \\
\text { tanto los niveles de ruido de fondo } \\
\text { como la variabilidad sonora en su } \\
\text { cálculo (Ribeiro et al., } 2013) \text {. }\end{array}$ \\
\hline
\end{tabular}




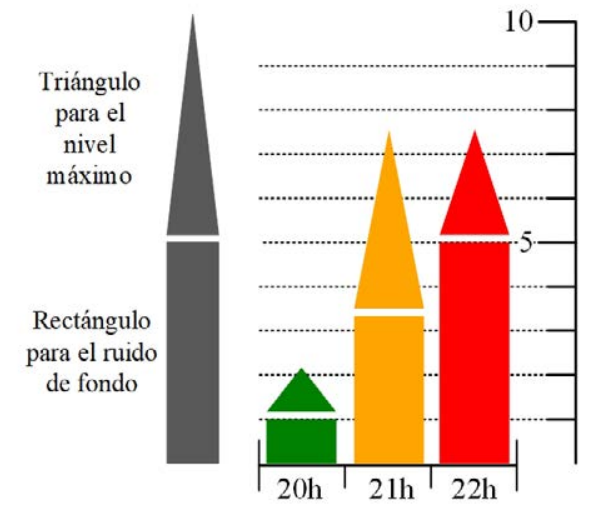

\begin{tabular}{|c|c|c|}
\hline Color & $\begin{array}{c}\text { Periodo de día } \\
\text { 6-22h }\end{array}$ & $\begin{array}{c}\text { Periodo de noche } \\
\text { 22-6h }\end{array}$ \\
\hline & $0-4$ & $0-3$ \\
\hline & $4-8$ & $3-7$ \\
\hline & $>8$ & $>7$ \\
\hline
\end{tabular}

Figura 1.6: Representación gráfica del índice Harmonica. Fuente: Elaboración propia basada en (Bruitparif, 2016, Mietlicki et al., 2014).

\subsubsection{Comunicación de la información de ruido}

Existen diversas formas de transmitir los datos de ruido, que pueden ser agrupadas en cuatro bloques: los mapas de ruido, la información proveniente de las redes de monitorado, los informes de ruido y la publicación de datos en abierto.

\subsubsection{Mapas de ruido}

Los mapas de ruido son gráficos bidimensionales de los niveles de presión sonora generados por una fuente de ruido en un área especifica mostrados sobre mapas cartográficos. Estos mapas son usados para conocer la exposición al ruido ambiental de la población en un área específica antes de aplicar un plan de acción de reducción de ruido.

En Europa, con la adopción de la Directiva 2002/49/CE, las grandes ciudades, aeropuertos, ejes viarios y ejes ferroviarios fueron obligados a producir mapas estratégicos de ruido cada cinco años (European Parliament, 2002). Esta normativa establece diferentes requerimientos entre los que se encuentran la necesidad de que los estados miembros de la UE compartan estos mapas sonoros con la ciudadanía, y que los indicadores utilizados en estos mapas sean el $L_{\text {den }}$ y el $L_{n}$, definidos en la sección 1.4.1.

Los mapas de ruido son herramientas utilizadas por los gestores ambientales para conocer y reducir la exposición al ruido en áreas específicas, pero debido a la naturaleza de la Directiva europea también tienen como objetivo ser mostrados al público general como herramienta de concienciación. Dado que la población no tiene por qué tener conocimientos técnicos sobre acústica ambiental, la manera de representar estos mapas es esencial para su correcta comprensión.

Existen tres formas de representar los mapas de ruido: Las dos primeras se usan para visualizar la contaminación acústica que se produce en entornos aeroportuarios y están basadas en los contornos de ruido (noise contours en inglés). La primera de ellas, mostrada en la Figura 1.7. A, utiliza isolíneas cuyos puntos interiores tienen al menos el nivel sonoro definido por el valor numérico de esta (Working Group on the Assessment of Exposure, 2008); existe una variante de esta visualización en la que se utiliza una escala de colores de forma que cada línea está asociada con un color que representa un nivel de ruido 
determinado, algo que mejora el visionado y la interpretación de los mapas. La segunda visualización consiste en colorear las áreas existentes entre dos isolíneas consecutivas, representando de este modo el rango de niveles de ruido existente en esas zonas. Debido a la existencia de estudios que demuestran que la segunda visualización mejora la comprensión del mapa por parte de la ciudadanía (Vincent y Lambert, 2008), esta visualización fue seleccionada por la UE para la representación de los mapas estratégicos de ruido (European Environment Agency, 2016) y se muestra en la Figura 1.7.B. La tercera opción es utilizada por ciudades y otras infraestructuras de transporte. Combina en un mismo gráfico tanto el mapa de la ciudad, incluyendo cada uno de los edificios y calles, como los niveles de ruido, utilizando áreas coloreadas que permiten visualizar la propagación de los niveles de ruido en las vías de la ciudad (Ayuntamiento de Madrid, 2016).
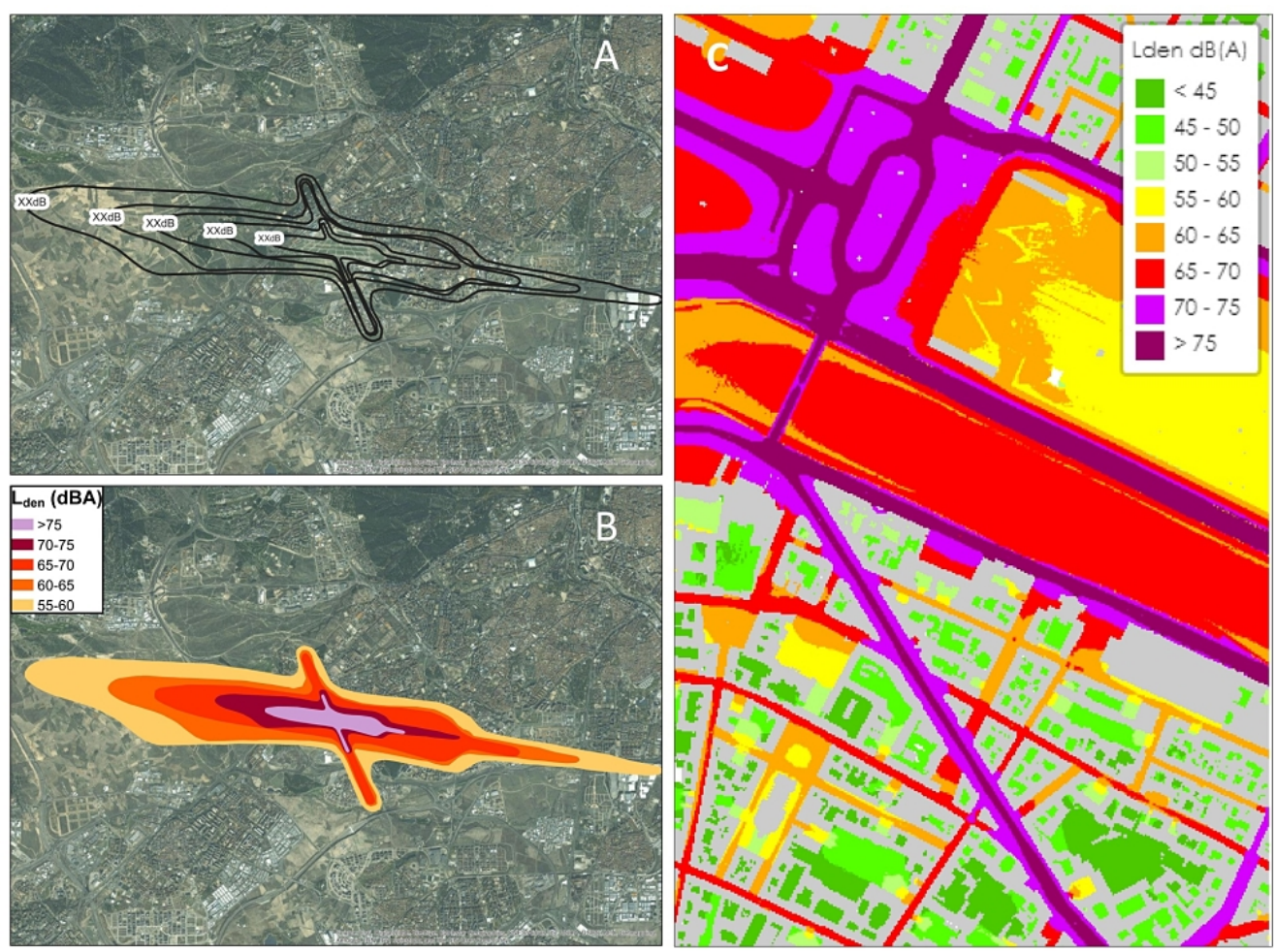

Figura 1.7: Métodos de representación de mapas de ruido: A. Contornos de ruido aeropuertos. Fuente: Elaboración propia. B. Areas coloreadas aeropuertos. Fuente: Elaboración propia. C. Areas coloreadas otras fuentes de ruido. Fuente: (BruitParif, 2019b).

Los mapas estratégicos de ruido europeos, tanto de aeropuertos como otras fuentes sonoras, también tienen que indicar el número de personas expuestas a los diferentes niveles de ruido. La mayoría de gestores optan por utilizar tablas para mostrar esta información. En el caso de aeropuertos también se suele informar sobre el área expuesta y el número de viviendas expuestas en cada rango de nivel de ruido (AENA, 2008, BruitParif, 2019b). Adicionalmente, algunos gestores aeroportuarios representan la exposición al ruido conjuntamente al mapa de ruido, coloreando áreas sobre el mapa con colores que indican la población expuesta en cada edificio o área (Finavia, 2014).

En los Estados Unidos de América, los aeropuertos siguen los requerimientos marcados por la FAA en el Aviation Safety and Noise Abatement Act de 1980 y por la Federal Aviation Regulation, Part 150; dichos requisitos se encuentran agrupados en el documento Advisory Circular (AC) 150 "Noise Control and compatibility Planning for Airports" (Federal Aviation Administration, 1982, U.S. Congress, 1980). La AC 150 describe la meto- 
dología específica para desarrollar mapas de exposición al ruido en entornos aeroportuarios. El documento establece el $L_{d n}$ como la métrica estándar en los mapas sonoros, aunque algunos estados, como California, utilizan el $C N E L$, índice similar al $L_{d e n}$ europeo (San Francisco Intertational Airport, 2015b). La visualización de los mapas de ruido es similar a la utilizada en la Unión Europea, siendo el sistema de isolíneas coloreadas el más común, e incorporando de forma adicional información sobre el uso del suelo en cada área. Esta información es representada coloreando áreas en el mapa en función de si el suelo es de uso industrial, residencial, educativo, hospitalario o de oficinas.

El conjunto de todos lo mapas de ruido de los Estados Unidos de América, tanto de aeropuertos como de autovías, está centralizado en la plataforma National Transportation Noise Map, donde se muestran todos los mapas normalizados utilizando el índice $L_{\text {Aeq,24h }}$ del año 2014 (U.S. Department of Transportation, 2019). En el momento de escribir esta memoria no se tenía constancia de la existencia de ninguna legislación que obligara a realizar mapas de ruido en las grandes ciudades de este país.

Australia es uno de los países más activos en temas relacionados con los mapas de ruido aeroportuarios. Han ideado su propio método de cálculo conocido como Australian Noise Exposure Forecast (ANEF). Este sistema utiliza el índice ANEF, cuyo valor numérico es aproximadamente igual a $L_{e q}-35$. El sistema ANEF propone tres tipos de mapas de ruido que son similares, pero que se calculan con distintos tipos de datos:

- Australian Noise Exposure Index (ANEI contours): Estos planos muestran la exposición al ruido histórica en las inmediaciones de aeropuertos australianos (Southgate, 2000). Se utilizan cinco contornos ANEI, entre 20 y 25 en pasos de 5. Cada isolínea se presenta en un mapa independiente, adjuntando una tabla que contiene el número de población expuesta en cada distrito y los datos del mapa ANEI del año anterior. Las cinco isólineas ANEI también se representan de forma conjunta en un mapa diferenciandolas con un código de colores, incluyendo también un mapa de densidad de eventos aéreos que han superado los $70 \mathrm{~dB}(\mathrm{~A})$ de nivel máximo.

- Australian Noise Exposure Forecast (ANEF contours): Este tipo de mapa representa una predicción de la exposición al ruido en función de la estimación de operaciones aeroportuarias en años venideros. Son utilizados por los gestores aeroportuarios para tomar decisiones respecto al uso del suelo cercano al aeropuerto (Southgate, 2000).

- Australian Noise Exposure Concept (ANEC contours): Estos gráficos presentan hipotéticos contornos de ruido en función de posibles cambios operacionales en el aeropuerto, como creación de nuevas pistas o cambios en las configuraciones de vuelo y aterrizaje (Airservices Australia 2018). Representan la exposición al ruido media en un día promedio para cada una de las situaciones disponibles y pueden ser visualizados de forma interactiva mediante un navegador web (Perth Airport, 2016)

Por otra parte, a diferencia de la Unión Europea y los Estados Unidos de América, el gobierno australiano no presenta mapas de ruido en relación al tráfico rodado y ferroviario. En su lugar, presentan planos de volumen de vehículos y ferrocariles en los principales ejes viarios y ferroviarios del país, indicando si superan el límite recomendado por la legislación estatal (NSW Government, 2019).

\subsubsection{Visualización de los sistemas de monitorado de ruido ambiental}

Como se comentó en la sección 1.2.1 los mapas de ruido y los indicadores de ruido utilizados son percibidos por la ciudadanía como un artificio matemático para camuflar la exposición real que sufren (Hooper et al. 2009). Esto ha provocado que los gestores 
medioambientales utilicen otras herramientas para transmitir la información sobre el ruido a la población, centradas en su mayoría en los datos obtenidos a través de los sistemas de monitorado de ruido ambiental.

\section{Aeropuertos}

Con la evolución tecnológica, los aeropuertos han implementado sistemas para visualizar información a tiempo real relativa a las operaciones aeroportuarias, incluyendo los niveles de ruido, accesibles mediante la web.

Los gestores aeroportuarios no tienen la obligación legal de comunicar datos a tiempo real a la ciudadanía, pero la mayoría de las grandes infraestructuras proporcionan acceso a esta información mediante aplicaciones web con la intención de mejorar la eficacia de sus estrategias de comunicación. Estas aplicaciones utilizan datos de los NOMS (Noise and Operations Monitoring Systems, Sistemas de Monitorado de Ruido y Operaciones), que son sistemas de sensores distribuidos en la periferia de los aeropuertos capaces de medir el ruido, la posición de las aeronaves y las condiciones ambientales en las inmediaciones de cada localización. De forma general permiten visualizar a tiempo real sobre un mapa del área del aeropuerto los niveles de ruido, las rutas seguidas por cada avión y notificar quejas sobre operaciones específicas.

Un aspecto clave de estas herramientas es tanto la información que muestran como la manera de mostrarla:

- Niveles de ruido: Se muestra el nivel de ruido instantáneo en cada punto en el que hay una unidad de monitorado de ruido. La métrica utilizada para dar este dato suele ser el $L_{A e q, 1 s}$, que es mostrada al usuario de dos maneras: utilizando un mapa dinámico que muestra la localización del sensor de ruido con etiquetas, en el que se actualiza el valor y color de dicha etiqueta en función del nivel de ruido AENA, 2016); o a través de gráficos de evolución temporal que son actualizados con cada medida segundo a segundo (Forum flughafen \& region, 2016).

Las unidades de medida son capaces de detectar los eventos sonoros asociados a un avión. Cuando esto ocurre, el sistema lo notifica a los usuarios cambiando la forma de la etiqueta y marcándolo en el gráfico de evolución temporal, tal y como se muestra en la Figura 1.8 .

- Rutas: Las aplicaciones muestran las rutas seguidas por los aviones a tiempo real. A pesar de que existen diversas maneras de mostrar las rutas, la más común es identificar la posición del avión mediante un icono y dibujar la ruta que sigue con colores según si aterriza o despega. En algunos aeropuertos esa línea se representa con un gradiente de color que indica la altura del aeronave en cada momento (Forum flughafen \& region, 2016, Gatwick Airport, 2016). El usuario también puede acceder a los datos de cada avión pulsando sobre el icono de éste, lo que abrirá una ventana en la que se suele mostrar contenido como el tipo de avión, la aerolínea, el destino y el origen del vuelo (AENA, 2016, Forum flughafen \& region, 2016). Esta ventana también puede informar acerca de la altura del avión e incluso en algunas ocasiones un gráfico de evolución de su altitud (Flughafen München, 2016, Forum flughafen \& region, 2016; Fraport, 2016). En algunos casos, como en el aeropuerto de Munich y Gatwick, también aparece información sobre la velocidad del avión (Flughafen München, 2016; Gatwick Airport, 2016).

- Quejas: Los NOMS también permiten notificar quejas a los gestores aeroportuarios de forma muy eficiente. Utilizando la aplicación, el ciudadano puede identificar el aeronave que le ha generado molestia y poner una queja específica sobre este para 
que posteriormente se analice si se produjo alguna irregularidad en esa operación. Esta funcionalidad ya ha sido implementada en los sistemas de algunos aeropuertos, como Madrid (AENA 2016).

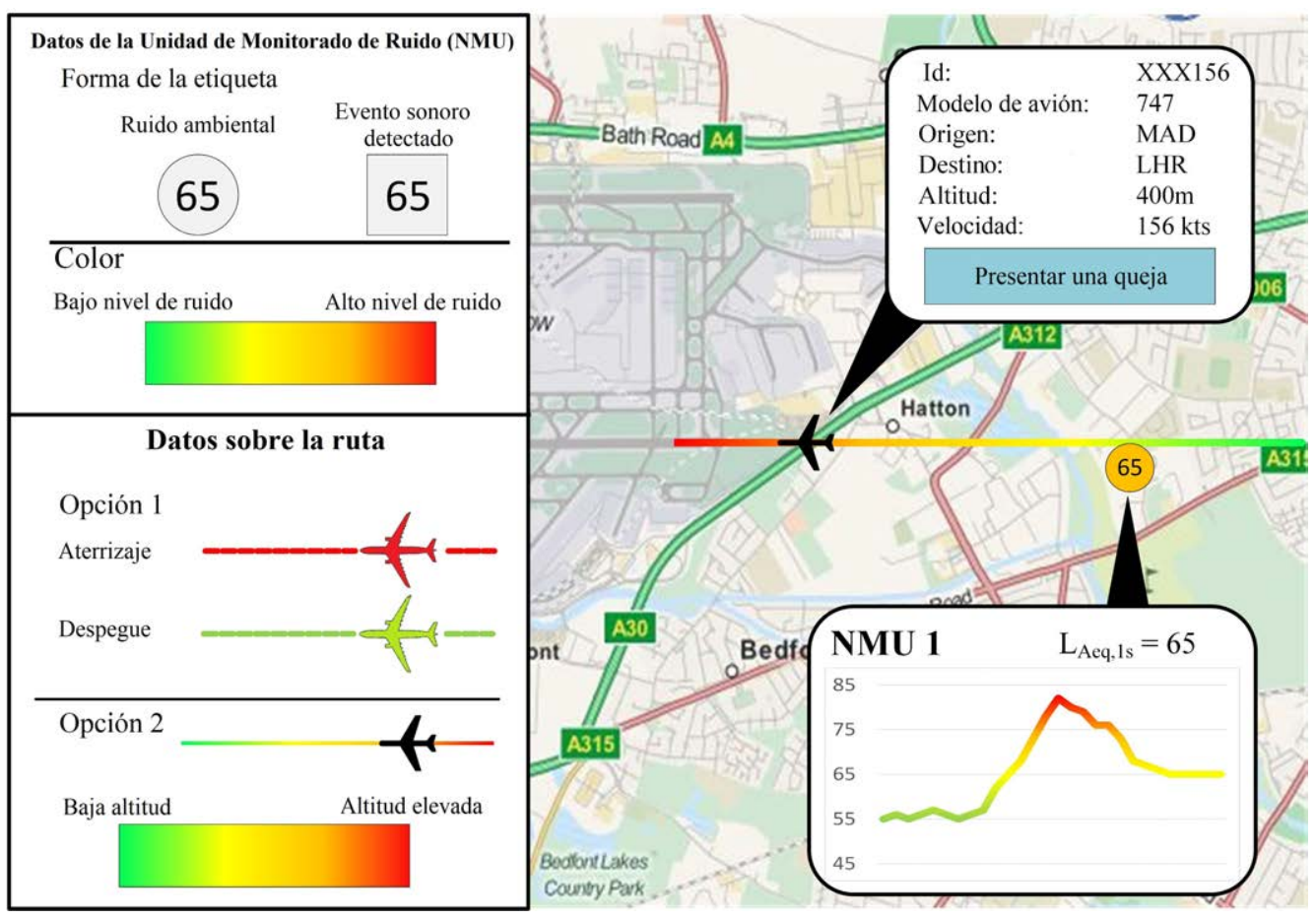

Figura 1.8: Imagen que resume las diferentes posibilidades de mostrar la información en los sistemas NOMS. Fuente: Elaboración propia.

La evolución de las tecnologías web ha mejorado la accesibilidad de la información. Algunos de los sistemas NOMS integran características adicionales como: mostrar tanto los niveles de ruido a tiempo real como los históricos; permitir al usuario elegir un periodo de tiempo y obtener un informe interactivo que muestra entre otras cosas, el número de operaciones por hora, la densidad de operaciones y el porcentaje de uso de las pistas en ese periodo; y mostrar histogramas con la distribución de niveles de ruido de las operaciones realizadas, como se describió en la sección previa Amsterdam Airport Schiphol, 2016. Brussels airport, 2016, Gatwick Airport, 2016).

\section{Ciudades}

A pesar de que hoy en día los sistemas de monitorado de ruido son comunes en las grandes ciudades, su desarrollo e implementación se llevó a cabo paulatinamente entre finales de la década de 1990 y comienzo de los 2000 con proyectos como DIAPASON o URBIS (Cordis Europe, 2019ac).

El reporte de información ha ido evolucionando del mismo modo que las tecnologías que implementan estos sistemas. Al principio se mostraban los datos mediante documentos de texto descargables vía Internet, pero el desarrollo de la web ha posibilitado las mejoras de visualización de forma que en la actualidad muchas ciudades tienen plataformas interactivas de visualización de datos con funcionamiento a tiempo real.

Una de las plataformas de visualización más completas es la de Bruitparif, el observatorio de ruido de París, que permite analizar la evolución temporal de los niveles de ruido en cada una de las localizaciones de medida permanentes, y conocer los datos históricos de 
campañas de monitorado en distintas áreas de la ciudad. Utiliza diversidad de indicadores, desde el $L_{A e q, 1 s}$ con su intervalo de confianza, a los niveles de ruido comunitarios, pasando por el índice harmonica (BruitParif, 2019a). Además, permite la exportación de los datos y la comparación entre distintos puntos de medida. En la Figura 1.9 se muestra una captura de la aplicación en la que se aprecian algunas de las características mencionadas. Otras plataformas como Acoucité, de la ciudad de Lyon, incorporan funcionalidades adicionales como la escucha del ambiente sonoro en cada localización mediante grabaciones binaurales (Acoucité, 2019).

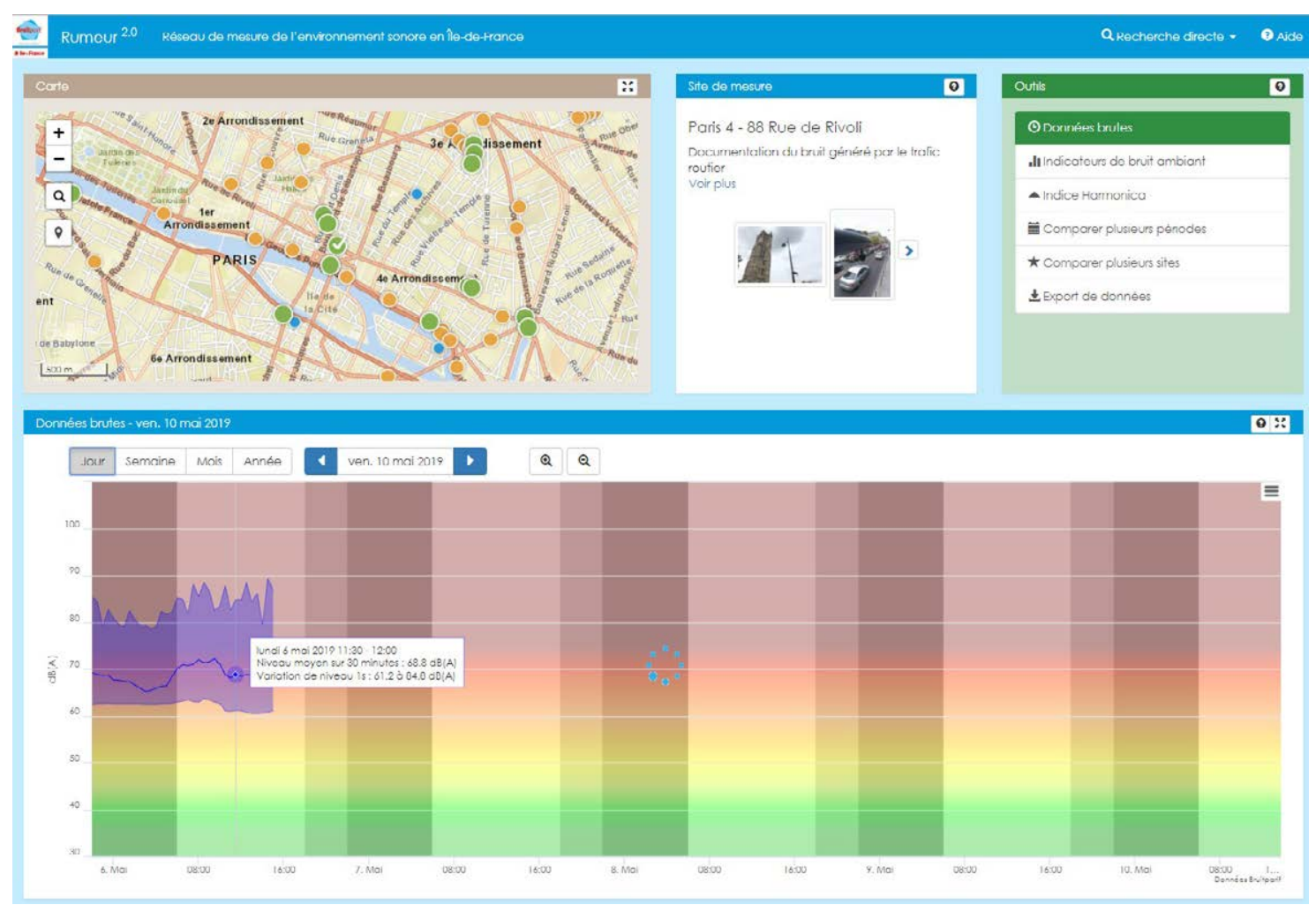

Figura 1.9: Site Rumeur 2.0.: Aplicación web para la visualización de datos de ruido desarrollada por Bruitparif. Fuente: (BruitParif, 2019a).

Hay ciudades que optan por incorporar sus datos de ruido en plataformas de smartcities como Sentilo, mostrada en la Figura 1.10, en la que se observan tanto los monitores de ruido instalados en la ciudad como los de temperatura o luminosidad Ajuntament de Barcelona. 2019). Existen otras plataformas comerciales, como Noisemote, expresamente diseñadas para sensores de ruido que además de ofrecer los niveles de ruido a tiempo real, muestran la localización del monitor y datos sobre su instalación, así como otros parámetros acústicos como los niveles percentiles o las estadísticas de multitud de indicadores y periodos de tiempo especificados por el usuario (Noisemote, 2019). 


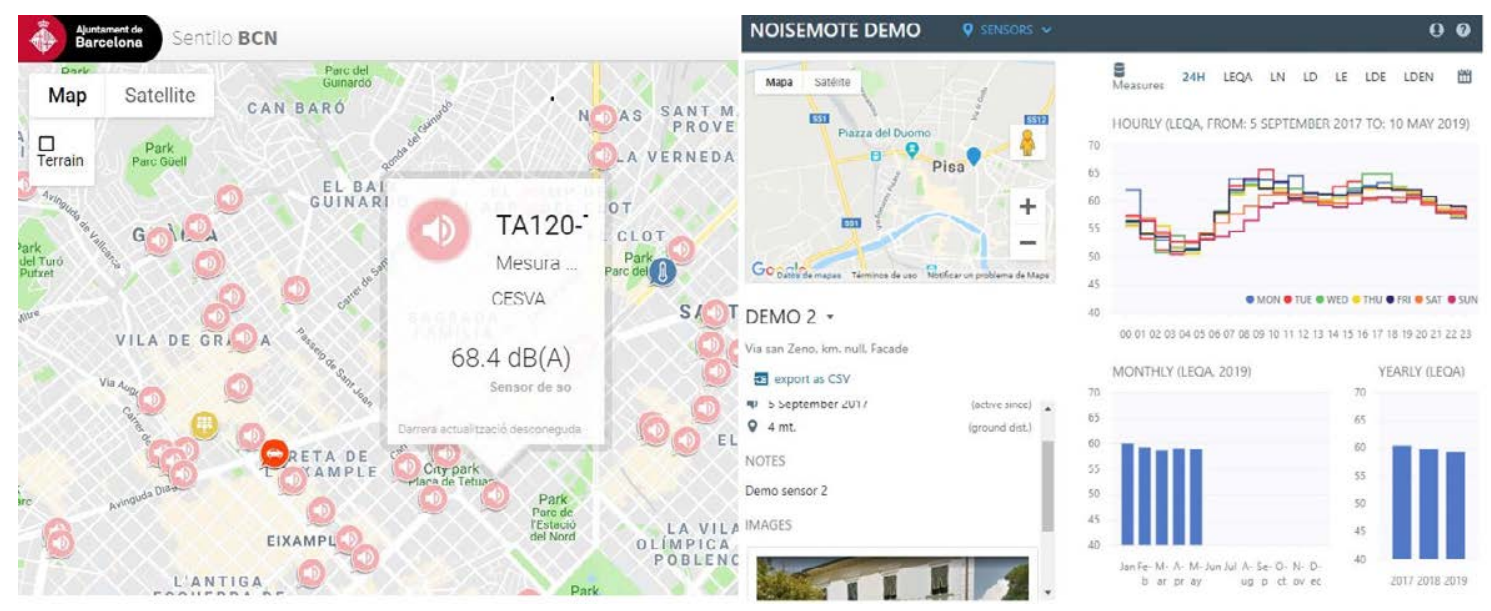

Figura 1.10: Plataformas de visualización de datos de ruido en ciudades: Izq.) Aplicación Sentilo, adaptada para Barcelona (Ajuntament de Barcelona, 2019) Der.) Aplicación Noisemote (Noisemote, 2019).

\subsubsection{Agregación de la información acústica en los informes de ruido}

Los informes de ruido ambiental son reportes periódicos que incluyen tanto información sobre mediciones de ruido como de otros parámetros que puedan afectar a las emisiones acústicas. Estos documentos, publicados periódicamente, son utilizados principalmente para comunicar la situación acústica en las proximidades de grandes infraestructuras aeroportuarias, siendo su uso residual en ciudades. Por ese motivo, en este apartado se resume la información que suele aparecer en los informes de ruido analizados provenientes de 70 aeropuertos internacionales.

En términos generales los datos contenidos en estos documentos pueden agruparse en tres grupos: información sobre rutas aéreas, quejas y emisiones acústicas.

\section{Rutas aéreas}

La configuración de pistas y rutas aéreas utilizadas en un aeropuerto están directamente relacionadas con el ruido emitido a las inmediaciones de la infraestructura y su efecto en la población. Los gestores aeroportuarios muestran el uso de las rutas existentes en el aeropuerto porque algunas configuraciones tienen mayor impacto acústico y por lo tanto existen restricciones en su uso. El empleo de las pistas se muestra mediante esquemas como los mostrados en la Figura 1.11. En estos gráficos se identifican cada una de las pistas y el porcentaje de uso de cada una de ellas en despegues y aterrizajes para cada configuración de operación durante un periodo de tiempo específico (Chicago Department of Aviation, 2016a).
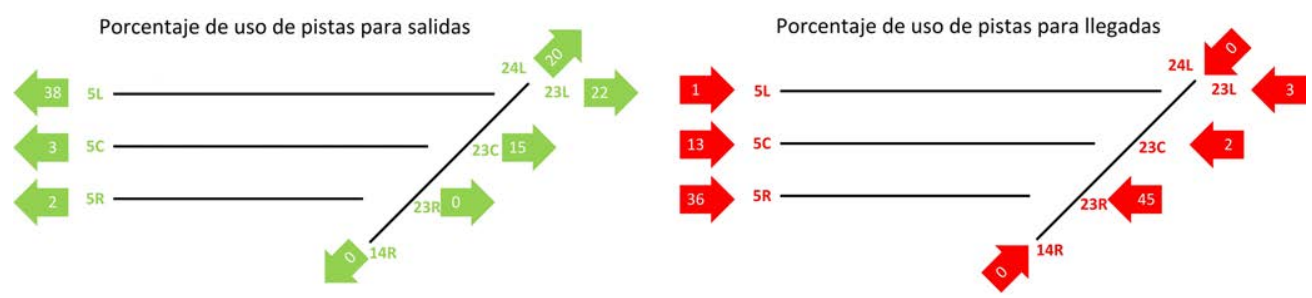

Figura 1.11: Esquema que representa el uso de pistas de un aeropuerto. Fuente: Elaboración propia basada en (Chicago Department of Aviation, 2016a). 
Esa información se complementa con datos sobre la desviación en las rutas óptimas pre-definidas por los gestores aeroportuarios. Esto se comunica utilizando gráficos de dispersión XY (Aeropuerto Adolfo Suárez Madrid-Barajas, 2016, Chicago Department of Aviation, 2016a) o marcando sobre el mapa del aeropuerto los despegues y aterrizajes realizados por todos los aviones en un periodo temporal, tal y como se muestra en la Figura 1.12. A y Figura 1.12B (Aéroport International de Genève, 2005; Aeropuerto Adolfo Suárez Madrid-Barajas, 2016, Heathrow Airport, 2013). Los aeropuertos australianos utilizan una variante de ese tipo de gráfico utilizando un gradiente de color en donde cada una de las lineas representa la altura del avión a lo largo de su trayectoria. Adicionalmente, utilizan una visualización que representa la densidad de sobrevuelos en las distintas áreas, como se muestra en la Figura 1.12 C (Airservices Australia, 2014a c, Chicago Department of Aviation, 2016a)

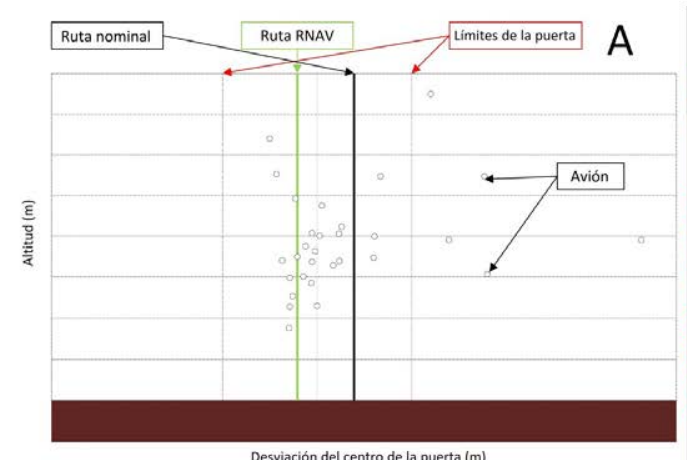

C

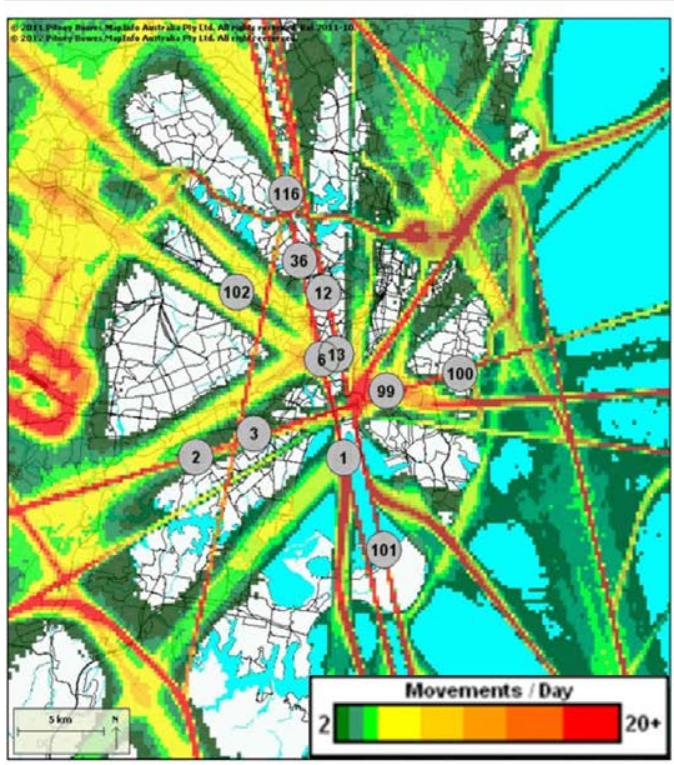

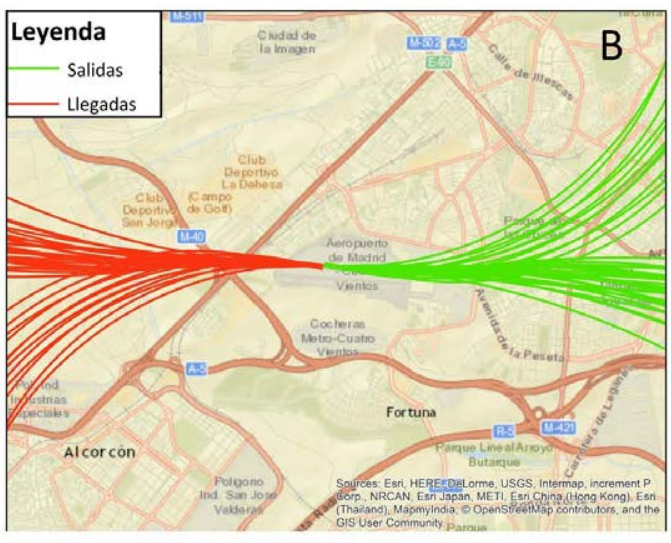

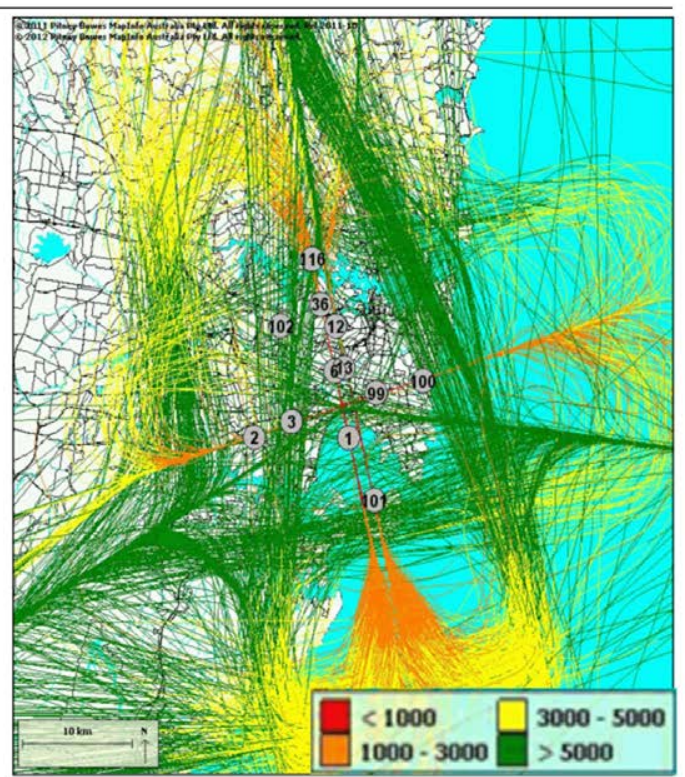

Figura 1.12: Dispersión de sobrevuelos: A. Fuente: Elaboración propia basada en Aeropuerto Adolfo Suárez Madrid-Barajas, 2016). B. Fuente: Elaboración propia basada en (Aéroport International de Genève, 2005). C. Fuente: (Airservices Australia, 2014a).

\section{Quejas sobre ruido}

La mayoría de los aeropuertos implementan sistemas que permiten a la ciudadanía reportar quejas sobre el ruido que sufren en sus domicilios. Dado que el número y la 
distribución de estas quejas puede ser un buen indicador de los efectos del ruido en la vecindad de los aeropuertos, son incluidas en muchos informes periódicos analizados. La información que se muestra relaciona el número de quejas con otros factores como las rutas aéreas, las áreas geográficas sobrevoladas (Airservices Australia 2014c Gatwick Airport, 2015) o el tipo de avión que produjo molestias (London Luton Airport 2014)

La representación gráfica más utilizada son las tablas de texto que muestran el número de quejas remitidas por la misma persona (Chicago Department of Aviation, 2016a; Gatwick Airport, 2015, Heathrow Airport, 2015), el número de quejas relacionadas con el mismo evento sonoro o el número de quejas relacionadas con el mismo modelo de avión (London Luton Airport, 2014). Además, los informes diferencian las quejas recibidas en periodo nocturno y las recibidas en las diferentes áreas geográficas Airservices Australia, 2014c; Chicago Department of Aviation, 2016a).

Otro método de visualización que mejora la comprensión de la información son los mapas cartográficos, mostrados en la Figura 1.13 en los que en las áreas cercanas a los aeropuertos se marcan el número de quejas por barrio, las provenientes de la misma dirección o las quejas individuales junto a la densidad de vuelos

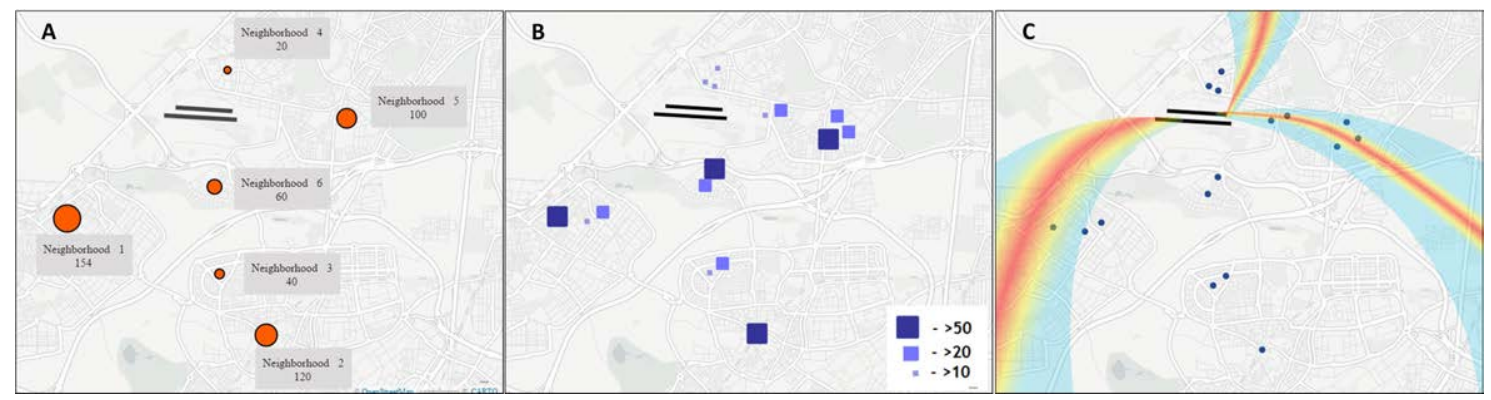

Figura 1.13: Opciones de representación las quejas de ruido en un mapa: A. Número de quejas por barrio. Fuente: Elaboración propia basada en (Heathrow Airport, 2015). B. Número de quejas por dirección postal. Fuente: Elaboración propia basada en (Chicago Department of Aviation, 2016a). C. Relación entre quejas y las rutas seguidas por las aeronaves durante los despegues y aterrizajes. Fuente: Elaboración propia basada en (Gatwick Airport, 2015).

\section{Emisiones acústicas}

Las emisiones acústicas registradas por los sistemas de monitorado de ruido suelen representar la mayoría del contenido de los informes periódicos publicados por los aeropuertos. A pesar de la existencia de normas nacionales referidas a las métricas de ruido, todos los aeropuertos utilizan alguna de las variantes del $L_{A e q, T}$. Utilizando estos índices los aeropuertos comunican el $L_{d n}$ o $L_{d e n}$ en función de la legislación de cada región. Estos descriptores son mostrados para cada día o semana y son presentados junto con métricas adicionales como los niveles percentiles $\left(L_{90}\right)$ para mostrar un nivel aproximado del nivel de ruido de fondo existente en cada punto de medida Airservices Australia 2014b Heathrow Airport, 2013 Peters y Holdich, 2016). Algunos aeropuertos, como Chicago O'Hare, muestran el nivel de ruido de cada operación que excede los límites de ruido utilizando el $L_{A E}$ y $L_{\text {Aeq, }}$ event (Chicago Department of Aviation, 2016b). 
Independientemente de las métricas utilizadas, el aspecto crítico de estos informes es cómo comunican la información a la población. Uno de los métodos más extendidos es utilizar gráficos que representan los niveles de ruido en un intervalo de tiempo específico, siendo dos de ellos los más comunes:

- Gráficos de barras: Incluyendo los histogramas, que son utilizados para representar el nivel de exposición medio en un intervalo de tiempo (Aeropuerto Adolfo Suárez Madrid-Barajas, 2016; Prague Airport, 2016a) o en diferentes estaciones de monitorado de ruido (Prague Airport, 2016b) (Figura 1.14.C). También se utilizan para mostrar la distribución de los niveles de ruido de las operaciones aéreas registradas en un intervalo temporal (Heathrow Airport, 2013; London Luton Airport, 2014) (Figura 1.14 B). Dentro de esta categoría también se incluyen los gráficos de columnas apiladas, que muestran de forma compacta la distribución de niveles de ruido de cada operación o aeropuerto para varios periodos de tiempo en un mismo gráfico (Brussels airport, 2015; London Luton Airport, 2013) (Figura 1.14.A).

- Gráficos de lineas: Estos esquemas son utilizados para relacionar indicadores de ruido con otras variables en la misma visualización. Por ejemplo, el aeropuerto de Sydney los utiliza para comparar el número de eventos detectados y sus niveles medios cada mes (Airservices Australia, 2014c). Los aeropuertos británicos lo usan para representar la evolución del número de personas expuestas a un nivel de ruido determinado y el número de operaciones a lo largo del tiempo (Lee et al. 2013). Otros aeropuertos utilizan estos gráficos para combinar varias métricas en un único panel; por ejemplo, en las campañas de monitorado de ruido de corta duración del San Francisco International Airports muestran la evolución del CNEL, junto al número de operaciones y el ruido medido por cada monitor de la campaña a lo largo de varios días (San Francisco Intertational Airport, 2015c). También aparecen en las campañas de monitorado de corta duración del aeropuerto de Gatwick (Peters y Holdich, 2016) y para mostrar la evolución del ruido de fondo utilizando el percentil 90 para diferentes configuraciones de operación en un aeropuerto (Heathrow Airport. 2013).

Algunos aeropuertos utilizan tablas para mostrar a la ciudadanía la información anteriormente mencionada. En ellos relacionan los niveles de exposición sonora con el area afectada, la población, y el número de viviendas afectadas, y lo comparan con datos de periodos anteriores (London Luton Airport, 2013). Aeropuertos como el de San Francisco especifican adicionalmente el número de edificios que requieren protección acústica especial, como colegios y hospitales (San Francisco Intertational Airport, 2015a).

\subsubsection{Disponibilidad de datos en plataformas abiertas}

Unidos a los cambios propiciados por la evolución tecnológica en los modelos de gestión y creación de políticas mencionados en la sección 1.2 ha aparecido un movimiento de transparencia por parte de las instituciones públicas en multitud de materias, incluyendo la medioambiental.

Martínez define transparencia como "la obligación de los poderes públicos de poner a disposición de todos sus gobernados la información que muestre la estructura y el funcionamiento de cada órgano gubernamental en el ejercicio de sus atribuciones"(Martínez, 2015). Con el avance tecnológico, se ha instaurado la idea de que una democracia requiere de la participación ciudadana en los procesos de policymaking, obtenida a través de plataformas diseñadas para ese fin, y en la que la población tenga acceso a los datos compartidos por la administración que les permitan evaluar su gestión (Reina, 2011). 


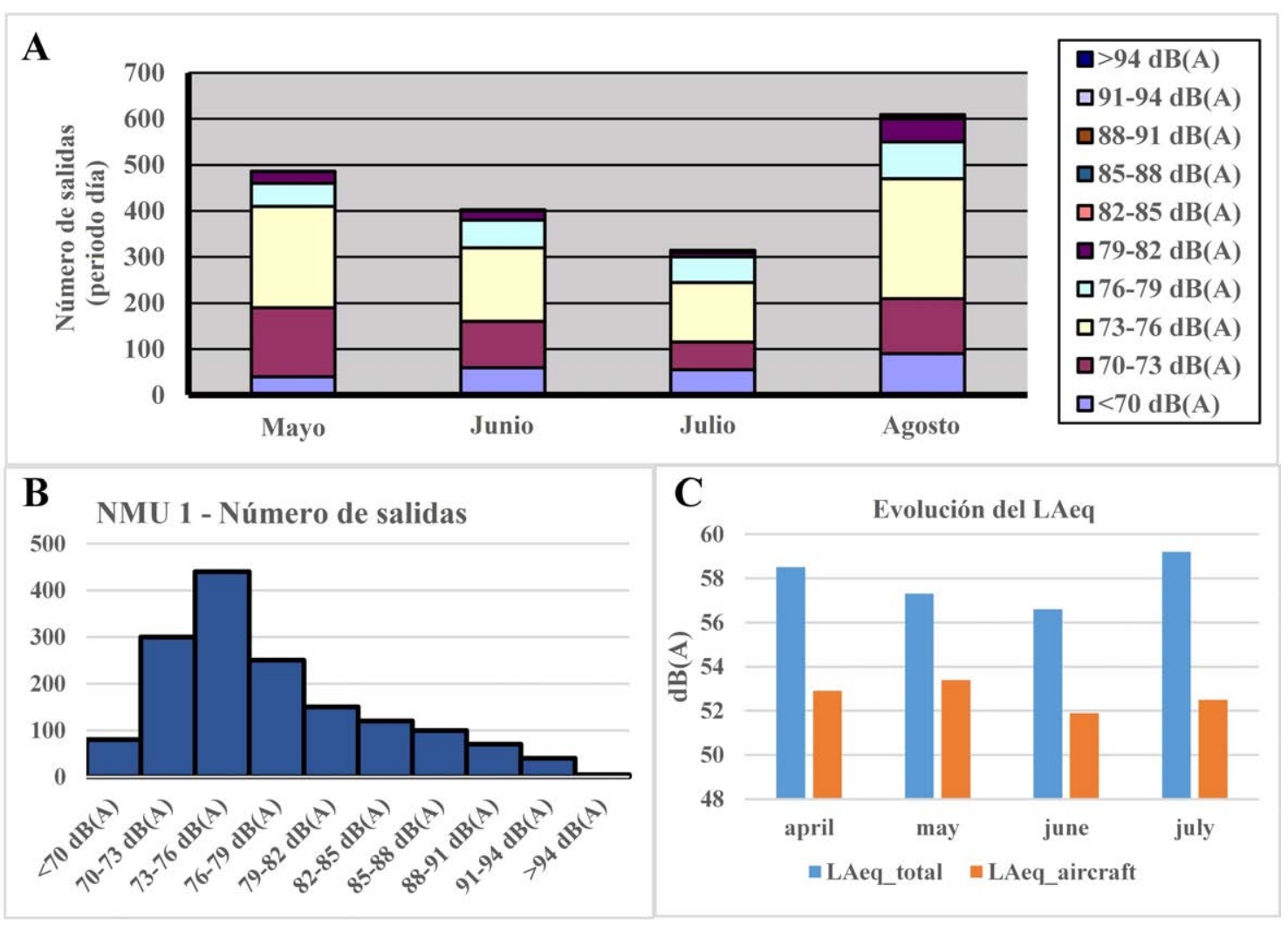

Figura 1.14: Gráficos de barras utilizados en informes sobre ruido de aeropuertos: A. Gráfico de columnas apiladas mostrando la densidad de niveles de ruido a lo largo de 4 meses. Fuente: Elaboración propia basada en (London Luton Airport, 2013). B. Histograma que muestra la distribución de niveles sonoros durante un periodo de tiempo. Fuente: Elaboración propia basada en (Heathrow Airport, 2013). C. Gráfico de columnas que compara el nivel producido por las aeronaves y el nivel de ruido total. Fuenta: Elaboración propia basada en (Aeropuerto Adolfo Suárez Madrid-Barajas, 2016).

Aunque la primera ley de transparencia data de 1766 en Suecia (Hofmann, 2017); no es hasta dos siglos después, con la publicación de leyes en Finlandia o Dinamarca durante la década de 1970, cuando aparece una tendencia de transparencia institucional en Europa tras el desarrollo de las primeras legislaciones modernas que fomentaban el intercambio de datos sobre gobernanza de forma pública a la población (Banisar, 2006). La creciente importancia de la transparencia en las instituciones europeas culmina con la publicación del Libro blanco de la Gobernanza Europea, en el que se proponen las lineas fundamentales para el fomento de la participación y la apertura de las instituciones (European Commission, 2001). Como consecuencia de ese documento, surgieron normas comunitarias como la Directiva 2003/4/CE que define los requerimientos específicos acerca de la publicación y acceso de la información medioambiental (European Parliament, 2003).

A partir de ese momento, y con la intención de implementar las recomendaciones europeas, han ido apareciendo gran número de plataformas para la comunicación de datos en abierto, comúnmente conocidos como open data, tanto a nivel comunitario, como a nivel estatal y local (Ayuntamiento de Madrid, 2018a; European Union, 2019, Gobierno de España, 2019a Mairie de Paris, 2019 Republique Française, 2019). La existencia de estas plataformas ha posibilitado la creación de iniciativas privadas que utilizan esos datos públicos para mejorar la calidad de vida de la ciudadanía, y que pueden ser utilizadas para la detección de problemas urbanos (Chipi, 2019; cleanSpot, 2019). 
Desde el punto de vista de los datos de ruido, se han analizado los portales de datos abiertos de 10 ciudades españolas para conocer la información compartida por los ayuntamientos. Dado que la comunicación de los mapas de ruido es obligatoria por parte de las gestores urbanos y que son publicadas en la web del SICA (Sistema de Información sobre Contaminación Acústica) en formato $p d f$, el análisis se ha centrado en la comunicación de datos sobre campañas de monitorización de ruido y de los sistemas de monitorado de forma pública y con qué periodicidad lo hacen (Gobierno de España, 2019b).

Se ha observado que grandes ciudades como Sevilla, Zaragoza o Murcia, no disponen de sistemas de monitorado de ruido fijo desplegados en la ciudad, o si lo tienen no lo comunican a la población en sus páginas web institucionales. Existen ciudades que comunican los datos de ruidos históricos obtenidos en estudios acústicos realizados previamente: Málaga comunica esta información en forma de documentos de texto indicando la localización de los monitores y las métricas $L_{d}, L_{e}, L_{n}$ y $L_{d e n}$ para cada día de medida (Ayuntamiento de Málaga, 2019). Cáceres comparte en diversos formatos (csv, xls, json, geoson y ttl) los datos de medidas realizadas en un estudio llevado a cabo por Laboratorio de Acústica de la Universidad de Extremadura en el que indican un valor medio de ruido, sin especificar las horas de medida ni la duración de éstas (Ayuntamiento de Cáceres, 2019).

Dentro del grupo de ciudades que tienen sistemas de monitorado de ruido permanentes, encontramos por un lado a Barcelona, cuyo sistema puede ser consultado públicamente en su plataforma Sentilo (Ajuntament de Barcelona, 2019), pero no permite el acceso a datos históricos ni a tiempo real de manera programática. Por el otro lado encontramos a un grupo de ciudades que si que permite acceder a sus datos históricos a través de las plataformas de datos abiertos mencionadas:

- Madrid: Ofrecen datos históricos diarios y mensuales del nivel $L_{d}, L_{e}, L_{n}, L_{A e q, 24 h}$ y percentiles para cada una de las estaciones de medida de ruido, así como su localización, en formato csv. Además, ofrece los datos diarios accesibles mediante API, para cada una de las localizaciones y métricas (Ayuntamiento de Madrid, 2018a).

- Valencia: El Ajuntament de València comparte con una frecuencia mensual los datos diarios de nivel de ruido promedio en las estaciones de monitorado presentes en la ciudad (Ajuntament de València, 2019).

- Santander: En la ciudad comunican el nivel de ruido en cada localización de medida a tiempo real, pero no especifican el tipo de sensor de ruido utilizado, ni las métricas utilizadas o la frecuencia de actualización. Se puede acceder a la información en diversos formatos como csv, html, json, xlm y rdf Ayuntamiento de Santander. 2019). 


\subsection{Retos, oportunidades y justificación de la investigación}

Hasta el momento se ha descrito el problema de la contaminación acústica y sus efectos sobre la salud; cómo el rápido crecimiento de las ciudades y la creciente importancia de las infraestructuras del transporte generan indirectamente un aumento de contaminación acústica que perjudica a la población; y cuáles han sido las legislaciones que han permitido comenzar a gestionar este contaminante de forma relativamente efectiva.

También se ha introducido el efecto de la Revolución Digital en el cambio de los paradigmas de gestión de políticas. Algo que ha posibilitado la mejora de los sistemas de obtención de datos, permitiendo el enriquecimiento del proceso de toma de decisiones y la incorporación de la opinión ciudadana dentro de este. Además, se ha presentado cómo se está implantando progresivamente este método de gestión a través de las mejoras tecnológicas en los sistemas de medida de ruido.

Se han presentado como afectan los factores de naturaleza no acústica en la percepción del ruido y como su modificación pueden provocar un incremento en la aceptación de las actividades que lo generan. Debido a la importancia económica de las infraestructuras aeroportuarias en las regiones y las dificultades en seguir disminuyendo las emisiones sin reducir el número de operaciones, la aplicación de medidas para modificar estos factores han sido explorados e implementados en varios aeropuertos internacionales.

Adicionalmente, se han mostrado los métodos utilizados por ciudades y aeropuertos, tanto histórica como actualmente, para comunicar información sobre contaminación acústica. Se ha expuesto la diversidad de métricas empleadas y se ha observado que, a pesar de las regulaciones existentes para la armonización de dichos índices, existen multitud de particularidades en las diferentes regiones, siendo especialmente significativas en aeropuertos. Se han analizado las estrategias de visualización en la comunicación del ruido y el acceso a la información pública y en relación a los sistemas de monitorado de ruido, se ha recopilado la forma de representar esta información en ciudades y aeropuertos, siendo el sistema de aplicación web el más utilizado.

El objetivo principal de la creación de políticas para la reducción de la contaminación acústica es mejorar el bienestar de la población y disminuir los efectos que el ruido tiene en su salud. Como se introdujo en la sección 1.2.2 los nuevos modelos de policymaking consideran el uso de las tecnologías para: presentar la información al público, incrementar la participación ciudadana y obtener evidencias científicas que permitan tomar las decisiones basadas en datos objetivos.

Sin embargo, a pesar de los avances tecnológicos, se identifica una falta de investigaciones que analicen el efecto de las herramientas de comunicación sobre la información acústica en la ciudadanía, algo de vital importancia puesto que, tal como se introdujo en las secciones 1.1.1 y 1.3 la comunicación de la información acústica es un factor no acústico que puede afectar a la percepción del ruido y puede influir indirectamente en la aceptación de un actividad ruidosa tras modificar factores de influencia como la confianza en las autoridades gestoras y la transparencia. Por ese motivo se define la necesidad de cuantificar la importancia de dicho factor antes de la mejora de los sistemas de visualización.

Por otra parte, se identifica que para recopilar datos sobre la opinión de la población en relación a la contaminación acústica se siguen utilizando técnicas tradicionales, como las encuestas o las plataformas de participación ciudadana. Estas herramientas, a pesar de estar implementadas en plataformas online, presentan dificultades para involucrar a la ciudadanía. Por ese motivo existe la oportunidad de desarrollar nuevos sistemas para conseguir la opinión pública de la situación acústica en ciudades mediante en análisis de las plataformas que ya están siendo utilizadas por esta, y de este modo esquivar la dificultad de involucrar a la población en los procesos de gestión.

Además, aunque los ciudadanos son capaces de reconocer cuando el ruido les gene- 
ra molestia, no pueden conocer las consecuencias que el ruido de su entorno provoca en su salud. A pesar de existir investigaciones que analizan los efectos de la contaminación acústica en el organismo, se ha identificado que suelen estar basados en pequeños grupos de población que proporcionan información de carácter personal mediante medios tradicionales. Sin embargo, existe la posibilidad de utilizar las TICs para obtener información que complemente la ofrecida en los estudios de efectos del ruido tradicionales, mediante la incorporación de nuevas fuentes de datos provenientes de plataformas digitales.

Con ese pretexto, se muestran las principales motivaciones y justificación que han llevado a realizar este trabajo de investigación:

1. La contaminación acústica es un motivo de preocupación medioambiental a nivel internacional, especialmente en la UE donde se han desarrollado leyes para mitigarlo. Por otra parte, organizaciones internacionales como la OMS y las NU han mostrado su preocupación por los efectos de este contaminante en la población y en el entorno, publicando tanto informes técnicos como guías de buenas prácticas (European Environment Agency, 2014, WHO Regional Office for Europe, 2009, 2011).

2. Al comienzo de esta investigación las organizaciones internacionales sólo trataban como fuentes de ruido ambiental problemáticas las asociadas al transporte y la industria, dejando de lado otras fuentes de ruido como las generadas por actividades de ocio, consideradas como ruido de vecindario. Estas fuentes de ruido de ocio tienen gran impacto en algunas regiones de Europa, debido a sus características climáticas, y en grandes ciudades europeas, debido a las grandes masas de población.

3. El crecimiento urbano y la importancia de las infraestructuras del transporte son esenciales para el desarrollo de la sociedad. La contaminación acústica es inherente a este proceso, por lo que es necesario la implementación de nuevos sistemas de gestión de ruido que permitan identificar problemas con rapidez para su tratamiento antes de que se extiendan.

4. Los factores no acústicos que afectan a la percepción sobre el ruido urbano no han sido extensamente investigados hasta el momento. Considerando que el número de personas molestas ha aumentado en los últimos años a pesar de la disminución de los niveles de ruido, es necesario cuantificar los efectos de estos factores que pueden alterar la sensación de molestia, para reducir el porcentaje de población afectada con un menor coste que la reducción de ruido tradicional.

5. Los sistemas de participación ciudadana desarrollados hasta el momento no permiten conocer de forma rápida la percepción sobre actividades ruidosas eventuales o de corta duración. Además, no han logrado obtener una participación lo suficientemente alta para evaluar correctamente el ambiente acústico, algo que es esencial para el correcto funcionamiento de los sistemas de gestión de políticas que se están implantando en la actualidad.

6. Las investigaciones que analizan los efectos del ruido en la salud no consideran fuentes de datos alternativas presentes en plataformas digitales. El uso de la información disponible de forma pública de este tipo de plataformas puede incrementar el conocimiento de los efectos del ruido en la salud y por lo tanto aumentar las evidencias científicas necesarias para crear políticas efectivas que mejoren la calidad de vida de la población.

Una vez identificadas las oportunidades de investigación y sus motivaciones. Se observa que, a pesar de que actualmente se utilizan las TICs en los sistemas de gestión del ruido, no existen investigaciones que analicen el efecto que tiene la implantación de estas 
tecnologías sobre la molestia percibida por la población. De un modo similar, no existen investigaciones que permitan verificar si la información presente en plataformas digitales puede ser utilizada para mejorar el conocimiento sobre los efectos del ruido urbano en la ciudad y la gestión de la contaminación acústica, ni tampoco existen las herramientas necesarias para explotar la información de las TICs al máximo.

\subsection{Hipótesis y objetivos de la investigación}

La investigación se basaba en la hipótesis de que las TICs y la información disponible en las plataformas digitales que funcionan sobre estas tecnologías esconden información relacionada con el ruido y sus efectos en el bienestar de la ciudadanía.

A raíz de esa hipótesis la investigación planteaba un gran objetivo general, que se refería al análisis de las TICs para encontrar información provechosa que permitiera mejorar los sistemas de gestión del ruido y los conocimientos sobre el efecto de este contaminante en la salud de la población. Ese objetivo se subdividió en tres, también con carácter de principales pero de alcance más específico. El primero de ellos se refería a la incorporación de las TICs a los sistemas de gestión de la contaminación acústica en ciudades mediante una implementación que permitiera medir la percepción de las actividades ruidosas en entornos urbanos y valorar el efecto de los factores no acústicos en la molestia. El segundo se refería al uso de fuentes de datos provenientes de Internet para extraer conocimiento acerca de las actividades ruidosas que afectan a la población, y el tercero al uso de datos públicos para medir los efectos del ruido sobre la salud de la población.

Para el cumplimiento del primer objetivo, a lo largo de la investigación se han planteado los siguientes objetivos específicos:

1. Definición de una metodología que permita valorar el efecto que tienen las actividades de comunicación del ruido como factor no acústico sobre la percepción del problema.

2. Definición de estrategias que permitan incrementar la participación de la ciudadanía en el proceso de gestión del ruido y obtener retroalimentación sobre los problemas no considerados en el proceso de gestión.

Para cumplir el segundo objetivo, se especificaron los siguientes objetivos específicos:

1. Definición de nuevas estrategias para la obtención de datos de valoración de actividades ruidosas.

2. Definición de una metodología que permita detectar y analizar automáticamente información sobre la percepción de actividades ruidosas compartidas por la ciudadanía en medios sociales online.

3. Creación de un sistema de monitorización de actividad social en redes sociales que permita identificar actividades ruidosas y su origen a partir del contenido de plataformas digitales.

Para cumplir el tercer objetivo, se especificaron los siguientes objetivos parciales:

1. Definición de una metodología para la estimación de población expuesta a diferentes niveles de ruido a partir de datos públicos.

2. Uso de datos de medios sociales relacionados con la presencia de fuentes sonoras para mejorar el conocimiento de los efectos del sonido en la salud de los ciudadanos de ciudades. 


\subsection{Estructura del documento}

El Capítulo 1 de esta tesis doctoral establece el marco de trabajo de la investigación. Se describe el problema de la contaminación acústica para la salud y cómo el crecimiento de las ciudades y sus infraestructuras están asociados al aumento de este contaminante. Además, se muestra cómo el uso de las tecnologías está cambiando los modelos de gestión de políticas, incluyendo la gestión del ruido. Por otra parte se presenta el conjunto de motivaciones que provocaron esta investigación y los objetivos de la misma. Adicionalmente, se realiza una revisión bibliográfica de las investigaciones en factores no acústicos de molestia y en las herramientas de comunicación implementadas por gestores urbanos y aeroportuarios. Finalmente, se introducen las hipótesis y objetivos de la investigación doctoral.

En el Capítulo 2 de esta memoria se desarrolla la investigación para cuantificar los efectos que la comunicación de la contaminación acústica tiene sobre la percepción de la molestia asociada al ruido de ocio en ciudades. En primer lugar se describe el problema del ruido de ocio existente en las ciudades del sur de Europa. A continuación se presenta la metodología para cuantificar los efectos de la comunicación, que está basada en el uso de las TICs para ofrecer datos a la ciudadanía a través de aplicaciones web y redes sociales, y recabar información sobre la molestia percibida de esta a través de encuestas. En la última sección del capítulo, se presenta los resultados obtenidos.

Durante el Capítulo 3 se muestra una novedosa forma de adquirir los datos de la ciudadanía sin solicitarlos. Debido a que gran parte de la población urbana utilizada medios sociales, se presenta un método basado en técnicas de análisis de lenguaje y de aprendizaje automático para la detección y el análisis de quejas relativas a actividades ruidosas en redes sociales online. Tras presentar y validar la metodología, se presenta un caso de estudio en el que se detectan las actividades molestas para la ciudadanía a través de la monitorización de estos medios online.

Tras verificar que es posible utilizar las redes sociales para obtener información sobre la ciudadanía, en el Capítulo 4 se plantea el estudio de los efectos del ruido utilizando exclusivamente la información disponible de forma pública en medios oficiales y la información extraída de medios sociales. Tras presentar las bases de datos utilizadas y el proceso de preparación de estos, se realiza un análisis estadístico para comprobar si el uso de estos medios sociales puede proporcionar información adicional sobre los efectos del ruido en la población urbana.

En los Capítulos 5 y 6 se presentan las conclusiones y aportaciones, así como la difusión realizada como consecuencia del desarrollo de la tesis doctoral.

En los Apéndices se incluye información y resultados extensos de las encuestas realizadas en el experimento del Capítulo 2. Por último, se ha desarrollado la web https: //luisgasco.github.io/doctoralthesis_website/ en la que se puede consultar contenido extra de las investigaciones realizadas. 


\title{
Capítulo 2
}

\section{Efecto de la comunicación en la percepción del ruido de ocio}

\author{
A good visualization is a representation of data \\ that helps you see what you otherwise would \\ have been blind to if you looked only at the \\ naked source.
}

Nathan You

\subsection{Introducción}

El ruido ambiental es reconocido como un contaminante que perjudica a la salud e interfiere con las actividades de la ciudadanía (Passchier-Vermeer, 1993, Passchier-Vermeer y Passchier, 2000 WHO Regional Office for Europe, 2009 World Health Organization, 1999). En las últimas dos décadas, los gestores medioambientales e investigadores han centrado sus esfuerzos en el estudio y gestión del ruido proveniente de los medios de transporte y de la industria porque son las fuentes sonoras más comunes y afectan a un gran número de personas en el mundo (Laszlo et al. 2012, Miedema y Vos, 1998; Paunovic et al. 2014 Suau-Sanchez et al. 2011). Para ello, la Unión Europea ha publicado normativas como la Directiva 2002/49/CE con el objetivo de reducir la contaminación acústica en la UE (European Parliament, 2002).

Sin embargo, estas normativas no han incluido el ruido de ocio, en gran medida debido a que, en comparación con las fuentes de contaminación acústica mencionadas anteriormente, son contaminantes restringidos a áreas específicas de algunos entornos urbanos, por lo que es considerado como ruido de vecindario (European Parliament, 2002).

El ruido de ocio se genera principalmente por el alboroto producido por aglomeraciones de gente en las proximidades de bares, pubs, terrazas y parques, pero también puede estar asociado a actividades turísticas o eventos especiales como festivales, celebraciones o competiciones deportivas. Estas fuentes de ruido relacionadas con actividades recreativas generan quejas continuas de la ciudadanía por tener efectos evidentes como molestias y alteraciones del sueño que los residentes experimentan de primera mano.

Aunque se produzca eventualmente, el ruido de ocio puede tener un efecto en la contaminación acústica global (Gajardo et al. 2014), y plantea un reto de difícil gestión para las autoridades locales, especialmente en los países del Sur de Europa. Por ese motivo, en los últimos años han sido llevadas a cabo varias investigaciones en este área, a medida que las ciudades se han visto cada vez más obligadas a diagnosticar el problema e implementar medidas de mitigación. De hecho, la OMS (Organización Mundial de la Salud) ha publicado recientemente una guía de buenas prácticas de gestión del ruido ambiental, en 
el que por primera vez, se considera el ruido de ocio como una amenaza para la salud de los ciudadanos europeos que debería reducirse, aunque solo hace referencia a los efectos auditivos que esta fuente sonora tiene sobre las personas que participan en las actividades recreativas (World Health Organization, 2018).

Algunas de las investigaciones se centran en los efectos que tiene el ruido en las personas que participan directamente en la actividad recreativa o que trabajan en ella, pero pocas se centran en el ruido desde el punto de vista de la contaminación ambiental, la salud de los residentes, su bienestar y como influye en los precios de la vivienda (Axelsson, 1991. Beach, 2017, Butterfield, 2006, Dalton et al., 2001, Dehnert et al., 2015, Gilliver et al. 2015. Peters, 2003 Serra et al. 2007, Tung y Chao, 2013).

Fimiani (Fiamini y Luzzi 2015) describe el problema del ruido de ocio en el centro de la ciudad de Bolonia (Italia), en el que se instaló una red de monitorado de ruido de bajo coste para evaluar el ruido. También en Italia, una investigación de Ottoz (Ottoz et al. 2015, 2016, 2018), detalla la situación en Milán y Turín, donde se realizaron encuestas online para analizar el bienestar de los residentes en las áreas de estudio y se llevó a cabo una campaña de monitorado de ruido que mostró los altos niveles de ruido a los que estaban expuestos los ciudadanos de esas zonas. Vinci (Vinci et al., 2017) decidió colocar sensores de ruido en domicilios privados del centro de Pisa (Italia) para mostrar que los mapas estratégicos de ruido no suelen estar bien dimensionados para el caso de las ciudades del Mediterraneo, debido al ruido de ocio.

Ballesteros (Ballesteros, 2014, Ballesteros et al., 2014) empleó un enfoque diferente: propone predecir los niveles de ruido a través de un modelo analítico basado en variables como el número de establecimientos de ocio, el ancho de la calle y la altura media de los edificios. Además, en sus investigaciones utiliza el método soundwalker, consistente en realizar medidas continuas a lo largo de un recorrido definido, para adquirir los niveles sonoros y evaluar las emisiones de ruido producidas por actividades individuales en áreas de alta densidad de locales de ocio (Ballesteros et al. 2015).

La monitorización de ruido a corto plazo ha sido utilizada en el pasado para evaluar el nivel de ruido que se produce en festivales de música, y ha sido utilizada para medir los niveles en zonas específicas donde el ocio es un problema en ciudades como Madrid, Barcelona y Palma de Mallorca (Garg et al., 2016, Lakin et al., 2001; Sound Solution Consultants, 2010).

Por otra parte, varios estudios han demostrado que las características del ruido, como la intensidad o la frecuencia, solo describen parte de la molestia que generan en la población, existiendo otros factores de naturaleza no acústica que también influyen sobre esta. Además, estudios recientes han señalado que esos factores no acústicos afectan tanto a las actividades ruidosas de larga duración como a las puntuales (Gille et al. 2017, Guski et al. 1999 Hume et al. 2004).

En el año 2007 Vader recopiló un conjunto de 31 factores no acústicos que podrían influir en la molestia por ruido en entornos aeroportuarios (Vader, 2007). Algunos de los factores que menciona Vader son la accesibilidad y transparencia institucional, reconocimiento del problema del ruido por parte de las autoridades y la confianza de la población en éstas. De hecho, a raíz de esas investigaciones se llevaron a cabo estudios con intención de modificar esos factores no acústicos para que disminuyeran la molestia global generada por los aeropuertos, de forma que pudieran coexistir de forma sana la infraestructura y la población (Sánchez et al. 2015).

Se ha mostrado que la problemática del ruido del ocio está cobrando importancia para los gestores urbanos, especialmente en las ciudades del sur de Europa donde el clima favorece las actividades al aire libre durante la mayor parte del año. La importancia económica de las actividades lucrativas en las ciudades, íntimamente relacionadas con el sector turístico y el de la restauración, hace que la reducción de este tipo de ruido sea complicada, lo 
que favorece la búsqueda de nuevos métodos para disminuir la molestia de la población, que afecta de forma indirecta sobre su salud. Este hecho, junto a la existencia de factores no acústicos que permiten modificar la sensación de molestia, que ya han sido sido estudiados previamente en entornos aeroportuarios, nos proporcionan un marco idóneo para experimentar si algunos de estos agentes puede tener influencia en la percepción de este tipo de ruido.

\subsection{Objetivos del experimento}

Este experimento de la tesis doctoral se apoya sobre la hipótesis de que es posible modificar la molestia generada por el ruido de ocio a través de factores no acústicos, específicamente los relacionados con la accesibilidad a la información sobre contaminación acústica y la transparencia institucional. Este capítulo se centra en el desarrollo de la investigación para cumplir el primer objetivo general de la tesis doctoral, que es la incorporación de las TICs a los sistemas gestión de la contaminación acústica en ciudades para beneficiar la comunicación entre la ciudadanía y los gestores.

Dicho objetivo global será abordado en este capítulo mediante la consecución de los siguientes objetivos parciales:

1. Definición de una metodología que permita valorar el efecto que tienen las actividades relativas a la comunicación de la contaminación acústica sobre la percepción de la molestia asociada al ruido de ocio.

2. Definición de estrategias que permitan incrementar la participación de la ciudadanía en el proceso de gestión del ruido y obtener retroalimentación sobre los problemas no considerados en el proceso de gestión.

\subsection{Málaga y el problema del ruido de ocio}

Málaga es una ciudad situada en la costa mediterránea del Sur de España, con una población de más de medio millón de habitantes y un término municipal de $398 \mathrm{~km}^{2}$. Su clima cálido y el gran número de días soleados han promovido el turismo durante años y favorecen las actividades al aire libre durante todo el año; de hecho, la ciudad recibe más de un millón de turistas anualmente (Ayuntamiento de Málaga, 2009, 2015). Esto provoca que haya grandes masas de personas en las calles, cuya afluencia a terrazas, bares de copas o establecimientos comerciales produce altos niveles de ruido, perjudicando el bienestar de los residentes permanentes. Como respuesta a esa problemática, las autoridades malagueñas identificaron el ruido de ocio como uno de los problemas medioambientales más importantes de la ciudad y en 2014 pusieron en marcha una iniciativa para abordar este problema, comenzando con un diagnóstico exhaustivo durante el año 2015 en dos áreas de especial preocupación: el centro histórico y el barrio Teatinos-Universidad.

El centro histórico es la parte más antigua de la ciudad. Tiene una extensión de 3.17 $\mathrm{km}^{2}$ con predominio de calles peatonales, calles estrechas y más de 1000 locales de ocio como restaurantes, bares, pubs y terrazas Ayuntamiento de Málaga, 2012a DonDeNegocios Geomarketing, 2017), debido a que este área ha experimentado un incremento sustancial de la actividad turística y recreativa en los últimos años. Desde los años 60, los residentes de esta zona han disminuido gradualmente. Para frenar la despoblación, en los años noventa se implementó el Plan Especial de Protección y Reforma Interior del Casco Histórico (PEPRI) (Gutiérrez, 2005). Esta iniciativa consistió en mejorar los problemas de seguridad y mitigar el abandono del centro de la ciudad mediante la remodelación de edificios históricos, el aumento del número de zonas verdes, el fomento de la rehabilitación de viviendas privadas y el estímulo en la creación de empresas locales para prestar servicios a 
los residentes (Ayuntamiento de Málaga 2010). Estas medidas lograron frenar el éxodo del centro histórico, pero con la llegada de la crisis económica del año 2008, muchas empresas locales se transformaron en restaurantes y centros de ocio (DonDeNegocios Geomarketing, 2017), tratando de aprovechar el rápido crecimiento de la ciudad como uno de los principales centros turísticos del Sur de España (Ayuntamiento de Málaga, 2009, 2015). Los destinos turísticos y las actividades de ocio han fomentado la afluencia de turistas y ciudadanos al centro de la ciudad, por lo que se trata de una zona muy concurrida durante el día. La actividad nocturna se ha centrado en algunos lugares específicos, especialmente durante los fines de semana. En el área del centro de la ciudad considerada en este experimento viven aproximadamente 1600 personas, según las estadísticas proporcionadas por el ayuntamiento.

El barrio Teatinos-Universidad, que en este capítulo se denominará como Teatinos para simplificar, es una nueva zona residencial creada en 1983 y ampliada en 1998 por los planes generales de expansión de la ciudad de Málaga en esos años (Marín, 2015). Esta zona residencial tiene una extensión de $5.4 \mathrm{~km}^{2}$ con calles y avenidas anchas (Ayuntamiento de Málaga 2012b y grandes aceras, a menudo ocupadas por terrazas exteriores de bares y restaurantes. El campus de la Universidad de Málaga está situado en este distrito, por lo que hay negocios de ocio nocturno en la zona y un gran número de gente joven entre los residentes. En las zonas del distrito en las que se desarrolló el experimento residen aproximadamente 2200 personas, según las estadísticas del ayuntamiento.

\subsection{El proyecto ETIC-GIRU}

El experimento que se presenta en este capítulo estuvo englobado dentro de un proyecto de mayor alcance denominado Explotación de las Tecnologías de la Información y las Comunicaciones en la Gestión Inclusiva del Ruido Urbano (ETIC-GIRU). Este proyecto realizado conjuntamente para el Ayuntamiento de Málaga, por el Grupo de Investigación en Instrumentación y Acústica Aplicada de la Universidad Politécnica de Madrid y la empresa VATIA Energía S.L., pretendía hacer una valoración del impacto del ruido de ocio en las áreas de la ciudad de Málaga especificadas anteriormente, involucrando a los grupos de población afectados por este problema mediante sistemas tradicionales y las TICs, teniendo en cuenta tanto a los gestores urbanos como a la ciudadanía.

En el proyecto se llevó a cabo una campaña de monitorado de ruido con 40 puntos de medida distribuidos en las zonas afectadas. La mayoría de las localizaciones de medida, 35, fueron instalados en el centro de la ciudad, mientras que las otras cinco estuvieron situadas en Teatinos. Estos puntos de medida se posicionaron en las áreas con el mayor número de actividades de ocio y número de quejas. Se realizaron medidas con un mínimo de 9 monitores midiendo simultáneamente en las diferentes localizaciones durante un periodo continuado de 6 meses, pero asegurando al menos 8 semanas de datos de ruido en cada una de ellas. Cada monitor consistía en un sonómetro de tipo 1 certificado y estaban instalados siguiendo las especificaciones de la norma ISO 1996-2 (International Organization for Standardization, 2007a).

De cara a presentar la información a la ciudadanía, los miembros del equipo de trabajo desarrollaron una aplicación web para mostrar públicamente los datos de los monitores a tiempo real, con la intención de mejorar la confianza y la transparencia del Ayuntamiento de Málaga. Los sonómetros medían niveles de presión sonora equivalente ponderado A en intervalos de 1 segundo $\left(L_{A e q, 1 s}\right)$. La plataforma mostraba esa información de ruido de forma interactiva, así como el nivel máximo y los niveles acumulados de día, tarde, noche y día-tarde-noche para cada una de las ubicaciones. En la aplicación también aparecía información sobre el equipo y su localización, mediante un mapa interactivo. En la Figura 2.1 se puede ver una captura de la aplicación. 


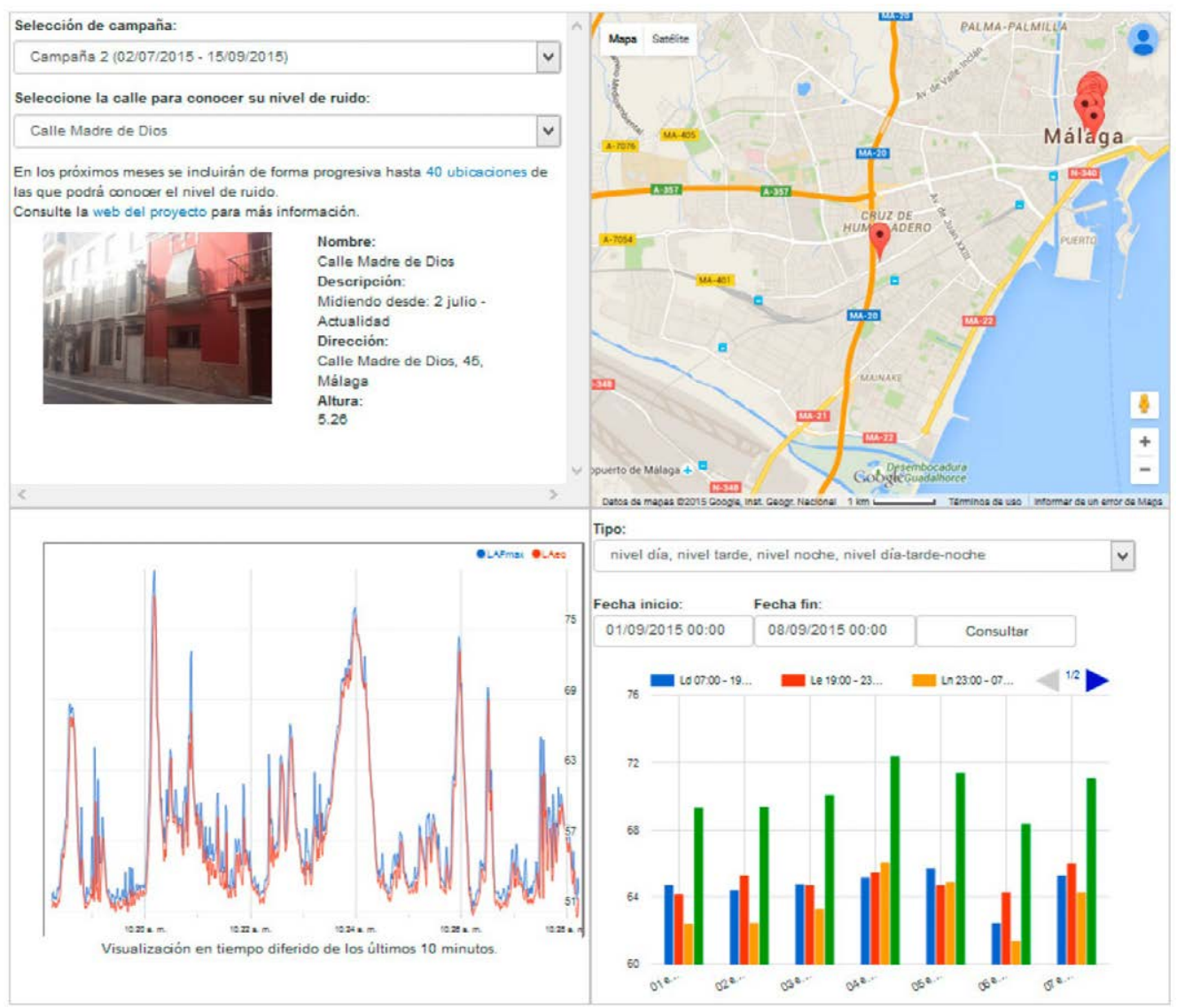

Figura 2.1: Interfaz gráfica de la aplicación de visualización de datos de ruido a tiempo real. El sistema fue optimizado para que pudiera accederse desde PC y dispositivos móviles.

\subsection{Metodología}

El objetivo de este experimento era cuantificar los efectos que la comunicación de la información sobre contaminación acústica tenía sobre la molestia percibida por la ciudadanía. Con ese fin se planteó una metodología, aprovechando las actividades e infraestructura implementadas en el proyecto ETIC-GIRU, que permitiera comprobar si ese factor afectaba a la percepción de molestia asociada al ruido de ocio y cuantificarlo.

El experimento se planteó en dos fases. En la primera, se llevó a cabo un estudio basado en encuestas para conocer la molestia de la población residente en las dos áreas donde los monitores de ruido iban a ser instalados. En la segunda se realizó otro cuestionario, difundido junto la información relativa al proyecto de monitorización, para cuantificar si existían diferencias en la molestia achacables a las campañas de comunicación del proyecto, la plataforma de visualización y la implantación del sistema de medida de ruido.

Por lo tanto, se quería realizar una evaluación PRE-POST para evaluar el efecto que la comunicación y visualización de los datos de ruido tuvo sobre la molestia percibida de los residentes en las zonas de estudio.

\subsubsection{Primera fase}

La primera fase experimental se dividió en dos etapas. En primer lugar se diseñó un cuestionario de valoración de ruido que permitiera conocer el impacto del ruido del ocio en la población. En esta fase la manera de participar en la encuesta fue mediante 
invitación por carta, sin que el ciudadano supiera que posteriormente se iba a llevar a cabo una campaña de monitorado, por lo que se definió un método para la obtención de participantes para la encuesta de forma controlada en las áreas de interés del estudio.

\subsubsection{Encuesta inicial}

Se decidió utilizar cuestionarios para medir la percepción ciudadana del ruido presente en el entorno de sus viviendas. Aunque esta investigación se centraba en las emisiones sonoras asociadas a las actividades de ocio, se optó por ampliar el alcance de la encuesta para obtener información acerca de otras fuentes de ruido que afectaran a la ciudadanía malagueña, como el tráfico rodado. El diseño de la encuesta desarrollada se basó en la Noise Attitude Survey desarrollada por DEFRA en el Reino Unido (DEFRA, 2014), adaptándola a las necesidades del proyecto.

A diferencia del cuestionario desarrollado por DEFRA, pensado para realizarse mediante entrevistas cara a cara, algo que posibilitaba aumentar la duración de la encuesta; se decidió utilizar un formato de cuestionario online para el proyecto, dado que uno de los objetivos de la investigación era la aplicación de las TICs en la gestión del ruido. Las encuestas online presentan la ventaja de obtener un gran número de respuestas sin grandes inversiones económicas, pero tienen la dificultad de conseguir que los encuestados respondan el cuestionario en su totalidad. Por ese motivo, se simplificó la encuesta de DEFRA para evitar que los ciudadanos la abandonaran sin completarla. Para ello se diseño un cuestionario en el que el usuario, tras responder preguntas generales sobre la molestia que le generaban distintas fuentes de ruido, se le redirigía a una sección en la que se le pedía opinión sobre la fuente de ruido que eligió como la más molesta. Debido a que el ruido de ocio era el origen sonoro con mayor número de quejas en los barrios afectados, se pretendía conseguir mucha información sobre esta fuente, sin perder información sobre otras fuentes de ruido que perturbaran a un porcentaje menor de la población residente en las áreas de interés.

El cuestionario fue implementado en la herramienta QuestionPro (Question Pro 2018), que es un servicio de encuestas multiplataforma que dispone de los protocolos de seguridad requeridos tanto para proteger la información personal de los ciudadanos como para evitar múltiples respuestas provenientes del mismo usuario mediante el uso de cookies, y que además incluye muchos formatos de preguntas y lógica diferentes. Esta herramienta permite diseñar la encuesta con una interfaz de usuario amigable, adaptable al tamaño de pantalla del dispositivo desde el cual se cumplimenta y permite integrar en una única pregunta la valoración de múltiples elementos, algo esencial para reducir la longitud de la encuesta. Por ejemplo, la Figura 2.2 muestra el formato utilizado para evaluar la molestia producida por diferentes fuentes de ruido relacionadas con los trenes. En vez de realizar la misma pregunta seis veces, una para cada fuente de ruido, todas las opciones se pueden agrupar bajo una misma pregunta, posibilitando además la inserción de texto libre por si el encuestado quiere dar información adicional. De este modo se consiguió reducir el número de pantallas por las que el usuario tuvo que navegar en la encuesta, disminuyendo la sensación de estar contestando una encuesta demasiado larga.

La encuesta estuvo organizada en seis secciones:

1. Datos sociodemográficos: En este bloque a cada encuestado se le preguntó su edad, sexo o su barrio de residencia.

2. Vivienda del encuestado: Se solicitó a los participantes que proveyeran información básica sobre su vivienda como el tiempo que llevaban residiendo en ella o la percepción que tenían sobre el aislamiento acústico de esta.

3. Relación del encuestado con el ruido: Se buscaba conocer la sensibilidad del 


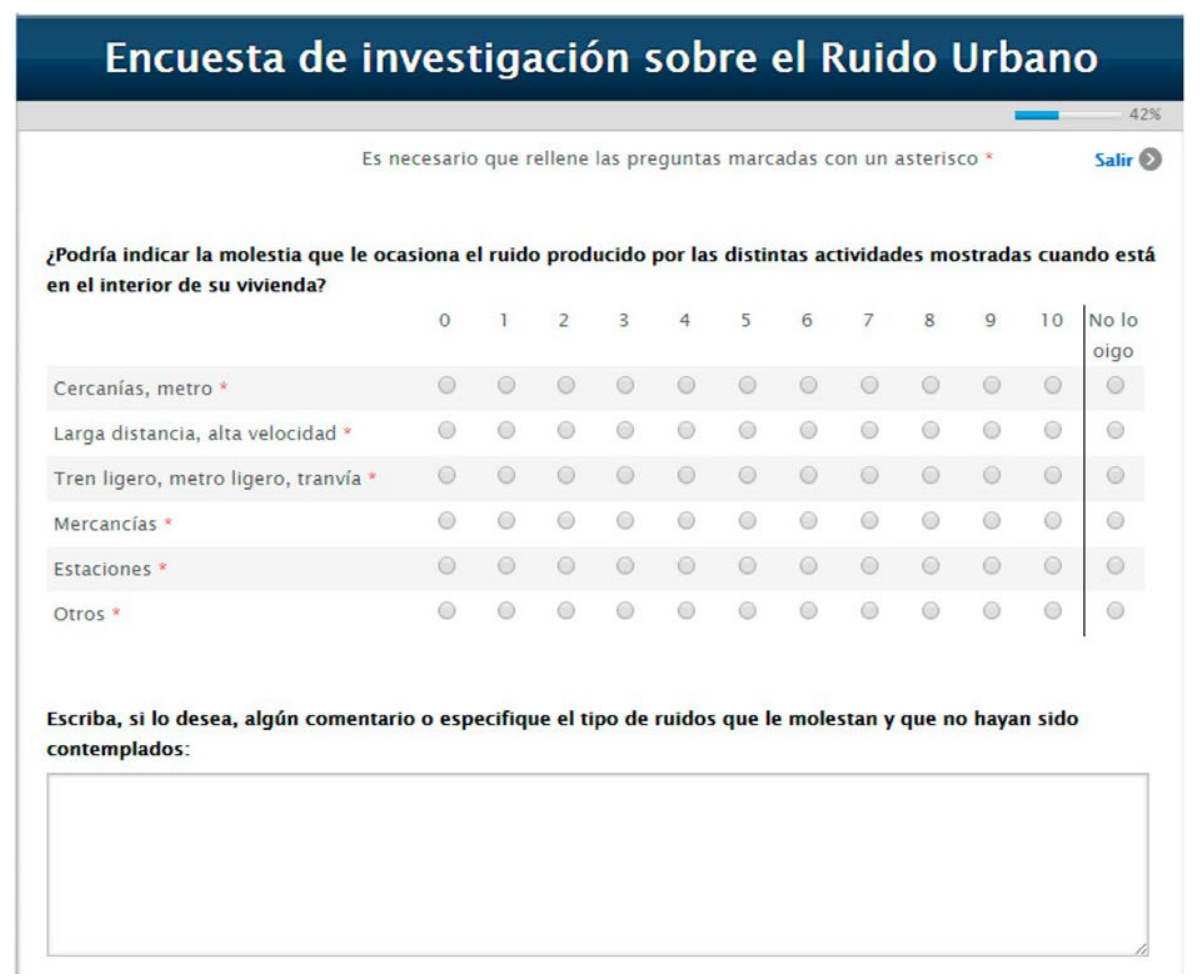

Figura 2.2: Ejemplo de la interfaz gráfica del cuestionario implementado en QuestionPro.

participante a los sonidos no deseados, su percepción sobre los niveles sonoros en su vecindario o la fuente de ruido más molesta para él.

4. Fuentes del ruido del vecindario: En el cuarto bloque se le solicitaba información sobre los efectos que tenía el ruido en su calidad de vida, si la situación acústica había mejorado o empeorado en los últimos años o si había tomado alguna acción para luchar contra las actividades ruidosas.

5. Fuentes de ruido específicas: En primer lugar se preguntaba por la fuente de ruido con mayor afección en la vivienda del encuestado. Después, en función de la fuente elegida, se le hicieron preguntas específicas sobre esta.

6. Sensaciones y frecuencia del ruido específico: Por último se le hicieron preguntas sobre la fuente elegida en el bloque anterior para conocer sus sensaciones cuando la escuchaba y la frecuencia de aparición de ese sonido en su día a día.

La Tabla 2.1 muestra de forma más extensa las preguntas realizadas en cada bloque. La columna "Encuesta" indica las preguntas que fueron realizadas tanto en el cuestionario inicial como en el final, indicándolo mediante el código "PRE/POST". Adicionalmente, se muestran los códigos que se utilizarán en análisis posteriores y cuales de ellas fueron de obligada contestación mediante un asterisco.

En el Apéndice A se puede consultar el extracto de la encuesta completa de QuestionPro, donde aparecen las opciones de respuesta utilizadas en cada una de las preguntas. Además, se ha desarrollado una web con contenido interactivo de esta tesis doctoral en el que se puede consultar la versión que fue cumplimentada por los ciudadanos ${ }^{1}$.

\footnotetext{
1/https://luisgasco.github.io/doctoralthesis_website/
} 
Tabla 2.1: Preguntas formuladas en los cuestionarios inicial y final del experimento.

\begin{tabular}{|c|c|c|c|}
\hline Bloque & Encuesta & Código & Pregunta \\
\hline \multirow{8}{*}{ Socio-demográficos } & \multirow{7}{*}{$\mathrm{PRE} / \mathrm{POST}$} & SD1 & Género \\
\hline & & SD2 & $\operatorname{Edad}^{*}$ \\
\hline & & SD3 & Nacionalidad* \\
\hline & & $\mathrm{SD} 4$ & Nivel de estudios \\
\hline & & SD5 & $\begin{array}{l}\text { ¿Cuál de las siguientes opciones describe mejor su situación } \\
\text { actual? }\end{array}$ \\
\hline & & SD6 & Municipio de residencia \\
\hline & & SD7 & ¿Cuánto tiempo hace que reside en esta ciudad?* \\
\hline & POST & sel_distr & ¿En qué distrito de Málaga reside?* \\
\hline \multirow{3}{*}{ Vivienda } & \multirow{3}{*}{$\mathrm{PRE} / \mathrm{POST}$} & $\mathrm{V} 1$ & ¿Cuánto tiempo lleva residiendo en esta vivienda? \\
\hline & & $\mathrm{V} 2$ & ¿Cómo valora el aislamiento acústico de esta vivienda?* \\
\hline & & $\mathrm{V} 3$ & $\begin{array}{l}\text { ¿Cuentan las ventanas de su vivienda con doble acristalamien- } \\
\text { to? }\end{array}$ \\
\hline \multirow{3}{*}{ Relación con el ruido } & \multirow{3}{*}{$\mathrm{PRE} / \mathrm{POST}$} & RR1 & ¿Cómo de sensible se considera usted con respecto al ruido?* \\
\hline & & RR2 & ¿Cómo de ruidoso considera que es su barrio?* \\
\hline & & RR3 & $\begin{array}{l}\text { ¿Pertenece usted, o alguno de los residentes en su vivienda a } \\
\text { alguna asociación o agrupación que tenga entre sus objetivos } \\
\text { la lucha contra el ruido? }\end{array}$ \\
\hline
\end{tabular}

\begin{tabular}{|c|c|c|c|}
\hline & & \\
\hline & & RR4 & $\begin{array}{l}\text { ¿Hasta que punto diría que le molesta, incomoda o afecta el } \\
\text { ruido que procede de la calle? } *\end{array}$ \\
\hline & & RR5 & $\begin{array}{l}\text { ¿Podría indicar cuánto le molesta o incomoda el ruido produ- } \\
\text { cido por las siguientes fuentes sonoras?* }\end{array}$ \\
\hline \multirow{5}{*}{ Todas las fuentes de ruido } & \multirow{5}{*}{$\mathrm{PRE} / \mathrm{POST}$} & TFR1 & ¿Considera que el ruido es un problema en su vida?* \\
\hline & & TFR2 & $\begin{array}{l}\text { ¿Podría valorar en qué medida el ruido existente en esta zona } \\
\text { deteriora su calidad de vida?* }\end{array}$ \\
\hline & & TFR3 & $\begin{array}{l}\text { ¿Considera que la situación respecto al ruido en esta vivienda } \\
\text { es mejor o peor que hace } 5 \text { años?* }\end{array}$ \\
\hline & & TFR4 & $\begin{array}{l}\text { ¿Usted o alguien de su familia ha emprendido alguna acción } \\
\text { para solucionar un problema relacionado con el ruido existente } \\
\text { en su zona o su vivienda? ¿Fue dicha acción efectiva? }\end{array}$ \\
\hline & & TFR5 & $\begin{array}{l}\text { ¿A cuáles de las siguientes fuentes de ruido estaban ligadas las } \\
\text { acciones que ha mencionado en la pregunta anterior? }\end{array}$ \\
\hline \multirow[t]{2}{*}{ Fuentes de ruido específicas } & \multirow[t]{2}{*}{$\mathrm{PRE} / \mathrm{POST}$} & RE1 & $\begin{array}{l}\text { ¿Podría indicar cuál de las siguientes fuentes de ruido le afecta } \\
\text { más cuando está en su vivienda?* (ocio, tráfico...) }\end{array}$ \\
\hline & & RExx & $\begin{array}{l}\text { Conjunto de preguntas específicas para la fuente de ruido es- } \\
\text { pecificada en la pregunta RE1 }\end{array}$ \\
\hline \multirow{6}{*}{ Tipo de ruido específico elegido } & \multirow{6}{*}{$\mathrm{PRE} / \mathrm{POST}$} & TR1 & $\begin{array}{l}\text { Seleccione un máximo de CINCO palabras que mejor descri- } \\
\text { ban su sentimiento cuando escucha ese tipo de ruido* }\end{array}$ \\
\hline & & TR2 & $\begin{array}{l}\text { ¿Interfiere ese tipo de ruido a alguna de las actividades que } \\
\text { realiza en su casa durante su vida cotidiana?* }\end{array}$ \\
\hline & & TR3 & $\begin{array}{l}\text { ¿En qué periodos del día le molesta o incomoda esta fuente de } \\
\text { ruido? }\end{array}$ \\
\hline & & TR4 & ¿Con qué frecuencia se produce el ruido que le molesta? $*$ \\
\hline & & TR5 & ¿En qué época le molesta más ese tipo de ruido?* \\
\hline & & TR6 & $\begin{array}{l}\text { ¿Diría que el ruido procedente de esa fuente en concreto ha } \\
\text { mejorado o empeorado a lo largo de los últimos } 5 \text { años? }\end{array}$ \\
\hline \multirow{5}{*}{ Red de monitorado de ruido } & \multirow{5}{*}{ POST } & TMR1 & $\begin{array}{l}\text { El Ayuntamiento ha instalado recientemente un sistema de } \\
\text { monitorado de ruido en Málaga, ¿conocía usted su existencia? }\end{array}$ \\
\hline & & TMR2 & ¿Se ha conectado a la aplicación web/móvil? * \\
\hline & & TMR3 & $\begin{array}{l}\text { ¿Cuáles de los siguientes objetivos considera que cubre esta } \\
\text { iniciativa? }\end{array}$ \\
\hline & & TMR4 & $\begin{array}{l}\text { ¿Que carencias encuentra en la aplicación que deberían ser } \\
\text { incluidas en el futuro? }\end{array}$ \\
\hline & & dir_mon & $\begin{array}{l}\text { ¿Desea facilitarnos su dirección postal para mejorar los resul- } \\
\text { tados del estudio?* }\end{array}$ \\
\hline
\end{tabular}




\subsubsection{Muestreo e invitación a participar}

Una de las retos encontrados a la hora de diseñar el experimento fue la obtención de la muestra necesaria para la encuesta inicial. Se necesitaba llegar a la ciudadanía residente en las áreas de estudio, que eran los más molestos por el ruido de ocio y los más cercanos a los monitores de ruido instalados en la ciudad. Además, el Ayuntamiento no podía intervenir en la difusión del cuestionario para evitar sesgos asociados a la gestión municipal o ideologías políticas en las respuestas y se necesitaba conocer el lugar de residencia de las personas que las cumplimentaran para que, en caso de que fuera necesario, se pudieran relacionar en los análisis los niveles de ruido con las valoraciones de los ciudadanos.

Para la obtención de respuestas únicamente de la población residente en las áreas de estudio, se decidió enviar invitaciones a las viviendas existentes en esas zonas. Únicamente pudieron acceder los ciudadanos que recibieron la invitación, que contestaron antes de que se difundiera públicamente el proyecto de monitorado de ruido.

Para seleccionar las viviendas se utilizó la información pública disponible en el Catastro (Gobierno de España, 2015). El Catastro es un registro administrativo que describe todos los bienes inmuebles del país, utilizando este registro es posible obtener las direcciones postales de las viviendas de una ciudad. Se delimitaron las calles de las zonas de estudio, mostradas en la Figura 2.3, identificando dos subáreas en el centro histórico y una tercera en Teatinos-Universidad. Se extrajo el censo de viviendas para cada una de las calles de las distintas zonas, obteniendo un total de 2226 viviendas: 1455 en la Zona 1, 223 en la Zona 2 y 548 en la Zona 3 .
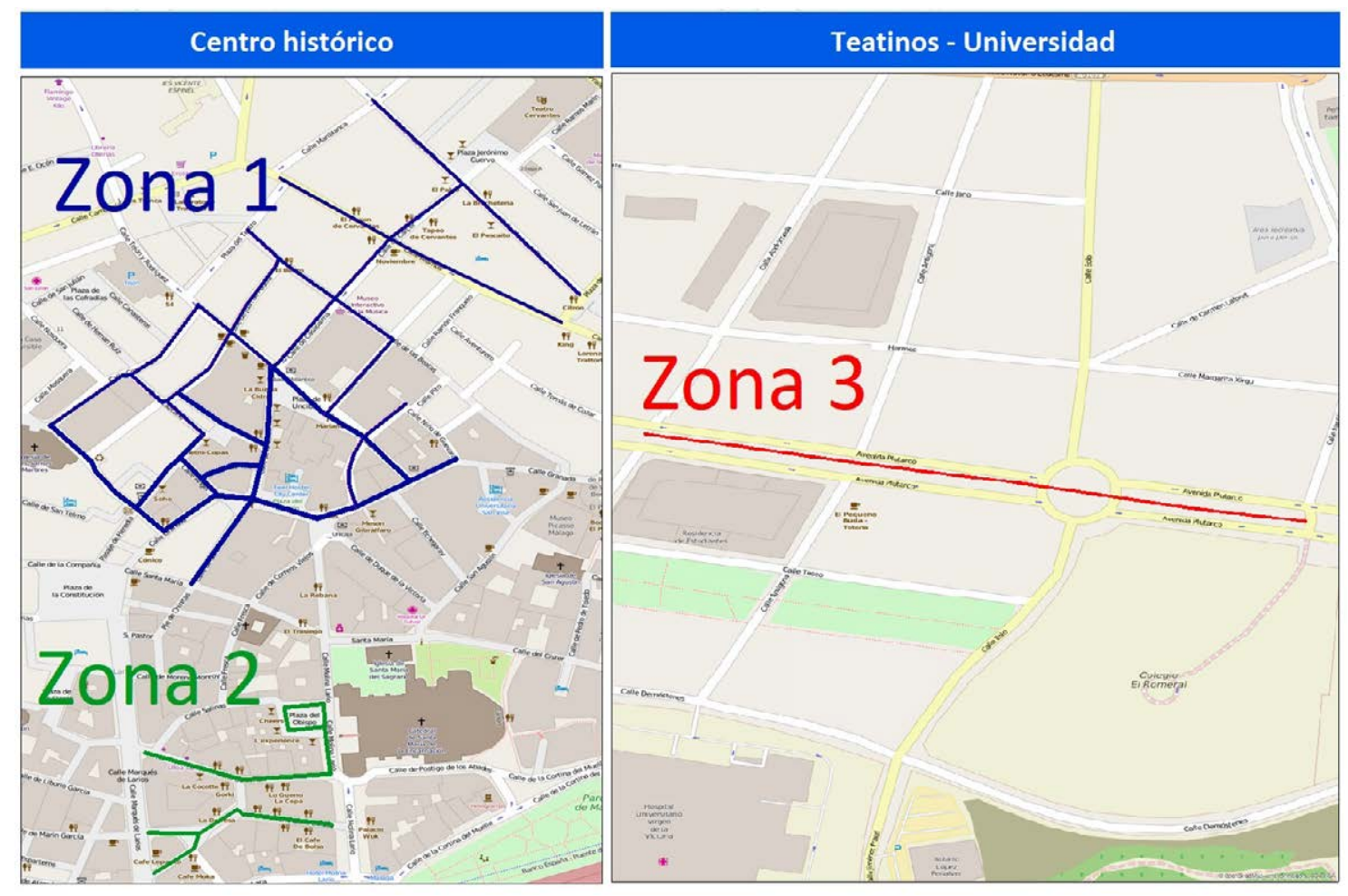

Figura 2.3: Delimitación de las calles consideradas en el estudio, indicando las subdivisión en zonas consideradas.

Debido a que cada una de las áreas podría tener una situación acústica diferente y el número de viviendas era desigual en cada vecindario, se optó por utilizar un muestreo aleatorio estratificado con afijación proporcional para calcular el número de respuestas que 
se necesitaban en cada una de las zonas para obtener resultados fiables (Vivanco, 2005). Teniendo en cuenta que se quería conseguir un margen de error menor del $10 \%$ y tener un nivel de confianza del $95 \%$ se utilizó la Ecuación 2.1 para calcular el tamaño muestral necesario (Vivanco, 2005):

$$
n=\frac{z^{2} * p *(1-p)}{c^{2}}=96 \approx 100
$$

donde $z$ depende del valor del nivel de confianza deseado, en este caso 1.96; $c$ es el margen de error expresando porcentaje con decimales, 0.1 ; y $p$ el porcentaje de individuos molestos por ruido en estas áreas, que como se desconoce se elige el peor de los escenarios, 0.5 .

Para cumplir los requerimientos marcados se necesitaban un total de 100 encuestas para obtener una muestra representativa. Como se ha mencionado, a priori se contaba con tres áreas diferenciadas, por lo que se utilizó el muestreo aleatorio estratificado con afijación proporcional, representada en la Ecuación 2.2, para calcular el número de participantes necesarios en cada una de las subáreas (Vivanco, 2005):

$$
\frac{N_{\text {Zona } 1}}{n_{1}}=\frac{N_{\text {Zona } 2}}{n_{2}}=\frac{N_{\text {Zona } 3}}{n_{3}}=\frac{N_{\text {Total }}}{n}
$$

donde $N_{Z_{o n a}}$ es el número de viviendas existentes en cada una de las áreas, $N_{\text {Total }}$ la suma de viviendas presentes en las tres zonas y $n$ toma el valor 100.

Resolviendo el sistema de ecuaciones se obtuvieron los tamaños muestrales necesarios para cada una de las zonas de estudio, mostrados en la Tabla 2.2. Además, debido a que se iban a enviar invitaciones por correo ordinario y que no todo el mundo que recibiera la invitación iba a contestar, fue necesario enviar más cartas de las obtenidas en los cálculos muestrales. Se asumió una tasa de respuesta del $10 \%$, un valor muy conservador si se compara con la utilizada en la bibliografía, que a pesar de ofrecer resultados dispares, suele estar entre el $30 \%$ - 50\% para encuestas online con invitación por carta o email (Fan y Yan, 2010, Manfreda et al., 2008, Millar y Dillman, 2011, Petrovcic et al., 2016, Rolstad et al. 2011, Sauermann y Roach, 2013; Shih y Fan, 2008). Teniendo en cuenta esa tasa de respuesta, hubo que multiplicar por 10 el número de invitaciones que debían enviarse a cada una de las zonas, obteniendo los resultados mostrados en la tercera columna de la Tabla 2.2.

Tabla 2.2: Resultados de cálculos muestrales y $\mathrm{n}^{\circ}$ de cartas a enviar teniendo en cuenta una tasa de respuesta del $10 \%$.

\begin{tabular}{ccc}
\hline Zona & $\mathbf{n}$ & $\mathbf{N}^{\circ}$ invitaciones \\
\hline 1 & 65 & 650 \\
2 & 10 & 100 \\
3 & 25 & 250 \\
\hline
\end{tabular}

Una vez determinado el número de invitaciones que se debían enviar para obtener la muestra deseada, se eligieron aleatoriamente de la base de datos los domicilios destinatarios. La carta de invitación, que se puede consultar en el Apéndice B, estaba compuesta por dos secciones:

1. Carta de presentación: Era un texto en el que se le explicaba al residente que la Universidad Politécnica de Madrid estaba realizando un estudio en relación al ruido urbano. En la carta no se involucraba al Ayuntamiento de Málaga en ningún momento para evitar algún tipo de sesgo. Además, se optó por comentar que se trataba de 
un estudio a nivel nacional, no centrado en la ciudad de Málaga, para evitar posibles cambios en las respuestas de los participantes.

Con intención de incrementar la participación se le entregaba un código para que, en el caso de que cumplimentara la encuesta en su totalidad, entrara a formar parte de un sorteo de varios regalos como recompensa. Adicionalmente, el ciudadano debía utilizar el código único que se le proporcionaba en la invitación para acceder al cuestionario. Cada código de invitación único estaba asociado con una dirección postal, de este modo se pudo saber la localización del encuestado sin preguntarle directamente, por ser una pregunta sensible que podría generar desconfianza en el estudio.

2. Folleto: En el folleto se mostró de forma más atractiva la información básica sobre el cuestionario con la intención de incrementar la participación. Este impreso también incorporaba un código QR para permitir el acceso rápido desde un dispositivo móvil, la clave de acceso a la encuesta y el número de participación al sorteo asignado.

\subsubsection{Segunda fase}

Una vez finalizada la primera fase del experimento comenzaron las campañas de monitorado, y con ellas las actividades de difusión del proyecto a la ciudadanía y el lanzamiento de una nueva encuesta asociada.

\subsubsection{Encuesta final}

El objetivo de la segunda encuesta era recabar información sobre la molestia de la ciudadanía en las áreas de estudio para comprobar si había sido modificada tras conocer y participar en el proyecto de monitorización de ruido llevado a cabo.

Con intención de aprovechar el posible impacto del proyecto en los medios de comunicación, se decidió que la encuesta fuera accesible por la población de toda la geografía española. Para ello, y partiendo de la encuesta inicial, se tuvo que modificar la lógica del cuestionario para detectar a los habitantes de Málaga y definir un camino de preguntas específico que permitiera conocer su grado de conocimiento sobre las actividades de monitorado llevadas a cabo en la ciudad. El esquema de la lógica de la encuesta se puede ver en la Figura 2.4 en donde se visualizan los bloques de preguntas mediante colores y aparece encuadrado en color azul las preguntas añadidas a la encuesta final.

En la ruta específica de la encuesta para los ciudadanos de Málaga, cada participante era preguntado por su municipio de residencia. Si vivía en Málaga, se le preguntaba sobre el distrito y barrio en el que se encontraba su vivienda, para conocer si esa persona vivía en las áreas en las que se llevó a cabo el proyecto. Además, al finalizar la encuesta a cada usuario se le preguntaron un conjunto de cuestiones para averiguar si conocía la nueva red de monitorado, si había entrado en la aplicación web de visualización o si nos podía facilitar su dirección postal para facilitar los análisis futuros. Estas preguntas pueden consultarse en el séptimo bloque de la Tabla 2.1. la encuesta completa se puede consultar en el Apéndice $\mathrm{C}$ y en la web con contenido interactivo de esta tesis doctora ${ }^{2}$.

\subsubsection{Difusión del estudio y de la encuesta}

Debido a que se pretendía medir el efecto que tenía la comunicación de la información sobre contaminación acústica en las molestias por ruido, las tareas de difusión se convirtieron en una parte central de los esfuerzos de la investigación. Se llevaron a cabo múltiples

\footnotetext{
$\sqrt[2]{\text { https://luisgasco.github.io/doctoralthesis_website/ }}$
} 


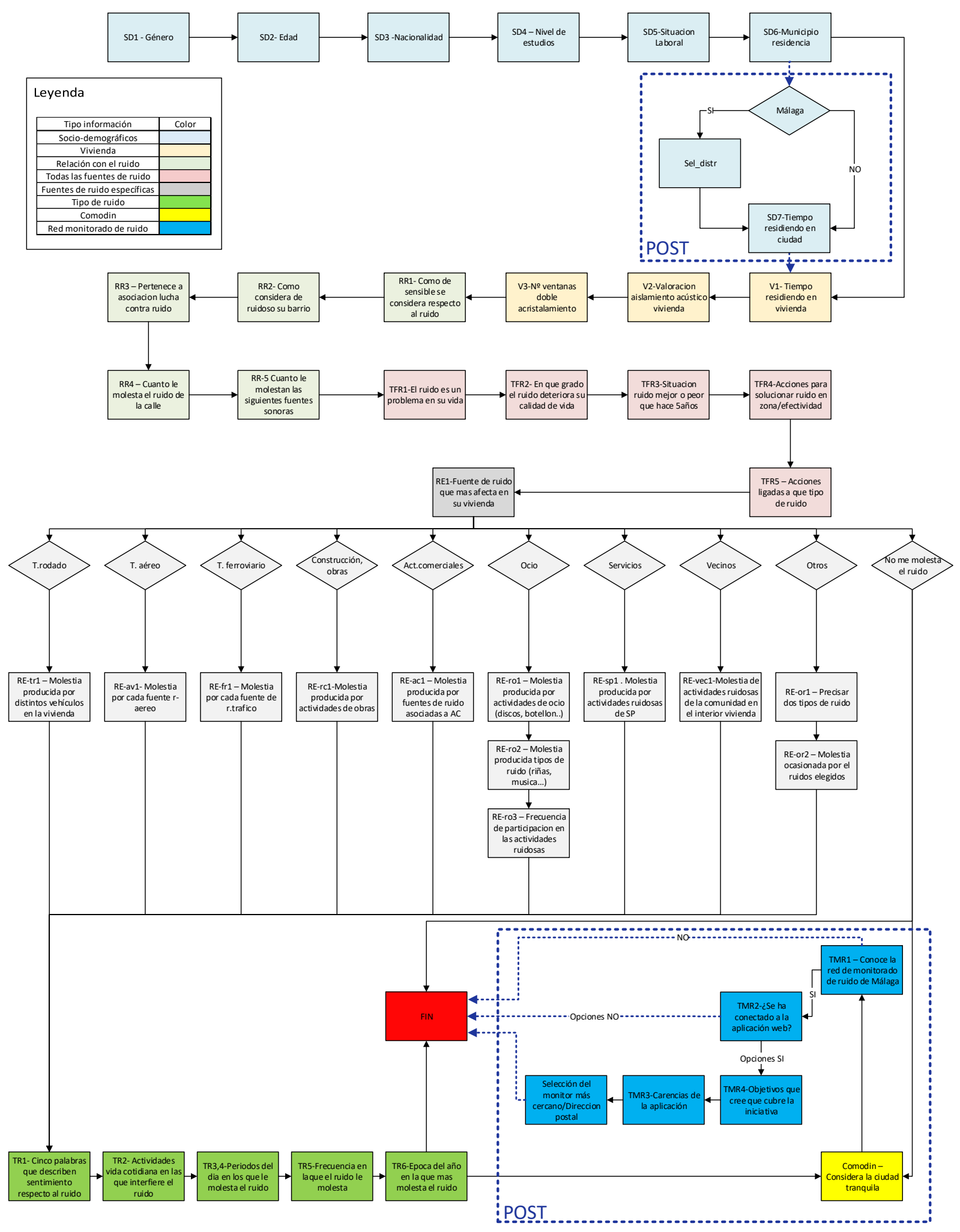

Figura 2.4: Estructura de la lógica de las preguntas implementadas en la encuesta final. 
iniciativas para dar a conocer el proyecto, que permitieran involucrar a más porcentaje de la población residente en Málaga, incluyendo su participación en la nueva encuesta.

Además del cuestionario descrito en la sección previa, se implementaron otras acciones buscando incrementar la participación ciudadana. Por una parte se diseñaron unos sondeos de frecuencia semanal que tras completarse redirigían al usuario a una página de información sobre la encuesta. Estas preguntas se difundieron a través de Internet para llegar al mayor número de usuarios posibles. Algunas de las preguntas presentadas en los sondeos fueron:

- ¿Es el ruido un problema en tu vida?

- ¿Alguna vez has puesto una denuncia o queja relacionada con el ruido o la contaminación acústica?

- ¿Alguna vez has empleado tapones para poder dormir?

- ¿A partir de que hora de la tarde/noche consideras que debes ser más silencioso?

Por otra parte, se utilizaron herramientas web para comunicar la evolución del día a día del proyecto con la ciudadanía interesada. Para ello se creó la página https:// ruidomalaga.vatia.es cuya portada se puede ver en la Figura 2.5 que informaba sobre los objetivos del proyecto, daba nociones básicas sobre contaminación acústica, ofrecía acceso a la plataforma de visionado de medidas de ruido y daba información sobre los socios participantes en el proyecto. Además incluía un blog de noticias en el que se comunicaba periódicamente el estado e hitos alcanzados en la iniciativa. También se creó un perfil de Twitter (@ruidomalaga) que fue utilizado tanto para difundir los avances e iniciativas del proyecto como los sondeos semanales, el cuestionario y la plataforma de visualización de datos de ruido.

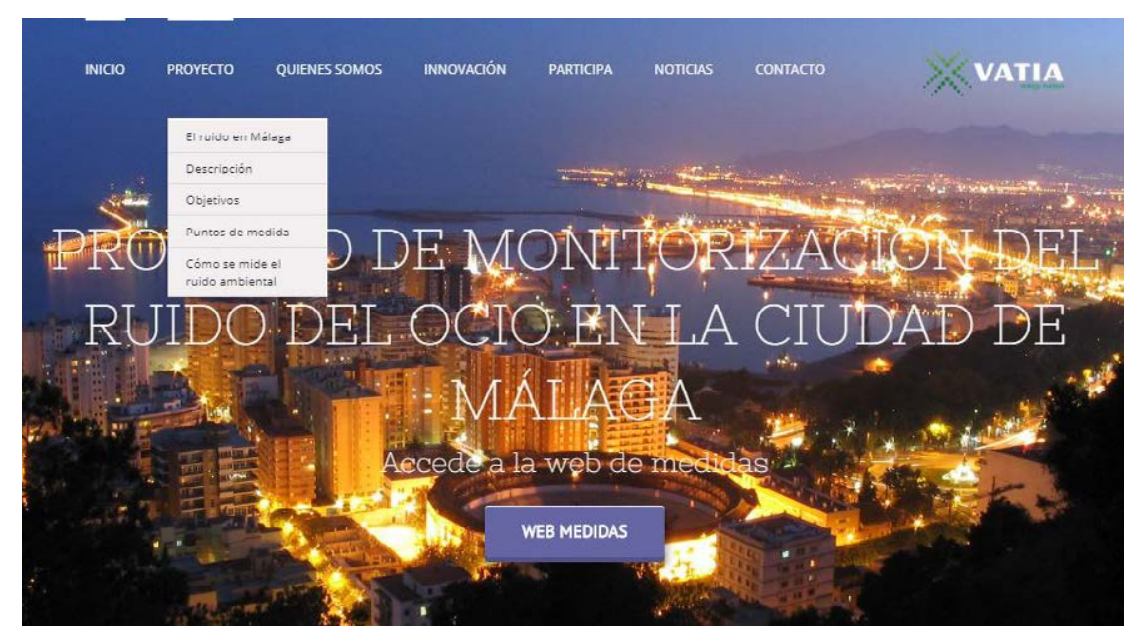

Figura 2.5: Página de inicio de la web del proyecto.

Adicionalmente, el Ayuntamiento de Málaga y la Universidad Politécnica de Madrid publicaron notas de prensa sobre el proyecto con intención de darlo a conocer al mayor número de personas posibles. Además, el Ayuntamiento celebró una rueda de prensa presentando la iniciativa, ya que marcó el inicio de una acción estratégica para luchar contra el ruido de ocio malagueño. 


\subsection{Resultados}

\subsubsection{Difusión pública}

Tal y como se comentó en la sección 2.5.2.2, el lanzamiento del proyecto, incluyendo la información sobre las campañas de monitorado y las encuestas, fue anunciado en la prensa y en los medios sociales por los departamentos de comunicación del Ayuntamiento de Málaga y de la Universidad Politécnica de Madrid. Estas notas de prensa fueron republicadas por múltiples medios de comunicación: 11 artículos en prensa local, 2 artículos en prensa regional y 4 en prensa nacional. Aumentando la cobertura mediática cuando se alcanzaron los principales hilos del proyecto, que fueron el comienzo de las campañas de monitorización, el lanzamiento de la encuesta y la finalización de esta.

Aunque la cobertura de los medios de comunicación fue significativa y se realizaron considerables esfuerzos para incrementar la visibilidad de la iniciativa, no se obtuvo la participación ciudadana esperada. El número de visitas al sitio web, tan solo 5410 usuarios únicos, no fue especialmente alto durante el proyecto, y tal y como se muestra en la Figura 2.6. tras un pico de visitantes durante las primeras semanas de ejecución, con la llegada del verano se redujo el interés en este recurso online permaneciendo así hasta la finalización del proyecto. Por otra parte, la tasa de rebote, que son el número de visitantes que abandonan la web sin interactuar con el contenido, fue del $80 \%$, lo que sugiere que el sitio web no era lo suficiente atractivo o que los visitantes tenían curiosidad por el proyecto más que estar verdaderamente interesados por la temática de este. No se encontró correlación entre el número de visitantes de la web y los niveles de ruido en las áreas de estudio.

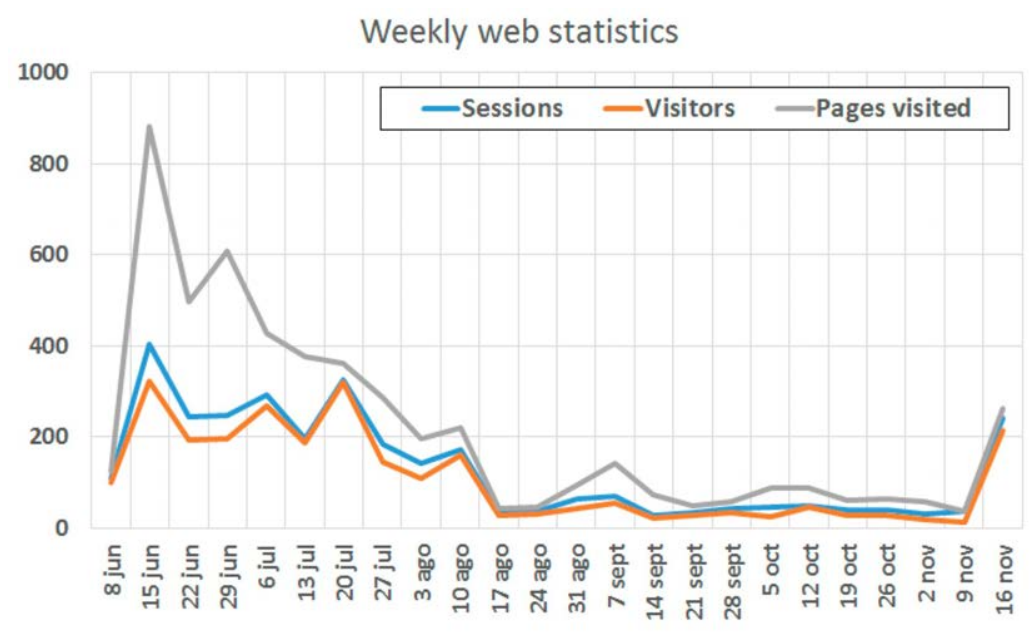

Figura 2.6: Evolución de las sesiones, visitantes y páginas visitadas en la web del proyecto durante la duración del proyecto.

En relación al resto de iniciativas de comunicación, la participación en los sondeos fue muy reducida, con un máximo de 32 respuestas a la pregunta formulada la segunda semana del proyecto; el número de quejas reportadas a través del sistema web, con 11; y las estadísticas de Twitter, con 75 seguidores y un total de 9270 impresiones de tweets, confirmaron que las actividades de comunicación no surtieron el efecto deseado, ya que se esperaba que la contaminación acústica fuera un tema candente en la ciudad de Málaga, y los datos obtenidos no lo demuestran. 


\subsubsection{Participación en las encuestas}

En relación a la participación de las encuestas de las 1000 invitaciones enviadas para el cuestionario inicial, 214 fueron devueltas por correos por diversos motivos. De las 786 invitaciones recibidas por los destinatarios, 42 personas iniciaron la encuesta, lo que corresponde a una tasa de respuesta del 5.3\%. De ellos, 35 la finalizaron, obteniéndose una tasa de finalización del más del $80 \%$. De las encuestas completadas $19(54 \%)$ provinieron del centro de la ciudad y $16(46 \%)$ de Teatinos.

Por otra parte, la encuesta final, abierta a toda la ciudadanía y promocionada mediante campañas de difusión, fue comenzada por 178 personas y completada por 143, obteniéndose de nuevo una tasa de finalización de más del $80 \%$. El $65 \%$ (93) de los cuestionarios completos provenían de los distritos correspondientes a las áreas de estudio, 56 (60\%) del centro ciudad y $37(40 \%)$ de Teatinos. Además, 67 de los encuestados residían en los barrios de los distritos en los que se realizó el estudio.

Aunque la participación de la encuesta final fue un $40 \%$ más alta que la llevada a cabo en el año 2012 por el Ayuntamiento (Sincosur, 2015), no se puede considerar que el objetivo de implicar a la ciudadanía se cumpliera, especialmente cuando la ciudad tiene más de medio millón de habitantes y solo se obtuvieron 143 respuestas completas. Por el contrario, el diseño y la longitud de la encuesta fue el adecuado como muestran las tasas de finalización por encima del $80 \%$, a pesar de que más del $50 \%$ de ellos utilizaron más de los 20 minutos que se estimaron que se tardaría en finalizar.

Para los análisis mostrados a continuación, en los que se comparan las dos encuestas, se utilizaron los resultados de la encuesta inicial, denominada PRE en el texto $(n=35)$, y las contestaciones de la encuesta final provenientes de los barrios en los que se realizó el estudio $(\mathrm{n}=67)$, denominada POST, ya que son las que permiten comparar de forma fiable la situación de la población afectada por el ruido en las áreas de monitorización. Es importante destacar que no se obtuvieron los objetivos de participación requeridos para considerar los resultados de la encuesta generalizables a la población residente en las áreas analizadas, dado que se requerían 100 participantes en cada una de las fases.

\subsubsection{Resultados de las encuestas}

El objetivo del experimento era cuantificar el efecto que la comunicación y visualización de la información acústica tenían sobre la molestia asociada al ruido de ocio. Para ello, tras finalizar el proceso de obtención de datos mediante cuestionarios se realizaron los análisis de estos. En primer lugar, se aplicaron métodos de estadística descriptiva inferencial para encontrar diferencias entre las preguntas contestadas por los participantes de las encuestas PRE y POST que pudieran ser introducidos en un modelo de molestias. Posteriormente, se aplicaron métodos multivariantes para generar un modelo que permitiera cuantificar el grado de influencia de estas acciones sobre la percepción hacia el ruido de ociq ${ }^{3}$

\subsubsection{Análisis descriptivo inferencial}

En relación a los resultados de los cuestionarios, la totalidad de los encuestados fueron de nacionalidad española. Aunque estuvo restringido a personas mayores de 18 años, no se obtuvieron respuestas del grupo de menores de 20 años en ninguna de las dos fases. Una gran parte de los participantes se encontraron en la franja de edad comprendida entre los 25 y 54 años, $71.4 \%$ en PRE y $80 \%$ en POST. Además, se observó una participación nula

\footnotetext{
${ }^{3}$ Para facilitar la lectura de esta sección, las distribuciones de las respuestas de cada una de las preguntas de las encuestas se agrupan en el Apéndice D en este apartado se tratará y mencionarán las preguntas con mayor interés para los objetivos del experimento.
} 
en los adultos mayores de 65 años, probablemente asociado al menor uso de las tecnologías digitales en esta franja de edad.

Del mismo modo que los resultados obtenidos en anteriores encuestas de actitud hacia el ruido en modalidad online, como las realizadas en Turín y Milan (Ottoz et al. 2015), el nivel educativo de los participantes fue superior al nivel medio de educación español: en ambas encuestas más del $60 \%$ de los participantes declararon tener estudios superiores universitarios. Esto puede explicarse como una consecuencia de la brecha digital provocada por el cuestionario online, de factores socioeconómicos asociados a las áreas de estudio, o de la alta participación de ciudadanos preocupados por el ruido y la relación entre las molestias por ruido y otros factores no acústicos, como la educación (Bluhm et al., 2004, Laszlo et al. 2012).

Se realizaron contrastes de homogeneidad para comprobar si existían diferencias significativas entre la muestra de los grupos PRE y POST para las preguntas con los siguientes códigos, cuyas descripciones completas se mostraron en la Figura 2.1 $R R 1$, sensibilidad respecto al ruido, variable numérica con rango $0-10 ; R R 3$, pertenencia a una asociación de lucha contra la contaminación acústica, variable binomial; $R R 5_{\text {ocio }}$, nivel de molestia producida por el ruido de ocio, variable numérica con rango 0-10; y $T F R 1$, el ruido como problema en la vida del participante, variable binomial.

En cuanto a los estadísticos utilizados para comprobar la homogeneidad de las muestras, se utilizó la Prueba U de Mann-Whitney con las variables numéricas y la Prueba Chi-cuadrado de Pearson con las variables binomiales. En esos contrastes la hipótesis nula es que la distribución de la variable a contrastar es similar entre los grupos PRE y POST, de modo que si se acepta no existirán diferencias entre las respuestas reportadas por las muestras de las dos encuestas.

La Tabla 2.3 muestra los resultados en términos del p-valor obtenido en dichos contrastes. Se observa que la variable relacionada con la sensibilidad hacia el ruido, $R R 1$, tiene un p-valor mayor que el nivel de significación de 0.05 , lo que nos indica que no existen evidencias estadísticamente significativas para rechazar la hipótesis nula y que por lo tanto se puede asumir que no existen diferencias en la distribución de las respuestas ofrecidas por los grupos PRE y POST; es decir que la sensibilidad hacia el ruido era similar en ambos grupos. Por otra parte, las variables relacionadas con la molestia producida por el ruido de ocio, $R R 5_{\text {ocio }}$; el ruido como problema en la vida del encuestado, $T F R 1$; y la pertenencia a asociación, $R R 3$, muestran diferencias significativas. Es decir que los encuestados en cada uno de los cuestionarios mostraban diferencias en la molestia asociada al ruido de ocio, a la consideración que tenían sobre el ruido en su vida y la pertenencia a asociaciones.

Tabla 2.3: Contrastes de homogeneidad realizados para las variables mostradas entre los grupos PRE y POST.

\begin{tabular}{lccc}
\hline Variable & Pregunta & p-valor & $\begin{array}{c}\text { Diferencia significativa } \\
\text { entre PRE-POST }\end{array}$ \\
\hline$R R 1$ & Sensibilidad hacia el ruido & $0.33^{1}$ & No \\
\hline$R R 3$ & Pertenencia a asociación de ruido & $<\mathbf{0 . 0 1}^{2}$ & $\mathrm{Si}$ \\
\hline$R R 5_{\text {ocio }}$ & Molestia al ruido del ocio & $\mathbf{0 . 0 3}^{1}$ & $\mathrm{Si}$ \\
\hline$T F R 1$ & El ruido es un problema en su vida & $<\mathbf{0 . 0 1}^{2}$ & $\mathrm{Si}$ \\
\hline
\end{tabular}

1 - Prueba U de Mann-Whitney

2 - Prueba de Chi-cuadrado de Pearson con correción de Yates

Analizando las respuestas a las preguntas $T M R 1$, correspondiente al conocimiento de la existencia de la red de monitorización de ruido, y $T M R 2$, correspondiente al acceso 
a la aplicación web de visualización de datos, se observó que de la muestra obtenida en la encuesta POST, un $25.4 \%$ de los participantes no conocía el proyecto en el momento de cumplimentación del cuestionario. Del $74.6 \%$ restante (50 personas), el $52 \%$ no había accedido al sistema online de visionado de datos, por lo que a este porcentaje de los encuestados la visualización de la información acústica no les pudo influir en la molestia percibida. La Tabla 2.4 muestra la distribución de las respuestas a la pregunta $T M R 2$, representada en la columna "Total".

Tabla 2.4: Tabla de contingencia de la pregunta $T M R 2$, respectiva al uso de la aplicación web, con la variable $R R 3$, pertenencia a una asociación de ruido. Los porcentajes están calculados por columnas.

\begin{tabular}{|c|c|c|c|c|}
\hline & \multicolumn{2}{|c|}{ Pertenencia a asociación contra el ruido } & \multirow[b]{2}{*}{ Total } \\
\hline & & $\mathrm{Si}$ & No & \\
\hline \multirow{6}{*}{ 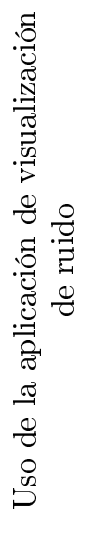 } & $\mathrm{Si}$, me he conectado más de una vez & $8(42.1 \%)$ & $3(9.7 \%)$ & $11(22 \%)$ \\
\hline & $\begin{array}{l}\mathrm{Si} \text {, me he conectado una vez y me } \\
\text { volveré a conectar }\end{array}$ & $5(26.3 \%)$ & $2(6.4 \%)$ & $7(14 \%)$ \\
\hline & $\begin{array}{l}\mathrm{Si} \text {, me he conectado solo para conocer } \\
\text { la iniciativa }\end{array}$ & $2(10.5 \%)$ & $4(12.9 \%)$ & $6(12 \%)$ \\
\hline & No, pero me conectaré en el futuro & $1(5.3 \%)$ & $8(25.8 \%)$ & $9(18 \%)$ \\
\hline & No, porque no conocía la aplicación & $2(10.5 \%)$ & $11(35.5 \%)$ & $13(26 \%)$ \\
\hline & No, porque no me resulta interesante & $1(5.3 \%)$ & $3(9.7 \%)$ & $4(8 \%)$ \\
\hline & Total & $19(100 \%)$ & $31(100 \%)$ & $50(100 \%)$ \\
\hline
\end{tabular}

Debido a que la molestia de los encuestados no podía haber sido modificada por la presencia de una red de monitorado si no conocían de su existencia, se excluyó a los participantes que no la conocían y se volvieron a calcular los contrastes de homogeneidad en este subconjunto de datos, obteniendo los resultados mostrados en la Tabla 2.5. Del mismo modo, las personas que no accedieron a la aplicación web no pudieron haber experimentado cambios en su molestia por este motivo, por lo que se calcularon los contrastes de homogeneidad únicamente teniendo en cuenta la muestra de la encuesta POST que había accedido a la aplicación, cuyos resultados se muestran en la Tabla 2.6. En ambas tablas se observa que los resultados obtenidos son similares a los mostrados en la Tabla 2.3 la sensibilidad hacia el ruido $(R R 1)$ de las dos muestras siguen siendo similares; y existen diferencias en la proporción de personas que forman parte de asociaciones de ruido, en la molestia percibida asociada al ruido de ocio, y a como de problemático consideran el ruido en su vida.

Es importante reseñar que, en una de las reuniones llevadas a cabo con los responsables de medioambiente del Ayuntamiento de Málaga, los gestores del proyecto fueron informados sobre el hecho de que en Málaga las asociaciones contra ruido jugaban un papel importante en el activismo y en la lucha contra la contaminación acústica de la ciudad, especialmente el asociado a las actividades recreativas, y que podrían haber compartido la encuesta en sus canales oficiales. Tras analizar las fuentes de difusión del cuestionario se descubrió que, efectivamente, la asociación de vecinos el Romeral contra el ruido realizó una campaña de difusión de la encuesta y del proyecto en su web y redes sociales (Vecinos el Romeral, 2015). La Tabla 2.4 muestra que los participantes que formaban parte de aso- 
Tabla 2.5: Contrastes de homogeneidad realizados para las variables mostradas entre los grupos PRE y POST tras filtrar a los participantes que no conocían la red de monitorado de ruido desplegada en Málaga.

\begin{tabular}{lccc}
\hline Variable & Pregunta & p-valor & $\begin{array}{c}\text { Diferencia significativa } \\
\text { entre PRE-POST que } \\
\text { conocen la red de } \\
\text { monitorado }\end{array}$ \\
\hline$R R 1$ & Sensibilidad hacia el ruido & $0.89^{1}$ & $\mathrm{No}$ \\
\hline$R R 3$ & Pertenencia a asociación de ruido & $<\mathbf{0 . 0 1}^{2}$ & $\mathrm{Si}$ \\
\hline$R R 5_{\text {ocio }}$ & Molestia al ruido del ocio & $\mathbf{0 . 0 3}^{1}$ & $\mathrm{Si}$ \\
\hline$T F R 1$ & El ruido es un problema en su vida & $<\mathbf{0 . 0 1}^{2}$ & $\mathrm{Si}$ \\
\hline
\end{tabular}

1 - Prueba U de Mann-Whitney

${ }^{2}$ - Prueba de Chi-cuadrado de Pearson con correción de Yates

Tabla 2.6: Contrastes de homogeneidad realizados para las variables mostradas entre los grupos PRE y POST tras filtrar a los participantes que no accedieron a la aplicación web de datos de ruido.

\begin{tabular}{lccc}
\hline Variable & Pregunta & p-valor & $\begin{array}{c}\text { Diferencia significativa } \\
\text { entre PRE-POSTque han } \\
\text { usado la aplicación de } \\
\text { visualización }\end{array}$ \\
\hline$R R 1$ & Sensibilidad hacia el ruido & $0.21^{1}$ & No \\
\hline$R R 3$ & Pertenencia a asociación de ruido & $<\mathbf{0 . 0 1}^{2}$ & $\mathrm{Si}$ \\
\hline$R R 5_{\text {ocio }}$ & Molestia al ruido del ocio & $<\mathbf{0 . 0 1}^{1}$ & $\mathrm{Si}$ \\
\hline$T F R 1$ & El ruido es un problema en su vida & $<\mathbf{0 . 0 1}^{2}$ & $\mathrm{Si}$ \\
\hline
\end{tabular}

1 - Prueba U de Mann-Whitney

2 - Prueba de Chi-cuadrado de Pearson con correción de Yates

ciaciones habían accedido más a la aplicación web que las que no, ya fuera por ese hecho, porque tuvieran un mayor nivel de concienciación hacia el ruido o una mayor sensación de molestia.

Si las personas que forman parte de las asociaciones tuvieran niveles de molestia significativamente diferentes a los que no, se produciría un sesgo en la encuesta dado que en la Tabla 2.3. Tabla 2.5 y ,Tabla 2.6 se mostró que existían diferencias significativas en la variable $R R 3$, correspondiente a la pertenencia a una asociación de lucha contra el ruido. Por ese motivo se calcularon las diferencias existentes entre la molestia de la población que formaba parte de una asociación y la que no. La Tabla 2.7 muestra los resultados de los contrastes de homogeneidad aplicados, agrupando la muestra mediante la respuesta a la variable $R R 3$.

Se observa que, aunque la sensibilidad hacia el ruido, $R R 1$, era similar entre ambos grupos de población, existían diferencias en las otras variables. Las personas que forman parte de estas agrupaciones consideran que el ruido es una problema en su vida con más frecuencia que los que no (variable $T F R 1$ ). Además, a estas personas el ruido de ocio les genera distinto nivel de molestia que a la ciudadanía común (variable $R R 5_{\text {ocio }}$ ). El hecho de formar parte de una asociación, que son instituciones que luchan activamente contra el ruido de ocio, y que el ruido les genere más problemas en su vida diaria que al resto de la población, podría explicar las diferencias existentes en la percepción de molestia asociada 
Tabla 2.7: Contrastes de homogeneidad realizados para las variables mostradas entre los participantes que formaban parte de una asociación del ruido y los que no.

\begin{tabular}{lccc}
\hline Variable & Pregunta & p-valor & $\begin{array}{c}\text { Diferencias significativas } \\
\text { entre asociación } / \mathbf{n o} \\
\text { asociación }\end{array}$ \\
\hline$R R 1$ & Sensibilidad hacia el ruido & $0.055^{1}$ & $\mathrm{No}$ \\
\hline$R R 5_{\text {ocio }}$ & Molestia al ruido del ocio & $<\mathbf{0 . 0 1}^{2}$ & $\mathrm{Si}$ \\
\hline$T F R 1$ & El ruido es un problema en su vida & $<\mathbf{0 . 0 1}^{2}$ & $\mathrm{Si}$ \\
\hline
\end{tabular}

1 - Prueba U de Mann-Whitney

2 - Prueba de Chi-cuadrado de Pearson con correción de Yates

a este tipo de origen ruidoso. Estas diferencias significativas podrían interpretarse como que las personas de la muestra que forman parte de una asociación tienen un perfil o una actitud hacia las fuentes de ruido diferente a las que no, además nos indican que esta variable podría ser una candidata para ser incluida en los modelos calculados con posterioridad.

\subsubsection{Creación del modelo de molestia al ruido de ocio}

Una vez analizadas las diferencias entre las muestras de las dos encuestas, se pretendía generar un modelo de regresión multivariable que permitiera evaluar el grado de influencia de las acciones de comunicación sobre la molestia. Este tipo de modelo, representado de forma paramétrica en la Ecuación 2.3 trataba de modelizar la molestia asociada al ruido de ocio, obtenida a través de la pregunta $R R 5_{\text {ocio, }}$ utilizando como variables predictoras las respuestas de las preguntas analizadas previament $4^{45}$

$$
\text { molestia_ruido ocio }=\beta_{0}+\beta_{1} P R E+\beta_{2} T M R 1+\beta_{2} T M R 2+\ldots+\beta_{n} v r_{n}
$$

En primer lugar, se calcularon los modelos de regresión lineal entre la molestia al ruido de ocio y cada una de las variables anteriormente consideradas. A pesar de que en el análisis inferencial de la sección 2.6.3.1 se observaron diferencias significativas en la molestia entre las encuestas PRE y POST, no se obtuvieron resultados similares en este caso. Si que lo fueron las variables conocimiento del proyecto, TMR1; entrada a la aplicación de visualización de datos, $T M R 2$; pertenencia a una asociación, $R R 3$; y el ruido como problema en la vida del encuestado, TFR1.

La variable $P R E$, que indica si el encuestado formaba parte de la encuesta PRE o POST, está influenciada por las variables $T M R 1$ y $T M R 2$, dado que son las preguntas que se efectuaron en el segundo cuestionario para conocer si las herramientas de comunicación tuvieron algún efecto en los participantes; y por factores que no pueden ser cuantificados a partir de los datos obtenidos con la encuesta, como la opinión del encuestado sobre la gestión municipal. Adicionalmente, también está influenciada por el cambio en el método experimental utilizado para obtener la muestra, ya que mientras que en el cuestionario PRE el acceso estuvo limitado a ciudadanos con invitación, en el POST se pudo acceder

\footnotetext{
${ }^{4}$ Los niveles de ruido no son incluidos en el modelo porque, por una parte el objetivo del experimento no era implementar un modelo de dosis-respuesta de la molestia, y por otra, los niveles de ruido eran similares en las zonas de estudio, por lo que se asumió que los cambios de la molestia no estaban asociados a estos.

${ }^{5}$ En la Ecuación la variable $P R E$ representa la fase del experimento; la variable $T M R 1$ indica si el ciudadano conocía el proyecto de monitorización; $T M R 2$ representa el acceso a la aplicación de visualización de datos.
} 
libremente, lo que generó cambios en la distribución de personas que formaban parte de asociaciones contra el ruido en cada uno de los grupos, que como se ha observado muestran una molestia mayor hacia el ruido de ocio.

Además, aunque parte de la muestra POST manifestó que no conocía el proyecto de monitorización, para llegar al cuestionario podrían haber recibido información acerca de su existencia ya que fueron difundidos de forma conjunta. El hecho de que $P R E$ no sea significativo y si que lo sea $T M R 1$, sitúa a los participantes de la encuesta inicial y a los participantes de la encuesta final que no manifestaron conocer el proyecto en el mismo grupo, aunque las situaciones de acceso y realización del cuestionario no fueran las mismas para ambos desde el punto de vista de la difusión de la información. Para evitar esos sesgos, se ha calculado el modelo únicamente para la muestra POST, cuyos participantes fueron obtenidos con el mismo método, y se puede asegurar que todos los encuestados tuvieron las mismas posibilidades de obtener información sobre el proyecto. El modelo calculado se muestra en la Tabla 2.8 .

Tabla 2.8: Modelo de molestia asociada al ruido de ocio.

\begin{tabular}{lc}
\hline \hline & Modelo molestia_ruido ocio \\
\cline { 2 - 2 } & Coeficiente (p-valor) \\
\hline RR3 (asociación) & $1.541(0.017)$ \\
TMR1 (conoce proyecto) & $1.331(0.044)$ \\
Constante & $7.388(<0.01)$ \\
\hline $\mathrm{n}$ & 67 \\
$\mathrm{R}^{2}$ & 0.147 \\
$\mathrm{R}^{2}$ ajustado & 0.120 \\
\hline \hline
\end{tabular}

Alineados con los resultados obtenidos en el análisis descriptivo, la sensibilidad hacia el ruido $(R R 1)$ no es significativa en la molestia provocada por el ruido de ocio en Málaga. Las personas que conocían el proyecto presentaron una molestia 1.3 puntos mayor que la ciudadanía que no manifestó conocer el estudio. Corroborando lo mostrado hasta el momento, las personas que pertenecían a asociaciones de ruido reportaron unos niveles de molestia 1.5 puntos superiores que los ciudadanos que no formaban parte de estas organizaciones. Aunque el valor de autodeterminación ajustado sea reducido, el modelo permite comprobar que existió un efecto de la comunicación sobre la molestia asociada al ruido de ocio por ser la variable $T M R 1$ significativa.

A lo largo de este capítulo se ha mostrado que el ruido de ocio es reconocido por las autoridades medioambientales de Málaga como un problema en la ciudad. De hecho, la presencia de asociaciones de ruido es un buen indicador del problema existente en las zonas de estudio. El comienzo de las actividades de monitorado de ruido, con herramientas para visualizar los niveles sonoros e información sobre los efectos del ruido, podría haber incrementado la concienciación de la población residente que, tras observar los altos niveles de ruido en áreas cercanas a su lugar de residencia, podría haber experimentado un incremento en su molestia. De hecho, la propia acción de comenzar una encuesta de acceso libre sobre valoración de actividades ruidosas en la ciudad, podría haber provocado que las personas más afectadas por esta fuente sonora accedieran al cuestionario con el objetivo de mostrar su disconfort a los gestores urbanos para que aplicaran acciones de control sonoro, ya que a pesar de que la encuesta no formaba parte del proyecto de forma oficial, fue difundida de forma conjunta con las actividades del proyecto de monitorización. 


\subsection{Conclusiones}

En el experimento mostrado en este capítulo se pretendía medir el efecto de la comunicación de la información de la contaminación acústica en la ciudadanía. A pesar de no haber podido validar la hipótesis de que la comunicación de los datos de ruido disminuye la sensación de molestia producida por el ruido de ocio, se pueden extraer las siguientes conclusiones:

- Se ha confirmado que la longitud de la encuesta era el adecuado para las personas que accedieron. Se obtuvo un ratio de finalización de las encuestas mayor del $80 \%$ que es sustancialmente mayor al reportado en otros cuestionarios sociales realizados en la web, que están en torno al $50 \%$.

- A pesar de haber obtenido un alto ratio de finalización, no se consiguieron los 100 participantes en cada una de las fases que eran necesarios para obtener resultados representativos. Incluso habiendo elegido un ratio de respuesta muy conservador en relación al reportado en otras investigaciones, no se obtuvo la participación necesaria en la encuesta inicial.

- La gran cobertura mediática del proyecto, en la que se publicaron multitud notas de prensa publicitando el proyecto, no se tradujo en los altos niveles de participación que se esperaban para la segunda encuesta. Además las iniciativas llevadas a cabo como los sondeos, redes sociales y página web no consiguieron conectar con la audiencia objetivo, traduciéndose en un número reducido de participantes en la encuesta teniendo en cuenta la información proporcionada por el Ayuntamiento respecto al problema social que representaba el ruido en las áreas de estudio.

- Dado que la encuesta final tuvo un $40 \%$ más de participantes que la realizada previamente en la ciudad mediante métodos tradicionales, se puede concluir que utilizar medios digitales para la realización de cuestionarios de valoración de ruido es una buena herramienta para conseguir participación ciudadana.

- El diseño experimental, en el que se abría la encuesta a toda la población de forma simultánea al inicio de las campañas de monitorización, no fue el óptimo para obtener la máxima participación. El aprovechamiento de la cobertura mediática del lanzamiento del proyecto y de la plataforma de visualización para publicitar la encuesta provocó que muchos participantes la cumplimentaran los primeros días del proyecto sin haber tenido tiempo suficiente para explorar la aplicación web. Desgraciadamente, por los requerimientos del experimento durante el análisis estas contestaciones tuvieron que ser excluidas, desaprovechando así un valioso porcentaje de gente que decidió participar en la iniciativa.

- La encuesta no formaba parte del proyecto de monitorización llevado a cabo por el Ayuntamiento de Málaga, pero su difusión junto con la información de la red de monitorado podría haber provocado que fuera asociada a ese proyecto y que los ciudadanos la utilizaran como herramienta para mostrar su malestar a los gestores urbanos de la ciudad.

- El acceso libre a una encuesta de valoración del ruido podría ser un buen método para obtener participantes, pero la existencia de agrupaciones de activismo contra el ruido puede provocar que se creen vías alternativas de difusión entre los miembros de estas asociaciones que podrían introducir sesgos en los resultados finales. De hecho, los análisis estadísticos realizados en las encuestas nos han permitido verificar que, al menos en Málaga, las personas que forman parte de asociaciones contra el ruido 
tienen sensación de molestia hacia el ruido de ocio diferente que las personas que no, a pesar de considerar sus barrios igual de ruidosos y tener una sensibilidad hacia el ruido similar.

- Los modelos calculados indican que la molestia se ve incrementada al llevar a cabo tareas de comunicación de la información de ruido. El hecho de que la comunicación sobre ruido incremente la molestia está en contra de las investigaciones realizadas en la misma materia para ruido aeroportuario (Forum Mediation, 2005 Phun et al. 2016), por lo que se podrían haber introducido sesgos durante la adquisición de datos que no pueden ser controlados con posterioridad. Uno de los posibles sesgos sería el uso del cuestionario como herramienta para mostrar el disconfort individual sobre la situación acústica de la ciudad, lo que modificaría las contestaciones para de algún hacer notar a los gestores que los ciudadanos sufren un gran problema en las áreas de estudio. 


\title{
Capítulo 3
}

\section{Detección de la opinión ciudadana sobre actividades ruidosas presente en medios sociales online}

\author{
Proliferation of mobile phones makes it possible \\ to leap beyond demographics to directly measure \\ human behavior \\ Prof. Alex Pentland \\ Co-founder \& former director of MIT MediaLab
}

\subsection{Introducción}

Dentro de la gestión de ruido la participación ciudadana es importante porque, por una parte, permite identificar problemas acústicos en las ciudades que de otro modo serían difíciles de descubrir y, por la otra, porque permite conocer la actitud frente al ruido de la ciudadanía. Las encuestas son la forma más habitual de preguntar a la población sobre sus sensaciones hacia las actividades ruidosas en las ciudades, tradicionalmente realizadas a través de encuestas telefónicas o cara a cara y, recientemente, mediante encuestas online (Silva et al. 2017). El uso de encuestas presenta algunos inconvenientes: como la dificultad para conseguir altas tasas de participación y la difícil lucha contra los sesgos, como se mostró en las conclusiones del Capítulo 2 y el alto costo en su desarrollo y su tiempo de ejecución, por ejemplo, el coste de la National Noise Attitude Survey del Reino Unido fue de $240.000 £$, utilizadas para obtener una muestra de 3200 sujetos y un trabajo de campo de 6 meses (DEFRA, 2014). Además, tienen otros problemas, como la imposibilidad de controlar las reacciones espontáneas a eventos de ruido puntuales o la medida de la actitud hacia el ruido en el corto plazo. Por otra parte, como las encuestas tienen como objetivo obtener la mayor cantidad de información posible sobre las opiniones del participante, suelen ser bastantes largas, abordando más de un tema o por el contrario demasiado centradas sobre una fuente de ruido que el encuestado no está sufriendo.

De forma simultánea al hecho de que el ruido se ha convertido en una preocupación y un problema común en las ciudades, se ha experimentado una revolución digital que ha cambiado radicalmente la forma en la que nos comunicamos y utilizamos la tecnología. Además, con la entrada en la Era de la Información hemos experimentado una transición de Internet como una herramienta para publicar y leer información, al Internet social. El Internet social ha generado cambios en los comportamientos de las personas, ya que ahora pueden interactuar con otros usuarios mediante plataformas digitales conocidas como medios sociales o social media. Específicamente, las RSO (Redes Sociales Online, Online 
Social Networks) se han convertido en la plataforma preferida para llevar a cabo esas interacciones (Smith y Anderson, 2018). En las RSO las personas se expresan libremente y, aunque no dan respuestas directas a cuestiones que nos preguntamos los investigadores, dan información muy útil sobre temas específicos de los que se puede extraer conocimiento.

Actualmente, los usuarios activos en RSO observan, analizan, crean y difunden información sobre sus opiniones e impresiones respecto a diversos temas mediante el uso de texto y archivos multimedia como fotografías, vídeos y audio (Sheth, 2009). Los textos provenientes de RSO pueden utilizarse para obtener información diversa mediante el uso de técnicas de análisis del sentimiento, que es un campo que tiene por objeto determinar las opiniones o actitudes de un texto escrito por una persona (Liu, 2012). Las empresas ya utilizan estas tecnologías, junto con métodos tradicionales como las encuestas, para conocer la opinión de los clientes sobre sus productos y marcas. Por ejemplo, las grandes corporaciones de comida rápida utilizan datos de RSO para conocer la opinión de la gente sobre sus nuevos productos y cuál es su popularidad respecto a los de la competencia (NETBASE, 2018). En otros sectores como en el de la automoción, los fabricantes utilizan estas técnicas para conocer la percepción de los clientes sobre su marca en cada uno de los mercados que operan para mejorar la eficiencia de sus campañas de marketing (NETBASE, 2016).

Por otra parte, la minería de textos y el análisis de sentimiento ya han sido explorados en otra áreas de investigación. Debido a los problemas en el abuso de medicamentos en algunos países, se desarrolló un sistema basado en técnicas de aprendizaje automático y técnicas de NLP (Natural Language Processing, Procesado de Lenguaje Natural) para detectar mensajes de Twitter que mostraran excesos en el consumo de algunos fármacos, lo que permitiría a los gobiernos mejorar la información proporcionada sobre los efectos secundarios de estos (Sarker et al. 2016). En el mismo área se han llevado a cabo estudios similares para monitorizar los efectos secundarios de algunos fármacos basados en el contenido existente en medios sociales (Sarker et al., 2015). En relación al medio ambiente, se ha encontrado correlación entre las publicaciones que tratan el tema de la contaminación del aire y los índices de calidad del aire diarios, lo que permitió a los investigadores pronosticar el valor de ese índice utilizando únicamente el contenido de estas plataformas (Jiang et al. 2015). El uso de análisis de sentimientos y NLP también ha sido útil para el desarrollo de sistemas que posibiliten una mejora en la gestión de situaciones de emergencia asociadas a desastres naturales como terremotos o inundaciones (Alfarrarjeh et al. 2017, Buscaldi y Villetaneuse, 2015 Sangameswar et al. 2017).

Los resultados obtenidos en el primer experimento de la investigación doctoral constataron los problemas de participación que presentan las encuestas online, en los que gran porcentaje de la ciudadanía no participó en el cuestionario a pesar de existir un claro problema de ruido de ocio. Por otra parte, el ruido se ha convertido en una preocupación ambiental más para la ciudadanía, y es razonable pensar que del mismo modo que la población expresa sus opiniones sobre la calidad del aire en medios online (Jiang et al. 2015), también lo harán sobre las actividades ruidosas (Gasco et al., 2017, King et al. 2017). Adicionalmente, el hecho de que las técnicas mostradas anteriormente ya hayan sido aplicadas con éxito en otros campos y que exista un interés creciente para conocer la opinión ciudadana para la creación de políticas, nos proporciona el marco idóneo para la definición de una metodología que permita recabar la información sobre las actitudes hacia el ruido que la ciudadanía comparte en Internet y que permita mejorar en el futuro los procesos de gestión urbana en relación al ruido. 


\subsection{Hipótesis y objetivos}

Este experimento de la tesis doctoral se apoya sobre la hipótesis de que la población afectada por el ruido utiliza canales alternativos de comunicación como las redes sociales para expresar su molestia. El presente capítulo se centra en el desarrollo de la investigación para cumplir el segundo objetivo general de la tesis doctoral, que es el uso de fuentes de datos provenientes de Internet para extraer conocimiento acerca de actividades ruidosas que afectan a la población.

Dicha objetivo global será abordado en este capítulo mediante la consecución de los siguientes objetivos parciales:

1. Diseño de una metodología que permita detectar y analizar automáticamente datos de percepción sobre actividades ruidosas compartidas por la ciudadanía en medios sociales online.

2. Diseño de una estrategia para la obtención de datos de valoración sobre ruido provenientes de medios sociales.

3. Diseño de un sistema que permita la detección automática de datos sobre la percepción de actividades ruidosas compartidas por la ciudadanía en medios sociales online.

4. Diseño de un método para identificar las fuentes sonoras tratadas en opiniones sobre ruido extraídas de medios sociales.

5. Desarrollo de una metodología de prueba de los sistemas diseñados, en lo referente a las tasas de rendimiento.

6. Realización de una prueba de concepto que utilice la metodología desarrollada y que permita identificar actividades ruidosas y su origen a partir de la monitorización de la actividad social en plataformas digitales.

Parte del desarrollo de este experimento fue realizado durante una estancia doctoral en Télécom ParisTech en París (Francia), bajo la supervisión de la Profesora Chloé Clavel, coordinadora de la línea de investigación de computación social en el GRETA Team.

\subsection{Metodología}

La creciente popularidad de las RSO ha animado a los ciudadanos a escribir y compartir sus opiniones sobre temas diversos en estas plataformas. El principal objetivo de la metodología propuesta en este apartado es detectar y clasificar las opiniones sobre ruido ambiental, específicamente quejas, escritas por los usuarios de RSO cuando están expuestos a sonidos molestos. Esas quejas serán detectadas mediante técnicas de análisis de texto, y serán clasificadas en función del origen del ruido al que se refieren. En este apartado de la tesis doctoral se propone una metodología de referencia para este tipo de análisis que cubre desde el proceso de adquisición de los datos hasta la detección de fuentes sonoras, pasando por la preparación de los textos con los que se trabajará y la identificación de cuales de ellos son quejas sobre ruido.

La implementación de esta metodología permitirá diseñar un sistema que detecte y clasifique de forma automática las quejas sobre ruido según su origen. Dado que el sistema se nutrirá de textos provenientes de RSO, el primer paso será la adquisición de datos de Internet. A continuación, en el paso de preparación de los datos, se normalizará el texto en un proceso que corregirá las faltas ortográficas y unificará la jerga utilizada comúnmente 
en Internet; además, se llevará a cabo un proceso de etiquetado manual de textos en el que técnicos expertos determinarán que documentos son quejas sobre ruido y cuales no. Como es la primera vez que se utiliza NLP y aprendizaje automático en la detección de valoraciones subjetivas sobre ruido, el diseño se ha centrado en la detección de quejas, sin tener en cuenta los niveles de molestia que estas expresan. Por último, se diseñará un sistema capaz de agrupar dichas quejas en función de la fuente sonora a la que hacen referencia mediante el uso de una taxonomía de fuentes de ruido construida con tal fin. La Figura 3.1 muestra el diagrama de bloques de esta metodología, en el que se observa tanto el flujo de los datos como los resultados obtenidos en cada bloque. Una vez que los modelos hayan sido construidos, se validará su funcionamiento y se desarrollará un prototipo que utilice los sistemas diseñados para obtener información útil.

Es importante reseñar que el experimento se ha llevado a cabo con textos escritos en inglés por la gran cantidad de recursos implementados para el procesado de lenguaje en este idioma, aunque a priori podría ser implementado en cualquier lengua, siempre que las herramientas de procesado necesarias estuvieran adaptadas a este.

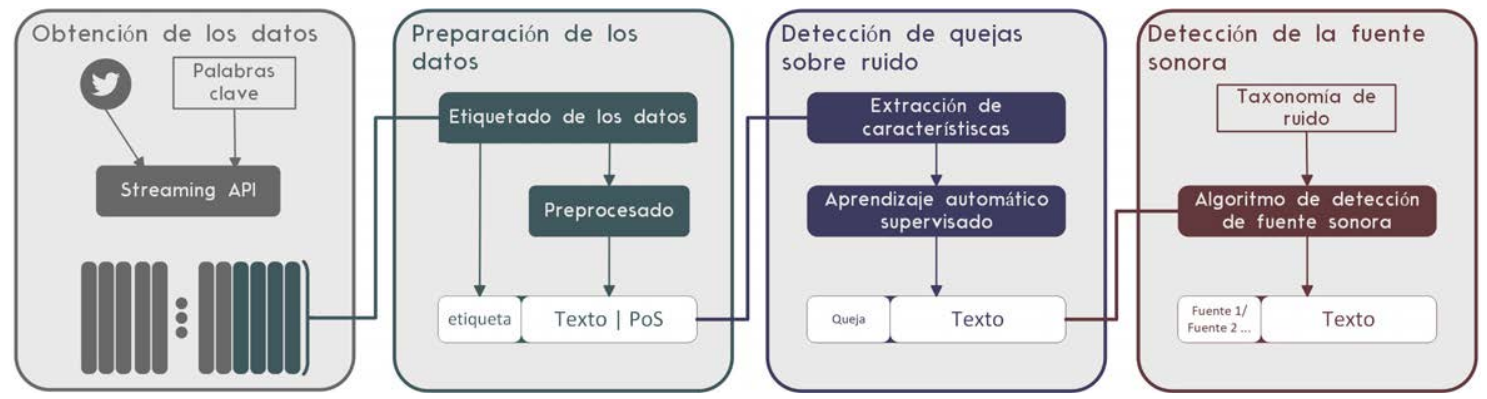

Figura 3.1: Metodología de análisis de RSO para la detección y clasificación de quejas sobre ruido.

\subsubsection{Obtención de los datos}

Los datos textuales son la materia prima de este trabajo, por lo que es esencial la definición de un proceso de adquisición de datos eficiente. De aquí en adelante se utilizará el término "datos textuales" a los documentos escritos por usuarios de RSO. Existen multitud de RSO pero, como primera aproximación al problema, se decidió centrar el análisis en las plataformas de microblogging, que son redes en las que los usuarios se expresan mediante textos cortos, porque los usuarios las utilizan para expresar sus opiniones sobre una gran diversidad de temas, incluyendo su percepción sobre el ruido de su entorno. Específicamente se ha seleccionado Twitter por disponer de un gran número de usuarios activos, más de 126 millones al mes; y de una extensa bibliografía en el análisis de textos provenientes de esta plataforma (Twitter, 2016, Zimbra y Abbasi, 2018). Además, los usuarios de esta red social tienden a expresar su opinión de forma directa por la limitación de caracteres en cada post. Aunque, por otra parte, esto provoca que utilicen multitud de jerga y diminutivos que requieren un proceso de normalización exhaustivo antes de realizar los análisis (Han et al. 2012, 2013).

Twitter es una red social de microblogging en la que los usuarios pueden publicar mensajes cortos, conocidos como tweets. Los tweets son documentos de texto con una extensión máxima de 140 caracteres, aunque desde el 1 de octubre del 2017 se incremento la longitud de estos hasta los 280 caracteres (Rosen, 2017). Los tweets suelen estar escritos de una manera característica, en la que la presencia de errores gramáticales y jerga es común para disminuir la longitud del texto y poder desarrollar las ideas de cada post en 
un mayor grado. Además, existen una serie de elementos textuales específicos presentes exclusivamente en esta red social:

- Hashtags: Son el nombre dado a las palabras que los usuarios utilizan para etiquetar los tweets en una categoría específica. Estas etiquetas se identifican por tener el símbolo "\#" delante de la palabra.

- Menciones y respuestas: Es la manera que tienen los usuarios de interactuar con otras personas y su contenido utilizando el símbolo "@” delante del nombre del usuario al que quieren referirse.

- Emoticonos o emojis: Son combinaciones de caracteres que los usuarios utilizan para expresar emociones y palabras de forma visual.

- Retweets: Es el nombre que se le da al contenido re-publicado por un usuario proveniente de otra persona.

Para llevar a cabo nuestro análisis se necesitaba un conjunto de datos provenientes de Twitter. Se utilizó la API (Application Programming Interface, Interfaz de programación de aplicaciones) de Twitter para recolectar y guardar en una base de datos los tweets en los que aparecía la palabra "noise" (Twitter, 2018b). Se utilizó este filtro en la adquisición porque la API sólo devuelve una muestra del $1 \%$ de los datos publicados por los usuarios para evitar abusos en su uso. Cuando se utilizan filtros como el mencionado, la búsqueda de tweets se centra en un menor número de documentos, consiguiendo de este modo evitar esas limitaciones y obteniendo la mayoría de posts que contengan esa palabra (Twitter Forum, 2014). La adquisición de datos se llevó a cabo entre el 1 de junio y el 1 de septiembre del 2017. Como resultado se obtuvo un conjunto de tweets originales, respuestas a tweets y retweets, además cada documento textual vino acompañado con una serie de metadatos como su idioma, información del autor y la hora en la que fue publicado (Twitter, 2018a).

El proceso de adquisición de datos concluyó con la obtención de un conjunto de más de 5.6 millones de tweets. La Tabla 3.1 muestra la distribución de los tipos de tweets presentes en la base de datos inicial. Se puede ver que el $60 \%$ de los documentos fueron retweets y el $10 \%$ fueron respuestas a otros tweets; por otra parte, sólo 9759 tweets tuvieron información acerca de la geolocalización entre sus metadatos, lo que impidió considerar la componente geoespacial en los análisis posteriores.

Tabla 3.1: Distribución del tipo de tweets de la base de datos original obtenida entre el 1 de junio y el 1 de septiembre del 2017.

\begin{tabular}{ll}
\hline Base de datos original & \\
\hline $\mathrm{N}^{0}$ de tweets & 5.637 .450 \\
$\mathrm{~N}^{0}$ de tweets geolocalizados & 9.759 \\
Tipo de tweets: & \\
$\quad$ Retweets & 3.460 .057 \\
Respuestas & 575.280 \\
Keywords & 758.780 \\
Originales & 843.300 \\
\hline
\end{tabular}

Se estableció la restricción de construir los modelos únicamente con tweets originales que la API de Twitter identificaba en lengua inglesa. Se decidió no considerar los retweets porque muestran la opinión de otra persona sobre una temática específica, aunque podrían ser utilizados en aplicaciones específicas en el futuro dado que de algún modo muestran el apoyo que tiene la gente respecto a una idea específica. También se decidió no considerar 
las respuestas a tweets, porque cuando una persona interactúa con otro usuario el contexto sobre el tema tratado puede perderse, dado que la respuesta hace referencia al contenido de un tweet del que no se conoce el tema y podría provocar un decremento en el rendimiento del sistema (Derczynski et al. 2015). Este tipo de contenido podría tenerse en cuenta en futuros desarrollos en los que se realizaran análisis sobre la interacción entre usuarios, pero ha sido descartado en este primer experimento, centrado en la problemática de la detección y clasificación de quejas sobre ruido, y no en como los usuarios interactúan con el contenido compartido inicialmente por otra persona. También se descartaron del análisis los tweets que contenían palabras clave relacionadas con el ruido, pero no con el ruido acústico, que era nuestro tema de estudio. Por ejemplo, los tweets que contenían palabras que se referían a marcas publicitando auriculares de reducción de ruido o palabras relacionadas con refranes en inglés como "Work hard in silence, let success make the noise" fueron eliminados.

Tras descartar los documentos textuales mencionados de nuestra base de datos, se obtuvo un conjunto de más de 800.000 tweets. La Tabla 3.2 muestra las estadísticas del nuevo grupo de tweets, en la que se muestra el número de tweets y de hashtags utilizados, que representan la variedad de temas que los usuarios quieren destacar en sus publicaciones. Aunque en este experimento no se consideraron los datos multimedia, es importante mencionar la importancia de este contenido en Twitter, especialmente el uso de fotografías, ya que el $16 \%$ de los tweets tienen al menos una fotografía adjunta. En relación a la interacción entre usuarios, se presenta una media de 0.1 menciones por tweet. Una media menor que la presencia de hashtags y URLs, con 0.4 por tweet, algo esperado dado que se han descartado previamente las respuestas a tweets que suelen tener más menciones que un tweet original.

Tabla 3.2: Estadísticas de la base de datos de tweets originales obtenidos entre el 1 de junio y el 1 de septiembre del 2017.

\begin{tabular}{ll}
\hline \multicolumn{2}{c}{ Base de datos de tweets originales } \\
\hline $\mathrm{N}^{\circ}$ de tweets & 843.300 \\
$\mathrm{~N}^{o}$ de hahtags distintos & 90.707 \\
$\mathrm{~N}^{o}$ de tweets con: & \\
$\quad$ Fotografías & 141.376 \\
$\quad$ Videos & 3.091 \\
$\quad$ GIF animados & 3.418 \\
$\quad$ Coordenadas & 8.152 \\
Estadísticas por tweet & \\
$\quad \mathrm{N}^{\circ}$ medio de menciones & 0,1 \\
$\mathrm{~N}^{o}$ medio de hashtags & 0,4 \\
$\mathrm{~N}^{o}$ medio de URLs & 0,4 \\
\hline
\end{tabular}

\subsubsection{Preparación de los datos}

Tras finalizar el proceso de adquisición de datos, se contaba con un conjunto de tweets que debían preprocesarse antes de construir y testear los modelos de detección. Además, como se utilizó un algoritmo de aprendizaje automático supervisado para la detección de las quejas de ruido, que necesita datos de entrenamiento con información sobre la clase a la que pertenecen, el primer paso en la preparación de los datos fue anotar parte de nuestra base de datos para entrenar y comprobar el rendimiento de los algoritmos. Debido a que en algunos en estudios previos se demostró que la normalización de errores ortográficos y jerga podrían mejorar el rendimiento de los clasificadores de texto (Sarker. 2017, Singh y Kumari, 2016), se corrigieron y normalizaron estos errores, la jerga y los 
acrónimos con el objetivo de aumentar la dimensionalidad de nuestros datos, encontrar más características que permitieran clasificar los tweets en las categorías apropiadas y aumentar así el rendimiento del modelo final.

\subsubsection{Etiquetado de los datos}

La palabra ruido tiene varias acepciones: puede ser utilizada para referirse a sonidos desagradables, problemas existentes en la transmisión de señal en un sistema electrónico o expresar un exceso de información que no es útil y puede ser ignorado (Cambridge Dictionary Online, 2018). En este estudio solo interesaba la acepción de ruido como sonido ambiental no deseado, por lo que se ideó un sistema que permitiera desambiguar ese significado de los otros existentes para ese término. Para entrenar un sistema que aprendiera a discriminar los tweets que contengan la palabra ruido con esa acepción, se llevó un proceso de etiquetado de textos en los que los tweets se categorizaron en cuatro categorías:

- Categoría A. "Queja de ruido": Se debía seleccionar esta categoría cuando el usuario mostraba una opinión negativa respecto a una fuente ruidosa como los vecinos, el tráfico o aeronaves. Un ejemplo de un tweet de estre tipo sería:

The construction at our place needs to finish already. The noise is disrupting my sleep.

- Categoría B. "Sonidos agradables": Se elegía esta categoría cuando la persona ofrecía un sentimiento positivo respecto a una fuente sonora como música o sonidos de pájaros. Un ejemplo de documento de esta categoría sería:

I love rainy days! That's because the noise the rain makes sounds like a song, right?

- Categoría C. "Noticias sobre ruido o opiniones sobre esas noticias": En esta categoría entraron los tweets cuyo contenido estaba relacionado con noticias sobre acústica, opiniones sobre estas o afirmaciones sobre acústica sin componente subjetivo. Un ejemplo de tweet de esta categoría es:

\section{How Amsterdams Airport Is Fighting Noise Pollution With Land Art - https://t.co/MUfoOPofaY via Shareaholic}

- Categoría D. "Otros": Aquí se agruparon los tweets que tuvieran un uso de la palabra ruido diferente de los anteriormente mencionados como ruido mediático, ruido eléctrico u otros usos genéricos, como por ejemplo:

$$
\begin{aligned}
& \text { - MASAKI YODA -Noise and tone(iTunes)- https://t.co/jPcWkGJfol } \\
& \text { \#musiikki \#Japani \#TIEDOT }
\end{aligned}
$$

Para facilitar el proceso de etiquetado se desarrolló una aplicación web que permitió a los anotadores colaborar con las tareas de etiquetado sin necesidad de desplazarse a una ubicación específica. La Figura 3.2 muestra una captura de la aplicación, tanto la versión de escritorio (izquierda) como la versión adaptada para móviles (derecha).

Con el objetivo de comprobar si las categorías habían sido definidas correctamente y por lo tanto que el proceso de etiquetado era fiable, se aplicó un método para medir el acuerdo entre anotadores (inter-annotator agreement). El grado de concordancia se mide mediante descriptores estadísticos que permiten cuantificar el consenso entre diferentes anotadores para las categorías existentes. Si los descriptores tuvieran un valor reducido, el consenso sería bajo y por lo tanto las categorías estarían definidas incorrectamente (Artstein, 2017). 


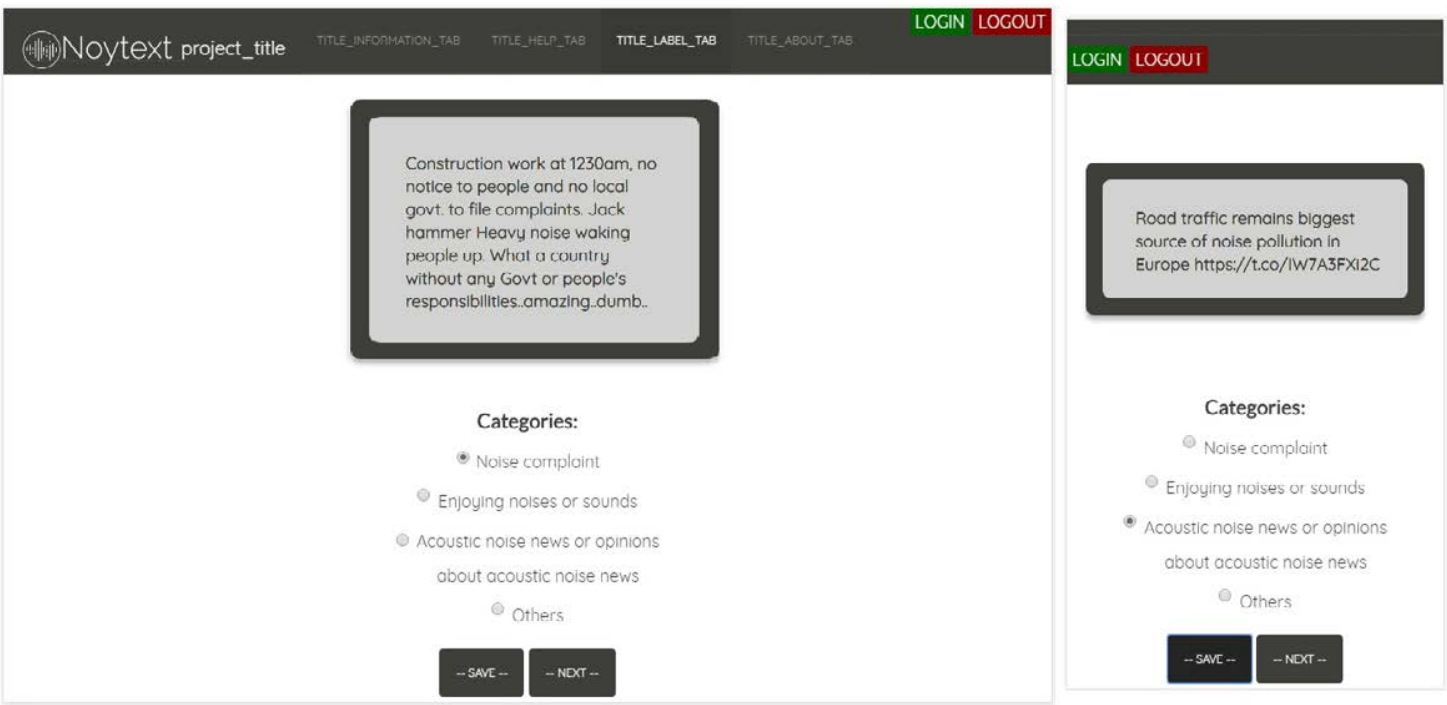

Figura 3.2: Captura de la aplicación web desarrollada para el etiquetado de textos cortos.

Para validar las categorías de etiquetado se seleccionaron aleatoriamente 150 tweets, que fueron etiquetados por el doctorando y otro especialista en acústica ambiental con experiencia en la gestión de problemas de ruido y el estudio de la percepción de la molestia. Se aplicó a las etiquetas de esos tweets el coeficiente Cohen Kappa, que permite medir el grado de acuerdo entre elementos categóricos (Carletta, 1996). La Tabla 3.3 muestra los resultados de ese estadístico para distintas combinaciones de las categorías disponibles, tal y como se realizó en estudios previos consultados (Charras et al. 2016). Basándonos en las interpretaciones de Landis sobre este índice, se encontró un alto grado de acuerdo cuando se re-agrupaban las categorías en dos: tweets relacionados con molestias sobre ruido (tweets de clase 1) y otros tweets (tweets de clase 0) (Landis y Koch 1977). Esto significa que los anotadores expertos fueron capaces de diferenciar tweets con una valoración negativa sobre el ruido del resto de textos.

Tabla 3.3: Resultados de las pruebas de "inter-annotator agreement" para cada combinación de categorías.

\begin{tabular}{lll}
\hline Categorías & Kappa de Cohen & Grado de consenso \\
\hline A, B, C, D & 0,54 & Consenso moderado \\
$\mathrm{A}+\mathrm{B}, \mathrm{C}, \mathrm{D}$ & 0,53 & Consenso moderado \\
$\mathrm{A}, \mathrm{B}+\mathrm{C}+\mathrm{D}$ & 0,61 & Fuerte consenso \\
$\mathrm{A}+\mathrm{B}, \mathrm{C}+\mathrm{D}$ & 0,55 & Consenso moderado \\
\hline
\end{tabular}

Después de validar las categorías con dos anotadores, el resto del etiquetado fue llevado a cabo por el doctorando. Se seleccionaron aleatoriamente 10007 tweets de la base de datos, cuyas estadísticas se muestran en la Tabla 3.4. Los tweets de la clase 1 corresponden a los etiquetados dentro de la "Categoría A", y los de clase 0 a los anotados en alguna de las otras categorías. Analizando las estadísticas de la tabla se observa que la distribución de tweets presentes en cada una de las clases era desbalanceada y que los tweets de ambas categorías tenían una longitud media de tokens ${ }^{1}$ similar. La mayor diferencia entre las dos clases se encontró en que los tweets de clase 0 tenían una mayor presencia de hashtags y URLs que los de clase 1, por lo que se descubrió una posible característica textual que

\footnotetext{
${ }^{1}$ los tokens son los elementos mínimos en los que un documento de texto puede ser dividido
} 
podría diferenciar ambas clases y que podría ser usada en el algoritmo de aprendizaje automático.

Tabla 3.4: Estadísticas de los tweets de clase 0 y clase 1.

\begin{tabular}{lll}
\hline & Clase 0 & Clase 1 \\
\hline $\mathrm{N}^{o}$ de tweets & 9427 & 580 \\
$\mathrm{~N}^{o}$ de tokens medio por tweet & 18,3 & 20,4 \\
$\mathrm{~N}^{o}$ de menciones medias por tweet & 0,13 & 0,07 \\
$\mathrm{~N}^{o}$ de hashtags medios por tweet & 0,40 & 0,11 \\
$\mathrm{~N}^{o}$ de URLs medios por tweet & 0,52 & 0,07 \\
\hline
\end{tabular}

\subsubsection{Preprocesado del texto}

Como se ha comentado anteriormente, los textos provenientes de Twitter normalmente están escritos con un estilo específico en el que abundan las palabras de jerga y la presencia de errores ortográficos utilizados de forma intencionada para reducir el tamaño de los textos. Por ello fue necesario especificar un método de preprocesado de textos, que utilizara herramientas para normalizarlos sin perder contenido de importancia para el análisis como los emojis, URLs o hashtags. Se implementó una versión del sistema personalizable de preprocesado de textos provenientes de medios sociales propuesto por Sarker con este fin (Sarker, 2017), que se representa en la Figura 3.3.

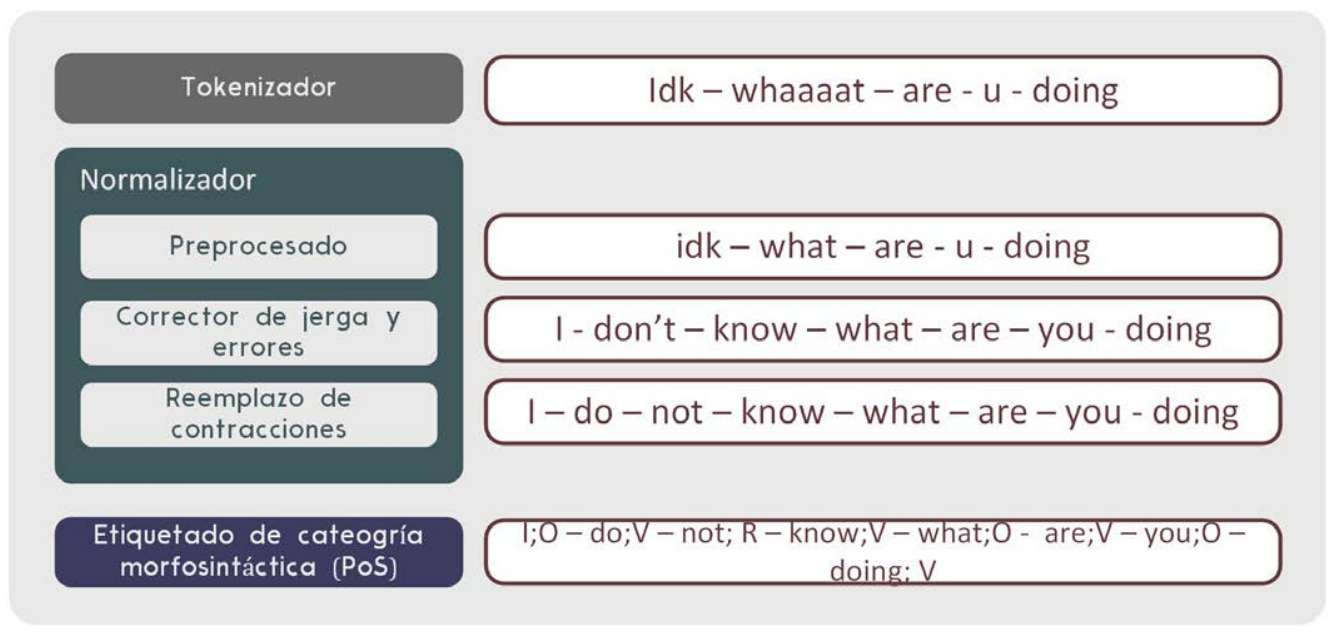

Figura 3.3: Flujo de pre-procesado de texto aplicado a los tweets.

En el flujo de preprocesado implementado, en primer lugar los tweets son dividido en fragmentos más pequeños llamados tokens. Los tokens pueden ser tanto palabras, emoticonos o símbolos de puntuación. Se tokenizaron los tweets utilizando el Carnegie Mellon tokenizer (Owoputi et al. 2013), que es capaz de trabajar con la sintaxis de Twitter, identificando correctamente los emojis, hashtags y URLs. A continuación, cada token se introdujo en un bloque normalizador donde se aplicaron tres procesos:

1. Preprocesado: Este paso estaba compuesto por tres tareas. En primer lugar los tokens fueron transformados a minúsculas. En segundo lugar, los elementos escritos con palabras específicas del inglés británico fueron transformados a su versión americana utilizando un diccionario. Por ejemplo, la palabra "lorry" (camión en inglés 
británico) fue reemplazada por "truck". Finalmente, los elementos que tenían caracteres repetidos fueron transformados a su forma original. Por ejemplo, la palabra "cooooool" se corrigió y sustituyó por "cool" para que pudiera ser detectada por los lexicons ${ }^{2}$ utilizados para detectar el sentimiento de un texto (Kouloumpis et al. 2011).

2. Jerga: Se creó un diccionario de palabras de jerga y su correspondiente corrección a partir de la base de datos de NoSlang, un repositorio online que contiene la jerga y acrónimos usados en Internet (NoSlang, 2017). También se utilizó el diccionario de normalización léxica de la UT Dallas, que añade algunas abreviaciones utilizadas comúnmente en inglés (Liu et al. 2012, 2011). Como ejemplo, se remplazaron palabras como "LOL" por "Lot of Laughs", lo que permitió incrementar la cantidad de palabras y por lo tanto la información que contenían los tweets.

3. Reemplazo de contracciones: Existen estudios que demuestran que el reemplazo de las contracciones y negaciones utilizadas en inglés incrementa la calidad de los clasificadores de análisis de sentimiento (Jianqiang, 2015), por lo que en este último paso del preprocesado se transformaron las contracciones con tal fin.

Por último, tras haber normalizado los tokens, se extrajeron las categorías morfosintácticas, que serán denominadas PoS (Part of Speech, Categoría morfosintáctica) en este documento, de cada uno de ellos ya que es una característica que puede proveer información útil a un clasificador. Se extrajo cada PoS mediante una herramienta desarrollada por la Universidad Carnegie Mellon, que además de ser capaz de detectar verbos y adjetivos, identifica cuando un elemento actúa como hashtag o cuando los símbolos de puntuación se utilizan para crear emoticonos (Gimpel et al. 2011).

$\mathrm{Al}$ finalizar este bloque metodológico en el que se corrigieron los errores, se normalizaron los términos en inglés, se reemplazó la jerga y se determinó la categoría gramatical de cada token, se obtuvo un conjunto de tweets preparados para ser procesados. Además, se anotó una parte de la base de datos que se utilizaría en las siguientes etapas de la metodología para la creación de los modelos de detección y clasificación de quejas sobre ruido.

\subsubsection{Detección de quejas sobre ruido}

El objetivo de esta etapa era construir un modelo capaz de detectar los tweets en los que la gente se quejara sobre el ruido. Para ello, mediante técnicas de aprendizaje automático supervisado, se construyó un clasificador de textos. El clasificador utiliza un conjunto de características calculadas a partir del contenido textual de los tweets etiquetados para entrenar un modelo capaz de discriminar entre tweets en los que la gente expresa una opinión negativa hacia una fuente de ruido y otros tweets. Se utilizó un clasificador de máxima entropía, cuya representación paramétrica se representa en la Ecuación 3.1 (Nigam et al. 1999). Este algoritmo expresa que la probabilidad de que un documento $d$ sea parte de una clase $c$ está dada por una distribución de probabilidad exponencial, donde $f_{i}(c, d)$ representa a una característica del documento de texto, y $\lambda_{i}$ es el peso que se da a dicha característica durante el proceso de entrenamiento.

$$
P(c \mid d, \lambda)=\frac{\exp \left(\sum_{i} \lambda_{i} f_{i}(d, c)\right)}{\sum_{c^{\prime} \in C} \exp \left(\sum_{i} \lambda_{i} f_{i}\left(d, c^{\prime}\right)\right)}
$$

\footnotetext{
${ }^{2}$ Un lexicon es el nombre común dado al conjunto de palabras conformadas para una determinada aplicación, en el caso de esta tesis doctoral cuando se habla de lexicon se refiere al conjunto de palabras con un coeficiente de sentimiento asignados y que son utilizadas para procesos de análisis de sentimiento en textos
} 
El clasificador se entrenó utilizando diversas características que fueron calculadas utilizando técnicas diferentes como: modelos de BoW (Bag of Words, Bolsa de Palabras), métodos estadísticos, características de sentimiento y word embeddings. Las características BoW representan un documento como un conjunto de sus palabras, sin tener en cuenta la posición gramatical que ocupan cada una de ellas (Manning et al. 2008). Las características estadísticas están basadas en operaciones matemáticas realizadas sobre cada tipo de PoS de cada texto. Las características de sentimiento indican si la opinión mostrada en el texto es positiva, negativa o neutral, y son calculadas a traves de lexicons de análisis de sentimiento. Los word embeddings son modelos que representan cada palabra matemáticamente mediante un vector n-dimensional. Se ha demostrado que el uso de estos vectores es útil para la obtención de características para la clasificación de textos (Mikolov et al., 2013).

Específicamente, las características utilizadas en el modelo fueron:

- N-gramas: Un n-grama es una secuencia de $n$ tokens proveniente de un texto. La combinación de n-gramas proporciona información sobre la temática de un texto, por lo que pueden ser utilizados como características para clasificarlo. Se calcularon los unigramas, bigramas, trigramas y 4-gramas, que son las combinaciones de una, dos, tres y cuatro palabras para cada tweet. También se aplicó la ponderación TFIDF (Term Frequency-Inverse Document Frequency,Frecuencia de término-frecuencia inversa de documento), que es un estadístico que pondera la importancia de los ngramas de un texto. Está basado en la idea de que cuando un n-grama aparece en todos los textos de una base de datos no proporciona información significativa sobre si ese texto es parte de una clase u otra, por lo que se le aplicaría un factor para disminuir su importancia (Manning et al., 2008).

- Características PoS: Se ha calculado tanto el número como el porcentaje de cada PoS en cada uno de los tweets. El número de PoS es el número de nombres, adjetivos, hashtags, números, signos de puntuación, URLs, verbos y emoticonos presentes en cada tweet. El porcentaje de PoS es el porcentaje de tokens con un PoS específico en relación a la longitud total de tokens del tweet.

- Características de sentimiento: Se han calculado características relacionadas con el sentimiento utilizando el lexicon SentiWordNet y el Emoji Sentiment Ranking. SentiWordNet es un lexicon que asigna a cada palabra tres puntuaciones de sentimiento: positividad, negatividad y objetividad. Se decidió utilizar SentiWordNet porque tiene una gran cobertura en términos del número de palabras disponibles con valoración de sentimiento (Esuli y Sebastiani, 2006), así como una gran simplicidad en su estructura si lo comparamos con otros como WordNet-Affect y LIWC (Tausczik y Pennebaker, 2010, Valitutti et al. 2004). Dado que los tweets tienen una longitud muy corta, cuando una persona expresa su opinión sobre ruido es improbable que exprese más de un sentimiento respecto a éste. Por esta razón se calculó una puntuación para positividad, negatividad y objetividad de cada tweet sumando los valores de dichas puntuaciones para cada adjetivo y adverbio presentes en el texto, que son las PoS que expresan más sentimiento en una frase (Liu, 2012).

Los emojis de los tweets pueden expresar sentimiento. Se ha utilizado el Emoji Sentiment Ranking, que es una base de datos que proporciona una puntuación de sentimiento y de neutralidad a cada emoticono existente (Kralj Novak et al. 2015$)$. Se utilizaron estas puntuaciones para calcular el valor medio, máximo y mínimo tanto de neutralidad como sentimiento de cada tweet en función de sus emojis.

- Glove embedding: Como se ha mencionado anteriormente, un word embedding es un modelo que representa cada palabra en un espacio vectorial con multitud de di- 
mensiones en el que las relaciones entre palabras pueden ser encontradas con mayor facilidad. Debido a que nuestra base de datos no era lo suficientemente extensa para construir nuestro propio word embedding, se utilizó el modelo de 50 dimensiones calculado por la Universidad de Stanford utilizando 2000 millones de tweets ( $\overline{\text { Pen- }}$ nington et al. 2014). Utilizando este modelo pre-entrenado se buscó cada palabra del tweet en el embedding, obteniendo para cada texto un conjunto de vectores de los que se calculó su suma, media y desviación típica, consiguiendo así tres vectores de 50 dimensiones que representaban matemáticamente cada tweet de la base de datos en un espacio multidimensional.

\subsubsection{Detección de la fuente sonora}

El último paso de la metodología pretendía detectar la fuente de ruido a la que se referían cada uno de los tweets. Se decidió utilizar un sistema que combinara los lexicons y las taxonomías. Una taxonomía es una ordenación de elementos en grupos que tienen algo en común; específicamente, una taxonomía de ruido es una estructura que permite clasificar las fuentes sonoras existentes de forma inequívoca. Se construyó una taxonomía basada en la utilizada en el proyecto Chatty maps porque fue producida utilizando datos de medios sociales y ofrecía categorías sonoras similares a las proporcionadas por Schafer (Schafer 1993). La taxonomía de Chatty maps fue construida basándose en las etiquetas más utilizadas en los clips sonoros de la plataforma Freesounds, está compuesta por un vocabulario de 228 palabras categorizadas en 6 categorías: transporte, naturaleza, humanos, música, interior y mecánico (Aiello et al. 2016). La representación esquemática de la taxonomía se muestra en la Figura 3.4

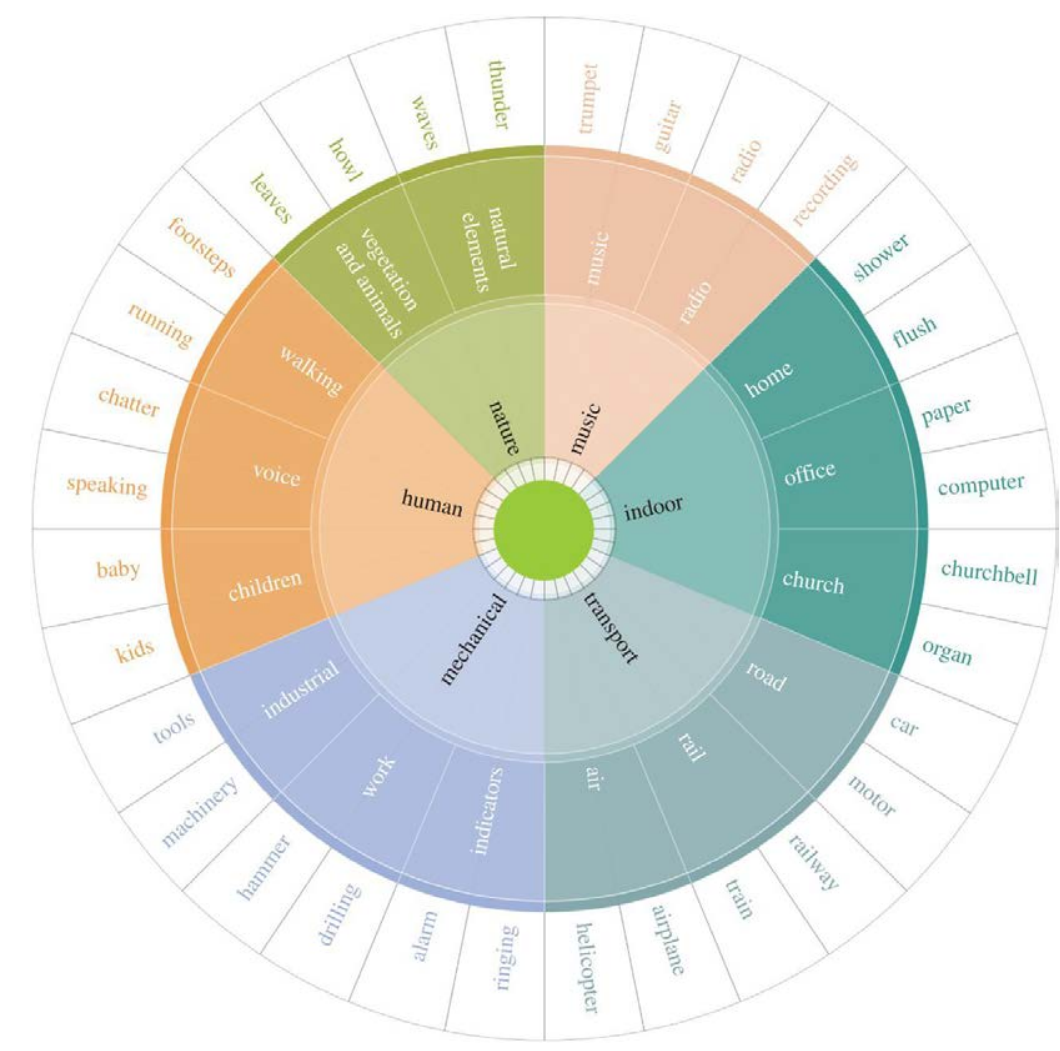

Figura 3.4: Taxonomía de ruido desarrollada en el proyecto Chatty maps. Fuente: Aiello et al., 2016). 
Debido a que la variedad de palabras utilizadas en Twitter es mayor que las etiquetas presentes en Freesounds, se expandió el lexicon de Chatty maps para cubrir la mayoría de las posibilidades del lenguaje cuando se habla sobre fuentes sonoras. La expansión del léxico se llevó a cabo utilizando WordNet 3.0 que es una base de datos léxica para la lengua inglesa (Miller, 1995). En WordNet, las palabras están organizadas en jerarquías definidas por hiperónimos, que son relaciones semánticas entre términos. Por ejemplo, perro es un hipónimo de animal, y animal es un hiperónimo de perro. La acepción de cada palabra de Wordnet es conocida como synset.

Se aprovechó ese tipo de jerarquía semántica para expandir el léxico de Chatty maps con más términos. Primero se determinó el PoS y la acepción de cada palabra del lexicon con su synset correspondiente en WordNet. Tratando de ampliar el tamaño del vocabulario automáticamente, se utilizó el algoritmo Lesk para encontrar el synset más apropiado de los hipónimos durante la expansión ( $\overline{\text { Lesk, }}$ 1986). Las entradas del algoritmo fueron la acepción de la palabra de la cual se querían obtener los hipónimos y las acepciones de sus hipónimos. El synset con la acepción con un valor más alto después de aplicar el algoritmo Lesk fue el añadido al léxico.

También se amplió el léxico utilizando DBPedia, un proyecto que tiene como objetivo estructurar el contenido de Wikipedia para acceder fácilmente a su información utilizando lenguajes de consulta semánticos para bases de datos, como SPARQL (Lehmann et al., 2015). Existen 318.000 elementos vinculados entre los synsets de WordNet y DBPedia (DBpedia, 2015). Se utilizaron estos enlaces para ampliar el número de palabras en la categoría "transport" de la taxonomía. Específicamente, obtuvimos todos los nombres de modelos de automóviles indexados en DBPedia, así como los nombres de aeropuertos con sus identificadores de ubicación IATA. Al finalizar el proceso de expansión del léxico de la taxonomía, se obtuvieron un total de 4506 palabras, con una relación jerárquica entre ellas.

La Figura 3.5 muestra un ejemplo del proceso llevado a cabo. Cada palabra del vocabulario original se le asignó un synset de forma manual. A continuación se aplicó el algoritmo Lesk entre la acepción de dicho synset y las diferentes acepciones de los synsets de sus hipónimos. El mejor resultado de ese cálculo fue el hipónimo del que obtuvimos la palabra asociada para ser añadida al léxico final. Por otro lado, también se usaron synsets de palabras específicas como "car" o "airport" para buscarlas en propiedades específicas de DBPedia y añadir dichos resultados en nuestro léxico final.
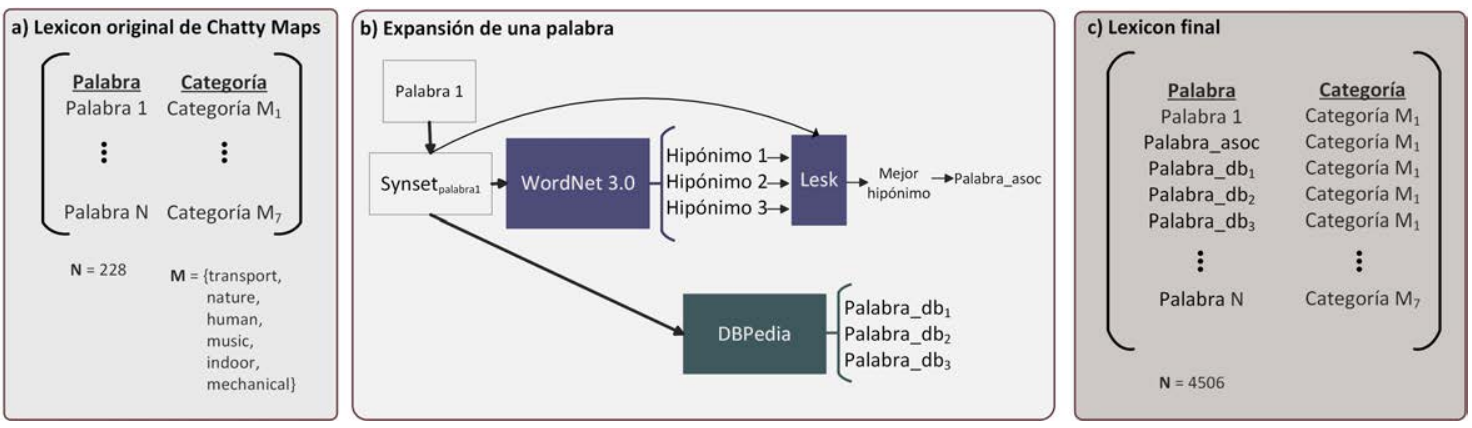

Figura 3.5: Ejemplo de la expansión léxica de la taxonomía con WordNet y DBPedia.

Por último, se utilizó dicho vocabulario y taxonomía para inferir la fuente sonora mencionada en cada tweet. Para ello, cada palabra del tweet se buscó en el vocabulario. Si el algoritmo encontraba la palabra en el vocabulario, se seguía la jerarquía de la taxonomía hasta el nivel inicial y se añadía la categoría al tweet. Al finalizar el proceso, se obtuvo una lista de categorías sonoras para cada tweet, es decir que cada queja sobre ruido estaba 
acompañada de las fuentes de ruido mencionadas en esta.

A modo de resumen de esta sección, la Tabla 3.5 muestra cada uno de los procesos llevados a cabo en la metodología, así como el bloque al que pertenecen y una pequeña descripción de lo realizado en cada etapa.

Tabla 3.5: Resumen de los pasos llevados a cabo para la implementación de la metodología.

\begin{tabular}{|c|c|c|c|}
\hline Orden & $\begin{array}{l}\text { Bloque } \\
\text { metodológico }\end{array}$ & Proceso & Descripción \\
\hline \multirow[t]{2}{*}{1} & \multirow[t]{2}{*}{$\begin{array}{l}\text { Adquisición de } \\
\text { datos }\end{array}$} & $\begin{array}{l}\text { Obtención de los } \\
\text { tweets }\end{array}$ & $\begin{array}{l}\text { Adquisición de datos de Twitter mediante el } \\
\text { uso de palabras clave en API pública. }\end{array}$ \\
\hline & & $\begin{array}{l}\text { Filtrado de los } \\
\text { tweets }\end{array}$ & $\begin{array}{l}\text { Filtrado de tweets originales excluyendo los } \\
\text { retweets, respuestas a otros tweets y tweets } \\
\text { específicos sobre usos de la palabra ruido. }\end{array}$ \\
\hline \multirow[t]{2}{*}{2} & \multirow[t]{2}{*}{$\begin{array}{l}\text { Preparación de los } \\
\text { datos }\end{array}$} & $\begin{array}{l}\text { Etiquetado de los } \\
\text { datos }\end{array}$ & $\begin{array}{l}\text { Anotación de un subconjunto de la base de } \\
\text { datos para especificar que tweets son quejas } \\
\text { de ruido. }\end{array}$ \\
\hline & & $\begin{array}{l}\text { Preprocesado del } \\
\text { texto }\end{array}$ & $\begin{array}{l}\text { Normalización del texto de los tweets dividién- } \\
\text { dolos en fragmentos más pequeños (tokens). } \\
\text { A continuación se uniformizan los tokens a su } \\
\text { forma de inglés británico y se eliminan los ca- } \\
\text { racteres repetidos. También se sustituyen las } \\
\text { palabras de jerga y las abreviaciones utiliza- } \\
\text { das en redes sociales online. Por último, se re- } \\
\text { emplazan las contracciones y negaciones uti- } \\
\text { lizadas en inglés y se extraen las categorías } \\
\text { morfosintácticas de cada token. }\end{array}$ \\
\hline \multirow[t]{2}{*}{3} & \multirow[t]{2}{*}{$\begin{array}{l}\text { Detección de } \\
\text { quejas sobre ruido }\end{array}$} & $\begin{array}{l}\text { Extracción de } \\
\text { características }\end{array}$ & $\begin{array}{l}\text { Extracción de las características de cada uno } \\
\text { de los tweets que permitan buscar patrones pa- } \\
\text { ra clasificar las quejas de ruido. Se extrajeron } \\
\text { n-gramas, características PoS, características } \\
\text { relacionadas con el sentimiento y característi- } \\
\text { cas calculadas a partir de la posición de las } \\
\text { palabras en espacios multidimensionales. }\end{array}$ \\
\hline & & $\begin{array}{l}\text { Clasificador de } \\
\text { textos }\end{array}$ & $\begin{array}{l}\text { Entrenamiento de un algoritmo de aprendizaje } \\
\text { automático supervisado capaz de detectar los } \\
\text { tweets que son quejas sobre ruido utilizando } \\
\text { las características calculadas previamente. }\end{array}$ \\
\hline 4 & $\begin{array}{l}\text { Detección de la } \\
\text { fuente sonora }\end{array}$ & $\begin{array}{l}\text { Clasificador } \\
\text { multietiqueta de } \\
\text { textos }\end{array}$ & $\begin{array}{l}\text { Uso del lexicon y taxonomía implementados } \\
\text { para detectar las fuentes sonoras mencionadas } \\
\text { en los tweets basados en un algoritmo de apa- } \\
\text { rición de palabras. }\end{array}$ \\
\hline
\end{tabular}

\subsection{Evaluación de la metodología}

Hasta este punto se ha mostrado el flujo de trabajo llevado a cabo en la implementación de la metodología para crear los modelos de detección. Empezando por la adquisición de datos de Twitter, pasando por la preparación de los textos y la extracción de sus características. También se ha presentado el modelo utilizado para detectar quejas sobre ruido, y el mecanismo ideado para organizar dichas quejas por fuente sonora. En esta sección, se evaluará el rendimiento de los modelos creados en la metodología. Se ha dividido el proceso en dos partes. En la primera, se evalúa el algoritmo desarrollado para detectar 
quejas de ruido. En la segunda, se evalúa la técnica utilizada para organizar los tweets por fuente sonora.

\subsubsection{Evaluación del modelo de detección de quejas sobre ruido}

Para valorar el rendimiento del modelo de detección de quejas desarrollado, se dividió la base de datos etiquetada utilizando un algoritmo de validación cruzada estratificado de 8 iteraciones; que divide el conjunto de datos en 8 partes, utiliza 7 para entrenar el modelo y el último para validarlo. Nuestra base de datos estaba altamente desbalanceada, debido a que el número de quejas de ruido, etiquetadas como clase 1, era sustancialmente menor que el número del resto de tweets, identificados como clase 0. Se decidió utilizar estratificación porque se quería mantener el porcentaje original de cada clase en cada iteración. Para decrementar el efecto del desbalanceo de clases en el rendimiento del clasificador, se definió una ponderación que fue aplicada a ambas clases. Esta ponderación se calculó como un factor multiplicador inversamente proporcional a la frecuencia de cada clase. En la Ecuación 3.2 se muestra el cálculo de este parámetro para la clase 0:

$$
w_{c_{0}}=\frac{N_{\text {samples }_{c_{1}}}}{N_{\text {classes }} * N_{\text {total-samples }_{\text {sam }}}}
$$

Donde $N_{\text {classes }}$ corresponde con el número de clases del clasificador, $N_{\text {samplesc }_{1}}$ es el número de elementos de la clase 1 y $N_{\text {total-samples }}$ es el número total de elementos de la base de datos.

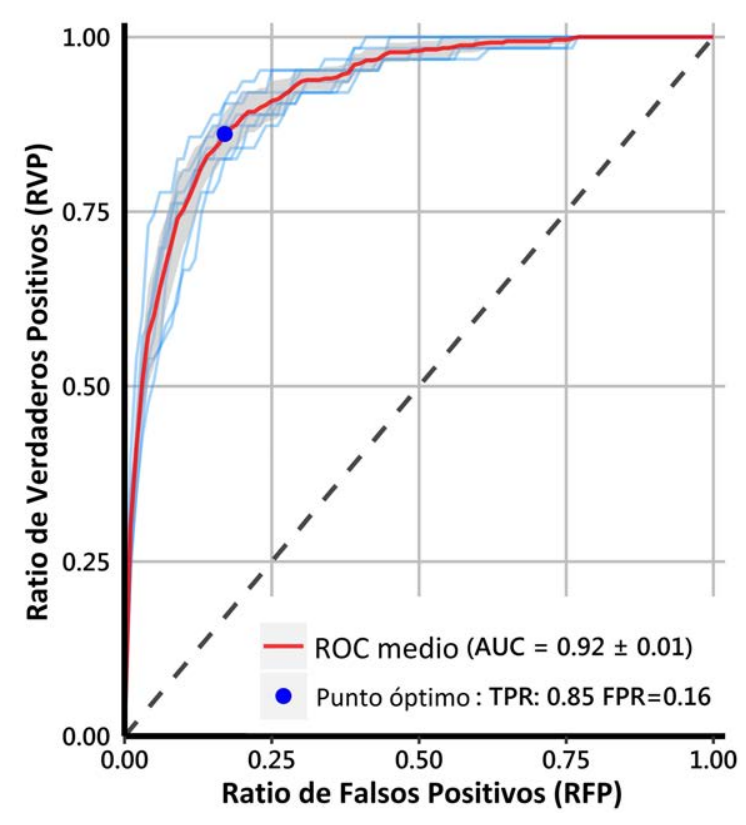

Figura 3.6: Curva ROC para el modelo de detección de quejas. Se muestra el ROC para cada una de las iteraciones, así como el ROC medio y el mejor punto de funcionamiento del clasificador.

En la Figura 3.6 se muestra el rendimiento del clasificador en términos de una curva ROC (Receiver Operating Characteristic, Característica Operativa del Receptor). El eje y representa la RVP (Razón de Verdaderos Positivos, True Positive Rate) del clasificador para diferentes puntos de corte; el eje $x$ indica la RFP (Razón de Falsos Positivos, False Positive Rate). Cuanto más cerca esté la curva del eje y, más precisa será la prueba. Se ha utilizado esta métrica porque tiene la particularidad de ser insensible a los cambios 
en la distribución de las clases, por lo que el valor del ROC no cambiará si la proporción de las clases cambia entre el entrenamiento y la validación (Fawcett, 2006, Majnik y Bosnić 2013). Para conocer el rendimiento global del clasificador, se calculó el AUROC (Area Under the Receiver Operating Characteristic, Area Bajo la curva de la Característica Operativa del Receptor), que tiene un valor de 0.92. Este valor representa la probabilidad de clasificar correctamente una queja de ruido en su clase (Mason y Graham, 2006).

Se calculó el punto en el que el clasificador funcionaba de forma óptima, considerando que era aquel que maximiza la diferencia entre el RVP y el RFP. En ese punto se obtuvo un valor de RVP de 0.85 , lo que significa que el $85 \%$ de las quejas de ruido eran correctamente identificadas, y un valor de RFP de 0.16 , lo que indica que el $16 \%$ de tweets que no eran quejas de ruido estaban siendo erróneamente catalogadas como tal. Se puede ver que el enfoque utilizado fue capaz de abordar el problema del desequilibrio de clases, ya que se obtuvo un clasificador en el que la mayoría de las quejas de ruido se identificaron correctamente y un porcentaje relativamente bajo de tweets no relacionados con el ruido se clasificaron erróneamente como queja.

Después de ajustar nuestro clasificador en el punto de mejor rendimiento, se entrenó el modelo. Algunos de los tweets clasificados por éste modelo se muestran en la Tabla 3.6 donde se muestra el texto del tweet original, el valor de la clase real y de la clase predicha por el clasificador. Se puede ver que los tweets que claramente no son quejas de ruido se clasifican correctamente. El modelo no es capaz de detectar el sarcasmo, por esta razón los tweets que hagan uso de esta peculiaridad del lenguaje podrían ser categorizados incorrectamente, como por ejemplo el tweet presente en la tercera fila. El sistema tampoco detecta los mensajes escritos por bots de Twitter reportando quejas de ruido recibidas mediante canales oficiales, como las llamadas telefónicas que recibe la policía alarmando sobre ruido y que son publicadas en plataformas de datos abiertos, dado que estos tweets no son escritos por personas reales que sufren el ruido y lo comunican utilizando este canal (tal y como ejemplifica el tweet de la cuarta fila).

Tabla 3.6: Ejemplos de predicciones realizadas por el detector de quejas sobre ruido.

\begin{tabular}{lcc}
\hline Tweet original & Clase verdadera & Clase predicha \\
\hline $\begin{array}{l}\text { Tell me why the maintenance guys were making so } \\
\text { much fucking noise at 7:30 am! } \oplus \text { I can't wait to }\end{array}$ & 1 & 1 \\
complain!!!!! & & 0 \\
\hline $\begin{array}{l}\text { I thought public noise (karaoke and whatnots) are } \\
\text { not allowed beyond 10pm anymore }\end{array}$ & & 1 \\
\hline $\begin{array}{l}\text { Feeling sleeping after waking up a 2 am because I } \\
\text { heard a noise. Not going to lie my first thought was } \\
\text { that it was a ghost }\end{array}$ & & \\
\hline $\begin{array}{l}\text { NOISE DISTURBANCE at 1900 BLOCK OF NW } \\
\text { PETTYGROVE ST, PORTLAND, OR [Portland }\end{array}$ & 0 & 0 \\
Police \#PP17000193734] 02:54 \#pdx911 & & \\
\hline \#trapmusic \#radio The Signals - Signals vs The Noi- \\
se (Invader! Remix) https://t.co/yjsUUaHuIx
\end{tabular}

\subsubsection{Evaluación del modelo de detección de fuentes sonoras}

Para evaluar el rendimiento del detector de fuentes de ruido, se anotó una pequeña base de datos de quejas de ruido compuesto por 510 tweets, en la que se asignó a cada tweet ninguna, una o más de las seis posibles fuentes de ruido definidas en la taxonomía descrita en la sección 3.3.4. El detector de fuentes de ruido puede ser considerado un problema de 
clasificación multietiqueta ya que un tweet puede hacer referencia a más de un tipo de ruido y por lo tanto el sistema podría asignar más de una fuente sonora (etiqueta) a un tweet. Por esta razón, se han utilizado dos métricas de rendimiento específicas para este tipo de clasificadores: una de ellas considera que una predicción es correcta cuando todas las etiquetas están bien clasificadas, la otra mide el porcentaje de etiquetas pronosticadas de forma incorrecta.

En primer lugar, se ha usado la métrica HL (Hamming Loss score), que mide la fracción de etiquetas mal predichas, es decir que un valor de HL bajo se traduce en un mejor resultado en la predicción (Dembczynski et al., 2010). La métrica HL se define de forma paramétrica como muestra la Ecuación 3.3 donde $N$ es el número de etiquetas que tiene el tweet, $y_{i}$ son las etiquetas asignadas por los anotadores y $w_{i}$ son las predicciones realizadas por el detector de fuentes sonoras que serán comparadas con las etiquetas verdaderas. Cuando los elementos de la tupla $\left(y_{i}, w_{i}\right)$ son diferentes, el operador xor asignará un 1 a esa predicción.

$$
L_{H L}(y, w)=\frac{1}{N} \sum_{i=1}^{N} \operatorname{xor}\left(y_{i}, w_{i}\right)
$$

En segundo lugar, se ha calculado la métrica Subset 0/1 Loss function. Este indice es más restrictivo, dado que solo considera una clasificación como correcta cuando todas las etiquetas predichas se corresponden con las asignadas por los anotadores (Dembczynski et al. 2010). Esta función se muestra matemáticamente en la Ecuación 3.4 donde $I$ es la función característica que asigna el valor 0 cuando todas las etiquetas han sido correctamente predichas y 1 cuando no. Este valor representa el porcentaje de tweets mal clasificados, teniendo en cuenta las restricciones mencionadas anteriormente.

$$
L_{0 / 1 \text { Loss }}(x, w)=I(x \neq w)
$$

Se obtuvo un valor de la métrica Subset 0/1 Loss function de 0.58, lo que indica que el $42 \%$ de los 510 tweets tuvieron todas sus etiquetas predichas correctamente. Como se ha comentado anteriormente, esta métrica es muy restrictiva porque penaliza en la misma medida que todas las etiquetas están mal clasificados o que solo una lo esté. Sin embargo, que una etiqueta no esté correctamente predicha no significa que la predicción sea completamente incorrecta, dado que las otras también podrían proporcionar información significativa. Por esta razón se calculó el índice HL, en el que se obtuvo un valor de 0.14, lo que significa que el $86 \%$ de las etiquetas de la base de datos de prueba se predijeron correctamente.

\subsection{Caso de estudio: Sistema de detección de eventos sono- ros}

Una vez entrenado el clasificador para detectar las opiniones sobre ruido provenientes de RSO y medido la eficacia del sistema, se usaron los modelos en un caso de estudio específico. Este ejemplo utilizó el poder del método presentado, junto con técnicas estadísticas, para detectar eventos que podrían plantear problemas de ruido y quejas en la población.

En primer lugar, se aplicó la metodología propuesta a la base de datos completa presentada en la Tabla 3.2 Después de utilizar el algoritmo de detección de quejas de ruido, se obtuvieron 32646 tweets. Posteriormente, aplicando el detector de fuentes de ruido sobre esos tweets, se identificó al menos una fuente de ruido en 18984 de ellos. Obteniendo 1924 quejas con origen de ruido humano, 3990 provenientes del interior de las viviendas, 3487 de origen mecánico, 4653 producidas por una fuente musical y 4930 por la naturaleza. 
En segundo lugar, se calculó el número de quejas detectadas cada día y para cada fuente sonora, con el objetivo de detectar fenómenos ruidosos y su duración. En la Figura 3.7 se muestra la progresión de quejas detectadas en Twitter a lo largo del tiempo. Se utilizó un modelo de intervención ARIMA (AutoRegressive Integrated Moving Average, Modelo Autorregresivo Integrado de Media Móvil) en la serie temporal para detectar anomalías en cada una ellas (Wei 2013). Este modelo detectó anomalías significativas tanto en las series temporales de quejas de ruido humano, como en las asociadas a fuentes sonoras mecánicas y naturales. Las anomalías estuvieron probablemente relacionadas con las festividades del Día de la Independencia de los Estados Unidos de América, celebradas entre el 3 y el 5 de julio. Con los resultados obtenidos aplicando nuestra metodología, y los modelos de intervención ARIMA, se pudo inferir fácilmente que el problema del ruido estuvo relacionado con un incremento en la molestia asociada a esas fuentes de ruido, ya que el número de quejas en esos días aumentó de forma significativa.

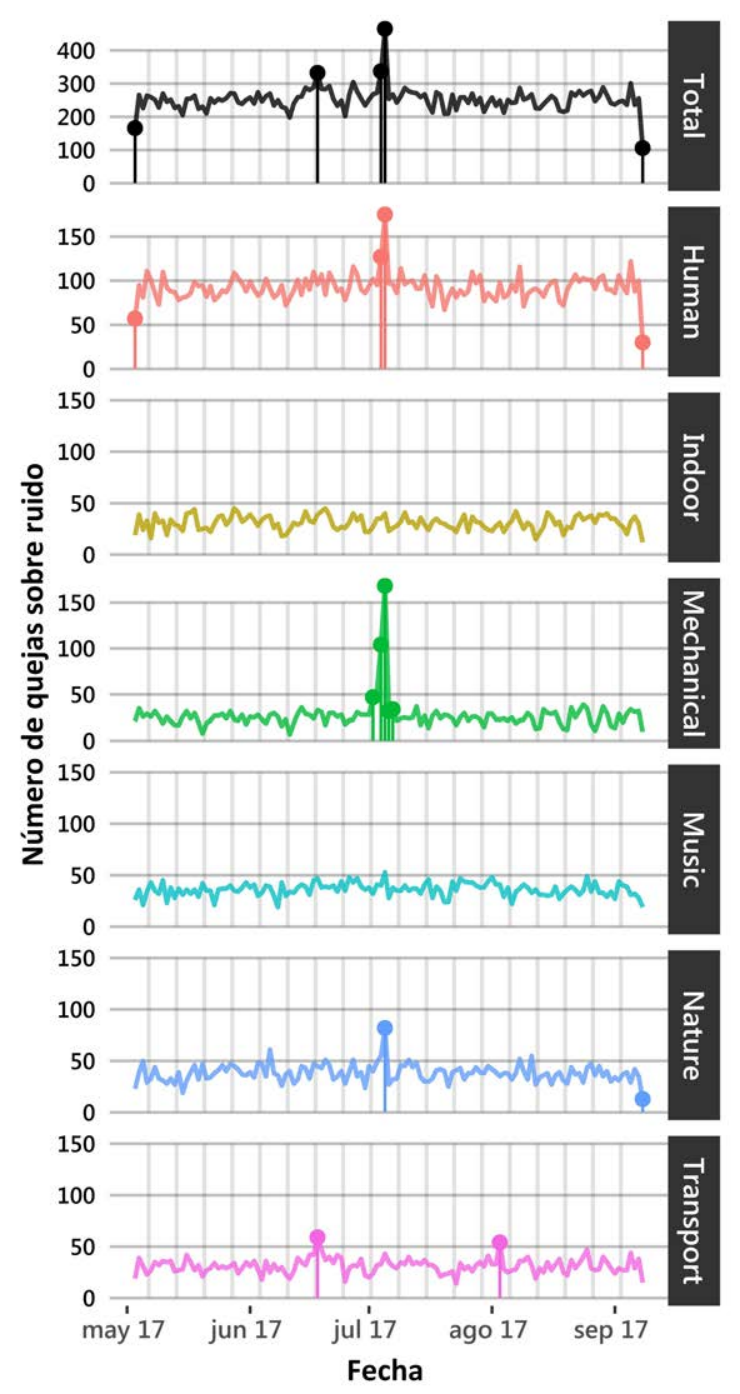

Figura 3.7: Series temporales con el número de quejas sobre ruido detectadas cada día para cada fuente sonora. Los puntos indican los días anómalos en relación al número de quejas para cada serie temporal. 
Para explicar los eventos acaecidos durante los días anómalos, se analizaron las palabras más utilizadas en los tweets durante ese tiempo. En primer lugar, se eliminaron las stopwords 3 que son términos como preposiciones o pronombres que no aportan nada al significado de una oración. En segundo lugar, se aplicó el algoritmo de Porter Stemming para eliminar las terminaciones morfológicas de las palabras con el objetivo de normalizar términos que tuvieran la misma raiz semántica (Porter, 1980)). Las palabras más frecuentes utilizadas en las quejas asociadas a cada fuente sonora pueden verse en la Figura 3.8. donde el eje $y$ representa la frecuencia de una palabra sobre el número total de palabras utilizadas en las quejas de esa fuente de ruido, y el eje $x$ corresponde al término en cuestión. En todas las categorías la palabra más utilizada es "noise", ya que es la palabra clave utilizada en el proceso de adquisición de datos y todos los tweets la contienen. La palabra "firework", fuegos artificiales, está presente como palabra más utilizada en muchas de las categorías; esto significa que el evento ruidoso probablemente fue producido por fuegos artificiales. Si se centra la atención en la categoría "human", se puede deducir que, dado que los fuegos artificiales se utilizan a menudo junto a la palabra "neighbor"(vecino), la gente se queja sobre el hecho de que sus vecinos utilicen fuegos artificiales. Algo similar ocurre en la categoría "nature", donde los usuarios de Twitter se quejan de los ladridos de los perros ("dog") cuando se produce el sonido de fuegos artificiales.

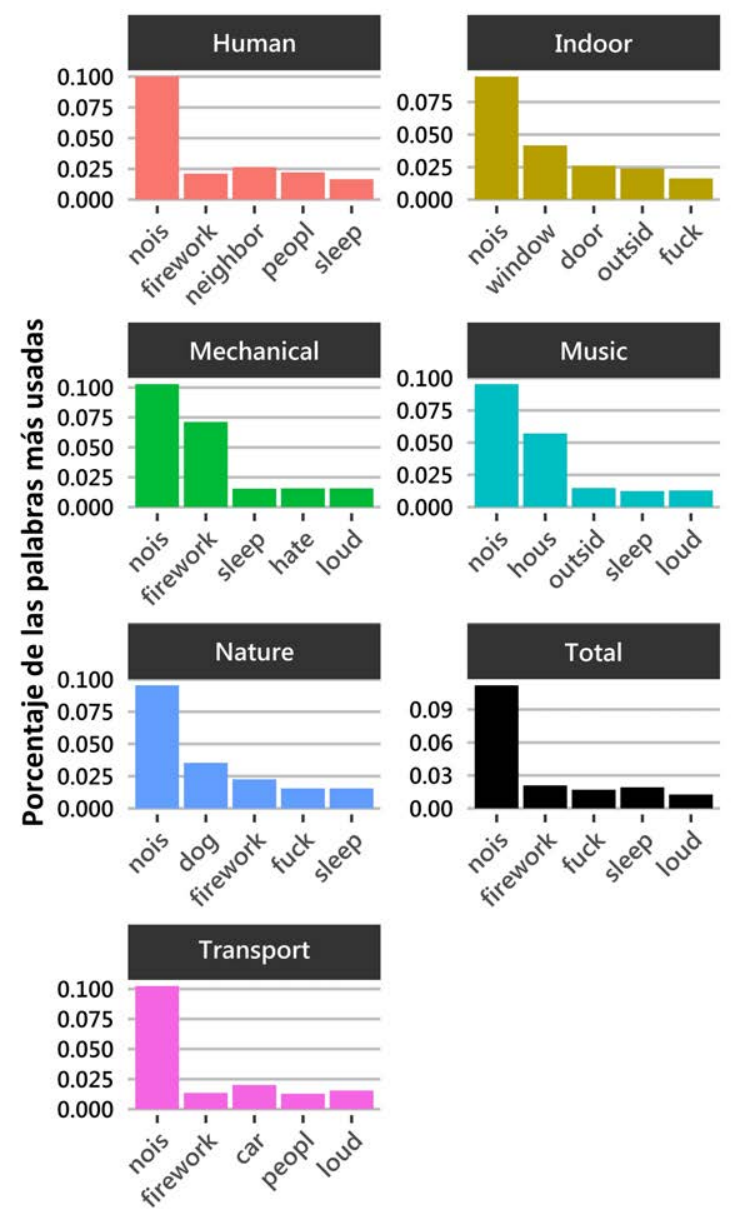

Figura 3.8: Top 5 de las palabras más utilizadas en las quejas escritas entre el 3 y el 5 de julio para cada fuente sonora.

\footnotetext{
${ }^{3}$ Término anglosajón utilizado en las técnicas de procesado de lenguaje para referirse a las palabras vacías, que son términos como preposiciones o pronombres que no aportan nada al significado de una oración
} 
Se ha aplicado la metodología presentada en este experimento para detectar eventos ruidosos y saber más sobre su origen. Analizando los gráficos se ha encontrado una posible asociación entre un evento y un aumento del ruido, y las palabras y las fuentes en las que se detectó la molestia nos permiten concluir que sin duda estaba relacionada con las fiestas del 4 de julio. Esta conclusión, que podría parecer obvia en un primer momento, es precisamente lo que nos permite validar la metodología presentada.

Con el fin de utilizar este procedimiento para predecir y detectar problemas relacionados con fuegos artificiales en el futuro, se podría utilizar el método mostrado junto a otras técnicas estadísticas, como la teoría de control estadístico de procesos (Winkel y Fan Zhang, 2007), para crear un sistema de alarmas basado en la presencia de palabras en las quejas de ruido. Con este fin se calculó la serie temporal del número de quejas que contenían las palabras más utilizadas dentro de la categoría "total" previamente mostradas en la Figura 3.8 y cuyo gráfico puede visualizarse en la Figura 3.9. Se observa que durante los días sin problemas de ruido asociados a los fuegos artificiales, el número de tweets que contenían esas palabras permaneció estacionario. Utilizando los datos de esos días se definieron unos límites de control estadístico, que se calcularon como el promedio más tres desviaciones estándar del número de tweets que contenían cada palabra, y que se representa mediante una línea discontinua en la Figura 3.9 . Esta línea cubriría el 99,7\% de los días normales. Si un día se superara ese límite, se podría concluir que se ha detectado un evento de ruido relacionado con fuegos artificiales.

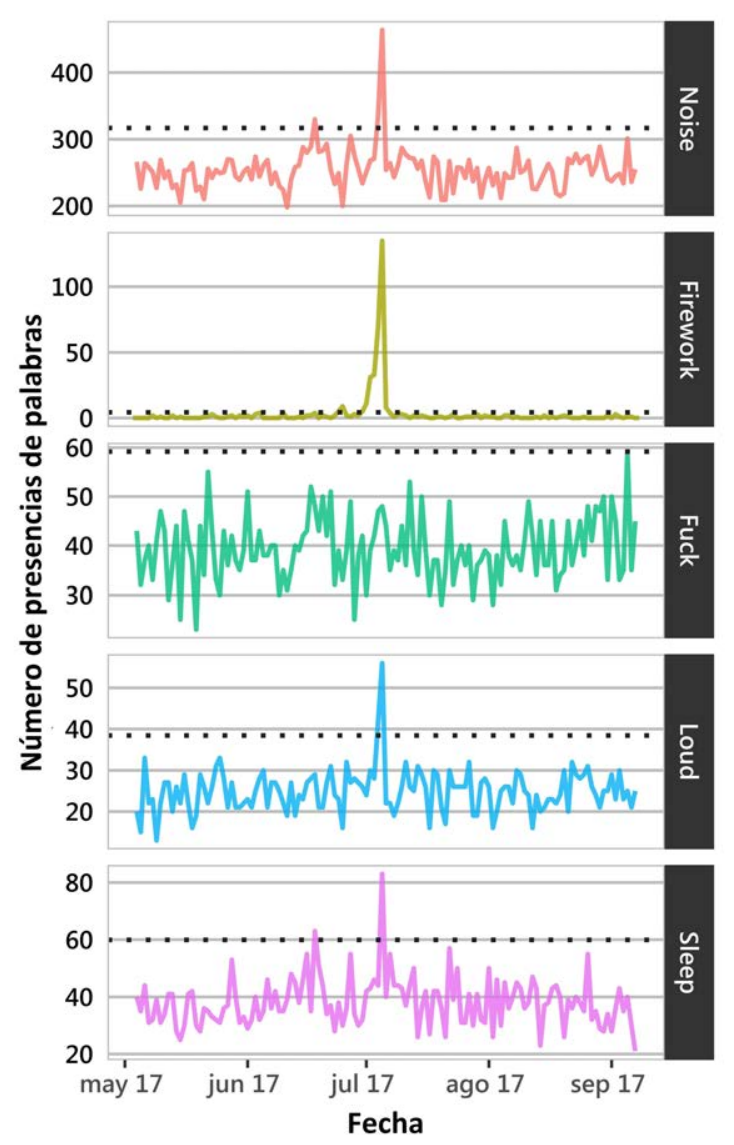

Figura 3.9: Evolución diaria de los tweets que contienen las palabras más utilizadas en la categoría "total" de la Figura 3.8. Las líneas de puntos representan el límite de control estadístico para detectar anomalías en las series temporales. 
Observando la Figura 3.9 se puede comprobar que efectivamente esos límites de control fueron excedidos el 4 de julio para las series temporales de tweets que contenían las palabras "noise", "firework", "sleep" y "loud". Se podría concluir que el análisis del número de veces que estas palabras aparecen en las quejas podría utilizarse como un sistema de alarma que advirtiera de un suceso sonoro molesto relacionado con este tipo de celebraciones. Este tipo de análisis, o sistema de alarma, basado en la metodología y las tecnologías presentadas en este capítulo podría extrapolarse a otros eventos ruidosos como el control horario de discotecas, o las molestias producidas por el ruido proveniente de las terrazas de bares. Con este enfoque, los gestores de la ciudad podrían medir el éxito de sus acciones contra el ruido de una manera conveniente.

\subsection{Conclusiones}

La investigación realizada en relación a la detección y análisis de la opinión ciudadana sobre actividades ruidosas compartidas en medios sociales permite obtener las siguientes conclusiones:

- Se ha confirmado que una parte de la ciudadanía publica información sobre las fuentes de ruido que les afectan negativamente en canales alternativos como las RSO para expresar su molestia.

- Esta información puede ser adquirida mediante una búsqueda basada en palabras clave y las APIs de algunas redes sociales, como Twitter. Este sistema permite la recolección de una gran cantidad de datos entre los que se encuentra tanto el contenido relacionado con la valoración de actividades ruidosas como otro contenido que utiliza las mismas palabras con otro sentido y que es necesario discriminar.

- Los métodos de preparación y limpieza de los textos provenientes de Internet han resultado útiles para incrementar el número de palabras de los textos cortos con los que se ha trabajado, este incremento de palabras incrementa la información disponible en el contenido y permite mejorar el rendimiento de los clasificadores implementados.

- El sistema de detección de quejas sobre ruido que utiliza técnicas de NLP para el cálculo de características semánticas del texto y el uso de éstas en un algoritmo de aprendizaje automático supervisado ha resultado un método válido para la discriminación de textos no relacionados con opiniones subjetivas sobre fuentes de ruido.

- El método de identificación de fuentes en un texto, basado en la presencia de palabras aparecen en un vocabulario con una taxonomia asociada, funciona con bastante éxito, ya que el $86 \%$ de estas fueron predichas correctamente.

- Las métodos elegidos para el entrenamiento y validación del sistema de detección de quejas desarrollado en este experimento ha resultado válidos para lidiar con los problemas de desbalanceo de clases presentes en nuestra base de datos de entrenamiento. Además, la estrategia de validación elegida ha permitido afinar el algoritmo de detección de quejas sobre ruido en un punto óptimo de funcionamiento, llegando a clasificar correctamente un $85 \%$ de las quejas.l

- Se ha confirmado que la metodología propuesta para analizar textos provenientes de Redes Sociales Online de esta tesis es válida a nivel global para la detección y clasificación de opiniones negativas sobre actividades ruidosas provenientes de RSO de microblogging. Además, esta metodología podría adaptarse a otras fuentes de datos 
textuales utilizando la misma estructura compuesta por los bloques de adquisición de datos, preparación de los textos, detección de las opiniones negativas y clasificación de estas por su origen.

- El enfoque metodológico presentado permite su incorporación a otros sistemas más complejos, como se ha demostrado con el caso de estudio mostrado en este experimento.

- La prueba de concepto del sistema de monitorización valida que el sistema de detección de quejas propuesto funciona correctamente y que es posible monitorizar la actividad en redes sociales para identificar problemas urbanos como son los eventos sonoros puntuales. Además de la identificación de dichos eventos, es posible realizar análisis semánticos para inferir el origen específico de estos y construir sistemas de alarmas que pudieran incluso llegar a predecir "picos"de molestia asociados a un futuro evento en la ciudad. Esto permitiría a los gestores urbanos mostrar más atención a estos eventos y actuar con mayor celeridad en caso de que finalmente ese problema acústico apareciera. 


\title{
Capítulo 4
}

\section{Uso de datos públicos para estudiar los efectos del ruido en la salud}

\author{
As the Internet makes our lives increasingly \\ connected, events seem to move faster and \\ faster. We are drowning in information, so \\ much so that we don't know what items to pay \\ attention to and which to ignore \\ Prof. Alex Pentland \\ Co-founder \& former director of MIT MediaLab
}

\subsection{Introducción}

Como se introdujo en el Capítulo 1, se estima que el $55 \%$ de la población que actualmente reside en ciudades se incremente hasta el $70 \%$ en el año 2050 (United Nations, 2018). Ese crecimiento progresivo será especialmente problemático en las grandes ciudades, en las que aumentarán los problemas asociados a la gentrificación, el tráfico y la contaminación ambiental (Andersson y Turner, 2014, Wachsmuth y Weisler, 2018; Wallsten, 2015).

Dentro de los contaminantes ambientales, el ruido es el segundo que más afecta a la salud de los ciudadanos (European Environment Agency, 2014). Sus efectos adversos en la salud han sido ampliamente estudiados: se ha demostrado su influencia en la aparición de síntomas de ansiedad (Beutel et al. 2016, Standing y Stace, 1980) y alteraciones del sueño (Evandt et al., 2017, Halonen et al. 2012 Kageyama et al. 1997); y se han constatado incrementos en la prevalencia de enfermedades cardiovasculares como la hipertensión en las personas expuestas (Barregard et al. 2009, Belojević et al. 2008, Bodin et al. 2009 , Dratva et al. 2011, Leon Bluhm et al. 2007; Sørensen et al. 2011). Tradicionalmente, estos estudios se realizan con pequeños grupos de población utilizando encuestas de valoración de ruido y medidas de parámetros biométricos, como la tensión arterial. Estas investigaciones suelen estar centradas en medir los efectos que tienen fuentes de ruido asociadas al transporte, dejando de lado los posibles efectos que tiene el ruido proveniente de otros orígenes como por ejemplo las actividades de ocio.

Por otra parte y como se mostró en la sección 1.2.2, el desarrollo tecnológico experimentado desde principios del siglo XXI ha favorecido la aparición e implantación de corrientes tecnológicas como el IoT (Internet of Things, Internet de las Cosas), que ha posibilitado la instalación masiva de sensores conectados a Internet para medir parámetros urbanos como el tráfico o la contaminación ambiental. Además, se ha experimentado un incremento en las exigencias de transparencia institucional por parte de la ciudadanía, que han posibilitado la creación de multitud de plataformas de datos abiertos en las que, 
además de publicar datos de los sensores, se comparte información de interés general como los presupuestos locales, los mapas de ruido o el censo de locales comerciales de una ciudad (Ajuntament de Barcelona, 2018b, Ayuntamiento de Madrid, 2018a, Ayuntamiento de Zaragoza, 2018a). Adicionalmente, la instauración de Internet como medio de comunicación social ha estimulado la creación de plataformas digitales, conocidas como medios sociales, en los que los usuarios publican sus propios contenidos e interactúan entre ellos.

La evolución experimentada en estas áreas ha favorecido la proliferación de investigaciones englobadas dentro de la rama de la computación social o social computing, que es el área que busca obtener información de la población a través de entornos digitales (Khosrow-Pour, 2015). La computación social se ha aplicado a diversos campos como la contaminación del aire (Jiang et al. 2015), la detección de desastres naturales (Alfarrarjeh et al. 2017, Buscaldi y Villetaneuse, 2015, Sangameswar et al., 2017) o la descripción de entornos urbanos para una mejor gestión (Quercia et al. 2014a b, 2015).

En el Capítulo 3 de esta tesis doctoral se demostró que era posible extraer información de las RSO (Redes Sociales Online, Online Social Networks) en relación a la opinión sobre actividades ruidosas compartidas por la ciudadanía. Este hecho, junto a la alta disponibilidad de datos públicos de ciudades en Internet, la creciente importancia del estudio de los efectos del ruido en la salud y la necesidad de identificar y medir la influencia en la salud de fuentes de ruido adicionales a las provenientes del transporte, proporcionan un marco idóneo en el que plantear un experimento que proporcione nueva información a los gestores urbanos sobre la influencia de múltiples fuentes sonoras en la salud de los ciudadanos en las distintas áreas de una gran ciudad y en el que:

- Se identifiquen nuevas variables relacionadas con los sonidos urbanos que pudieran afectar a la prevalencia de una enfermedad cardiovascular como la hipertensión.

- Se obtengan resultados provenientes de la totalidad de la población urbana, y no solo de un grupo de personas seleccionados.

- Se utilicen datos accesibles de forma pública, ya sea mediante plataformas de datos abiertos o RSO.

\subsection{Objetivos del experimento}

Dado que en el Capítulo 3 se demostró que en los medios sociales, como las RSO, hay información sobre actividades ruidosas; este capítulo se centra en explotar dicha información con objetivo de ampliar el conocimiento existente de los efectos del ruido en la salud. El capítulo está centrado en el desarrollo de una investigación para el cumplimiento del tercer objetivo de la tesis doctoral, que es el uso de datos públicos para medir los efectos del ruido sobre la salud de la población.

Dicha objetivo global será abordado en este capítulo mediante la consecución de los siguientes objetivos parciales:

1. Definición de una metodología para la estimación de la población expuesta a niveles de ruido de tráfico y ferroviario a partir de datos públicos.

2. Uso de los datos provenientes de medios sociales para estimar la presencia de determinadas fuentes sonoras en una ciudad.

3. Diseño de un experimento que permita conocer los efectos de los sonidos urbanos en la población utilizando datos disponibles de forma pública. 
4. Uso de datos disponibles de forma pública, incluyendo datos de medios sociales, relacionados con actividades ruidosas para mejorar el conocimiento de los efectos del sonido en la salud, tanto positivos como negativos, en ciudades.

Cabe mencionar que parte del desarrollo de este experimento fue realizado durante una estancia predoctoral en la sede de Nokia Bell Labs en Cambridge (Reino Unido), bajo la supervisión del Dr. Daniele Quercia, director del departamento de Social Dynamics.

\subsection{Datos}

Para el desarrollo del experimento se requería una gran ciudad, que dispusiera de una plataforma de datos abiertos y que tuviera alta densidad de población. Esto era necesario para que el volumen de contenido georeferenciado publicado por los ciudadanos en medios sociales fuera el suficiente para extraer información significativa sobre las fuentes sonoras presentes en las distintas áreas de la ciudad.

La ciudad británica de Londres cumplía con dichos requisitos. Londres y su periferia son la zona más poblada del Reino Unido. Con una superficie de $1772 \mathrm{~km}^{2}$ y más de 14 millones de habitantes, Londres es el mayor centro económico en Europa. Está considerada como una de las mayores ciudades globales del mundo con una población en constante aumento y que se ha incrementado en más de un millón de personas en los últimos 10 años. Además, dispone de una plataforma de datos abiertos, London Datastore, que cuenta con de más de 1200 conjuntos de datos con información sobre medio ambiente, demografía y transporte, entre otros (Mayor of London, 2018a).

El Gran Londres, el condado que cubre la mayor parte del área metropolitana de Londres, se divide en un conjunto de áreas geográficas creadas con el objetivo de facilitar el cálculo de los índices de pobreza en Reino Unido, y que son utilizadas para mostrar estadísticas sociodemográficas en el país. Estas zonas, conocidas como OAs (Output Areas), tienen una extensión similar y sus límites geográficos, a diferencia de los distritos electorales, no cambian, lo que facilita la comparativa de las series históricas de datos. La ONS (Office for National Statistics ), la entidad británica encargada de la creación y publicación de estadísticas para Reino Unido, agrupa los OAs en áreas más grandes: los LSOAs (Lower Layer Super Output Areas ) y los MSOAs (Middle Layer Super Output Areas ).

En este estudio se trabajó con las estadísticas disponibles para los MSOAs, porque tenían un nivel de agregación lo suficientemente grande para conocer los efectos del ruido en grandes grupos poblacionales. En el Gran Londres hay 984 MSOAs, con una población media de 8300 residentes.

Este experimento pretendía estudiar los efectos del sonido en la salud utilizando exclusivamente datos abiertos. Para ello se utilizaron los siguientes datos disponibles de forma pública:

Prescripciones médicas: La principal fuente de información de datos médicos en el Reino Unido es el NHS (National Health Service, Servicio Nacional de Salud Británica), que es el organismo encargado de la gestión de los sistemas e infraestructuras de atención sanitaria en el país. Para modelar el consumo de medicamentos se han utilizado los datos de prescripciones médicas, proporcionadas públicamente por el NHS, recetadas por los médicos de cabecera, farmacéuticos, dentistas y otros profesionales de la salud en Inglaterra (NHS, 2018). Los datos sobre prescripciones se organizan según la sintomatología para la que se utilizan los fármacos siguiendo los códigos del British National Formulary (BNF), que es un libro de referencia farmacéutica que contiene consejos sobre la prescripción de fármacos para diferentes enfermedades clasificando todos los fármacos jerárquicamente según sus usos (EBM DataLab, 2017). Este sistema de clasificación puede verse como 
una taxonomía en la que todos los medicamentos prescritos en Inglaterra se agrupan en grupos según la enfermedad que pretenden tratar. Para caracterizar la prevalencia de la hipertensión, se consideraron las prescripciones de todas las sustancias presentes en la sección 2.5: Hypertension and Heart Failure del BNF.

Ruido: El Departamento de Medio ambiente del Reino Unido (DEFRA) publica los mapas estratégicos de ruido de areas urbanas de más de 100.000 habitantes siguiendo los criterios marcados por le Directiva 2002/49/CE (European Parliament, 2002). En este estudio, se consideran los mapas estratégicos de ruido de Londres publicados en el año 2012, que tienen en cuenta el ruido de trenes y de tráfico rodado. Se utilizaron los mapas de ruido que muestran los niveles de ruido utilizando las métricas recomendadas por la Unión Europea, definidas en la ISO 1996-2 (International Organization for Standardization, 2016). Estas métricas son el $L_{d e n}$, que indica el nivel de ruido promedio anual estableciendo penalizaciones a los niveles producidos durante los periodos vespertinos y nocturnos; y el $L_{n}$, que representa el nivel de ruido nocturno promedio durante un año.

Sociodemográficos: La ONS es la encargada del censo en el Reino Unido y proporciona datos abiertos sobre las características socioeconómicas, culturales y demográficas medidas en el censo nacional, cuya última actualización se realizó en 2011. En los análisis se utilizan las siguientes variables, que han sido vinculadas a enfermedades del sistema cardiovascular e hipertensión en la literatura:

- Edad: El porcentaje de población afectada con problemas circulatorios incrementa con la edad (Pinto, 2007), por lo que las áreas con población más envejecida podrían tener más incidencia de enfermedades como la hipertensión. Se consideraron los datos de edad presentes en el UK Age Structure del año 2011, que indican el porcentaje de población residente en cada MSOA con edades comprendidas entre 0-44, 45-64 y más de 65 años.

- Ingresos medios: Algunos estudios muestran un incremento de la hipertensión en áreas con bajo poder adquisitivo, por eso se incorporó al estudio una variable que representara los ingresos medios para controlar ese efecto. Dado que los ingresos están correlacionados con el nivel cultural y los hábitos alimenticios, de algún modo es una forma de controlar también estos factores (Kaplan et al., 2010, Keenan et al. 2011). Esta variable fue tomada de las estimaciones de ingresos medios por hogar del año 2011 dadas para cada MSOA del Reino Unido.

- Porcentaje de género: Las enfermedades cardiovasculares no tienen la misma prevalencia en hombres que en mujeres. Específicamente la hipertensión afecta más a los hombres, por lo que el ratio de medicamentos para tratar esta enfermedad puede verse influenciado por el porcentaje de mujeres que viven en cada área (Hayes y Taler, 1998). Para controlar este fenómeno, se incluyó el porcentaje de hombres y mujeres que residía en cada MSOA.

Medios sociales: Para caracterizar la presencia de fuentes sonoras en Londres, se han utilizado los recursos generados en el proyecto Chatty maps (Aiello et al. 2016). Por una parte se usó las taxonomía de sonidos producida a partir de las etiquetas más utilizadas en la plataforma Freesounds, y que ordenaba un léxico de 228 palabras en 6 categorías sonoras, similares a las proporcionadas por Schafer (Schafer, 1993): transporte, naturaleza, humano, música, interior y mecánica. Por otra parte se usó la base de datos de 17 millones de fotografías de Flickr utilizada en ese estudio, que fueron tomadas entre 2010 y 2015 y que incluían metadatos adicionales como su geolocalización y etiquetas indicando los elementos presentes en la imagen. 


\subsection{Metodología}

En esta sección se describe la metodología utilizada para el cálculo de la tasa o ratio de prevalencia de la hipertensión, de la exposición al ruido y de las fuentes sonoras presentes en cada MSOA en la región de Londres. Por último, se presenta el modelo de regresión lineal multivariable que se utilizó para estudiar las posibles relaciones existentes entre la hipertensión y otras variables como la exposición al ruido y la presencia de fuentes sonoras específicas.

\subsubsection{Tasa de prevalencia de hipertensión}

Para caracterizar la incidencia de la hipertensión en Londres, se define el ratio de prescripciones, $H T_{\text {prescriptions }}(m)$, como el número medio de fármacos antihipertensivos prescritos a un paciente en un periodo temporal de referencia en cada MSOA $m$. Se asume que las áreas con un mayor ratio de prescripciones asociadas a la hipertensión tendrán una mayor prevalencia de la enfermedad. El ratio de medicamentos en una región $m$ se calcula como:

$$
\operatorname{HT}_{\text {prescriptions }}(m)=\frac{i_{\text {hypertension }}(m)}{p(m)}
$$

donde $i_{\text {hypertension }}(m)$ es la estimación del número total de medicamentos prescritos en el MSOA $m$, y $p(m)$ es el número total de pacientes viviendo en el MSOA $m$. El término $i_{\text {hypertension }}(m)$ se calcula como:

$$
i_{\text {hypertension }}(m)=\sum_{g \in g(m)} i_{\text {hypertension }}(g, m)
$$

donde $i_{\text {hypertension }}(g, m)$ es el número de medicamentos recetados por el profesional médico $g$ a alguien viviendo en el MSOA $m$. Desafortunadamente no se pudo obtener ese término de forma directa con los datos disponibles, pero considerando que el número de medicamentos recetados por un médico es uniforme entre todos los médicos de un MSOA, se puede definir como:

$$
i_{\text {hypertension }}(g, m)=r_{\text {hypertension }}(g) \cdot p(g, m)
$$

donde $p(g, m)$ representa el número de pacientes asociados al profesional $g$ y que viven en el MSOA $m$. Para calcular el ratio de fármacos para tratar la hipertensión en una clínica, $r_{\text {hypertension }}(g)$, se utiliza la relación:

$$
r_{\text {hypertension }}(g)=\frac{i_{\text {hypertension }}(g)}{p(g)}
$$

En la que $p(g)$ es el número de pacientes cuyo médico es $g$, calculados como:

$$
p(g)=\sum_{m \in m s o a(g)} p(g, m)
$$

De este modo se puede obtener una estimación del ratio de prescripciones en cada MSOA $m$. La Figura 4.1 muestra la distribución espacial y univariante del ratio de prescripciones per capita $H T_{\text {prescriptions }}$, calculado. 
A.

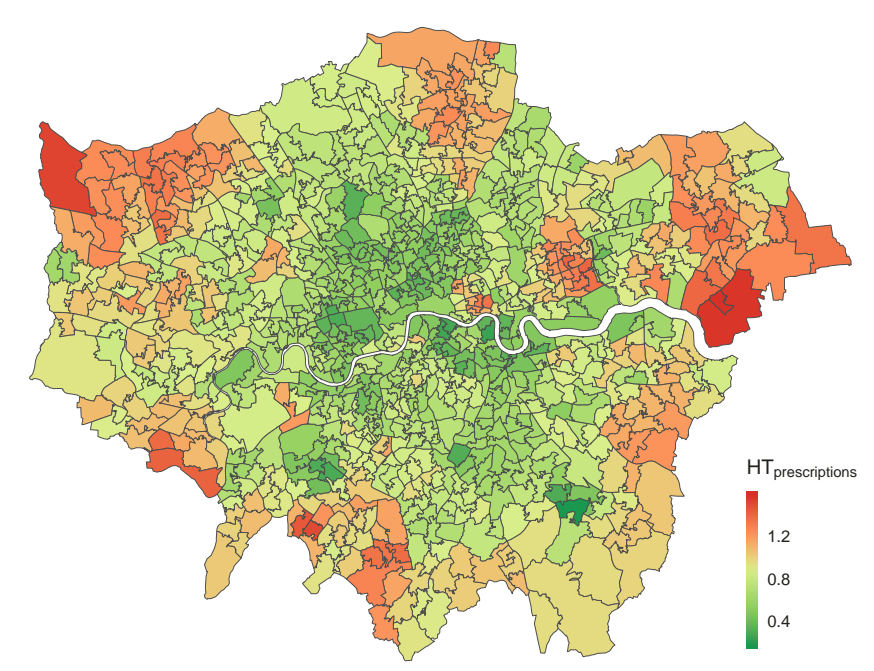

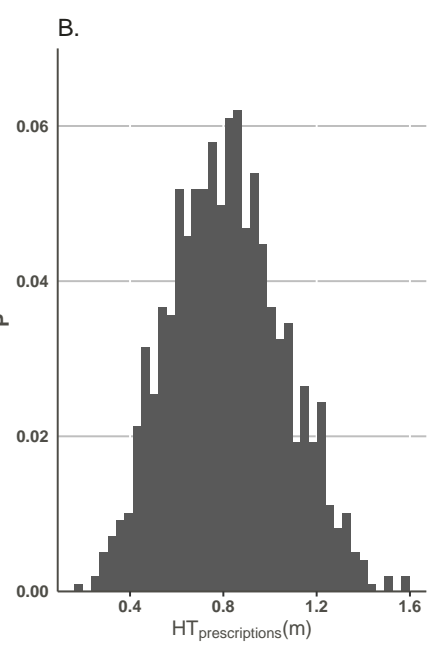

Figura 4.1: A. Representación geográfica de las prescripciones per capita de fármacos para tratar la hipertensión en Londres. B. Distribución de la variable $H T_{\text {prescriptions }}$.

\subsubsection{Exposición al ruido}

Siguiendo las directrices de la Directiva 2002/49/CE, las aglomeraciones de más de 100.000 habitantes deben producir mapas estratégicos de ruido cada 5 años (European Parliament, 2002). Estos mapas de ruido dan información sobre las áreas expuestas al ruido en el rango comprendido entre los $55 \mathrm{~dB}$ y más de $75 \mathrm{~dB}$ para la métrica $L_{\text {den }}$ (nivel de ruido día-tarde-noche); y entre $50 \mathrm{~dB}$ y más de $70 \mathrm{~dB}$ para el $L_{n}$ (nivel de ruido nocturno); en pasos de $5 \mathrm{~dB}$.

Los gestores urbanos deben compartir con la ciudadanía tanto el mapa de ruido como los planes de acción planteados para mejorar la situación acústica de la ciudad. Esto se suele realizar mediante los informes de los planes de acción, el mapa de ruido en formato $p d f$ y los ficheros cartográficos que contienen el mapa del ruido. Adicionalmente, tienen obligación de comunicar la población expuesta a los diferentes niveles de ruido, que se suele presentar de forma agregada en los informes, sin tener la posibilidad de conocer el número de personas expuestas en cada área de la ciudad.

Debido a que en este experimento se necesitaba conocer el porcentaje de población expuesta al ruido en cada MSOA y esta información no es mostrada en los mapas estratégicos de ruido de Londres, se ideó un método para estimar la población expuesta en cada MSOA a partir cálculos geoespaciales utilizando: el mapa de ruido de Londres del año 2012, la cartografía de los MSOAs de Londres y la cartografía que indicaba los edificios residenciales de la ciudad, disponibles en la plataforma London Datastore (Mayor of London 2018b c). La metodología aplicada se dividió en tres pasos:

- En primer lugar, se aplicó una intersección espacial entre las capas del mapa de ruido, que indicaban las áreas expuestas a los distintos niveles de ruido, y el uso residencial del suelo en cada MSOA, obteniendo el área de zonas residenciales expuestas a diferentes niveles de ruido.

- A continuación, dado que se conocía tanto el área residencial total como las áreas residenciales expuestas a cada nivel de ruido, se calculó el porcentaje de área residencial expuesta a cada nivel de ruido en cada MSOA. 
- Entonces, asumiendo que la población de cada MSOA vive uniformemente distribuida dentro del suelo residencial, se calculó el porcentaje de personas expuestas a los distintos niveles de ruido.

Aunque la exposición al ruido generalmente se ofrece en términos del número de población expuesta en una ciudad, se optó por utilizar el porcentaje de población expuesta por permitir comparar el impacto del ruido ambiental entre distintos MSOAs de forma independiente a la población de estos. De este modo, utilizando el método mostrado previamente, se calculó el porcentaje de población expuesta a más de 55, 60, 65, 70 y $75 \mathrm{~dB}$ de nivel $L_{d e n}$; y el porcentaje de población expuesta a más de 50, 55, 60, 65 y $70 \mathrm{~dB}$ de nivel $L_{n}$, tanto para ruido de tráfico rodado como ferroviario, siendo estas variables independientes de cara al estudio.

La Figura 4.2 muestra el porcentaje de población expuesta a más de $55 \mathrm{~dB}$ de la métrica $L_{\text {den }}$ tanto para ruido ferroviario como para tráfico rodado. Observando los mapas, se puede ver que en Londres el tráfico rodado tiene más impacto acústico en la población que el proveniente de los trenes. Se visualiza que el porcentaje de ciudadanía expuesta es significativamente mayor en áreas cercanas a los accesos a Londres por autopistas, especialmente en el Este y Norte de la ciudad, probablemente por una mayor concentración de vehículos en esas localizaciones que se distribuyen cuando acceden a la ciudad. En el caso del ruido ferroviario, las zonas más expuestas se encuentran cerca de áreas de líneas férreas no soterradas que unen el centro de Londres con la periferia.

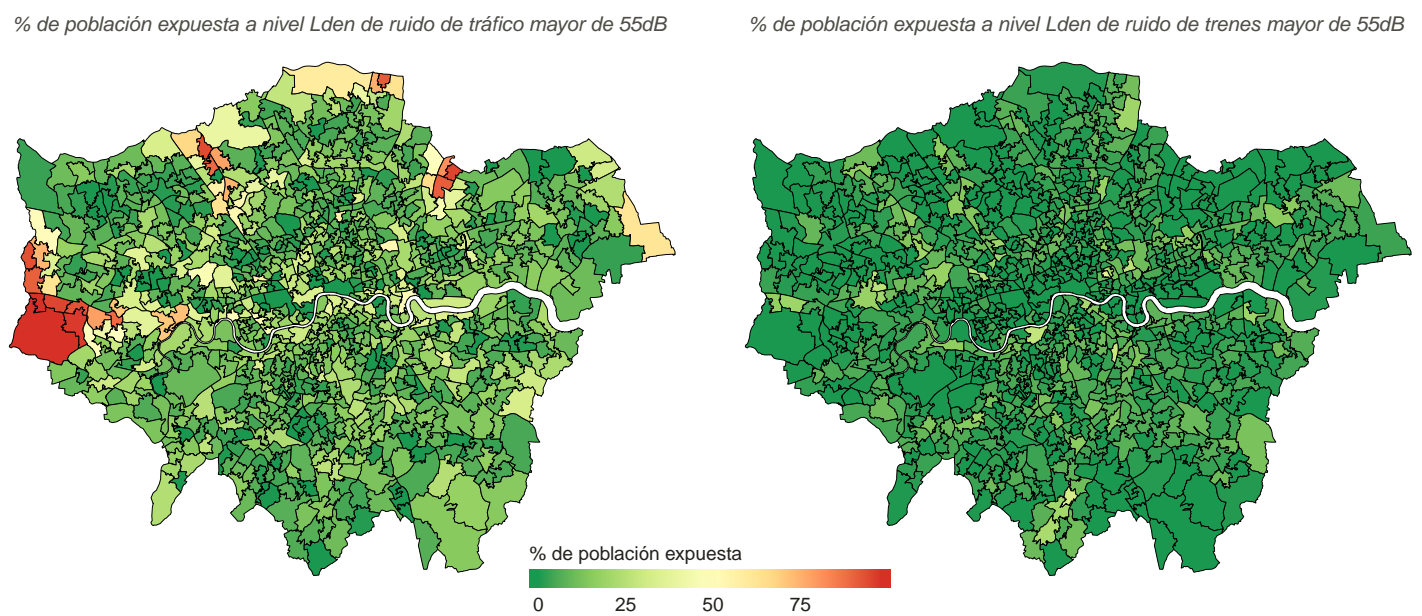

Figura 4.2: Representación gráfica de la estimación de exposición a más de 55dB de ruido de tráfico y de trenes en la ciudad de Londres.

Los cálculos de exposición al ruido provenientes de mapas de ruido se refieren a los niveles en el exterior de las viviendas. Sin embargo, la población urbana pasa parte de su día en el interior de sus hogares. Es importante considerar la calidad de construcción de las viviendas, ya que puede afectar al aislamiento acústico y por lo tanto a la exposición al ruido que experimentan las personas que viven en el interior. Si una vivienda tiene una mejor calidad de construcción, probablemente el aislamiento acústico sea mayor, la exposición al ruido de sus habitantes menor y por lo tanto pueda decrementar el posible efecto del ruido externo en la hipertensión. Por ese motivo se calculó el índice $E E_{\text {building }}$, que tenía en cuenta la calidad de construcción de la vivienda, y de manera indirecta su aislamiento acústico. 
Este índice se obtuvo mediante los certificados de eficiencia energética accesibles públicamente a través de la API proporcionada por el Ministerio de Vivienda, Comunidades y Gobierno Local del Reino Unido (Ministry of Housing, Communities \& Local Government, 2018). Estos certificados ofrecían un índice numérico comprendido entre 0 y 100 que representaba la eficiencia energética de una propiedad considerando variables como el tipo de ventana instalada o la calidad de construcción de la fachada. Se utilizó la API para obtener los 2.5 millones de certificados disponibles en Londres, y se calculó el índice de rendimiento energético medio para cada MSOA con los certificados disponibles en cada área. Los resultados de esta variable se muestran en la Figura 4.3

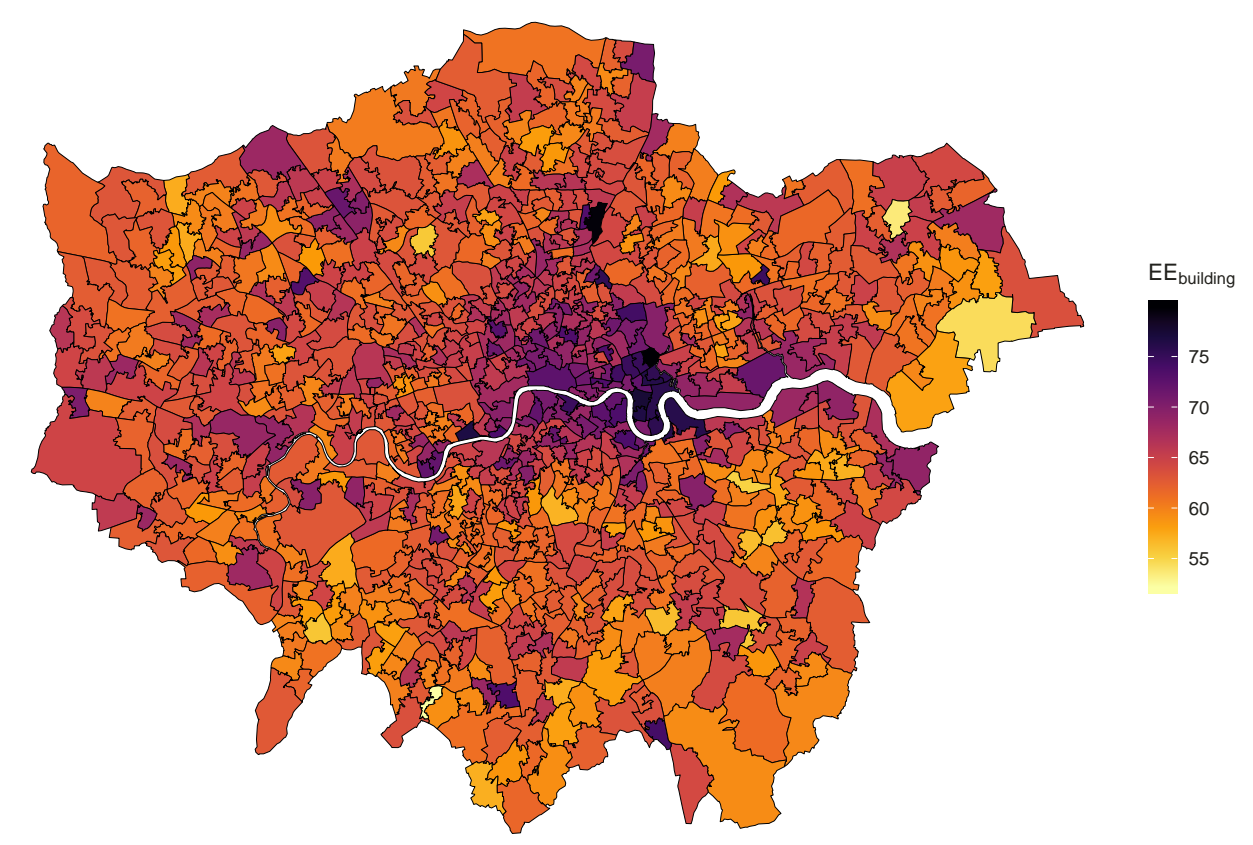

Figura 4.3: Mapa del índice de eficiencia energético medio de las viviendas de cada MSOA de Londres.

\subsubsection{Presencia de fuentes sonoras}

Los mapas estratégicos de ruido muestran la exposición al ruido únicamente para el tráfico rodado, trenes y aeronaves. Sin embargo, existen otros sonidos que pueden afectar a la población de las ciudades. Dado que se querían considerar estas fuentes sonoras adicionales en los análisis, y que en el Capítulo 3 se validó la hipótesis de que se podía obtener información sobre actividades ruidosas en medios sociales online, se utilizaron datos provenientes de estas plataformas con este fin.

Se utilizó la metodología utilizada en el proyecto Chatty Maps (Aiello et al. 2016), que extrajo los sonidos predominantes en las calles de Londres mediante una taxonomía de sonidos urbanos, que ordenaba un léxico de 228 palabras en 6 categorías sonoras, similares a las proporcionadas por Schafer (Schafer, 1993): transporte, naturaleza, humano, música, interior y mecánica.

Se utilizó para los cálculos la base de datos de 17 millones de fotografías de Flickr tomadas entre 2010 y 2017. Cada imagen contaba con etiquetas que indicaban la presencia de elementos en la fotografía. Algunas de estas etiquetas eran palabras "sonoras", o soundwords, término que se utilizó para denominar a las palabras presentes en el léxico de Chatty Maps. De ese modo, se calculó el porcentaje de fotografías con soundwords de una 
categoría $c$ respecto al número de total de fotografías con una soundword cualquiera para cada MSOA $m$ como:

$$
f_{\text {pics }}(m, c)=\frac{\# \text { imagenes con soundwords en la categoria } c @ m}{\text { imagenes con soundwords } @ m}
$$

Que representa la fracción de fotografías con fuentes sonoras relacionadas con: transporte, naturaleza, seres humanos, música, interior o mecánico, y se puede interpretar como la importancia, o mayor presencia, de algunas fuentes respecto a otras en cada área. De este modo, tras realizar los cálculos se obtuvo, para cada MSOA, un vector de 6 elementos que representaba la probabilidad de presencia de sonidos asociados a cada una de las categorías definidas en la taxonomía. La Figura 4.4 muestra la categoría sonora más probable obtenida para cada MSOA. Las áreas con predominancia de sonidos relacionados con naturaleza y transporte predominan en la perifera de Londres. En el centro de la ciudad la mayoría de los sonidos están relacionados con actividades musicales y personas. Es importante destacar que categorías como construcción y mecánica son una minoría cuando se habla de fuente de ruido predominante. Con el propósito de trabajar con datos representativos, se decidió excluir de los análisis los MSOAs en los que hubiera menos de 100 fotografías.
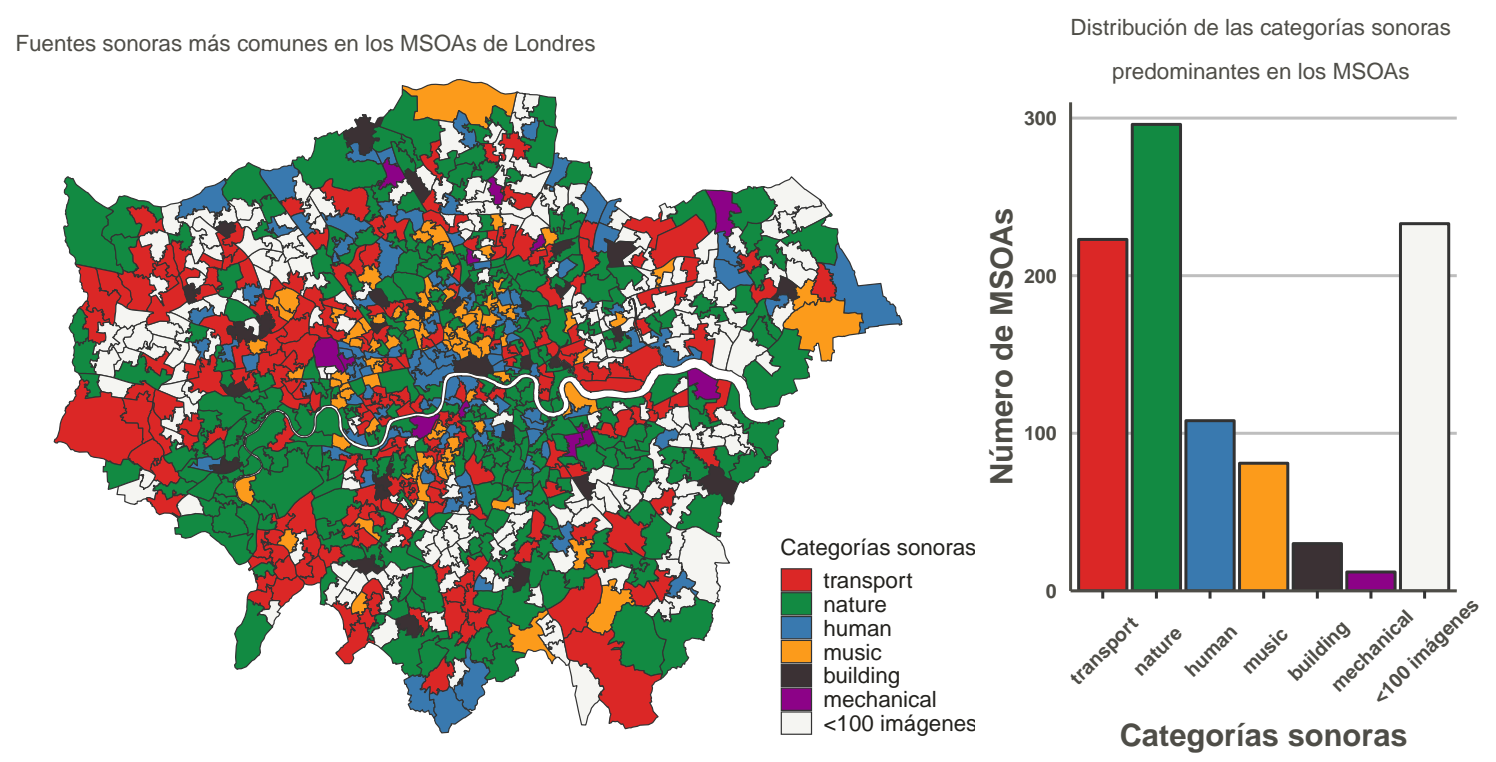

Figura 4.4: Fuente sonora predominante para cada MSOA, calculada a partir de datos de medios sociales.

Londres es un centro económico mundial y una de las ciudades europeas con mayor afluencia de turistas. Esto provoca que haya un gran número de visitantes ocasionales que tienden a tomar fotografías cerca de atracciones turísticas y monumentos históricos, que se encuentran en su mayoría en el centro de la ciudad y que provoca que el número de imágenes publicadas en Flickr sea desigual entre los suburbios y el casco antiguo.

Por ese motivo se calculó la variable $P R_{F l i c k r}$, que representaba la tasa de penetración de esta RSO y que permitía controlar en nuestros modelos el uso desigual de Flickr entre el centro de Londres y sus alrededores, corrigiendo así el efecto del turismo en los análisis.

Adicionalmente, dado que una mayor tasa de penetración de Flickr estaba relacionada con un mayor número de imágenes, y basándose en la hipótesis de que las personas suelen tomar fotografías en ambientes que consideran agradables; un mayor número de fotografías podría estar relacionado con áreas visualmente más hermosas, algo que podría afectar a la percepción del ruido por ser un factor no acústico que conforma el paisaje sonoro y por 
lo tanto influir de manera indirecta en la salud.

El índice de pentración de Flickr se calculó como la fracción entre el número de usuarios únicos de Flickr en un MSOA $m$, obtenido a partir de las fotografías subidas por los usuarios de esta plataforma; y el número de residentes de ese MSOA, como muestra la Ecuación 4.2

$$
P R_{\text {Flickr }}(m)=\frac{\# \text { Usuarios Flickr } @ m}{\# \text { Residentes } @ m}
$$

\subsubsection{Análisis}

En la última parte del experimento, se utilizaron regresiones lineales multivariables para estudiar hasta que punto la exposición al ruido, la presencia de fuentes sonoras y las variables sociodemográficas estaban relacionadas con problemas de salud; en particular, el estudió se centró en la hipertensión dado que en la literatura se muestra que la exposición al ruido puede favorecer su aparición. En la Tabla 4.1 se presenta el listado de variables dependientes utilizadas en el estudio, junto a la tipología u origen de estas, el nombre con las que se referenciarán en el resto del capítulo, la transformación realizada para satisfacer las condiciones de las regresiones lineales y la descripción sobre lo que representan.

Tabla 4.1: Lista de variables consideradas para generar los modelos de regresión multivariable.

\begin{tabular}{|c|c|c|c|}
\hline Grupo & Nombre de la variable & Transformación & Descripción \\
\hline \multirow[t]{5}{*}{ Datos relacionados con la exposición al ruido } & $R D . L d e n . o v e r X X(m)$ & \multirow[t]{4}{*}{ Raíz cuadrada } & $\begin{array}{l}\text { Porcentaje de población expuesta a un ni- } \\
\text { vel de ruido de tráfico rodado superior a } \\
\text { XXdB de } L_{d e n} \text { en el MSOA } m \text {. }\end{array}$ \\
\hline & RL.Lden.over $X X(m)$ & & $\begin{array}{l}\text { Porcentaje de población expuesta a un ni- } \\
\text { vel de ruido de ferrocarril superior a XXdB } \\
\text { de } L_{d e n} \text { en el MSOA } m \text {. }\end{array}$ \\
\hline & RD.Ln.over $X X(m)$ & & $\begin{array}{l}\text { Porcentaje de población expuesta a un ni- } \\
\text { vel de ruido de tráfico rodado superior a } \\
\text { XXdB de } L_{n} \text { en el MSOA } m \text {. }\end{array}$ \\
\hline & RL.Ln.over $X X(m)$ & & $\begin{array}{l}\text { Porcentaje de población expuesta a un ni- } \\
\text { vel de ruido de ferrocarril superior a XXdB } \\
\text { de } L_{n} \text { en el MSOA } m \text {. }\end{array}$ \\
\hline & $E E_{\text {building }}(m)$ & Ninguna & $\begin{array}{l}\text { Valor medio de los certificados de eficiencia } \\
\text { energética de las viviendas de cada MSOA } \\
(\mathrm{m}) \text {. }\end{array}$ \\
\hline \multirow[t]{2}{*}{ Datos provenientes de medios sociales online } & $f_{p i c s}(m, c)$ & \multirow[t]{2}{*}{ Raíz cuadrada } & $\begin{array}{l}\text { Porcentaje de imágenes que forman parte } \\
\text { de la categoría } c \text { en un MSOA } m \text {, siendo c } \\
=\{\text { transport, nature, human, music, buil- } \\
\text { ding, mechanical }\}\end{array}$ \\
\hline & $P R_{\text {Flickr }}(m)$ & & $\begin{array}{l}\text { Relación entre el número de usuarios úni- } \\
\text { cos de Flickr y la población residente en el } \\
\text { MSOA } m\end{array}$ \\
\hline \multirow{5}{*}{ Información sociodemográfica } & $\operatorname{age}_{0-44}(m)$ & \multirow{4}{*}{ Ninguna } & $\begin{array}{l}\text { Porcentaje de personas de } 0 \text { a } 44 \text { años en } \\
\text { el MSOA } m\end{array}$ \\
\hline & $\operatorname{age}_{45-64}(m)$ & & $\begin{array}{l}\text { Porcentaje de personas de } 45 \text { a } 64 \text { años en } \\
\text { el MSOA } m\end{array}$ \\
\hline & $\operatorname{age}_{\text {over } 65}(m)$ & & $\begin{array}{l}\text { Porcentaje de personas de más de } 65 \text { años } \\
\text { en el MSOA } m\end{array}$ \\
\hline & income $(m)$ & & Ingresos medios por hogar en el MSOA $m$ \\
\hline & $p_{\text {female }}(m)$ & Cuadrado & Porcentaje de mujeres en el MSOA $m$ \\
\hline
\end{tabular}

Como se ha introducido previamente, el poder económico de las personas podría afectar al nivel de prevalencia de algunas enfermedades del sistema circulatorio (Kaplan et al. 2010 Keenan et al. 2011). Por ese motivo, se decidió realizar el análisis agrupando las áreas que presentaban características similares de ingresos. Para ello, se asignó una clase económica a cada MSOA utilizando como base las clases identificadas en la Great British class survey (Savage et al. 2013). Esta encuesta llevada a cabo en todo el Reino Unido 
identificó siete clases económicas, que se decidieron reagrupar en cuatro basándose en los límites de ingresos definidos en el estudio para cada grupo social: clase alta, MSOAs con unos ingresos medios por vivienda de más de $68 \mathrm{k} £$; clase medio-alta, zonas con ingresos promedios comprendidos entre los $42 \mathrm{k}$ y $68 \mathrm{k} £$; clase medio-baja, que disponían de una capacidad económica anual media de 33-45k £; y clase baja, áreas con unos ingresos medios por vivienda menores de 33k £. La Figura 4.5 muestra la distribución geográfica de los MSOAs en función de la clase definida, se observa que la mayoría de los vecindarios de clase alta se encuentran principalmente en el Noroeste y Suroeste de la ciudad, los de clase media-alta se encuentran distribuidos de manera uniforme sin patrón aparente y los de clase medio-baja y baja se encuentran tanto en el Sur del centro de Londres, como en el Norte, Este y Oeste.

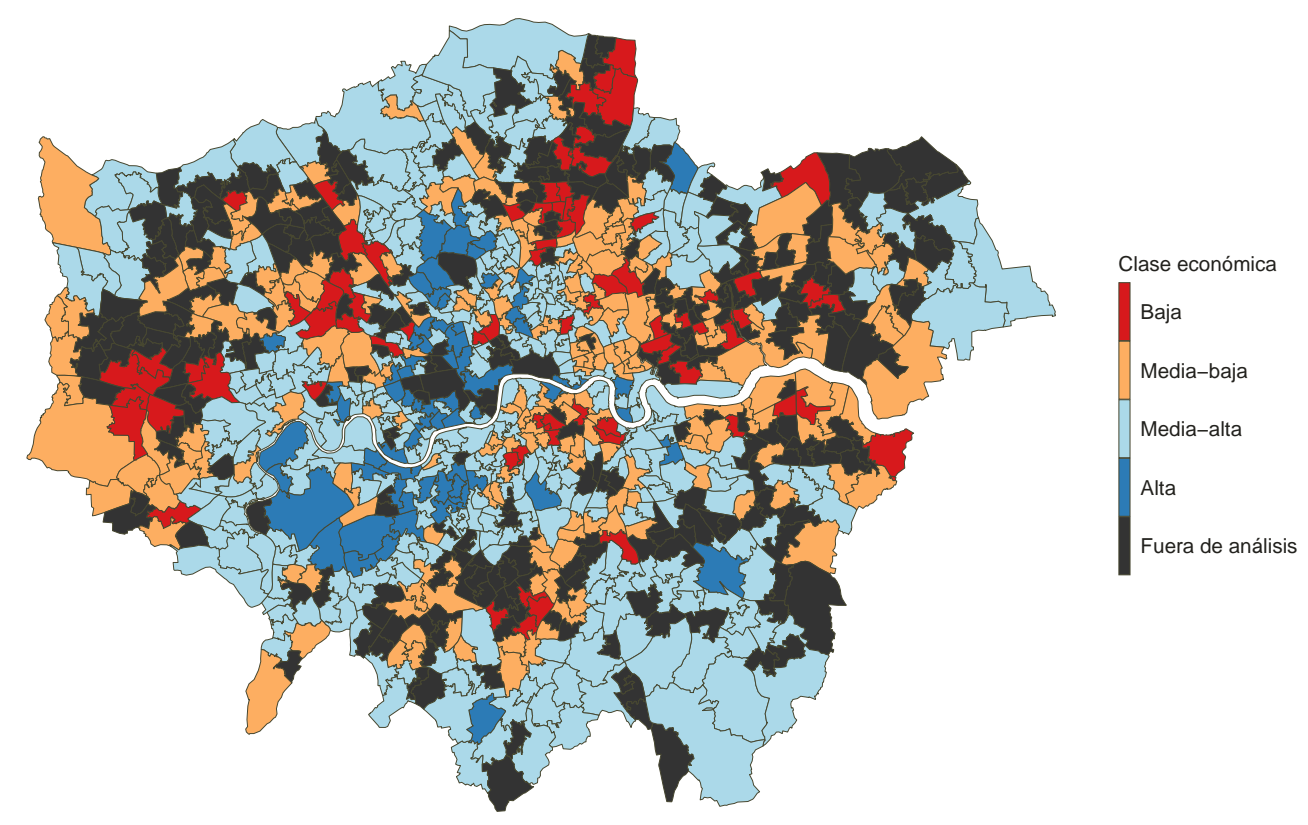

Figura 4.5: Clasificación de los MSOAs de Londres en función de su clase social.

Por otra parte, la Figura 4.6 representa la categoría de sonido predominante, basada en datos de Flickr para cada MSOA en función de las diferentes clases sociales establecidas. Se observa una mayor presencia de sonidos relacionados con el transporte en las clases bajas, mientras que los sonidos naturales, la música y los ruidos relacionados con el ser humano crecen a medida que aumenta el poder económico.

Adicionalmente, antes del análisis se definieron algunas restricciones:

1. Se puede afirmar que si no hay exposición al ruido en un MSOA, la hipertensión existente en ese área no estará influenciada por este contaminante. Dado que se está estudiando la asociación entre hipertensión y ruido, se excluyeron de los análisis los 45 MSOAs que no tenían afección por ruido, que eran aquellos cuyo porcentaje de personas expuestas a más de $55 \mathrm{~dB}$ era igual a cero.

2. Tras analizar la distribución de la variable del porcentaje de personas expuestas a más de $75 \mathrm{~dB}$, se observó que el porcentaje de población afectada por estos niveles ere insignificante (con un valor medio de $0.002 \%$ entre todos los MSOAs), tan bajo que no podría afectar el número de prescripciones medias de medicamentos para la hipertensión en un MSOA, por lo que también se excluyó esta variable de los análisis. 


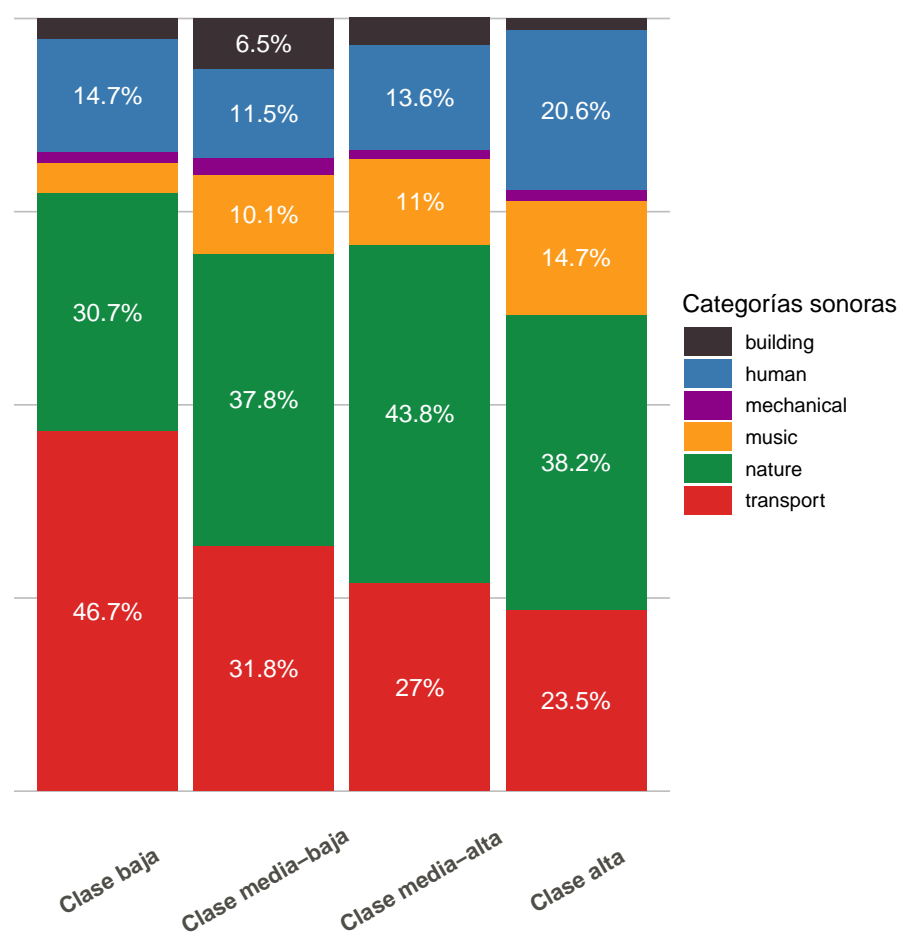

Figura 4.6: Distribución de la fuente sonoras predominantes para los MSOAs de cada clase social de Londres.

Tras establecer esas limitaciones, se llevó a cabo el análisis para los cuatro grupos económicos definidos de forma separada. Para cumplir con los requisitos de las regresiones lineales, se aplicaron las transformaciones mostradas en la Tabla 4.1 antes de realizar los análisis para cada uno de los grupos. Además, se aplicó la siguiente fórmula para normalizar los coeficientes de regresión y facilitar su comparación:

$$
\text { variable }=\frac{\text { variable }-\min (\text { variable })}{\max (\text { variable })-\min (\text { variable })}
$$

Los análisis se desarrollaron en tres fases para cada clase económica. En primer lugar se calculó un modelo únicamente con las variables de control y que fue utilizado como modelo de referencia en los análisis posteriores, que buscaban conocer el efecto explicativo de las variables de ruido y medios sociales en la hipertensión. Después, se recalculó el modelo incorporando las variables de exposición al ruido para verificar si estas eran significativas. Por último, se incorporaron al modelo las variables procedentes de medios sociales para comprobar si permitían explicar la prevalencia de hipertensión de mejor manera.

\subsection{Resultados}

En esta sección se presentan los resultados de las regresiones obtenidas para cada una de las clases económicas definidas en la sección 4.4.4.

\subsubsection{Subareas de clase baja}

Considerando la clasificación por clases anteriormente establecida, Londres cuenta con 75 MSOAs de clase económica baja. Estos MSOAs se encuentran principalmente en el Norte y el Oeste de Londres, como ilustraba la Figura 4.5. 
En la Tabla 4.2 se muestran los resultados obtenidos de cada una de las regresiones para esta clase económica. Se observa que todos los modelos identifican sistemáticamente la edad, el sexo y los ingresos como variables explicativas significativas para la tasa de hipertensión. Consecuentemente con investigaciones realizadas con anterioridad, las áreas con porcentaje de población mayor de 65 años $\left(a_{\text {gge }}\right.$ over65) muestran tasas de incidencia más altas que las áreas con población más joven (Pinto, 2007). Además, la hipertensión parece ser más frecuente en los hombres que en las mujeres, como se describió en la investigación de Hayes (Hayes y Taler, 1998) y denota el signo negativo del coeficiente de la variable $p_{\text {female }}$. Adicionalmente, los ingresos (income) juegan un papel importante en los hábitos alimenticios de la población, que han demostrado tener un impacto significativo en las enfermedades cardiovasculares (Kaplan et al., 2010, Keenan et al. 2011).

Tabla 4.2: Modelos calculados para los MSOAs de clase baja de Londres.

\begin{tabular}{lccc}
\hline \hline & \multicolumn{3}{c}{ Modelo $H R_{\text {prescriptions }}:$} \\
& \multicolumn{1}{c}{ Control } & Ruido & Ruido + Social media \\
\cline { 2 - 4 } & Coeficiente(p-valor $)$ & Coeficiente(p-valor $)$ & Coeficiente(p-valor $)$ \\
\hline age $_{\text {over65 }}$ & $0.674(<0.001)$ & $0.619(<0.001)$ & $0.728(<0.001)$ \\
$p_{\text {female }}$ & $-0.496(<0.001)$ & $-0.429(0.002)$ & $-0.431(0.001)$ \\
income & $-0.357(<0.001)$ & $-0.374(<0.001)$ & $-0.326(<0.001)$ \\
EE $E_{\text {building }}$ & & $-0.254(0.031)$ & \\
RD.Lden.over 70 & & $-0.190(0.031)$ & $-0.177(0.004)$ \\
$f_{\text {pics }}$ (nature $)$ & & & $-0.171(0.039)$ \\
PR $R_{\text {Flickr }}$ & & $0.906(<0.001)$ & $-0.450(0.006)$ \\
Constante & $0.774(<0.001)$ & 0.389 & $0.886(<0.001)$ \\
\hline $\mathrm{R}^{2}$ & 0.298 & 0.345 & 0.430 \\
$\mathrm{R}^{2}$ ajustado & 0.268 & & 0.380 \\
\hline \hline
\end{tabular}

En comparación con el modelo de control, cuando se incorporan al modelo las variables de exposición al ruido, se observa un aumento del $9 \%$ en el coeficiente de determinación corregido, que pasa de 0.268 a 0.345 . En este escenario se obtuvieron dos variables significativas: $E E_{\text {building y }} R D$.Lden.over70, es decir, la eficiencia energética de los edificios y el porcentaje de personas expuestas a ruido de tráfico con un nivel de ruido mayor de 70dB. El coeficiente negativo de la variable de eficiencia energética se interpreta como que una mayor calidad de construcción de las viviendas se relaciona con menor número de población hipertensa, probablemente porque la exposición al ruido es menor en el interior de las viviendas con mayor eficiencia energética, que suelen tener un mejor aislamiento al ruido exterior; además, una vivienda de mayor calidad de construcción implica un mayor nivel económico y mejores hábitos alimenticios. Por otra parte, la interpretación de la variable RD.Lden.over 70 no es sencilla, y su coeficiente negativo podría tener diferentes interpretaciones: en primer lugar, y tal como muestran algunos estudios (Sørensen et al., 2011, Van Kempen y Babisch, 2012), el ruido de tráfico no siempre está asociado a un incremento claro de la hipertensión, por lo que podríamos estar analizando áreas geográficas en las que el ruido no está asociado con esta enfermedad; que el nivel de agregación de los datos no permite obtener resultados alineados con parte de la literatura, ya que al estudiar el ratio de hipertensión en áreas geográficas tan extensas homogeneizamos a la población expuesta y no expuesta, algo que podría estar enmascarando los efectos que tiene el ruido sobre las personas más afectadas por la contaminación acústica en estas áreas; o bien, que no se está teniendo en cuenta una variable de control importante en el modelo.

Cuando se consideraron las variables de la presencia de fuentes sonoras calculadas 
con datos de medios sociales online, se obtuvo el mejor rendimiento en términos de $R^{2}$ ajustado (0.38). Se observa que la presencia de sonidos naturales, $f_{\text {pics }}$ (nature), es un factor que frena las altas prevalencias de la enfermedad, lo que está en línea con las hipótesis de investigación en el campo de los paisajes sonoros (Aletta et al. 2018). Además, la significación y el signo del coeficiente de la variable $R D$. Lden.over70 indica que la presencia de sonidos específicos podría ser más relevante que la exposición al ruido para explicar la hipertensión. Por último, el signo negativo de la variable $P R_{F l i c k r}$ podría validar la hipótesis de que una tasa de penetración más alta podría ser un indicio de lo agradable que es el entorno, afectando a la percepción subjetiva del ambiente sonoro como factor no acústico y, por lo tanto, repercutiendo también a la salud.

Por último se calculó la importancia relativa de cada variable en los modelos utilizando el método $l m g$ (Lindeman et al. 1980). La Figura 4.7 muestra el porcentaje relativo de la varianza que es explicada por cada variable en cada modelo. Se observa que la edad y los ingresos explican la mayor parte de la varianza de los modelos, siendo el género también relevante aunque con una importancia decreciente. Cabe destacar que cuando se añaden las variables de medios sociales, estas juegan un papel más relevante que la exposición al ruido en el modelo final, siendo particularmente interesante el caso de $P R_{F l i c k r}$, que se convierte en la tercera variable en importancia, superando incluso a la variable de control $p_{\text {female. }}$.

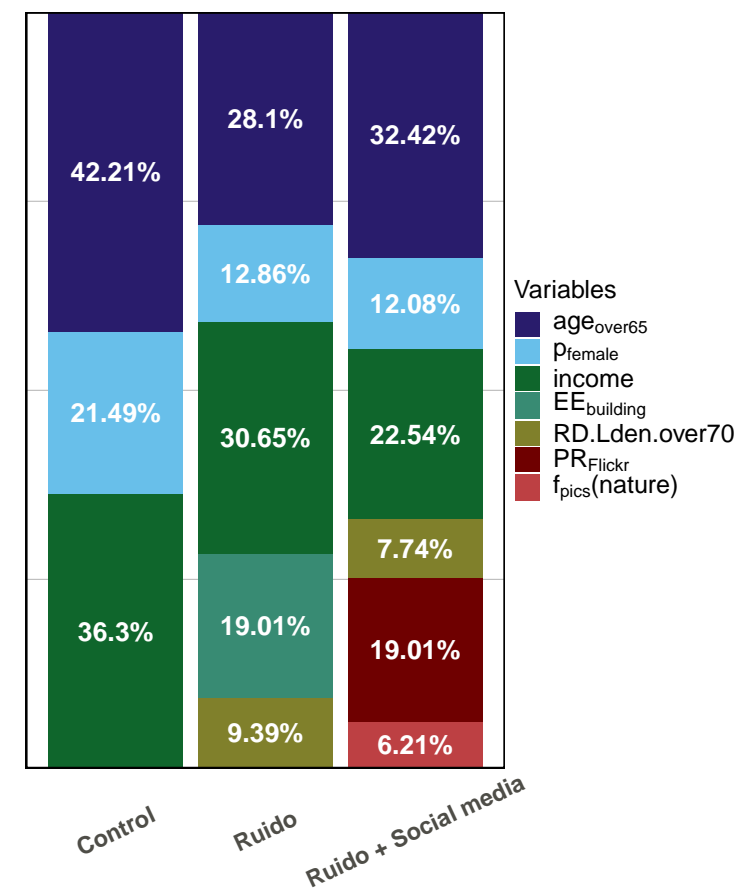

Figura 4.7: Importancia relativa de las variables de los modelos calculados para la clase baja.

\subsubsection{Subareas de clase media}

La mayoría de los MSOA de Londres pertenecen a la clase media. Se encuentran 217 zonas de clase media-baja y 345 de clase media-alta. La Tabla 4.3 y Tabla 4.4 resumen el resultado de los modelos de regresión obtenidos para cada clase. Los factores socioeconómicos como la edad, género e ingresos son significativos tanto en la clase media-baja como en la media-alta; obteniéndose un valor de $R^{2}$ ajustado de 0.262 y 0.308 respectivamente en los modelos de control. 
Tabla 4.3: Modelos calculados para los MSOAs de clase media-baja de Londres.

\begin{tabular}{|c|c|c|c|}
\hline & \multicolumn{3}{|c|}{ Modelo $H R_{\text {prescriptions }}$ : } \\
\hline & Control & Ruido & Ruido + Social media \\
\hline & Coeficiente(p-valor) & Coeficiente(p-valor) & Coeficiente(p-valor) \\
\hline age $e_{\text {over } 65}$ & $0.611(<0.001)$ & $0.587(<0.001)$ & $0.528(<0.001)$ \\
\hline$p_{\text {female }}$ & $-0.267(<0.001)$ & $-0.250(0.001)$ & $-0.281(<0.001)$ \\
\hline income & $-0.096(0.009)$ & $-0.081(0.028)$ & \\
\hline RD.Lden.over 70 & & $-0.152(0.004)$ & $-0.119(0.031)$ \\
\hline$P R_{\text {Flickr }}$ & & & $-0.284(0.005)$ \\
\hline Constante & $0.443(<0.001)$ & $0.494(<0.001)$ & $0.514(<0.001)$ \\
\hline$\overline{R^{2}}$ & 0.272 & 0.300 & 0.310 \\
\hline $\mathrm{R}^{2}$ ajustado & 0.262 & 0.286 & 0.297 \\
\hline
\end{tabular}

Tabla 4.4: Modelos calculados para los MSOAs de clase media-alta de Londres.

\begin{tabular}{|c|c|c|c|}
\hline & \multicolumn{3}{|c|}{ Modelo $H R_{\text {prescriptions }}$ : } \\
\hline & Control & Ruido & Ruido + Social media \\
\hline & Coeficiente(p-valor) & Coeficiente(p-valor) & Coeficiente(p-valor) \\
\hline age $e_{\text {over } 65}$ & $0.602(<0.001)$ & $0.549(<0.001)$ & $0.547(<0.001)$ \\
\hline$p_{\text {female }}$ & $-0.139(0.035)$ & $-0.158(0.014)$ & $-0.219(0.001)$ \\
\hline income & $-0.117(<0.001)$ & $-0.125(<0.001)$ & $-0.102(<0.001)$ \\
\hline EE $E_{\text {building }}$ & & $-0.145(0.014)$ & \\
\hline RD.Lden.over 70 & & $-0.213(<0.001)$ & $-0.194(<0.001)$ \\
\hline$f_{\text {pics }}($ music $)$ & & & $-0.088(0.044)$ \\
\hline$P R_{\text {Flickr }}$ & & & $-0.301(0.002)$ \\
\hline Constante & $0.384(<0.001)$ & $0.547(<0.001)$ & $0.562(<0.001)$ \\
\hline $\mathrm{R}^{2}$ & 0.314 & 0.359 & 0.380 \\
\hline $\mathrm{R}^{2}$ ajustado & 0.308 & 0.350 & 0.369 \\
\hline
\end{tabular}

Considerando las variables de exposición al ruido, la hipertensión en las áreas de clase media-baja y media-alta muestra una relación negativa con el porcentaje de población expuesta a niveles de ruido de tráfico mayores de $70 \mathrm{~dB}$ (RD.Lden.over 70). Tal y como se explicó en los análisis de clase baja, el valor negativo de la pendiente podría estar relacionado a una falta de asociación del ruido con la hipertensión; a que la alta agregación de los datos esté enmascarando el efecto del ruido sobre las personas; o bien, que no se estén teniendo en cuenta variables de control importantes en el modelo. En ambas clases medias, la incorporación de las variables de exposición al ruido no se traduce en una gran mejora en el $R^{2}$ ajustado, experimentando un incremento entre el 2 y el 5 por ciento.

Los modelos que incorporan las variables de medios sociales confirman la importancia de la variable $P R_{F l i c k r}$, asociada a la tasa de penetración de esta plataforma, siendo una de las variables más influyentes. Adicionalmente, en la clase medio-alta la presencia de sonidos musicales tienen una influencia positiva en la hipertensión de los residentes, lo que verificaría las investigaciones de Teng y do Amaral a grandes grupos de población (do Amaral et al. 2016, Teng et al. 2007) .Cuando se incorporan estas variables el $R^{2}$ ajustado se ve incrementado entre el 2 y el 3 por ciento.

En relación a la importancia de los regresores, mostrados en la Figura 4.8 las variables socioeconómicas vuelven nuevamente a ser las más significativas de todos los modelos, 
especialmente las relacionadas con la edad, que representan entre el 61 y 88 por ciento de la varianza total. Los ingresos y el género muestran una menor importancia si se comparan con el caso de la clase económica de bajos ingresos. Es importante destacar que, después de la edad, $P R_{F l i c k r}$ es el regresor más influyente.

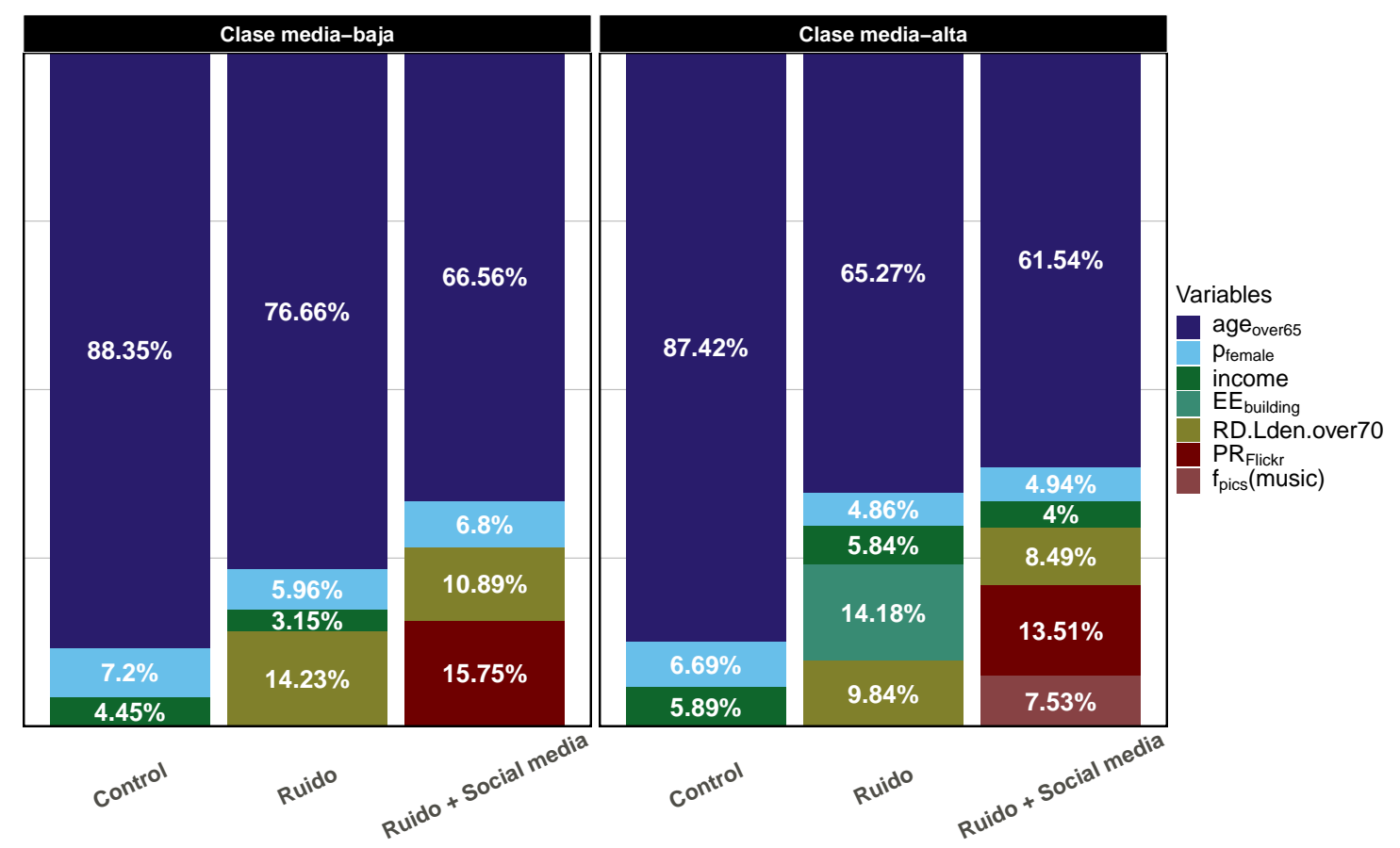

Figura 4.8: Importancia relativa de las variables de los modelos calculados para la clase media-baja y media-alta.

\subsubsection{Subareas de clase alta}

En último lugar, se calcularon los modelos en los MSOAs de clase alta existentes en Londres, mostrados en la Tabla 4.5. Se observa que en el conjunto de las 68 áreas de altos ingresos de la ciudad aparece una tendencia diferente. Si bien la edad y los ingresos reproducen los patrones anteriores, el género no parece jugar un papel importante, puesto que no es significativo en ninguno de los tres modelos. Esto ocurre porque probablemente los hábitos de vida de la población con altos ingresos son similares independientemente del sexo.

Además, las variables de exposición al ruido dejan de ser significativas y no tienen ninguna contribución en términos de mejora del coeficiente de determinación ajustado.

Sin embargo, cuando se incorporan las variables relacionadas con la presencia de fuentes sonoras, se experimenta un aumento del $12 \%$ en el $R^{2}$ ajustado, que se incrementa de 0.243 a 0.364 , obteniendo el mayor incremento en términos de coeficiente de autodeterminación cuando se añaden las variables de medios sociales. En este modelo se obtiene significación para las variables que denotan presencia de sonidos mecánicos, tales como alarmas y maquinaria en las calles, que producen un incremento del ratio de la hipertensión; y la presencia de sonidos procedentes edificios o experimentados en el interior de estos, como sonidos de oficinas, que lo disminuyen.

El hecho de que las variables de ruido no sean significativas indica que, en las zonas económicamente privilegiadas, la exposición al ruido calculada por métodos tradicionales, que solo tiene en cuenta el ruido de tráfico y de trenes, no es capaz de explicar una enfermedad cardiovascular como la hipertensión. Sin embargo, las variables calculadas a 
Tabla 4.5: Modelos calculados para los MSOAs de clase alta de Londres.

\begin{tabular}{lccc}
\hline \hline & & Modelo $H R_{\text {prescriptions }}:$ \\
& Control & Ruido & Ruido + Social media \\
\cline { 2 - 4 } & Coeficiente(p-valor $)$ & Coeficiente(p-valor $)$ & Coeficiente(p-valor $)$ \\
\hline age $_{45-64}$ & $0.459(<0.001)$ & $0.459(<0.001)$ & $0.522(<0.001)$ \\
income $_{\text {pics }}$ (building) & $-0.182(0.026)$ & $-0.182(0.026)$ & $-0.188(0.029)$ \\
$f_{\text {pics }}$ (mechanical $)$ & & & $0.360(0.029)$ \\
Constante & $0.168(<0.001)$ & $0.168(<0.001)$ & $0.063(0.365)$ \\
\hline $\mathrm{R}^{2}$ & 0.266 & 0.266 & 0.393 \\
$\mathrm{R}^{2}$ ajustado & 0.243 & 0.243 & 0.364 \\
\hline \hline
\end{tabular}

partir de datos provenientes de medios sociales, que representan la presencia de una mayor variedad de fuentes sonoras, logran captar las relaciones tanto negativas como positivas de estos sonidos en la salud de los ciudadanos. Estos resultados están conectados a las investigaciones realizadas en el ámbito de los paisajes sonoros, en los que no solo se estudia el efecto del nivel de ruido producido por fuentes sonoras del transporte, si no la calidad y cualidades particulares de otras fuentes sonoras presentes en entornos urbanos Aletta et al. 2018). En la Figura 4.9 se ve que las variables calculadas a partir de datos de medios sociales explican más del $35 \%$ de la varianza relativa. De hecho, en esta clase económica la importancia de estos regresores es sustancialmente mayor a la del resto de clases económicas, proporcionando en algunos casos más información que las variables de control en otros grupos económicos. Por ejemplo, $f_{\text {pics }}$ (building) explica un $25.43 \%$ de la varianza del modelo en la clase alta, mientras que el género solo explica el $12 \%$ del modelo de clase baja.

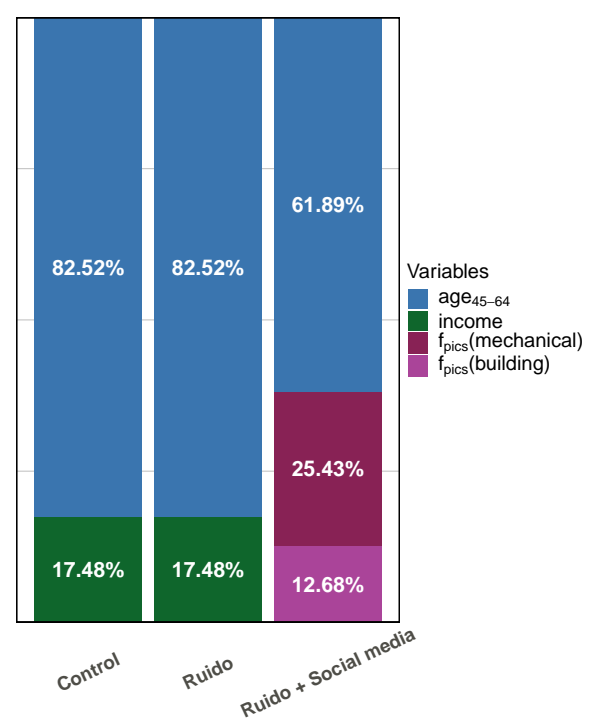

Figura 4.9: Importancia de las variables de los modelos calculados para la clase alta. 


\subsection{Conclusiones}

El experimento realizado en relación al uso de datos públicos para el estudio de los efectos del ruido en la ciudadanía permite obtener las siguientes conclusiones:

- Se ha confirmado que en una gran ciudad como Londres existen suficientes fuentes de datos públicas para realizar investigaciones que permitan estudiar si los sonidos urbanos favorecen la aparición de algunas enfermedades, como la hipertensión. Estas fuentes de datos se adquieren de tres maneras distintas: directamente de las plataformas de datos abiertos; procesando los conjuntos de datos provenientes de plataformas open data para obtener variables de interés en el estudio; y de medios sociales.

- Se ha definido una metodología para estimar el porcentaje de población expuesta a los distintos niveles de ruido en un área específica, utilizando únicamente datos disponibles de forma pública.

- Se ha definido un método para estimar la presencia de fuentes sonoras en áreas de Londres a partir de medios sociales, basado en la metodología del proyecto Chatty Maps. Para ello se utilizó la plataforma Flickr, que cuenta con millones de fotografías geolocalizadas y con información en forma de etiquetas sobre los elementos que aparecen en las imágenes. El método implementado se basa en la presencia de etiquetas relacionadas con una categoría sonora específica definida en una taxonomía de fuentes sonoras.

- La metodología experimental propuesta, en la que se dividieron las áreas de Londres en clases económicas, ha resultado ser adecuada para realizar estudios de los efectos del ruido en la salud. Además, el método de análisis basado en modelos de control a los que se les incorporaron paulatinamente las variables de interés ha permitido comprobar la importancia relativa de las variables de exposición al ruido y de los medios sociales para explicar enfermedades asociadas a la contaminación acústica.

- Se ha comprobado que en ninguno de los modelos presentados la exposición al ruido ferroviario afecta a la hipertensión de la población. A pesar de la existencia de estudios que muestran que si que existe relación, en esta investigación no se ha conseguido encontrar ninguna evidencia capaz de confirmar este hecho en Londres (Sørensen et al. 2011), probablemente porque el nivel de agregación o la metodología experimental utilizada, que se basa en utilizar todos los datos disponibles que son representativos, no permitió discriminar las pequeñas áreas en las que existe una alta exposición a esta fuente sonora.

- Se ha observado que en Londres el ruido nocturno no está relacionado con la prevalencia de la hipertensión. En ninguno de los modelos calculados la exposición al ruido en periodo nocturno fue significativa, presumiblemente porque el porcentaje de personas a estos niveles de ruido no era lo suficientemente grande.

- La estimación de la presencia de fuentes sonoras mediante medios sociales ha permitido inferir que en algunos casos la presencia de algunos sonidos podría tener más importancia en la prevalencia de la hipertensión que la exposición al ruido en si misma. Además, la presencia de algunos de ellos, como los procedentes de la naturaleza o la música, mejorarían la salud de los ciudadanos en relación a esta enfermedad. Esto demostraría que la presencia, calidad y cualidades de sonidos específicos podrían afectar a la salud de la población, más allá de los niveles de ruido que produzcan. 
- El nivel de ruido proveniente del tráfico y de los trenes presente en los barrios de clase alta no explican la hipertensión de sus residentes. Sin embargo, la presencia de otras fuentes sonoras, como las provenientes de orígenes mecánicos, si que podrían estar influyendo en esta enfermedad.

- Se ha incorporado una variable que permite medir el efecto del ambiente global en la percepción subjetiva del ruido presente en un área específica. Esta variable ha resultado significativa y ha permitido demostrar que este factor podría afectar a como la gente reacciona ante actividades ruidosas y el efecto que tienen estas reacciones de estrés sobre la salud.

\subsubsection{Limitaciones del experimento}

Nivel de agregación. Los estudios que analizan los efectos del ruido en la población suelen ser de cohorte, por lo que se realizan en individuos concretos expuestos a condiciones acústicas específicas. En este caso, al tratar con datos promedio para cada una de las áreas de Londres (MSOAs) se podrían estar introduciendo algunos sesgos que deberían ser cuantificados en trabajos futuros, o trabajar con un nivel de agregación menor de esas áreas.

Estimación de datos. Dado que se quería trabajar con datos abiertos, se tuvieron que hacer estimaciones sobre la exposición al ruido en cada uno de los MSOAs de Londres. Esto podría introducir sesgos en los resultados que deberían ser cuantificados en futuros trabajos. Además, sólo se ha considerado el ruido de las carreteras y los ferrocarriles, excluyendo del análisis la exposición al ruido producido por los aeropuertos, ya que sólo unas pocas zonas de Londres se ven afectadas por este tipo de fuentes de ruido. 



\title{
Capítulo 5
}

\section{Conclusiones y aportaciones}

\author{
Nothing in life is to be feared, \\ it is only to be understood. \\ Now is the time to understand more, \\ so that we may fear less. \\ Marie Curie
}

En esta tesis se plantearon tres objetivos generales claramente diferenciados:

- Incorporación de las TICs al nuevo enfoque de la gestión de la contaminación acústica en ciudades mediante una implementación que permita medir la percepción de las actividades ruidosas en entornos urbanos.

- Uso de fuentes de datos provenientes de Internet para extraer conocimiento acerca de las actividades ruidosas que afectan a la población.

- Uso de datos disponibles de forma pública para medir los efectos del ruido sobre la salud de la población de grandes ciudades.

En la primera sección de este capítulo se detallan, de forma diferenciada para cada uno de ellos, el grado de cumplimiento de los objetivos y las conclusiones derivadas del desarrollo de los experimentos realizados para lograr su cumplimiento.

En la sección Aportaciones se enumeran las aportaciones derivadas del desarrollo de la investigación. Posteriormente, en el apartado Publicaciones, se enumeran las acciones de difusión llevadas a cabo en forma de artículos en revistas científicas, publicaciones en congresos, actividades de divulgación y colaboraciones relacionadas con la temática de la investigación. Por último, en la sección Líneas futuras de investigación, se introducen las posibles vías de continuación de la investigación comenzada en esta tesis doctoral. 


\subsection{Conclusiones}

Incorporación de las TICs al nuevo enfoque de la gestión de la contaminación acústica en ciudades mediante una implementación que permita medir la percepción de las actividades ruidosas en entornos urbanos.

Para el cumplimiento del primer objetivo general de esta tesis doctoral se llevó a cabo un estudio en la ciudad de Málaga (España) para cuantificar el efecto que tiene la comunicación de la información sobre contaminación acústica en la percepción de la molestia asociada al ruido. El experimento se centró en las emisiones sonoras producidas por actividades recreativas por ser un problema de creciente importancia para los gestores urbanos de las ciudades del Sur de Europa y por ser uno de los focos de molestia más importantes para los residentes de la ciudad. La investigación se realizó a través de una metodología basada en encuestas online. En primer lugar, se realizó un cuestionario para conocer la molestia de la población antes de informar de la existencia de una campaña de monitorización de ruido de ocio. A continuación, se llevaron a cabo tareas de difusión del proyecto y se abrió al público una plataforma de visionado de la información acústica a tiempo real. De forma paralela se realizó otro cuestionario para comprobar si se habían experimentado cambios en la molestia que pudieran asociarse a las tareas de comunicación y difusión de la información acústica.

Desde el punto de vista de la metodología diseñada, se ha demostrado que la evaluación PRE-POST utilizando el uso de cuestionarios online es un sistema válido para medir la variación de la molestia generada por las actividades de ocio antes y después de llevar a cabo una serie de acciones que pudieran modificar la percepción de una actividad ruidosa.

Esa metodología ha permitido conocer que la plataforma online de visualización de datos de ruido no ha afectado a la molestia asociada al ruido de ocio. No obstante, los datos apuntan a la dirección de que conocer la existencia de la red de monitorado instalada en Málaga incrementó la molestia de la ciudadanía en 1.3 puntos. Ese incremento de molestia se podría relacionar a un incremento de la concienciación sobre el problema del ruido, ya que al desplegar una red de monitorado la ciudadanía podría haber percibido que los niveles de ruido eran lo suficientemente altos como para tener que ser controlados. Por otra parte, al ser una encuesta de acceso libre, las personas más afectadas podrían haber accedido libremente a la aplicación, provocando un incremento de la molestia que no es representativo de la población general.

Se observó que las asociaciones de lucha contra el ruido de la ciudad difundieron la encuesta en sus propios canales de comunicación, lo que produjo cambios en la distribución de la muestra entre la encuesta inicial (mediante invitación) y la final (acceso libre). Esto pone de relevancia la importancia de explorar los medios públicos en los que se difunden los cuestionarios online para controlar posibles sesgos asociados a la distribución de la muestra.

Además, se ha demostrado que la población que forma parte de esas asociaciones presenta patrones de molestia diferentes a los de la ciudadanía estándar, con una sensación de molestia 1.5 puntos superior hacia el ruido de ocio. Lo que pone de manifiesto la necesidad de incluir una cuestión preguntando este hecho.

Desde el punto de vista de la difusión y su relación con la participación, se ha cumplido el objetivo de obtener una gran cobertura del proyecto en los medios, aunque esto no se tradujo en una alta tasa de participación en las encuestas. Aunque el ruido de ocio es un tema reconocido por la ciudadanía y por los gestores medioambientales como uno de los orígenes de mayor molestia en Málaga, no se obtuvo una participación acorde a esas expectativas. A pesar de eso, el uso de encuestas online ha demostrado ser una herramienta válida para incrementar la participación, dado que se incrementó en un $40 \%$ el número de ciudadanos que cumplimentaron el cuestionario respecto a encuestas de ruido 
anteriormente realizadas en la ciudad mediante entrevistas cara a cara.

Por otra parte, se obtuvo un ratio de finalización de los cuestionarios del $80 \%$, muy por encima del $50 \%$ reportado en otras investigaciones con encuestas online, lo que verifica que la longitud de la encuesta desarrollada fue la adecuada dada la temática y los objetivos.

Desde el punto de vista de diseño experimental, se ha observado que aprovechar la cobertura mediática del lanzamiento del proyecto para anunciar la existencia de la encuesta no ha sido el más óptimo para el experimento. Muchas personas accedieron a la encuesta sin disponer de un tiempo razonable para explorar la aplicación de visualización de datos acústicos, por lo que tuvieron que ser excluidas de algunos de los análisis al no cumplir los requerimientos del experimento. En futuras investigaciones esto debe ser tenido en cuenta para sacar mayor partido de la participación ciudadana, que de por si ya es complicada de obtener.

\section{Uso de fuentes de datos provenientes de Internet para extraer conocimiento acerca de las actividades ruidosas que afectan a la población.}

Se ha propuesto una metodología para la obtención, clasificación y análisis de textos de valoración de actividades ruidosas provenientes de redes sociales online. Mediante técnicas de aprendizaje automático y de procesado de lenguaje natural se implementó un detector y clasificador de quejas de ruido escritas en la red social Twitter. Además, se propuso un método de análisis de las quejas detectadas que permitió la detección de eventos ruidosos, conocer el origen de la molestia y predecirlos con cierta antelación.

El desarrollo de la investigación ha permitido confirmar que una parte de la ciudadanía publica información sobre las fuentes de ruido que les afectan negativamente en canales alternativos a los oficiales, como las redes sociales online, para expresar su molestia. Esta información puede ser adquirida mediante una búsqueda basada en palabras clave y las APIs de algunas redes sociales, como Twitter. Esto posibilita la obtención de una gran cantidad de datos entre los que se encuentran los textos de valoración de actividades ruidosas.

En relación a la preparación de los datos, se ha demostrado que el método de preprocesado de textos implementado, en el que se normalizan las palabras de jerga y diminutivos y se corrigen los fallos gramaticales, es válido para incrementar la dimensionalidad de los textos cortos. Lo que ha permitido contar con una mayor riqueza léxica en el contenido de los textos, facilitar la extracción de características representativas y mejorar de ese modo el rendimiento de los clasificadores implementados.

Dado que es la primera experiencia en el uso de técnicas de NLP en la detección de quejas sobre ruido, se han definido un conjunto de clases para poder utilizar el contenido textual procedente de redes sociales en sistemas de aprendizaje automático supervisado. El proceso llevado a cabo para validar las clases definidas, mediante la medida del grado de acuerdo entre distintos anotadores, ha permitido demostrar que las categorías creadas fueron correctamente especificadas y que pueden ser utilizadas de forma óptima en este tipo de clasificadores.

El uso combinado de características textuales calculadas mediante técnicas de NLP, como los n-gramas, características morfosintácticas, características de sentimiento y embeddings; han sido válidas para entrenar un clasificador automático de textos capaz de detectar quejas de ruido, obteníendose un rendimiento similar al de las investigaciones del estado del arte. Además, la expansión de la taxonomía desarrollada en otras investigaciones utilizando tecnologías de la web semántica y diccionarios léxico-jerárquicos ha resultado ser un método idóneo para el desarrollo de un sistema capaz de clasificar las quejas de ruido por fuente sonora en función de las palabras presentes en estas.

Para la realización de las pruebas de rendimiento del sistema, se ha propuesto una 
metodología que implementa técnicas de validación cruzada estratificada y coeficientes de ponderación a cada una de las clases existentes en los datos. Este enfoque ha permitido gestionar el desbalanceo de clases existentes en los datos de entrenamiento del sistema. Además, el hecho de que el $85 \%$ de las quejas sobre ruido han sido detectadas correctamente por el clasificador y que el $86 \%$ de las quejas fueron asignadas a sus categorías sonoras de forma adecuada demuestran que la metodología implementada para el análisis de estos textos es válida para la obtención de información sobre la percepción negativa de fuentes ruidosas presentes en redes sociales.

Adicionalmente, se ha demostrado que el uso combinado de los modelos implementados con modelos de intervención ARIMA permite detectar periodos temporales en los que se están produciendo situaciones anómalas de molestia asociada al ruido, y conocer además el origen general de esas quejas.

El enfoque adoptado para conocer el origen específico del evento ruidoso detectado, basado en el análisis semántico de las quejas para conocer la frecuencia de uso de las palabras en los textos, ha sido probado como un método válido para conocer los sonidos específicos a los hacen referencia las quejas de ruido detectadas durante un evento ruidoso.

Además, el uso de técnicas de control estadístico de procesos y de análisis de series temporales ha posibilitado la creación de un sistema de alarmas capaz de detectar eventos sonoros molestos específicos a partir del contabilizar el número de quejas y la presencia de palabras específicas.

Los sistemas desarrollados para cumplir el segundo objetivo de la tesis doctoral demuestran que, efectivamente, se puede obtener información sobre actividades ruidosas de las redes sociales. Además, estas herramientas son de interés para que los gestores urbanos detecten problemas relacionados con el ruido a tiempo real a través de la información que los ciudadanos comparten en redes sociales online. Por una parte, el sistema de alarmas podría ser entrenado para detectar eventos relacionados con ruido recreativo y detectar incumplimientos en los horarios de discotecas y bares de copas. Además, el sistema de detección de eventos sonoros y la fuente específica origen de las quejas podrían ser utilizados para una rápida actuación frente a situaciones acústicas molestas para la ciudadanía, y para medir la efectividad de esas actuaciones basándose en la disminución de quejas publicadas tras ser llevadas a cabo.

\section{Uso de datos disponibles de forma pública para medir los efectos del ruido sobre la salud de la población de grandes ciudades.}

Dado que el desarrollo tecnológico y el avance de las políticas de gestión han facilitado que hoy en día sea posible la obtención de multitud de datos de distinta índole de forma pública; que la ciudadanía, además de compartir textos sobre su actitud hacia el ruido en redes sociales online, comparte datos multimedia que pueden proporcionar información sobre el ambiente acústico en una ciudad; y la creciente importancia de la línea de investigación que estudia los efectos del ruido en la salud, se ha realizado un experimento en el que se han obtenido la influencia de diferentes fuentes sonoras en la salud de los ciudadanos de Londres.

El experimento ha demostrado que en una gran ciudad existen suficientes fuentes de datos públicas para realizar investigaciones que permitan conocer si el ruido o la presencia de sonidos específicos afectan a la salud de la población urbana.

Los métodos implementados para estimar el porcentaje de población expuesta a distintos niveles de ruido y para evaluar la presencia de fuentes sonoras en áreas específicas de una ciudad han resultado válidos para estudiar el efecto del ruido en la hipertensión de la población.

Además, los resultados de los análisis realizados han permitido llegar a algunas con- 
clusiones:

- En primer lugar, cabe destacar que en ninguno de los modelos calculados la exposición al ruido ferroviario parecía tener un efecto sobre la hipertensión, a pesar de la existencia de estudios previos que mostraban lo contrario. Esto podría ser debido a que el nivel de agregación espacial encubría las pequeñas áreas en las que esta fuente sonora tenía un alto impacto, o a que las áreas cercanas a las vías férreas estaban protegidas por pantallas acústicas que reducían el impacto de la población residente. De forma similar los niveles de ruido nocturno no han sido relevantes, presumiblemente porque el porcentaje de población expuesta al ruido en esta franja sonora no era elevado en cada MSOA.

- En segundo lugar, los resultados del experimento sugieren que los factores socioeconómicos son la principal fuente de información cuando se estudian enfermedades a nivel de MSOA. Además, aunque es conocido que el poder económico afecta a la prevalencia de la hipertensión, el estudio realizado arroja luz sobre los límites de los modelos tradicionales de exposición al ruido, que consideran solo medios de transporte, para medir los efectos que tiene la contaminación acústica en el bienestar de los ciudadanos. De hecho, la inclusión de variables que tienen en cuenta una mayor diversidad de fuentes sonoras, tanto de carácter positivo como negativo, permite una mayor comprensión de esta enfermedad cuando no existe posibilidad de conocer la exposición al ruido en un área o por algún motivo no es explicativa.

Los resultados podrían conducir a nuevas formas de la gestión del ruido y podrían ser de interés para los profesionales del urbanismo. Dado que los análisis sugieren que la exposición a algunas fuentes sonoras específicas podrían mejorar la hipertensión, los resultados abren la puerta a nuevos estudios para medir en detalle el efecto de estos sonidos en la salud con el fin de diseñar entornos acústicos en las ciudades beneficiosos para la población urbana. Además, se ha demostrado la usabilidad y eficiencia de las plataformas de medios sociales para medir la presencia de fuentes sonoras, que podrían complementar a las redes de sensores con capacidad de detección de fuentes sonoras que se utilizan en este tipo de estudios.

Por otro lado, se ha demostrado que la importancias de las variables procedentes de medios sociales se dispara al estudiar el efecto del ruido sobre la hipertensión en algunos barrios donde las métricas tradicionales, como el porcentaje de gente expuesta al ruido de tráfico, son incapaces de explicar la enfermedad debido a un menor flujo de vehículos o condiciones específicas de estas zonas, algo que en el caso del experimento ha ocurrido en los barrios ricos de Londres. Esto vuelve a ser de interés para los urbanistas, que podrían estudiar a fondo los ambientes sonoros en estos vecindarios de clase alta y replicarlos en zonas más humildes con la intención de mejorar la calidad de vida y salud de los residentes.

\subsection{Aportaciones}

Como principales aportes y utilidades derivadas de esta investigación doctoral se pueden destacar:

- Se ha descrito una metodología basada en encuestas que permite evaluar el efecto de la comunicación de datos de contaminación acústica en la ciudadanía utilizando exclusivamente TICs, como cuestionarios y sistemas de visualización online.

- Se ha descrito una metodología que permite detectar las quejas que la ciudadanía expresa sobre actividades ruidosas en redes sociales online, así como un sistema para clasificarlas por la fuente sonora a la que hacen referencia. 
- Se ha desarrollado una taxonomía y vocabulario de términos sobre fuentes sonoras, partiendo de los resultados de investigaciones previas, en las que se ha aumentado el número de palabras asociadas a fuentes sonoras presentes en el vocabulario de 228 a 4506 términos, utilizando bases de datos léxico-jerárquicas y herramientas proporcionadas por las tecnologías de la web semántica.

- Se ha desarrollado la herramienta Noytext, que es una aplicación web cuyo fin es facilitar y acelerar los procesos de asignación de clases a documentos de textos cortos que se vayan a utilizar en investigación de minado de textos aplicada a la acústica ambiental y la percepción del ruido.

- Se han incorporado los modelos de detección y clasificación de quejas de ruido a una prueba de concepto capaz de monitorizar las redes sociales para identificar automáticamente eventos molestos para la ciudadanía por el ruido que generan. Adicionalmente, se ha mostrado un sistema para inferir el origen específico de la molestia dentro de los eventos detectados mediante análisis semántico.

- Se ha propuesto una metodología para la creación de sistemas de alarma capaces de detectar actividades específicas que son molestas para la ciudadanía por su nivel de ruido y que además tiene capacidad potencial de predecir esas situaciones. El sistema está construido utilizando técnicas de control estadístico de procesos y las series temporales de quejas detectadas.

- Se ha propuesto una metodología para estimar el porcentaje de población expuesta a los distintos niveles de ruido en un área específica mediante el uso de datos abiertos.

- Se ha comprobado la relación que tiene la presencia de fuentes sonoras de origen específico, distintas a los medios de transporte consideradas en los mapas de ruido, con enfermedades cardiovasculares asociadas a la contaminación acústica como la hipertensión. Además, se ha demostrado que el uso de datos provenientes de medios sociales para estimar la presencia de esas fuentes sonoras es un método válido para realizar estudios de esta índole.

- El análisis por clases socioeconómicas ha permitido demostrar que el ruido proveniente del tráfico y de los trenes presente en áreas de clase alta no son capaces de explicar la hipertensión que sufren sus residentes. Sin embargo, la información sobre la presencia de fuentes sonoras, extraídas de medios sociales, si que la explica parcialmente, como por ejemplo los ruidos mecánicos. 


\subsection{Publicaciones}

Los resultados de los experimentos y análisis llevados a cabo se han traducido en una serie de aportaciones científicas en revistas, congresos, prensa y sesiones técnicas.

\subsubsection{Artículos científicos publicados}

Como resultados de la tesis doctoral se han realizado las siguientes publicaciones en revistas científicas:

\begin{tabular}{|c|c|c|c|c|}
\hline Artículo & WoS & JCR & Clasificación & Estado \\
\hline $\begin{array}{l}\text { Gasco, L.; Schifanella, R.; Aiello, L.; Asensio, C.; Quercia, D.; de Arcas, } \\
\text { G.; Social media and open data to quantify the effects of noise } \\
\text { on health }\end{array}$ & - & - & - & $\begin{array}{l}\text { Revisión } \\
\text { por autores }\end{array}$ \\
\hline $\begin{array}{l}\text { Asensio, C.; Gasco, L.; de Arcas, G.; López, J.M.; Alonso, J. As- } \\
\text { sessment of Residents Exposure to Leisure Noise in Málaga } \\
\text { (Spain). Environments 2018, 5, doi:10.3390/environments5120134. }\end{array}$ & $\mathrm{Si}$ & No & - & Publicado \\
\hline $\begin{array}{l}\text { Gasco, L.; Clavel, C.; Asensio, C.; de Arcas, G. Beyond sound le- } \\
\text { vel monitoring: Exploitation of social media to gather citi- } \\
\text { zens subjective response to noise. Sci. Total Environ. } 658,6979 \text {, } \\
\text { doi: } 10.1016 / \text { j.scitotenv.2018.12.071. }\end{array}$ & $\mathrm{Si}$ & $\mathrm{Si}$ & $\begin{array}{l}2018 \text { Q1 "Environmental } \\
\text { Sciences" }(27 / 250)\end{array}$ & Publicado \\
\hline $\begin{array}{l}\text { Asensio, C.; Gasco, L.; de Arcas, G. A Review of Non-Acoustic } \\
\text { Measures to Handle Community Response to Noise around } \\
\text { Airports. Curr. Pollut. Reports } 2017,3,230244 \text {, doi:10.1007/s40726- } \\
017-0060-\mathrm{x} .\end{array}$ & $\mathrm{Si}$ & $\mathrm{Si}$ & $\begin{array}{l}2018 \text { Q1 "Public, envi- } \\
\text { ronmental \& occupational } \\
\text { health" }(30 / 185)\end{array}$ & Publicado \\
\hline $\begin{array}{l}\text { Gasco, L.; Asensio, C.; de Arcas, G. Communicating airport noise } \\
\text { emission data to the general public. Sci. Total Environ. 2017, } 586 \text {, } \\
\text { 836848, doi:10.1016/j.scitotenv.2017.02.063. }\end{array}$ & $\mathrm{Si}$ & $\mathrm{Si}$ & $\begin{array}{l}2017 \text { Q1 "Environmental } \\
\text { Sciences" }(27 / 242)\end{array}$ & Publicado \\
\hline
\end{tabular}

\subsubsection{Artículos en congresos}

Como resultado de la tesis doctoral se han participado en tres congresos internacionales, presentando los siguientes comunicaciones orales:

\begin{tabular}{lc}
\hline Título & Internacional \\
\hline $\begin{array}{l}\text { Gasco, L, C Asensio, C Clavel, and G de Arcas (2019). Noytext: A Web platform to annotate } \\
\text { social media documents on noise perception for their use in opinion mining research. }\end{array}$ & $\mathrm{Si}$ \\
In: InterNoise 2019 - 48th International Congress and Exposition on Noise Control Engineering & \\
\hline $\begin{array}{l}\text { Gasco, L, C Clavel, C Asensio, and G de Arcas (2019). Evaluating noise perception through } \\
\text { online social networks: A text mining approach to design a noise-event alarm system }\end{array}$ & $\mathrm{Si}$ \\
based on social media content. In: InterNoise 2019 - 48th International Congress and Exposition & \\
on Noise Control Engineering. & \\
\hline $\begin{array}{l}\text { Gasco, L, C Asensio, and G de Argas (2017). Towards the assessment of community response } \\
\text { to noise through social media. In: InterNoise 2017 - 46th International Congress and Exposition }\end{array}$ & \\
on Noise Control Engineering. & \\
\hline $\begin{array}{l}\text { Asensio, C, G de Arcas, L Gasco, J Lopez, J Alonso, L Medina-Montoya, A Ruiz, and A Castillo } \\
\text { Igartua (2016). Recreational Noise Assessment in Malaga (Spain). In: Proceedings of the }\end{array}$ & Si \\
$23 e r d$ International Congress on Sound and Vibration (ICSV 23). & \\
\hline
\end{tabular}

\subsubsection{Divulgación científica, posters y participación en sesiones técnicas}

Además, a lo largo de la tesis doctoral se han llevado a cabo diversas actividades divulgación científica, colaboraciones y presentación de posters en reuniones de investigación y workshops con el objetivo de incrementar la difusión e impacto de los resultados de la investigación: 


\begin{tabular}{|c|c|c|}
\hline Título & Fecha & Tipo de aportación \\
\hline $\begin{array}{l}\text { Entrevista para EFE Verde "Investigadores UPM analizan la contami- } \\
\text { nación acústica a través de las redes sociales" }\end{array}$ & 05-04-2019 & $\begin{array}{l}\text { Entrevista para artícu- } \\
\text { lo de divulgación }\end{array}$ \\
\hline Artículo "Cómo utilizar Twitter contra el ruido" en The Conversation & 03-04-2019 & $\begin{array}{l}\text { Artículo de divulga- } \\
\text { ción }\end{array}$ \\
\hline Entrevista en el programa "Longitud de Onda" de Radio Clásica (RTVE) & $27-03-2019$ & Entrevista de radio \\
\hline $\begin{array}{l}\text { Entrevista para InnovaSpain "Las quejas en Twitter servirán para ges- } \\
\text { tionar eventos de contaminación acústica" }\end{array}$ & 25-03-2019 & $\begin{array}{l}\text { Entrevista para artícu- } \\
\text { lo de divulgación }\end{array}$ \\
\hline $\begin{array}{l}\text { Presentación "Beyond noise monitoring: assessment of community res- } \\
\text { ponse to noise issues through social media" en el EIT Digital Workshop } \\
\text { on Digital Cities Action Line }\end{array}$ & $23-10-2018$ & $\begin{array}{l}\text { Presentación en sesión } \\
\text { técnica }\end{array}$ \\
\hline $\begin{array}{l}\text { Ponente invitado en la EIT Digital Cities } 2018 \text { summer school (Rennes, } \\
\text { Francia). Presentación: "Towards the assessment of community response } \\
\text { to environmental issues through social media". }\end{array}$ & 02-07-2018 & $\begin{array}{l}\text { Presentación en sesión } \\
\text { técnica }\end{array}$ \\
\hline $\begin{array}{l}\text { Elaboración de la ontología sobre contaminación acústica del libro "DA- } \\
\text { TOS ABIERTOS. Guía estratégica para su puesta en marcha. Conjuntos } \\
\text { de datos mínimos a publicar." }\end{array}$ & $05-2017$ & Colaborador \\
\hline $\begin{array}{l}\text { Gasco, L.; Asensio, C.; de Arcas, G. "Noise data communication as a non- } \\
\text { acoustic factor for mitigating aviation noise". In: Industriales Research } \\
\text { Meeting } 17\end{array}$ & 03-2017 & Poster \\
\hline $\begin{array}{l}\text { Asensio, C.; Gasco, L.; de Arcas, G. "Exploitation of ICTS for community } \\
\text { noise management". In: Industriales Research Meeting } 16\end{array}$ & 03-2016 & Poster \\
\hline
\end{tabular}

\subsection{Líneas futuras de investigación}

A lo largo del desarrollo de estas tesis doctoral, y mientras se iban obteniendo resultados favorables, han ido apareciendo futuras líneas de trabajo para continuar con la investigación que no han podido ser exploradas durante el periodo doctoral y se convierten en retos de cara a futuras investigaciones. Estas líneas están centradas en el uso de las tecnologías del lenguaje en el campo de la acústica y el uso de datos abiertos para estudiar los efectos del ruido:

Futuras líneas en relación al análisis de texto provenientes de medios sociales:

- Actualizar la metodología con un enfoque basado en el deep learning: Dado que la metodología de análisis de textos de redes sociales online ha sido validada utilizando tecnologías maduras dentro del campo del aprendizaje automático, existe la posibilidad de utilizar algoritmos que tienen gran rendimiento en la clasificación de textos. Las técnicas de deep learning permiten la extracción automática de características textuales y un rendimiento mayor respecto a las técnicas tradicionales de aprendizaje automático (Araque et al. 2017). Específicamente las redes neuronales recurrentes (RNN) han mostrado un buen rendimiento en el análisis de sentimientos basado en aspectos (Ma et al. 2018, Wang et al. 2016), por lo que podrían utilizarse para clasificar los tweets en cada categoría de ruido y extraer los aspectos más relevantes de cada queja en lugar de utilizar algoritmos basados en el léxico. Por otro lado, las redes neuronales convolucionales (CNN) han demostrado ser útiles para clasificar el sentimiento de textos cortos (Severyn y Moschitti, 2015), aunque tienen el problema de necesitar grandes bases de datos etiquetadas para lograr resultados representativos.

- Identificación de la localización: La metodología desarrollada no tiene en cuenta la detección del lugar en el que se están produciendo las valoraciones sobre el ruido. En futuras actualizaciones de la metodología, se podría añadir un detector de ubicación 
para detectar los lugares en los que se está produciendo la molestia, y obtener de ese modo información más precisa sobre el evento que la está generando.

- Niveles de molestia: El clasificador implementado solo diferencia entre textos de carácter negativo y positivo. Sin embargo, sería posible ampliar el alcance del sistema para diferenciar entre distintos niveles de molestia, y proporcionar información más precisa a los gestores sobre la percepción ciudadana para que prioricen las acciones hacia las situaciones más molestas.

- Desarrollo de herramientas para facilitar la investigación en este campo: La aplicación de técnicas de procesado de lenguaje natural para la detección de la actitud hacia al ruido no había sido utilizada con anterioridad. Dado que es una tecnología de nueva aplicación en el campo de la acústica ambiental, no existen herramientas adaptadas a las necesidades de este campo y por lo tanto investigadores interesados en la temática podrían echarse atrás en su aplicación. Por ese motivo es conveniente desarrollar las herramientas necesarias para facilitar las investigaciones en esta rama a los profesionales en acústica ambiental. Por ejemplo, es necesario crear bases de datos estandarizadas que permitan evaluar la eficacia de los modelos de detección de quejas para que los futuros modelos desarrollados puedan ser intercomparados, o son necesarias herramientas similares a Noytext, desarrollada en esta investigación doctoral, para facilitar y acelerar la obtención de resultados.

- Adaptación de la metodología para analizar otras fuentes de datos: Twitter no es la única red social de la que se puede extraer información sobre la percepción del ruido. Se decidió utilizar porque facilitaba la obtención de datos necesarios para desarrollar los algoritmos, y existía multitud de bibliografía relativa al análisis de textos de esta red social. Existen muchas otras fuentes de datos textuales que pueden ser exploradas, como las plataformas para compartir opiniones sobre restaurantes, hoteles y lugares públicos. Habría que adaptar la metodología presentada en la tesis a textos de mayor longitud, ya que las posibilidades de análisis de este tipo de textos son diferentes a los de los textos cortos. Además, muchas de estas fuentes de datos proporcionan información acerca de la localización, lo que abriría la puerta a detectar puntos negros acústicos en entornos urbanos basándose en datos de redes sociales.

- Adaptación de la metodología a otros campos de la acústica ambiental: La metodología introducida podría ser adaptada a otros campos en los que se necesite participación ciudadana. Por ejemplo, en el campo de los paisajes sonoros, se llevan a cabo soundwalks para conocer la percepción subjetiva de los sonidos en una ciudad. La información obtenida en esos soundwalks podría ser complementada y validada con información de redes sociales, en los que las personas expresan lo agradable que les ha resultado un lugar teniendo en cuenta también el entorno sonoro que experimentó.

\section{Futuras líneas en relación al uso de datos públicos para estudiar los efectos del ruido en la población urbana:}

- Verificación y mejora del método para estimar la exposición de la población: Se ha mostrado un método para estimar el porcentaje de población expuesta en áreas de una ciudad. Por ese motivo, existe una línea de trabajo para mejorar y validar la metodología aplicada en la que se consideren distintos factores como la geometría urbana o la distribución de los habitantes dentro del área de cálculo.

- Ampliación de resultados a otras enfermedades asociadas al ruido: Del mismo modo que se ha llevado a cabo un estudio de prevalencia de la hipertensión, podría ampliarse este tipo de análisis a otras enfermedades asociadas al ruido como el insomnio 
o la ansiedad. Para estos análisis se necesitaría investigar las variables adicionales que podrían tener influencia y proponer una metodología para su cálculo.

- Incorporación de variables alternativas que permitan explicar las enfermedades : En el experimento se utilizó la información de Flickr para inferir las fuentes sonoras de una región. Sin embargo, sería posible la aplicación de otras fuentes de datos, como las web de opiniones de lugares públicos, para estimar la molestia generada por diferentes fuentes sonoras e incorporarlas al estudio de las enfermedades del ruido. 


\title{
Capítulo 6
}

\section{Conclusions and contributions}

\author{
Nothing in life is to be feared, \\ it is only to be understood. \\ Now is the time to understand more, \\ so that we may fear less. \\ Marie Curie
}

There were three main general objectives in this thesis:

- Incorporation of ICTs into a new approach to noise pollution management in cities through an implementation that allows measuring the perception of noisy activities in urban environments.

- Use of data sources from the internet to extract knowledge about noisy activities that impact the population.

- Use of publicly available data to measure the effects of noise on the health of the population of large cities.

The degree of compliance with the objectives, as well as the conclusions derived from the experiments carried out to achieve them, is shown in the first section of this chapter.

The Contributions section provides a list of the contributions derived from the research activities. Subsequently, the Publications section details the dissemination actions carried out in the form of manuscripts in scientific journals, publications at congresses, dissemination activities, and collaborations related to the research topic. Finally, in the Future research section, the possible paths of continuation of the research begun in this doctoral thesis are introduced. 


\subsection{Conclusions}

Incorporation of ICTs into a new approach to noise pollution management in cities through an implementation that allows measuring the perception of noisy activities in urban environments.

For the fulfillment of the first general objective of this doctoral thesis, a study was carried out in the city of Malaga (Spain) to quantify the effect that the communication of noise pollution information has on the perception of annoyance associated with noise. The experiment focused on noise emissions produced by recreational activities since they are a problem of growing importance for urban managers in Southern European cities and one of the most important causes of disturbance for city residents. The research was done using an online survey-based methodology. First, a questionnaire was carried out to find out the population's noise annoyance before announcing the existence of a leisure noise monitoring campaign. Then, the project was disseminated and a platform for displaying acoustic information in real-time was made public. At the same time, another questionnaire was conducted to check whether there had been any changes in the annoyance that could be associated with the communication and dissemination of noise pollution information.

In terms of the methodology designed, it has been demonstrated that PRE-POST evaluation using online questionnaires is a valid system for measuring the variation in the annoyance generated by leisure activities before and after carrying out a series of actions that could modify the perception of a noisy activity.

This methodology has shown that the online platform for displaying noise data has not affected the annoyance associated with leisure noise. However, the results point in the direction that being aware of the existence of the monitoring network installed in Malaga increased the annoyance of citizens by 1.3 points. This increase in discomfort could be related to an increase in awareness of the noise problem, since by deploying a monitoring network the citizens could have perceived that noise levels were high enough to have to be controlled. On the other hand, given that the survey was freely accessible, the most affected people could have accessed the questionnaire more frequently, causing a general increase in annoyance that does not represent the overall population.

It was observed that the city's anti-noise associations spread the survey through their own communication channels, resulting in changes in the distribution of the sample between the initial survey (by invitation) and the final one (free access). This highlights the importance of exploring the public media in which online questionnaires are shared in order to control possible biases associated with the distribution of the sample.

In addition, it has been demonstrated that the population which belongs to these associations presents different patterns of annoyance from those of standard citizens, with a feeling of discomfort 1.5 points higher towards leisure noise. This highlights the need to include a question asking about this factor.

From the point of view of the survey dissemination and its relationship with participation, the objective of getting wide coverage of the project in the media has been achieved, although this did not translate into high participation rates on the surveys. Although leisure noise is an issue that both citizens and environmental managers recognized as one of the most disturbing sources in Malaga, the participation obtained did not meet the expectations. Despite this, the use of online surveys has proved to be a valid tool to increase participation, since the number of citizens who completed the questionnaire compared to other noise surveys previously conducted in the city through face-to-face interviews was increased by $40 \%$.

On the other hand, a completion rate of $80 \%$ was obtained in the questionnaires, well above the $50 \%$ reported in other investigations with online surveys, which verifies that the length of the survey developed was adequate. 
From the experimental design point of view, it has been observed that taking advantage of the media coverage during the project launch to announce the existence of the survey has not been the most optimal method for the experiment. Many people accessed the survey without having a reasonable time to explore the application of acoustic data visualization, so they had to be excluded from some of the analyses because they did not meet the requirements of the experiment. In future research, this must be taken into account to attain greater public participation, which is in itself already difficult to obtain.

\section{Use of data sources from the internet to extract knowledge about noisy activi- ties that impact the population.}

A methodology has been proposed to obtain, classify, and analyze texts for the purposes of investigating noisy activities coming from online social networks. By means of machine learning and natural language processing techniques, a detector and classifier of noise complaints written on the social media network Twitter was implemented. In addition, a method for the analysis of the complaints detected was proposed. This method allowed the detection of noisy events, to know the origin of the disturbing sound and predicting them some time in advance.

The investigation has confirmed that some in the public publish information about the noise sources that negatively affect them in alternative channels to official ones, such as online social networks, to express their discomfort. This information can be acquired through a search based on keywords and the APIs of some social networks, such as Twitter. This makes it possible to obtain a large amount of data for use in evaluating the level of annoyance social media users experience due to noisy activities.

Concerning data preparation, it has been demonstrated that the implemented text preprocessing method, in which slang and diminutive words are normalized and grammatical mistakes are corrected, is valid to increase the dimensionality of short texts. This has allowed a greater lexical richness in the content of the texts, facilitating the extraction of representative text features and thus improving the performance of the implemented classifiers.

Since it is the first time NLP techniques are being used in the detection of complaints about noise, a set of classes has been defined to use the texts coming from social networks in supervised machine learning algorithms. The process carried out to validate the defined classes, based on measuring the degree of agreement between different annotators, has allowed demonstrating that the created categories were correctly specified and that they can be used optimally in this type of classifier.

The combined use of textual features computed using NLP techniques, such as n-grams, morphosyntactic features, sentiment features, and embeddings, have been valid for training an automatic text classifier capable of detecting noise complaints, obtaining a performance similar to the shown in the state-of-the-art investigations. In addition, the expansion of the taxonomy developed in other investigations using semantic web technologies and lexicalhierarchical dictionaries has been proved to be an ideal method for the development of a system capable of classifying noise complaints by sound source according to the words present in them.

For the performance tests of the system, a methodology that implements stratified cross-validation techniques and weighting coefficients to each of the existing classes in the data has been proposed. This approach has managed the imbalance between the classes in the training data of the system. In addition, the fact that $85 \%$ of noise complaints have been correctly detected by the classifier and $86 \%$ of the complaints were adequately assigned to their sound categories demonstrates that the methodology implemented for the analysis of these texts is valid for obtaining information on the negative perception of 
noisy sources present in social networks.

Additionally, the use of the classifiers designed together with ARIMA intervention techniques makes it possible to detect time periods in which anomalous noise-related annoyance situations occur, as well as to know the general origin of these complaints.

The approach used sought to know the specific origin of the noisy event detected, based on the semantic analysis of complaints to know the frequency of use of words in the texts, has been tested as a valid method to know the specific sounds to which noise complaints detected during a noisy event refer to.

In addition, the use of statistical process control and time series analysis techniques has enabled the creation of an alarm system capable of detecting specific annoying sound events by counting the number of complaints and the presence of specific words.

The systems developed to fulfill the second objective of the doctoral thesis demonstrate that, indeed, information about noisy activities can be obtained from social networks. In addition, these tools are of interest for urban managers to detect problems related to noise in real time through the information that citizens share through online social networks. On the one hand, the alarm system could be trained to detect events related to recreational noise and detect non-compliance in the closing hours of nightclubs and pubs. In addition, the system for detecting sound events and the specific source of complaints could be used for rapid action in the face of acoustic situations that disturb citizens, and to measure the effectiveness of these actions based on the decrease in complaints published after they have been carried out.

\section{Use of publicly available data to measure the effects of noise on the health of the population of large cities.}

Technological development and the advancement of management policies have made it possible today to obtain a large number of different types of data in a public manner. Citizens, in addition to sharing texts about their attitudes toward noise in online social networks, share multimedia data that can provide information about the acoustic environment in a city. Furthermore, the growing importance of research that studies the effects of noise on human health has led to an experiment carried out in London to analyze the influence of different sound sources on public health.

The experiment has shown that in a large city, there are enough public data sources to carry out research that makes it possible to know if noise or the presence of specific sounds impacts the health of the urban population.

The methods implemented for estimating the percentage of the population exposed to different noise levels and evaluating the presence of sound sources in specific areas of a city have been proved valid to study the impacts of noise on the population's hypertension.

In addition, the results of the analysis done in this study have allowed to reach some conclusions:

- First, it should be noted that exposure to railway noise did not seem to have an effect on hypertension in any of the models calculated, despite the existence of previous studies showing the opposite. This could be because the level of spatial aggregation masked small areas where this sound source had a high impact, or because areas near railways were protected by acoustic screens that reduced the impact of noise on the resident population. Similarly, night-time noise levels have not been relevant, presumably because the percentage of the population exposed to noise in this time span was not high in each MSOA.

- Second, the results of the experiment suggest that socioeconomic factors are the main source of information when studying diseases at the MSOA level. Furthermore, 
although it is known that economic power affects the prevalence of hypertension, the study sheds light on the limits of traditional noise exposure models, which consider only means of transport to measure the effects of noise pollution on the well-being of citizens. In fact, the inclusion of variables that take into account a greater diversity of sound sources, both positive and negative, allows for a greater understanding of this disease when there is no possibility of knowing the exposure to noise in an area.

The results could lead to new methods of noise management and could be of interest to urban planning professionals. Since the results suggest that exposure to certain specific sound sources improves hypertension, the results open the door to new studies to measure in detail the impacts of these sounds on health in order to design acoustic environments in cities that are beneficial to the urban population. Furthermore, the usability and efficiency of social media platforms to measure the presence of sound sources has been demonstrated, which could complement the information given by the sensor networks with the capacity to detect sound sources in this type of study.

On the other hand, it has been shown that the importance of social media variables is boosted when studying the effect of noise on hypertension in some neighborhoods where traditional metrics, such as the percentage of people exposed to traffic noise, are unable to explain the disease due to a lower flow of vehicles or specific conditions of these areas, something that in the case of the experiment has occurred in the most wealthy neighborhoods of London. This is again of interest to urban planners, who could thoroughly study the sound environments in these upper-class neighborhoods and replicate them in other areas with the intention of improving the quality of life and health of the residents.

\subsection{Contributions}

The main contributions and tools resulting from this doctoral research are:

- A survey-based methodology has been described as one that allows for evaluating the impact of noise pollution data communication on citizens using ICTs exclusively, such as questionnaires and online visualization systems.

- A methodology has been described that allows the detection of complaints that citizens share about noisy activities in online social networks, as well as a system to classify them by the sound source to which they refer.

- A taxonomy and vocabulary of terms on sound sources has been developed, based on the results of a previous research study, in which the number of words associated with sound sources present in the vocabulary has been increased from 228 to 4506 terms, using lexicon-hierarchical databases and tools provided by semantic web technologies.

- The Noytext tool has been developed, which is a web application with the purpose of facilitating and accelerating the process of assigning classes to short text documents that will be used in text mining research applied to environmental acoustics and noise perception.

- The noise complaint detection and classification models have been incorporated into a proof-of-concept capable of monitoring social networks to automatically identify events that are annoying for citizens due to the noise they generate. Additionally, a system to infer the specific origin of the discomfort within the events detected by semantic analysis has been shown. 
- A methodology has been proposed for the creation of alarm systems capable of detecting specific activities that are annoying to the public because of their noise level, and that also has the potential to predict these situations. The system is built using statistical process control techniques and the time series of complaints detected.

- A methodology has been proposed to estimate the percentage of the population exposed to different noise levels in a specific area through the use of open data.

- The relationship between the presence of sound sources, other than the means of transport considered in the noise maps, with cardiovascular diseases associated with noise pollution such as hypertension has been verified. In addition, using data from social media to estimate the presence of these sound sources is a valid method for conducting studies of this nature in the future.

- Socioeconomic class analysis has shown that noise from traffic and trains in upperclass areas cannot explain the hypertension suffered by its residents. However, information on the presence of sound sources, taken from social media, such as mechanical noises, does explain it partially.

\subsection{Publications}

The results of the experiments and analyses carried out have been translated into a series of scientific contributions in journals, congresses, press and technical sessions.

\subsubsection{Papers in scientific journals}

The following papers have been published in scientific journals:

\begin{tabular}{|c|c|c|c|c|}
\hline Paper & WoS & JCR & Clasification & Status \\
\hline $\begin{array}{l}\text { Gasco, L.; Schifanella, R.; Aiello, L.; Asensio, C.; Quercia, D.; de Arcas, } \\
\text { G.; Social media and open data to quantify the effects of noise } \\
\text { on health }\end{array}$ & - & - & - & $\begin{array}{l}\text { In review } \\
\text { by the } \\
\text { authors }\end{array}$ \\
\hline $\begin{array}{l}\text { Asensio, C.; Gasco, L.; de Arcas, G.; López, J.M.; Alonso, J. As- } \\
\text { sessment of Residents Exposure to Leisure Noise in Málaga } \\
\text { (Spain). Environments } 2018,5 \text {, doi:10.3390/environments5120134. }\end{array}$ & Yes & No & - & Published \\
\hline $\begin{array}{l}\text { Gasco, L.; Clavel, C.; Asensio, C.; de Arcas, G. Beyond sound le- } \\
\text { vel monitoring: Exploitation of social media to gather citi- } \\
\text { zens subjective response to noise. Sci. Total Environ. 658, 6979, } \\
\text { doi:10.1016/j.scitotenv.2018.12.071. }\end{array}$ & Yes & Yes & $\begin{array}{l}2018 \text { Q1 "Environmental } \\
\text { Sciences" }(27 / 250)\end{array}$ & Published \\
\hline $\begin{array}{l}\text { Asensio, C.; Gasco, L.; de Arcas, G. A Review of Non-Acoustic } \\
\text { Measures to Handle Community Response to Noise around } \\
\text { Airports. Curr. Pollut. Reports } 2017,3,230244 \text {, doi:10.1007/s40726- } \\
017-0060-x \text {. }\end{array}$ & Yes & Yes & $\begin{array}{l}2018 \text { Q1 "Public, envi- } \\
\text { ronmental \& occupational } \\
\text { health" }(30 / 185)\end{array}$ & Published \\
\hline $\begin{array}{l}\text { Gasco, L.; Asensio, C.; de Arcas, G. Communicating airport noise } \\
\text { emission data to the general public. Sci. Total Environ. 2017, 586, } \\
\text { 836848, doi:10.1016/j.scitotenv.2017.02.063. }\end{array}$ & Yes & Yes & $\begin{array}{l}2017 \text { Q1 "Environmental } \\
\text { Sciences" }(27 / 242)\end{array}$ & Published \\
\hline
\end{tabular}

\subsubsection{Papers in conferences}

As a result of this doctoral thesis, the following conference papers have been published: 
Gasco, L, C Asensio, C Clavel, and G de Arcas (2019). Noytext: A Web platform to annotate social media documents on noise perception for their use in opinion mining research. In: InterNoise 2019 - 48th International Congress and Exposition on Noise Control Engineering

Gasco, L, C Clavel, C Asensio, and G de Arcas (2019). Evaluating noise perception through online social networks: A text mining approach to design a noise-event alarm system based on social media content. In: InterNoise 2019 - 48th International Congress and Exposition on Noise Control Engineering.

Gasco, L, C Asensio, and G de Argas (2017). Towards the assessment of community response to noise through social media. In: InterNoise 2017 - 46th International Congress and Exposition on Noise Control Engineering.

Asensio, C, G de Arcas, L Gasco, J Lopez, J Alonso, L Medina-Montoya, A Ruiz, and A Castillo Igartua (2016). Recreational Noise Assessment in Malaga (Spain). In: Proceedings of the 23erd International Congress on Sound and Vibration (ICSV 23).

\subsubsection{Scientific dissemination, posters and participation in technical sessions}

Throughout the doctoral thesis have been carried out activities such us interviews for the press, collaborations with other research groups, presentation of posters in research meetings, and participation in workshops with the aim of increasing the dissemination and impact of research results:

\begin{tabular}{lll}
\hline Title & Date & $\begin{array}{l}\text { Type of contribu- } \\
\text { tion }\end{array}$ \\
\hline $\begin{array}{l}\text { Interview for EFE Verde "Investigadores UPM analizan la contaminación } \\
\text { acústica a través de las redes sociales" }\end{array}$ & $05-04-2019$ & $\begin{array}{l}\text { Interview for a scienti- } \\
\text { fic dissemination press } \\
\text { article }\end{array}$ \\
\hline Press article "Cómo utilizar Twitter contra el ruido" in The Conversation & $03-04-2019$ & $\begin{array}{l}\text { Press article of scienti- } \\
\text { fic dissemination }\end{array}$ \\
\hline $\begin{array}{l}\text { Interview on the "Longitud de Onda" program of Radio Clásica (RTVE) } \\
\text { Interview for InnovaSpain "Las quejas en Twitter servirán para gestionar }\end{array}$ & $25-03-2019$ & Radio interview \\
eventos de contaminación acústica" & $\begin{array}{l}\text { Interview for a scienti- } \\
\text { fic dissemination press } \\
\text { article }\end{array}$ \\
\hline $\begin{array}{l}\text { Presentation "Beyond noise monitoring: assessment of community res- } \\
\text { ponse to noise issues through social media" in the EIT Digital Workshop } \\
\text { on Digital Cities Action Line }\end{array}$ & & $\begin{array}{l}\text { Presentation in techni- } \\
\text { cal session }\end{array}$ \\
$\begin{array}{l}\text { Invited speaker in the EIT Digital Cities } 2018 \text { summer school (Rennes, } \\
\text { Francia). Presentation: "Towards the assessment of community response } \\
\text { to environmental issues through social media". }\end{array}$ & & $\begin{array}{l}\text { Presentation in techni- } \\
\text { cal session }\end{array}$ \\
\hline $\begin{array}{l}\text { Elaboration of the ontology on acoustic pollution of the book "DATOS } \\
\text { ABIERTOS. Guía estratégica para su puesta en marcha. Conjuntos de } \\
\text { datos mínimos a publicar." }\end{array}$ & $05-2017$ & Collaboration \\
$\begin{array}{l}\text { Gasco, L.; Asensio, C.; de Arcas, G. "Noise data communication as a non- } \\
\text { acoustic factor for mitigating aviation noise". In: Industriales Research } \\
\text { Meeting 17 }\end{array}$ & $03-2017$ & Poster \\
$\begin{array}{l}\text { Asensio, C.; Gasco, L.; de Arcas, G. "Exploitation of ICTS for community } \\
\text { noise management". In: Industriales Research Meeting 16 }\end{array}$ & $03-2016$ & Poster \\
\hline
\end{tabular}

\subsection{Future research}

Throughout the development of this doctoral thesis, and while favorable results were obtained, future lines of investigation have appeared to continue with the research that could not be explored during the doctoral period and will become challenges for future 
research. These lines are focused on the use of natural language processing technologies in the field of acoustics and the use of open data to study the effects of noise:

\section{Future lines of research related to analyzing texts from social media:}

- Update the methodology with a deep learning approach: Since the methodology to analyze texts from OSN has been validated using mature machine learning algorithms, state-of-the-art technologies could be used to perform the same task. Deep learning techniques allow the automatic extraction of textual features and a higher performance compared to traditional machine learning algorithms (Araque et al. 2017). Specifically, Recurrent Neural Networks (RNN) have shown good performance in aspect-based opinion mining (Ma et al., 2018, Wang et al., 2016), so they could be used to classify tweets in each noise category and extract the most relevant aspects of each complaint instead of using lexicon-based algorithms. On the other hand, convolutional neural networks (CNNs) have proven useful for classifying the sentiment of short texts (Severyn y Moschitti, 2015), although they have the problem of needing large databases tagged to achieve representative results.

- Location identification: The methodology developed has not taken into account the detection of the place where the noise complaints are taking place. In future updates of the methodology, a location detector could be added to detect the places that people are complaining about ni their tweets, and thus obtain more accurate information about where the event is generating annoyance.

- Noise annoyance levels: The implemented classifier only differenciates between negative and positive sentiment texts. However, it might be possible to extend the functionalities of the system to differentiate between several levels of annoyance, and to provide more precise information to managers on citizen perception so that they prioritize actions towards the most annoying situations.

- Development of tools to facilitate research in this field: Natural language processing techniques had not been used previously to detect attitudes towards noise on the population. Since it is a new technology in the field of environmental acoustics, there are no tools adapted to the needs of this field, and therefore researchers interested in this topic could go back in their application. For this reason, it is convenient to develop tools for professionals in environmental acoustics to facilitate the research in this field. For example, it is necessary to create standardized databases that allow for evaluating the effectiveness of complaint detection models, so that future models developed can be intercompared, or even tools similar to Noytext, developed in this doctoral research, are needed to be facilitated to accelerate the achievement of results.

- Adaptation of the methodology to analyze other data sources: Twitter is not the only social network from which information about noise perception can be extracted. It was chosen because it facilitated the obtaining of necessary data to develop the algorithms, and there was a multitude of bibliography related to the analysis of texts of this social network. There are many other sources of textual data that can be explored, such as platforms for sharing opinions about restaurants, hotels, and public places. It would be necessary to adapt the methodology presented in the thesis to texts of greater length since the possibilities of analysis of this type of texts are different from those of short texts. In addition, many of these data sources provide information about the location, which would open the door to detecting acoustic black spots (areas in a city with important problems related to noise annoyance) in urban environments based on social network data. 
- Adaptation of the methodology to other fields of environmental acoustics: The methodology introduced could be adapted to other fields in which citizen participation is needed. For example, in the field of soundscapes, soundwalks are carried out to know the subjective perception of sounds in a city. The information obtained in these soundwalks could be complemented and validated with information from social networks, in which people express how pleasant a place has been for them, also taking into account the sound environment they experienced.

Future research lines in relation to the use of public data to study the effects of noise on the urban population:

- Verification and improvement of the method to estimate population exposure: A method to estimate the percentage of population exposed in areas of a city has been shown. For this reason, there is a work path to improve and validate the methodology applied in which different factors are considered, such as urban geometry or the distribution of the inhabitants within the calculation area.

- Extension of results to other diseases associated with noise: In the same way that a study of the prevalence of hypertension has been carried out, this type of analysis could be extended to other diseases associated with noise such as insomnia or anxiety. For these analyses, it would be necessary to investigate the additional variables that could have an influence on the problem and propose a methodology for their calculation.

- Incorporation of alternative variables that explain diseases: In the experiment, Flickr information was used to infer the sound sources of a region. However, it would be possible to apply other data sources, such as the opinions about public spaces from the web, to estimate the discomfort generated by different sound sources and incorporate them into the study of noise diseases. 



\section{Bibliografía}

Accordino, F. The futurium - a foresight platform for evidence-based and participatory policymaking. Philosophy É Technology, vol. 26(3), páginas 321-332, 2013. ISSN 22105441.

Acoucité. Acoucité - Réseau permanent de mesure. http://www.acoucite.org/ observatoire/reseau-de-mesures/reseau-permanent-de-mesure/, 2019. Accessed: 2019-05-10.

AENA. Actualización de los Mapas Estratégicos de ruido de los grandes aeropuertos. Aeropuerto de Madrid-Barajas. Informe técnico, Aeropuertos Españoles y Navegación Aérea, 2008.

AENA. Aeropuerto Adolfo Suárez Madrid-Barajas Bruel \& Kjaer webtrack. http:// webtrak5.bksv.com/mad5, 2016. Accessed: 2016-07-13.

Aéroport International De Genève. GVA Environnement - Information environnementale destinée aus riverains de lÁéroport International de Genève. Les trajectoires aériennes. Automne 2005. Informe técnico, Aéroport International de Genève, 2005.

Aeropuerto Adolfo Suárez Madrid-Barajas. Informe mensual acústica - Marzo 2016. Informe técnico, AENA, Madrid, 2016.

Aiello, L. M., Schifanella, R., Quercia, D. y Aletta, F. Chatty maps: constructing sound maps of urban areas from social media data. Royal Society Open Science, vol. 3(3), página 150690, 2016. ISSN 2054-5703.

AIrbus. Getting to Grips with Aircraft Noise. Informe técnico, Airbus, 2003.

Airservices Australia. Noise and Flight Path Monitoring System - Sydney Quartely Report - October-December 2013. Informe técnico, Airservices Australia, 2014a.

Airservices Australia. Short Term Monitoring Program-Fingal Head, NSW. Informe técnico, Airservices Australia, 2014b.

Airservices Australia. Sydney Basin - Aircraft Noise Information Report- Quarter 3 2014 ( July to September ). Informe técnico, Airservices Australia, 2014c.

Airservices Australia. Sydney Airport and Associated Airspace Long Term Operating Plan. Informe técnico, Airservices Australia, 2018.

Ajuntament de Barcelona. Decidim Barcelona. https://www.decidim.barcelona/, 2018a. Accessed: 2018-12-20.

Ajuntament De Barcelona. Open data ben. http://opendata-ajuntament. barcelona.cat/es/, 2018b. Accessed: 2018-12-20. 
Ajuntament DE Barcelona. Sentilo BCN. https://connecta.bcn.cat/ connecta-catalog-web/component/map, 2019. Accessed: 2019-05-10.

Ajuntament De Palència. Portal de Transparencia y Datos Abiertos. http://gobiernoabierto.valencia.es/es/dataset/?id= datos-diarios-ultimo-mes-estaciones-ruido, 2019. Accessed: 2019-05-14.

Aletta, F., Oberman, T. y Kang, J. Positive health-related effects of perceiving urban soundscapes: a systematic review. The Lancet, vol. 392, 2018. ISSN 0140-6736.

Alfarrarjeh, A., Agrawal, S., Kim, S. H. y Shahabi, C. Geo-Spatial Multimedia Sentiment Analysis in Disasters. En 2017 IEEE International Conference on Data Science and Advanced Analytics (DSAA), páginas 193-202. 2017.

do Amaral, M. A. S., Neto, M. G., De Queiroz, J. G., Martins-Filho, P. R. S., Saquetto, M. B. y Carvalho, V. O. Effect of music therapy on blood pressure of individuals with hypertension: A systematic review and meta-analysis. International journal of cardiology, vol. 214, páginas 461-464, 2016.

Amsterdam Airport Schiphol. Schipol NOMOS website. http://noiselab.casper. aero/ams/\{\#\}page=home, 2016. Accessed: 2016-07-13.

Andersson, R. y Turner, L. M. Segregation, gentrification, and residualisation: from public housing to market-driven housing allocation in inner city Stockholm. International Journal of Housing Policy, vol. 14(1), páginas 3-29, 2014.

Araque, O., Corcuera-Platas, I., Sánchez-Rada, J. F. y Iglesias, C. A. Enhancing deep learning sentiment analysis with ensemble techniques in social applications. Expert Systems with Applications, vol. 77, páginas 236-246, 2017. ISSN 0957-4174.

Ardura, A., Lorente-Riverola, I. y Ruiz", J. P2P Tourism and Gentrification in Madrid. 2019. Working paper.

Arntzen, M. y Simons, D. G. Modeling and synthesis of aircraft flyover noise. 2014.

Artstein, R. Inter-annotator Agreement. En Handbook of Linguistic Annotation (editado por N. Ide y J. Pustejovsky), páginas 297-313. Springer Netherlands, Dordrecht, 2017. ISBN 978-94-024-0881-2.

Asensio, C. Air transport noise. Applied Acoustics, vol. 84, páginas 1-2, 2014.

Asensio, C., De Arcas, G., López, J. M., Pavón, I. y Gascó, L. Awareness: A parallel approach against noise. En 22nd International Congress on Sound and Vibration, ICSV. 2015 .

Asensio, C., Recuero, M. y Pavón, I. Citizens'perception of the efficacy of airport noise insulation programmes in Spain. Applied Acoustics, vol. 84, páginas 107-115, 2014.

Aumond, P., Can, A., Mallet, V., De Coensel, B., Ribeiro, C., Botteldooren, D. y LAVANDier, C. Acoustic mapping based on measurements: space and time interpolation. En INTER-NOISE and NOISE-CON Congress and Conference Proceedings, vol. 255-5, páginas 2287-2298. Institute of Noise Control Engineering, 2017.

Aumond, P., Jacquesson, L. y CAn, A. Probabilistic modeling framework for multisource sound mapping. Applied Acoustics, vol. 139, páginas $34-43,2018$. ISSN 0003-682X. 
Axelsson, A. Leisure noise exposure in adolescents and young adults. Journal of Sound and Vibration, vol. 151(3), páginas 447-453, 1991.

Ayuntamiento de Cáceres. Open data Cáceres. http://opendata.ayto-caceres. es/dataset/medicion-ruidos-caceres, 2019. Accessed: 2019-05-14.

Ayuntamiento de Madrid. Mapa Estratégico de Ruido de la Ciudad de Madrid 2016. Informe técnico, Ayuntamiento de Madrid, 2016.

Ayuntamiento De Madrid. Datos abiertos madrid. https://datos.madrid.es/ portal/site/egob, 2018a. Accessed: 2018-12-20.

Ayuntamiento De Madrid. Decide Madrid. https://decide.madrid.es/, 2018b. Accessed: 2018-12-20.

Ayuntamiento de Málaga. Observatorio Turístico de la ciudad de Málaga 2009. Informe técnico, Ayuntamiento de Málaga, 2009.

Ayuntamiento de Málaga. Análisis de la población en el ámbito del PePRI Centro. Ayuntamiento de Málaga. Informe técnico, Ayuntamiento de Málaga, 2010.

Ayuntamiento de Málaga. Mapa de Trabajo Social de Málaga 2012. Volumen 1. Distrito Málaga Centro. Informe técnico, Ayuntamiento de Málaga, 2012a.

Ayuntamiento de Málaga. Mapa de Trabajo Social de Málaga 2012. Volumen 11. Distrito Teatinos-Universidad. Informe técnico, Ayuntamiento de Málaga, 2012b.

Ayuntamiento de Málaga. Observatorio Turístico de la ciudad de Málaga Noviembre 2014-Octubre 2015. Informe técnico, Ayuntamiento de Málaga, 2015.

Ayuntamiento de Málaga. Datos abiertos Málaga. https://datosabiertos.malaga. eu/dataset/monitorizacion-de-ruido-de-ocio, 2019. Accessed: 2019-05-14.

Ayuntamiento de Santander. Santander datos abiertos. http://datos.santander. es/dataset/?id=sensores-ambientales, 2019. Accessed: 2019-05-14.

Ayuntamiento de Zaragoza. Catálogo de datos abiertos. https://www.zaragoza. es/sede/portal/datos-abiertos/, 2018a. Accessed: 2018-12-20.

Ayuntamiento de Zaragoza. Participación y Colaboracion. Gobierno Abierto de Zaragoza. https://www.zaragoza.es/sede/portal/participacion/, 2018b. Accessed: 2018-12-20.

Babisch, W., Houthuijs, D., Perhhagen, G., Cadum, E., Katsouyanni, K., Velonakis, M., Dudley, M.-L., Marohn, H.-D., Swart, W., Breugelmans, O., Bluhm, G., Selander, J., Vigna-Taglianti, F., Pisani, S., Haralabidis, A., Dimakopoulou, K., Zachos, I. y JÄrup, L. Annoyance due to aircraft noise has increased over the years?results of the hyena study. Environment International, vol. 35(8), páginas 1169 - 1176, 2009. ISSN 0160-4120.

Ballesteros, M. J. Análisis del ruido de ocio, propuesta de procedimientos y herramientas de gestión. Tesis Doctoral, Universidad Politécnica de Madrid, 2014.

Ballesteros, M. J., Fernández, M. D. y Ballesteros, J. A. Acoustic evaluation of leisure events in two mediterranean cities. Applied Acoustics, vol. 89, páginas 288-296, 2015 . 
Ballesteros, M. J., Fernández, M. D., Flindell, I., Torija, A. J. y BallesteRos, J. A. Estimating leisure noise in Spanish cities. Applied Acoustics, vol. 86, páginas $17-24,2014$.

BANisAR, D. Freedom of information around the world 2006: A global survey of access to government information laws. Privacy International, 2006.

Barregard, L., Bonde, E. y Öhrström, E. Risk of hypertension from exposure to road traffic noise in a population-based sample. Occupational and Environmental Medicine, vol. 66(6), páginas 410-415, 2009. ISSN 1351-0711.

Bartels, S and Marki, F and Muller, U . The influence of acoustical and nonacoustical factors on short-term annoyance due to aircraft noise in the field The COSMA study. Science of The Total Environment, vol. 538, páginas 834-843, 2015.

Barthelemy, M. A global take on congestion in urban areas. Environment and Planning B: Planning and Design, vol. 43(5), páginas 800-804, 2016.

Beach, E. F. Leisure Noise and Hearing. Seminars in Hearing, vol. 38(4), páginas 263-265, 2017.

Bello, J. P., Silva, C., Nov, O., Dubois, R. L., Arora, A., Salamon, J., Mydlarz, C. y Doraiswamy, H. Sonyc: A system for monitoring, analyzing, and mitigating urban noise pollution. Commun. ACM, vol. 62(2), páginas 68-77, 2019. ISSN 0001-0782.

Belluci, P., Peruzzi, L. y Nencini, L. LIFE DYNAMAP: accuracy, reliability and sustainability of dynamic noise maps. En Proceedings of the INTER-NOISE 2019 - 48th International Congress and Exposition on Noise Control Engineering: Noise control for a better environment. 2019.

Belojević, G. A., Jakovluević, B. D., Stojanov, V. J., Slepčevic, V. Ž. y PaunoVIĆ, K. Ž. Nighttime road-traffic noise and arterial hypertension in an urban population. Hypertension research, vol. 31(4), página 775, 2008.

Benocci, R. y Roman H, E. Optimization of Dynamap noise mapping predictive scheme in Milan urban area. En Proceedings of the INTER-NOISE 2019 - 48th International Congress and Exposition on Noise Control Engineering: Noise control for a better environment. 2019.

Beutel, M. E., Jünger, C., Klein, E. M., Wild, P., Lackner, K., Blettner, M., Binder, H., Michal, M., Wiltink, J., BrÄhler, E. y Münzel, T. Noise annoyance is associated with depression and anxiety in the general population- the contribution of aircraft noise. PLOS ONE, vol. 11(5), páginas 1-10, 2016.

Bluhm, G., Nordling, E., Berglind, N. et Al. Road traffic noise and annoyance-an increasing environmental health problem. Noise and Health, vol. 6(24), página 43, 2004.

Bodin, T., Albin, M., Ardö, J., Stroh, E., Östergren, P.-O. y Buörk, J. Road traffic noise and hypertension: results from a cross-sectional public health survey in Southern Sweden. Environmental Health, vol. 8(1), página 38, 2009. ISSN 1476-069X.

Brooker, P. Do people react more strongly to aircraft noise today than in the past? Applied Acoustics, vol. 70(5), páginas 747-752, 2009.

Brooker, P., Critchley, J., Monkman, D. y Richmond, C. DC Report 8402 United Kingdom Aircraf Noise Index Study: main report. Informe técnico, Civil Aviation Authority, 1985. 
Bruitparif. Methodological Guide. Use of tools developed in the Life Harmonica project. Informe técnico, Bruitparif, 2016.

BRUitPARIF. BruitParif - Site Rumeur 2.0. https://rumeur.bruitparif.fr/, 2019a. Accessed: 2019-05-10.

BruttParif. Cartes du bruit des transports Paris. https://carto.bruitparif.fr/, 2019b. Accessed:2019-01-09.

Brussels airport. Custom Noise Measurement Report 1/10/2015-26/10/2015. Informe técnico, Brussels airport, 2015.

Brussels AIRPORT. Brussels airport - Noise reporting. http://www.brusselsairport. be/en/env/noisemonitoring/, 2016. Accessed: 2016-07-13.

Buscaldi, D. y Villetaneuse, F. Sentiment Analysis on Microblogs for Natural Disasters Management : A Study on the 2014 Genoa Floodings. En Proceedings of the 24th International Conference on World Wide Web, páginas 1185-1188. 2015. ISBN 9781450334730.

Butterfield, D. Research Report RR517 - Measurement of noise levels that staff are exposed to at live music events. Health and Safety Executive 2006, 2006.

Cambridge Dictionary Online. "noise". 2018.

CANSO. Managing the Impacts of Aviation Noise. A Guide for Airport Operators and Air Navigation Service Providers. Informe técnico, Civil Air Navigation Services Organisation - Airports Council International, 2015.

Carletta, J. Assessing agreement on classification tasks: the kappa statistic. Computational linguistics, vol. 22(2), páginas 249-254, 1996.

Charras, F., Duplessis, G. D., Letard, V., Ligozat, A.-L. y Rosset, S. Comparing System-response Retrieval Models for Open-domain and Casual Conversational Agent. En WOCHAT workshop, IVA. 2016.

Chichgo Department of Aviation. Airport Noise Management System - March 2016 Monthly Report. Informe técnico, Chicago Department of Aviation, 2016a.

Chichgo Department of Aviation. Single Event Noise Data in O'Hare Airport. http://www.flychicago.com/OHare/EN/AboutUs/NoiseManagement/Pages/ SingleEventNoiseData.aspx, 2016b. Accessed: 2016-05-09.

CHIPI. Aplicación Chipi para smartphones. https://itunes.apple.com/es/app/ chipi-mytaxi-uber-cabify-car2go-o-emov/id1209038905?mt=8, 2019. Accessed: 2019-05-14.

CLEANSpot. Aplicación cleanSpot para smartphones. http://cleanspotapp.com/, 2019. Accessed: 2019-05-14.

Cordis EuROPE. DIAPASON Project website. https://cordis.europa.eu/project/ rcn/39396/factsheet/es, 2019a. Accessed: 2019-05-10.

CORDIS EUROPE. EAR-IT project website. https://cordis.europa.eu/project/rcn/ 105468/factsheet/en 2019b. Accessed: 2019-05-08.

Cordis Europe. URBIS Project website. https://cordis.europa.eu/project/rcn/ 39240/factsheet/en, 2019c. Accessed: 2019-05-10. 
Critchley, J. B. y Ollerhead, J. B. DORA Report 9023 - The Use of Leq as an Aircraft Noise Index. Informe técnico, Civil Aviation Authority, 1990.

Dalton, D. S., Cruickshanks, K. J., Wiley, T. L., Klein, B. E. K., Klein, R. y Tweed, T. S. Association of Leisure-Time Noise Exposure and Hearing Loss. Audiology: Journal of Auditory Communication, vol. 40(1), páginas 1-9, 2001.

Davidson, S. Spinning the wheel of empowerment. Community Planning, vol. 1262(3), páginas $14-15,1998$.

DBPeDiA. Use cases DBPedia: Multi-domain ontology. 2015.

De Coensel, B., Sun, K., Wei, W., Van Renterghem, T., Sineau, M., Ribeiro, C., Can, A., Aumond, P., Lavandier, C. y Botteldooren, D. Dynamic noise mapping based on fixed and mobile sound measurements. En 10th European Congress and Exposition on Noise Control Engineering (Euronoise 2015), páginas 2339-2344. 2015 .

DEFRA. National Noise Attitude Survey 2012 (NNAS2012). Summary Report. Informe técnico, Department for Environment, Food and Rural Affairs., 2014.

Dehnert, K., Raab, U., Perez-Alvarez, C., Steffens, T., Bolte, G., Fromme, H. y Twardella, D. Total leisure noise exposure and its association with hearing loss among adolescents. International Journal of Audiology, vol. 54(10), páginas 665-673, 2015 .

Dembczynski, K., Waegeman, W., Cheng, W. y Hüllermeier, E. Regret Analysis for Performance Metrics in Multi-Label Classification : The Case of Hamming and Subset Zero-One Loss. En European Conference on Machine Learning and Principles and Practice of Knowledge Discovery in Databases (ECML PKDD) 2010, páginas 280-295. 2010.

Derczynski, L., Maynard, D., Rizzo, G., van Erp, M., Gorrell, G., Troncy, R., Petrak, J. y Bontcheva, K. Analysis of named entity recognition and linking for tweets. Information Processing \& Management, vol. 51(2), páginas 32-49, 2015. ISSN 0306-4573.

DonDenegocios Geomarketing. Comercio y Hostelería en el Centro de Málaga 20012017. Informe técnico, Agencia de geomarketing DonDeNegocios, 2017.

Dratva, J., Phuleria, H. C., Foraster, M., Gaspoz, J.-M., Keidel, D., Künzli, N., Liu, L.-J. S., Pons, M., Zemp, E., Gerbase, M. W. Et Al. Transportation noise and blood pressure in a population-based sample of adults. Environmental health perspectives, vol. 120(1), páginas 50-55, 2011.

DynamaP. DYNAMAP Website. http://www.life-dynamap.eu/, 2019. Accessed: 201905-08.

EAGAN, M. E. Using supplemental metrics to communicate aircraft noise effects. Informe técnico, Harris Miller Miller Hanson Inc., 2007.

EBM DataLab. OpenPrescribing.net, EBM DataLab, University of Oxford. https: //openprescribing.net/bnf/, 2017. Accessed: 2018-11-26.

Esuli, A. y Sebastiani, F. SentiWordNet : A Publicly Available Lexical Resource for Opinion Mining. En In Proceedings of the 5th Conference on Language Resources and Evaluation (LREC'06), páginas 417-422. 2006. 
Eurocontrol. Specification for Collaborative Environmental Management (CEM). Informe técnico, Eurocontrol, 2013.

EUROCONTROL. Low-cost aviation infographic. https://www.eurocontrol.int/sites/ default/files/infographics/file/low-cost-aviation-infographic-2016.pdf, 2016. Accessed: 2018-12-19.

European Aviation Safety Agency. European aviation environmental report 2016. Informe Técnico 2016, European Aviation Safety Agency, 2016.

European Commission. Future Noise Policy. European commission Green Paper. Office for Official Publications of the European Communities, Luxembourg, 1996. ISBN 9278107301.

European Commission. Libro Blanco sobre la gobernanza. Office for Official Publications of the European Communities, Luxembourg, 2001.

European Commission. White paper on transport : roadmap to a single European transport area : towards a competitive and resource-efficient transport system. Office for Official Publications of the European Communities, Luxembourg, 2011.

European Commission. Eurostat - transport data main tables. https://ec.europa. eu/eurostat/web/transport/data/main-tables, 2018. Accessed: 2018-12-17.

European Environment Agency. Noise in Europe 2014. 10/2014. Publications Office of the European Union, Luxembourg, 2014. ISBN 9789292135058.

European Environment Agency. NOISE - Noise Observation and Information Service for Europe. http://noise.eionet.europa.eu/viewer.html, 2016. Accessed:2016-0503.

European Parliament. Directive 2002/49/EC relating to the assessment and management of environmental noise. 2002.

European Parliament. Directive 2003/4/EC on public access to environmental information. 2003.

European Union. Portal de datos abiertos de la UE. https://data.europa.eu/euodp/ es/data/, 2019. Accessed: 2019-05-14.

Evandt, J., Oftedal, B., Huertager Krog, N., Nafstad, P., Schwarze, P. E. y Marit Aasvang, G. A Population-Based Study on Nighttime Road Traffic Noise and Insomnia. Sleep, vol. 40(2), 2017.

FAn, W. y YAN, Z. Factors affecting response rates of the web survey: A systematic review. Computers in Human Behavior, vol. 26(2), páginas 132 - 139, 2010. ISSN 0747-5632.

Fawcett, T. An introduction to ROC analysis. Pattern Recognition Letters, vol. 27(8), páginas 861-874, 2006. ISSN 0167-8655.

Federal Aviation Administration. FAR Part 150 - Airport Noise Compatibility Planning. 1982.

Federal Aviation Administration. AC 150/5020-1 - Noise Control and Compatibility Planning For Airports. 1983. 
Federal Aviation Administration. Community involvement manual. The Office of Environment and Energy, Washington, D.C., 2016.

Fiamini, F. y Luzzi, S. Monitoring and reducing noise related to Movida: real cases and smart solutions. En 22nd International Congress on Sound and Vibration 2015 (ICSV 22), páginas 1959-1965. 2015. ISBN 978-1-5108-0903-1.

Fidell, S., Barber, D. S. y Schultz, T. J. Updating a dosage-effect relationship for the prevalence of annoyance due to general transportation noise. The Journal of the Acoustical Society of America, vol. 89(1), páginas 221-233, 1991.

Fidell, S., Silvati, L. y Haboly, E. Social survey of community response to a step change in aircraft noise exposure. The Journal of the Acoustical Society of America, vol. 111(1), páginas 200-209, 2002.

FIELDS, J. M. A review of an updated synthesis of noise/annoyance relationships. Informe técnico, Georgia Institute of Technology, 1994.

Fields, J. M. An updated catalog of 360 social surveys of residents reactions to environmental noise (1943-1993). Atlanta, GA: Georgia Institute of Technology, páginas 1943-1993, 1999.

Finavia. Annual Report 2014 - Environment. Informe técnico, Finavia, 2014.

Finegold, L. S., Harris, C. S. y Vongierke, H. E. Community Annoyance and Sleep Disturbance - Updated Criteria for Assessing the Impacts of General Transportation Noise on People. Noise Control Engineering Journal, vol. 42(1), páginas 25-30, 1994.

Florida, R. The New Urban Crisis: Gentrification, housing bubbles, growing inequality, and what we can do about it. Oneworld Publications, 2017. ISBN 1786072122.

Flughafen München. München Airport WebTrack. https://travis-web01. munich-airport.de/data/travis.php?lang=en, 2016. Accessed: 2016-07-13.

Forum Flughafen \& Region. INAA Fluglärm-Monitoring tool. http://www. forum-flughafen-region.de/startseite/, 2016. Accessed: 2016-07-13.

Forum Mediation. The mediation process at Vienna International Airport - an overview. Informe técnico, Vienna Airport Dialogue Forum Association, 2005.

FRAPORT. Frankfurt Airport webtrack. http://franom.fraport.de/franom.php, 2016. Accessed: 2016-07-13.

Gajardo, C. P., Morillas, J. M. B., Escobar, V. G., Vílchez-Gómez, R. y GoZALO, G. R. Effects of singular noisy events on long-term environmental noise measurements. Polish Journal of Environmental Studies, vol. 23(6), páginas 2007-2017, 2014.

Galt, R. H. Results of noise surveys part i. noise out-of-doors. The Journal of the Acoustical Society of America, vol. 2(1), páginas 30-58, 1930.

Garg, N., Sinha, A. K., Gandhi, V., Bhardwaj, R. M. y Akolkar, A. B. A pilot study on the establishment of national ambient noise monitoring network across the major cities of India. Applied Acoustics, vol. 103, Part, páginas 20-29, 2016.

Gasco, L., Asensio, C. y De Arcas, G. Towards the assessment of community response to noise through social media. En INTER-NOISE 2017 - 46th International Congress and Exposition on Noise Control Engineering: Taming Noise and Moving Quiet. 2017. 
Gatwick Airport. Gatwick Airport - Flight Performance Report - Q4 2015. Informe técnico, Gatwick Airport, 2015.

Gatwick AirPorT. Gatwick NoiseLab. http://noiselab.casper.aero/lgw/ $\{\#\}$ page $=$ flight\{_\}tracker, 2016. Accessed: 2016-07-13.

Gille, L.-A., Marquis-Favre, C. y Weber, R. Aircraft noise annoyance modeling: Consideration of noise sensitivity and of different annoying acoustical characteristics. Applied Acoustics, vol. 115, páginas 139-149, 2017.

Gilliver, M., Beach, E. F. y Williams, W. Changing beliefs about leisure noise: Using health promotion models to investigate young people's engagement with, and attitudes towards, hearing health. International Journal of Audiology, vol. 54(4), páginas 211-219, 2015 .

Gimpel, K., Schneider, N., Connor, B. O., Das, D., Mills, D., Eisenstein, J., Heilman, M., Yogatama, D., Flanigan, J. y Smith, N. A. Part-of-Speech Tagging for Twitter : Annotation, Features, and Experiments. En Proceedings of the 49th Annual Meeting of the Association for Computational Linguistics:shortpaper, páginas 42-47. 2011.

Gobierno De España. Sede electrónica del catastro. http://www.sedecatastro.gob. es/ 2015. Accessed:2019-06-10.

Gobierno de España. Portal de datos abiertos de España. https://datos.gob.es/es, 2019a. Accessed: 2019-05-14.

Gobierno de España. Web del Sistema de Información sobre Contaminación Acústica (SICA). http://sicaweb.cedex.es/mapas-intro.php 2019b. Accessed: 2019-05-13.

GoldschagG, P. L. Using supplemental aircraft noise information to assist airport neighbours understand aircraft noise. Transportation Research Part D: Transport and Environment, vol. 21, páginas 14-18, 2013.

Griefahn, B., Bolin, K., Flindell, I. y Lambert, J. Moderators that influence annoyance of residents near 6 European airports. En INTER-NOISE 2013 - 42nd International Congress and Exposition on Noise Control Engineering: Noise Control for Quality of Life. 2013.

Gulllaume, G., Can, A., Petit, G., Fortin, N., Palominos, S., Gauvreau, B., Bocher, E. y Picaut, J. Noise mapping based on participative measurements. Noise Mapping, vol. 3(1), 2016.

Guski, R., Felscher-Suhr, U. y Schuemer, R. The concept of noise annoyance: how international experts see it. Journal of sound and vibration, vol. 223(4), páginas 513-527, 1999.

Gutiérrez, A. El centro histórico de Málaga: Perspectiva de su recuperación. VIVA LA CALLE las actuaciones de revitalización del centro histórico de Málaga desde 1994 a 2005. Ayuntamiento de Málaga, 2005.

Halonen, J. I., Vahtera, J., Stansfeld, S., Yli-Tuomi, T., Salo, P., Pentti, J., KIVIMÄKI, M. y LANKI, T. Associations between nighttime traffic noise and sleep: the finnish public sector study. Environmental Health Perspectives, vol. 120(10), página 1391, 2012. 
Han, B., Cook, P. y Baldwin, T. Automatically Constructing a Normalisation Dictionary for Microblogs. En Proceedings of the 2012 Joint Conference on Empirical Methods in Natural Language Processing and Computational Natural Language Learning, EMNLP-CoNLL '12, páginas 421-432. Association for Computational Linguistics, Stroudsburg, PA, USA, 2012.

Han, B., Cook, P. y BAldwin, T. Lexical Normalization for Social Media Text. ACM Transactions on Intelligent Systems and Technology, vol. 4(1), 2013. ISSN 2157-6904.

Haveloc, P. y Jones, K. ECDR Report 1104.Environmental metrics for FAS. Informe técnico, Civil Aviation Authority, 2011.

Hayes, S. N. y Taler, S. J. Hypertension in women: Current understanding of gender differences. Mayo Clinic Proceedings, vol. 73(2), páginas 157 - 165, 1998. ISSN 00256196.

Heathrow Airport. Heathrow Community Noise and Track-keeping Report: Teddington. Informe técnico, Heathrow Airport, 2013.

Heathrow Airport. Complaints Report Period From 01/01/2015 to 31/3/2015. Informe Técnico March, Heathrow Airport, 2015.

Hoeger, R., Schreckenberg, D., Felscher-Suhr, U. y Griefahn, B. Night-time noise annoyance: state of the art. Noise and Health, 2002.

Hofmann, H. Individual Rights and Information in EU Public Law. Transparency in the future-Swedish openness 250 years, 2017.

Hooper, P. y Flindell, I. Exchanging aircraft noise information with local communities around airports: the devil is in the detail! En INTER-NOISE 2013 - 42nd International Congress and Exposition on Noise Control Engineering: Noise Control for Quality of Life. 2013.

Hooper, P., Maughan, J., Flindell, I. y Hume, K. OMEga Community Noise Study - Indices to enhance understanding \& management of community responses to aircraf noise exposure. Informe técnico, Manchester Metropolitan University \& University of Southampton, 2009.

Hume, K., Morley, H. y Thomas, C. Review of complaints and social surveys at Manchester Airport. Project: Attitudes To Aircraft Annoyance Around Airports. Informe técnico, Eurocontrol, 2004.

ICAO. ICAO Environmental Report 2016. Aviation and Climate Change. Informe técnico, International Civil Aviation Organization, 2016.

ICAO. Circular 351-Circular for Community Engagement for Aviation Environmental Management. Informe técnico, International Civil Aviation Organization, 2017.

International Organization for Standardization. ISO 1996-2:2007 Acoustics Description, measurement and assessment of environmental noise - Part 2: Determination of environmental noise levels. 2007a.

International Organization for Standardization. ISO 80000-8:2007 Quantities and units - Part 8: Acoustics. 2007b.

International Organization for Standardization. ISO 20906:2009 Acoustics Unattended monitoring of aircraft sound in the vicinity of airports. 2009. 
International Organization for Standardization. ISO 1996-1:2016 Acoustics - Description, measurement and assessment of environmental noise - Part 1: Basic quantities and assessment procedures. 2016.

JiAng, W., WAng, Y., Tsou, M. H. y Fu, X. Using social media to detect outdoor air pollution and monitor air quality index (AQI): A geo-targeted spatiotemporal analysis framework with sina weibo (Chinese twitter). PLoS ONE, vol. 10(10), páginas 1-18, 2015. ISSN 19326203.

JianqIang, Z. Pre-processing Boosting Twitter Sentiment Analysis? En IEEE International Conference on Smart City/SocialCom/SustainCom, páginas 748-753. 2015. ISBN 9781509018932.

Jones, K. y CADoux, R. ERCD Report 0904 Metrics for Aircraft Noise. Informe técnico, Civil Aviation Authority, 2009.

Kageyama, T., Kabuto, M., Nitta, N., Kurokawa, Y., Taira, K., Suzuki, S. y TAKemoto, T. A cross-sectional study on insomnia among japanese adult women in relation to night-time road traffic noise. Journal of Sound and Vibration, vol. 205(4), páginas 387 - 391, 1997. ISSN 0022-460X.

Kaplan, M. S., Huguet, N., Feeny, D. H. y McFarland, B. H. Self-reported hypertension prevalence and income among older adults in canada and the united states. Social Science ES Medicine, vol. 70(6), páginas 844 - 849, 2010. ISSN 0277-9536.

Keenan, N. L., Rosendorf, K. A., for Disease Control, C., (CDC), P. et AL. Prevalence of hypertension and controlled hypertensionunited states, 2005-2008. MMWR Surveill Summ, vol. 60(Suppl), páginas 94-97, 2011.

Khosrow-Pour, editor. "Social Computing" in Encyclopedia of Information Science and Technology, Third Edition. IGI Global, 2015. ISBN 9781466658882.

King, E. A., Punla-Green, S. y Genovese, S. Soundscapes, social media, and big data: The next step in strategic noise mapping. The Journal of the Acoustical Society of America, vol. 141(5), página 3622, 2017.

Knowles, A. y Porter, N. Developing trust between the local community and airports. En Proceedings of the INTER-NOISE 2016 - 45th International Congress and Exposition on Noise Control Engineering: Towards a Quieter Future, páginas 852-857. 2016.

Kouloumpis, E., Wilson, T. y Moore, J. D. Twitter Sentiment Analysis: The Good the Bad and the OMG! En Proceedings of the Fifth International Conference on Weblogs and Social Media, Barcelona, Catalonia, Spain, July 17-21, 2011, páginas 538-541. AAAI Press, 2011.

Kralu Novak, P., Smailovic, J., Sluban, B. y Mozetic, I. Sentiment of emojis. PLOS ONE, vol. 10(12), páginas 1-22, 2015.

Lakin, C., Brown, S. y Williams, M. Noise monitoring at Glastonbury Festival. Noise and Vibration Worldwide, 2001.

Landis, J. R. y Koch, G. G. The Measurement of Observer Agreement for Categorical. Biometrics, vol. 33(1), páginas 159-174, 1977.

Laszlo, H. E., McRobie, E. S., Stansfeld, S. A. y Hansell, A. L. Annoyance and other reaction measures to changes in noise exposure A review. Science of The Total Environment, vol. 435-436, páginas 551-562, 2012. 
Lavandier, C., Delaitre, P., D’Hondt, E., Gonzalez Boix, E. y Kambona, K. Urban sound quality assessment with mobile technology: The cart_asur project. En Proceedings of Acoustics. 2013.

Lawton, R. N. y Fujiwara, D. Living with aircraft noise: Airport proximity, aviation noise and subjective wellbeing in England. Transportation Research Part D: Transport and Environment, 2016. ISSN 13619209.

Le Masurier, P., Bates, J., Taylor, J., Flindell, I., Humpheson, D., Pownall, C. y Woolley, A. Attitudes to noise from aviation sources in england (anase): Final report for department for transport. Informe técnico, Her Majesty's Stationery Office, 2007.

Le Masurier, P., Taylor, J., Roberts, M., POWnall, C. y Flindell, I. A national study of attitudes to aircraft noise, and willingness to pay. En Proceedings of the European Transport Conference. 2008.

Lee, J., Beaton, D., Edmonds, L. y Rhodes, D. ERCD REPORT 1402. Noise Exposure Contours for Gatwick Airport 2013. Informe Técnico October, Civil Aviation Authority, 2013.

Lehmann, J., Isele, R., Jakob, M., Jentzsch, A., Kontokostas, D., Mendes, P. N., Hellmann, S., Morsey, M., van Kleef, P., Auer, S. y Bizer, C. DBpedia A Large-scale, Multilingual Knowledge Base Extracted from Wikipedia. Semantic Web, vol. 6(2), páginas 167-195, 2015.

Leon Bluhm, G., Berglind, N., Nordling, E. y Rosenlund, M. Road traffic noise and hypertension. Occupational and Environmental Medicine, vol. 64(2), páginas 122126, 2007. ISSN 1351-0711.

Lesk, M. Automatic Sense Disambiguation Using Machine Readable Dictionaries: How to Tell a Pine Cone from an Ice Cream Cone. En Proceedings of the 5th Annual International Conference on Systems Documentation, SIGDOC '86, páginas 24-26. ACM, New York, NY, USA, 1986. ISBN 0-89791-224-1.

Lindeman, R. H., Merenda, P. y Gold, R. Z. Introduction to bivariate and multivariate analysis,. Scott: Foresman and company, 1980.

Liu, B. Sentiment Analysis and Opinion Mining. Morgan \& Claypool Publishers, 2012. ISBN 1608458849, 9781608458844 .

Liu, F., Weng, F., JiAng, X. y Llc, R. B. A Broad-Coverage Normalization System for Social Media Language. En Proceedings of the 50th Annual Meeting of the Association for Computational Linguistics, July, páginas 1035-1044. 2012.

Liu, F., Weng, F., Wang, B. y Liu, Y. Insertion, Deletion, or Substitution ? Normalizing Text Messages without Pre-categorization nor Supervision. En Proceedings of the 49th Annual Meeting of the Association for Computational Linguistics:shortpapers, páginas 71-76. Association for Computational Linguistics, 2011.

London City Airport. Sound Insulation Scheme Guide. 2010.

London Luton Airport. Annual Monitoring Report 2013. Informe técnico, London Luton Airport, London, 2013.

London Luton Airport. Annual Monitoring Report 2014. Informe técnico, London Luton Airport, London, 2014. 
LoRa Alliance. LoRa Alliance website. https://lora-alliance.org/ 2018. Accessed: 2018-12-21.

Ma, Y., Peng, H., Khan, T., Cambria, E. y Hussain, A. Sentic LSTM: a Hybrid Network for Targeted Aspect-Based Sentiment Analysis. Cognitive Computation, vol. 10(4), páginas 639-650, 2018. ISSN 1866-9964.

MAIRIE DE PARIS. Paris - Budget Participatif. https://budgetparticipatif.paris. fr/, 2018. Accessed: 2018-12-20.

Mairie De PARIs. Paris Data. https://opendata.paris.fr/ 2019. Accessed: 2019-0514.

Maisonneuve, N., Stevens, M. y Ochab, B. Participatory noise pollution monitoring using mobile phones. Information Polity, vol. 15(1, 2), páginas 51-71, 2010.

Majnik, M. y Bosnić, Z. ROC Analysis of Classifiers in Machine Learning: A Survey. Intelligent Data Analysis, vol. 17(3), páginas 531-558, 2013. ISSN 1088-467X.

Manfreda, K. L., Bosnjak, M., Berzelak, J., Haas, I. y Vehovar, V. Web surveys versus other survey modes: A meta-analysis comparing response rates. International journal of market research, vol. 50(1), páginas 79-104, 2008.

Manning, C. D., Raghavan, P. y Schütze, H. Introduction to Information Retrieval. Cambridge University Press, New York, NY, USA, 2008. ISBN 0521865719, 9780521865715.

MaRín, P. El proceso de urbanicación de la ciudad, compactar la dispersión urbana. Informe técnico, Ayuntamiento de Málaga, 2015.

Maris, E., Stallen, P. J., Vermunt, R. y Steensma, H. Noise within the social context: Annoyance reduction through fair procedures. The Journal of the Acoustical Society of America, vol. 121(4), páginas 2000-2010, 2007.

MARTí, J. B. El territorio como espacio de radicalización democrática. una aproximación crítica a los procesos de participación ciudadana en las políticas urbanas de madrid y barcelona. Athenea Digital: revista de pensamiento e investigación social, vol. 12(1), páginas 15-28, 2012.

Martínez, J. M. G. Transparencia y corrupción. la percepción social ante comportamientos corruptos. Revista de Derecho de la UNED (RDUNED), vol. 1(17), páginas 73-107, 2015.

Mason, S. y Graham, N. Areas beneath the relative operating characteristics (ROC) and relative operating levels (ROL) curves: Statistical significance and interpretation. Quarterly Journal of the Royal Meteorological Society, vol. 128(584), páginas 2145-2166, 2006.

MAY, M. y HiLL, S. B. Questioning airport expansion - A case study of Canberra International Airport. Journal of Transport Geography, vol. 14(6), páginas 437-450, 2006 .

MAYOR OF London. London datastore. https://data.london.gov.uk/, 2018a. Accessed: 2018-12-20.

Mayor of London. London Datastore. Noise Pollution in London Dataset. https:// data.london.gov.uk/dataset/noise-pollution-in-london 2018b. Accessed: 2018$11-28$. 
Mayor of London. London Datastore. OpenStreetMaps. https://data.london.gov. uk/dataset/openstreetmap, 2018c. Accessed: 2018-11-28.

Miedema, H. M. y Vos, H. Exposure-response relationships for transportation noise. The Journal of the Acoustical Society of America, vol. 104(6), páginas 3432-3445, 1998.

Miedema, H. M. y Vos, H. Demographic and attitudinal factors that modify annoyance from transportation noise. The Journal of the Acoustical Society of America, vol. 105(6), páginas 3336-3344, 1999.

Mietlicki, C., Mietlicki, F., Ribeiro, C., Gaudibert, P. y Vincent, B. The HARMONICA project, new tools to assess environmental noise and better inform the public. En Proceedings of Forum Acusticum, October. 2014.

Mietlicki, F., Mietlicki, C., Ribeiro, C., Gaudibert, P., Vincent, B. y GissinGER, V. New tools to inform the public about environmental noise in cities and to assist decision-making. En Euronoise 2015, páginas 251-256. Maastricht, 2015.

Mikolov, T., Sutskever, I., Chen, K., Corrado, G. S. y Dean, J. Distributed Representations of Words and Phrases and their Compositionality. En Advances in Neural Information Processing Systems 26, páginas 3111-3119. Curran Associates, Inc., 2013.

Millar, M. M. y Dillman, D. A. Improving response to web and mixed-mode surveys. Public opinion quarterly, vol. 75(2), páginas 249-269, 2011.

Miller, G. A. WordNet : A Lexical Database for English. Communications of the ACM, vol. 38(11), páginas 39-41, 1995.

Ministry of Housing, Communities \& Local Government. Energy performance of buildings data. https://epc.opendatacommunities.org, 2018. Accessed: 2019-4-5.

Moreno, R. M., Martinez, R., Walliser, A., Cruz, H. y Blanco, I. De la crítica a la innovación en la gobernanza participativa. En XII Congreso Español de Sociología. 2016.

Mydlarz, C., Salamon, J. y Bello, J. P. The implementation of low-cost urban acoustic monitoring devices. Applied Acoustics, vol. 117, páginas $207-218,2017$. ISSN 0003-682X. Acoustics in Smart Cities.

National Economic Council. An economic analysis of transportation infrastructure investment. Informe técnico, USA Government-The White House, 2014.

NETBASE. Netbase Chevrolet customer insights case study. Informe técnico, Netbase, 2016.

NETBASE. Netbase Arbys Onlinse Social Networks sentiment analysis case study. Informe técnico, Netbase, 2018.

Netherlands Aerospace Centre. Virtual Community Noise Simulator. https:// www.nlr.org/capabilities/noise-simulator/, 2016. Accessed: 2019-07-04.

New York University. SONYC - Sounds of New York City Website. https://wp. nyu.edu/sonyc/, 2019. Accessed: 2019-05-08.

NHS. NHS Digital. Practice Level Prescribing Data. https:// digital.nhs.uk/data-and-information/publications/statistical/ practice-level-prescribing-data, 2018. Accessed: 2018-11-26. 
Nigam, K., Lafferty, J. y Mccallum, A. Using Maximum Entropy for Text Classification. En In IJCAI-99 Workshop on Machine Learning for Information Filtering, páginas 61-67. 1999.

Noisemote. Noisemote demo. https://demo.noisemote.com/sensors?sensorId= demo0004\&subSection=sensors_statistics, 2019. Accessed: 2019-05-10.

NoSlang. NoSlang. Internet \& text slang dictionary \& translator. 2017.

NSW Government. Traffic volume maps for Infrastructure SEPP. \begin{tabular}{l} 
https://www.rms.nsw.gov.au/about/environment/reducing-noise/ \\
\hline traffic-volume-maps-for-infrastructure-sepp.html, 2019. Accessed:2019-04-22.
\end{tabular}

Ottoz, E., Rizzi, L. y Nastasi, F. Recreational noise in Turin and Milan: Impact and costs of movida for disturbed residents. En 22nd International Congress on Sound and Vibration, ICSV. 2015.

Ottoz, E., Rizzi, L. y Nastasi, F. Recreational noise: Impact and costs of movida for disturbed residents in Italy. En Proceedings of the INTER-NOISE 2016 - 45th International Congress and Exposition on Noise Control Engineering: Towards a Quieter Future, páginas 7284-7293. 2016.

Ottoz, E., Rizzi, L. y Nastasi, F. Recreational noise: Impact and costs for annoyed residents in Milan and Turin. Applied Acoustics, vol. 133, páginas 173-181, 2018.

Owoputi, O., Connor, B. O., Dyer, C., Gimpel, K., Schneider, N. y Smith, N. A. Improved Part-of-Speech Tagging for Online Conversational Text with Word Clusters. En Proceedings of NAACL-HLT 2013, páginas 380-390. 2013.

Passchier-Vermeer, W. Noise and health. The Hague, Health Council of the Netherlands, 1993. ISBN 90-5549-025-3.

Passchier-Vermeer, W. y Passchier, W. F. Noise Exposure and Public Health. Environmental health perspectives, vol. 108, páginas 123-131, 2000.

Paunovic, K., Belojevic, G. y Jakovluevic, B. Noise annoyance is related to the presence of urban public transport. Science of the Total Environment, vol. 481(1), páginas 479-487, 2014.

Pennington, J., Socher, R. y Manning, C. D. GloVe: Global Vectors for Word Representation. En Proceedings of the 2014 Conference on Empirical Methods in Natural Language Processing (EMNLP), páginas 1532-1543. 2014.

PERTh Airport. Future noise impacts. http://perthmasterplan.bksv.com/ future-noise-impacts/2016. Accessed: 2016-08-31.

Peruzzi, L., Bellucci, P., Cerniglia, A. y Coppi, P. Informing the public on noise impacts through the web-gis dynamap software application. The Journal of the Acoustical Society of America, vol. 141(5), páginas 3803-3803, 2017.

Peters, R. The role of hearing protectors in leisure noise. Noise and Health, vol. 5(18), páginas $47-55,2003$.

Peters, R. y Holdich, A. Report of Noise Monitoring At Bidborough - September 2013 -August 2015. Informe técnico, Applied Acoustic Design, 2016. 
Petrovcic, A., Petric, G. y Manfreda, K. L. The effect of email invitation elements on response rate in a web survey within an online community. Computers in Human Behavior, vol. 56, páginas 320 - 329, 2016. ISSN 0747-5632.

Phun, V. K., Hirata, T. y Yai, T. Effects of noise information provision on aircraft noise tolerability: Results from an experimental study. Journal of Air Transport Management, vol. 52, páginas 1-10, 2016.

Pinto, E. Blood pressure and ageing. Postgraduate Medical Journal, vol. 83(976), páginas 109-114, 2007. ISSN 1469-0756.

Porter, M. F. An algorithm for suffix stripping. Program, vol. 14(3), páginas 130-137, 1980.

Porter, N., Kershaw, A. y Ollerhead, J. The adverse effects of night-time aircraft noise: review of 1992 UK findings and introduction to new UK work. En INTER-NOISE 2000 - 29th International Congress on Noise Control Engineering. 2000.

Prague Airport. Continous environmental monitoring - Day Night Noise Climate June 2016. Informe técnico, Prague Airport, Prague, 2016a.

Prague Airport. Continous environmental monitoring - Monthly LAeq,T February 2016. Informe técnico, Prague Airport, Prague, 2016b.

Quercia, D., O'Hare, N. K. y Cramer, H. Aesthetic capital: what makes london look beautiful, quiet, and happy? En Proceedings of the 17th ACM conference on Computer supported cooperative work \& social computing, páginas 945-955. ACM, 2014a.

Quercia, D., Schifanella, R. y Aiello, L. M. The shortest path to happiness: Recommending beautiful, quiet, and happy routes in the city. En Proceedings of the 25th ACM conference on Hypertext and social media, páginas 116-125. ACM, 2014b.

Quercia, D., Schifanella, R., Aiello, L. M. y Mclean, K. Smelly maps: the digital life of urban smellscapes. arXiv preprint arXiv:1505.06851, 2015.

Question Pro. QuestionPro website. https://www.questionpro.com/es/, 2018. Accessed:2018-11-20.

ReinA, E. G. Transparencia y acceso a la información pública en españa: Análisis y propuestas legislativas. Documentos de trabajo, 2011.

RÉPUBLIQUE FrAnÇAISE. Loi n $85-696$ du 11 juillet 1985 relative à lúrbanisme au voisinage des aérodromes. 1985.

Republique Française. Plateforme ouverte des données publiques françaises. https: //www.data.gouv.fr/fr/, 2019. Accessed: 2019-05-14.

Ribeiro, C., Anselme, C., Mietlicki, F. y Silva, R. D. At the heart of Harmonica project : the Common Noise Index ( CNI ). En INTER-NOISE 2013 - 42nd International Congress and Exposition on Noise Control Engineering: Noise Control for Quality of Life, páginas 1-10. Inssbruck, Austria, 2013.

Rolstad, S., Adler, J. y Rydén, A. Response burden and questionnaire length: Is shorter better? a review and meta-analysis. Value in Health, vol. 14(8), páginas $1101-$ 1108, 2011. ISSN 1098-3015.

Rosen, A. Tweeting Made Easier. 2017. Twitter Blog. 
Sahai, A., Wefers, F., Pick, S., Stumpf, E., Vorländer, M. y Kuhlen, T. Interactive simulation of aircraft noise in aural and visual virtual environments. Applied Acoustics, vol. 101, páginas 24-38, 2016.

Salamon, J. y Bello, J. P. Deep convolutional neural networks and data augmentation for environmental sound classification. IEEE Signal Processing Letters, vol. 24(3), páginas 279-283, 2017. ISSN 1070-9908.

San Francisco Intertational Airport. Chapter 5 - Noise Exposure Maps and Effects on Land Use. En 14 Code of Federal Regulations (CFR) Part 150 Study Update.. San Francisco International Airport, 2015a.

San Francisco Intertational Airport. San Francisco International Airport. 14 CFR Part 150 Noise Exposure Noise Report. Informe técnico, San Francisco Intertational Airport, 2015b.

San Francisco Intertational Airport. Short Term Aircraft Noise Monitoring Portola Valley and Woodside Communities. Informe técnico, San Francisco Intertational Airport, 2015c.

Sánchez, D., Naumann, J., Porter, N. y Knowles, A. Current issues in aviation noise management: a non-acoustic factors perspective. En International Congress of Sound and Vibration (ICSV22). 2015.

Sangameswar, M. V., Nagabhushana Rao, M. y Satyanarayana, S. An algorithm for identification of natural disaster affected area. Journal of Big Data, vol. 4(1), página 39, 2017. ISSN 2196-1115.

SARker, A. A customizable pipeline for social media text normalization. Social Network Analysis and Mining, vol. 7(1), páginas 1-13, 2017. ISSN 1869-5469.

Sarker, A., Connor, K. O., Ginn, R., Scotch, M., Smith, K., Malone, D. y Gonzalez, G. Social Media Mining for Toxicovigilance : Automatic Monitoring of Prescription Medication Abuse from Twitter. Drug Safety, vol. 39(3), páginas 231-240, 2016. ISSN 1179-1942.

Sarker, A., Ginn, R., Nikfarjam, A., Connor, K. O., Smith, K., Jayaraman, S., Upadhaya, T. y Gonzalez, G. Utilizing social media data for pharmacovigilance : A review. Journal of Biomedical Informatics, vol. 54, páginas 202-212, 2015. ISSN 1532-0464.

Sassen, S. The Global City: New York, London, Tokyo, Princeton. NJ: Princeton, 1991.

Sauermann, H. y RoACH, M. Increasing web survey response rates in innovation research: An experimental study of static and dynamic contact design features. Research Policy, vol. 42(1), páginas 273 - 286, 2013. ISSN 0048-7333.

Savage, M., Devine, F., Cunningham, N., Taylor, M., Li, Y., Huellbrekke, J., Roux, B. L., Friedman, S. y Miles, A. A New Model of Social Class? Findings from the BBCs Great British Class Survey Experiment. Sociology, vol. 47(2), páginas 219-250, 2013.

Schafer, R. M. The soundscape: Our sonic environment and the tuning of the world. Simon and Schuster, 1993. 
Schreckenberg, D. y Meis, M. Effects of Aircraft Noise on Noise Annoyance and Quality of Life around Frankfurt Airport. Informe técnico, Regional Dialogue Forum Frankfurt Airport, D-64625 Bensheim, 2006.

Schreckenberg, D. y Meis, M. Noise annoyance around an international airport planned to be extended. En INTER-NOISE 2007 - 36th International Congress and Exhibition on Noise Control Engineering. 2007.

Schultz, T. J. Synthesis of social surveys on noise annoyance. The Journal of the Acoustical Society of America, vol. 64(2), páginas 377-405, 1978.

Serra, M. R., Biassoni, E. C., Skarp, A. H. O., Serra, M. y Joekes, S. Sound immission during leisure activities and auditory behaviour. Applied Acoustics, vol. 68(4), páginas 403-420, 2007.

Severyn, A. y Moschitti, A. Twitter Sentiment Analysis with deep convolutional neural networks. En SIGIR 2015 - Proceedings of the 38th International ACM SIGIR Conference on Research and Development in Information Retrieval, páginas 959-962. 2015 .

Sheth, A. P. Citizen Sensing, Social Signals, and Enriching Human Experience. IEEE Internet Computing, vol. 13(August), páginas 87-92, 2009.

SHIH, T.-H. y FAn, X. Comparing response rates from web and mail surveys: A metaanalysis. Field Methods, vol. 20(3), páginas 249-271, 2008.

Silva, B., Santos, G., Eller, R., Guestland, T., Silva, B., Santos, G. y Eller, R. Annoyance survey by means of social media. The Journal of the Acoustical Society of America, vol. 141(2), páginas 1019-1026, 2017.

Sincosur. Revisión y actualización de los planes de acción contra el ruido en Málaga. Informe técnico, Ayuntamiento de Málaga, 2015.

Singh, T. y Kumari, M. Role of Text Pre-processing in Twitter Sentiment Analysis. Procedia Computer Science, vol. 89, páginas 549-554, 2016. ISSN 18770509.

SMARTSAnTANDER. SmartSantander project website. http://www.smartsantander.eu/, 2019. Accessed: 2019-05-08.

Smith, A. y Anderson, M. Social Media Use in 2018. Informe técnico, Pew Research Center, 2018.

Socoró, J. C., Alías, F. y Alsina-Pagès, R. M. An anomalous noise events detector for dynamic road traffic noise mapping in real-life urban and suburban environments. Sensors, vol. 17(10), 2017. ISSN 1424-8220.

Sony Computer Science Laboratory Paris. NoiseTube website. http://www. noisetube.net/, 2019. Accessed: 2019-05-08.

Sørensen, M., Hvidberg, M., Hoffmann, B., Andersen, Z. J., Nordsborg, R. B., Lillelund, K. G., Jakobsen, J., Tuønneland, A., Overvad, K. y RaAschouNielsen, O. Exposure to road traffic and railway noise and associations with blood pressure and self-reported hypertension: a cohort study. Environmental health, vol. 10(1), página 92, 2011.

Sound Solution Consultants. The Black Horse Festival Noise Impact Assessment. Informe técnico, Sound Solution Consultants, 2010. 
Southgate, D. Discussion Paper- Expanding Ways to Describe and Assess Aircraft Noise. Informe técnico, Australian Department of Transport \& Regional Services, 2000.

Standing, L. y Stace, G. The effects of environmental noise on anxiety level. The Journal of General Psychology, vol. 103(2), páginas 263-272, 1980. PMID: 7441223.

States General of the Netherlands. Wet houdende regels inzake het voorkomen of beperken van geluidhinder. 1979 .

Suau-Sanchez, P., Pallares-Barbera, M. y PAüL, V. Incorporating annoyance in airport environmental policy: noise, societal response and community participation. Journal of Transport Geography, vol. 19(2), páginas 275-284, 2011.

Sustainable Aviation. The SA Noise road-map. A Bluepirnt for Managing Noise from Aviation Sources to 2050. Informe técnico, Sustainable Aviation, 2014.

Tausczik, Y. R. y Pennebaker, J. W. The psychological meaning of words: LIWC and computerized text analysis methods. Journal of language and social psychology, vol. 29(1), páginas 24-54, 2010.

Teng, X., Wong, M. Y. M. y Zhang, Y.-T. The effect of music on hypertensive patients. En 2007 29th Annual International Conference of the IEEE Engineering in Medicine and Biology Society, páginas 4649-4651. IEEE, 2007.

Tung, C.-Y. y CHAO, K.-P. Effect of recreational noise exposure on hearing impairment among teenage students. Research in developmental disabilities, vol. 34(1), páginas 126-132, 2013.

Twitter. Selected Twitter Company Metrics and Financials. Informe técnico, Twitter, 2016.

TwITTER. Tweet objects overview. https://developer.twitter.com/en/docs/tweets/ data-dictionary/overview/intro-to-tweet-json.html, 2018a. Accessed: 2018-0530 .

TwiTTER. Twitter streaming API website. https://developer.twitter.com/en/docs/ tweets/filter-realtime, 2018b. Accessed: 2018-09-05.

Twitter Forum. Official Twitter Developers Forum. https://twittercommunity.com/ $t /$ diffence-between-sample-and-filter-streaming-api/15094/3, 2014. Accessed: 2017-05-25.

United Nations. World Urbanization Prospects: The 2018 Revision. Key facts. Informe técnico, United Nations, 2018.

U.S. Congress. Noise Control Act of 1972, P.L. 92-574, 86 Stat. 1234. 1972.

U.S. Congress. Public Law 96-193 - Aviation Safety and Noise Abatement Act of 1979. 1980.

U.S. Department of Transportation. National Transportation Noise Map. https://maps.bts.dot.gov/arcgis/apps/webappviewer/index.html?id= a303ff5924c9474790464cc0e9d5c9fb, 2019. Accessed:2019-04-22.

VADER, R. D/R\&D 07/026 Noise Annoyance Mitigation at Airports by Non-Acoustic Measures. Informe técnico, Air Traffic Control the Netherlands, Amsterdam, 2007. 
Valitutti, A., Strapparava, C. y Stock, O. Developing affective lexical resources. PsychNology Journal, vol. 2(1), páginas 61-83, 2004.

VAn Kempen, E. y BABISCh, W. The quantitative relationship between road traffic noise and hypertension: a meta-analysis. Journal of hypertension, vol. 30(6), páginas 1075-1086, 2012.

Vecinos el Romeral. Asociación de vecinos "El Romeral contra el ruido". https://elromeralcontraelruido.wordpress.com/2015/10/04/ monitorizacion-en-directo-del-ruido-del-ocio/, 2015. Accessed:2019-06-10.

Vidović, A., Steiner, S. y Babić, R. Š. Impact of low-cost carriers on the european air transport market. En 10th International Conference on Traffic Science ICTS 2006: Globalization and Transportation. 2006.

Vincent, B. y LAmBert, J. Informing and communicating on noise in the light of research work relating to Greater First research task. En Workshop on Presenting Noise Mapping Data to the Public, October. London, 2006.

Vincent, B. y LAMBeRT, J. Informing and communicating on noise in the light of research work relating to Greater Lyon. En Workshop on Presenting Noise Mapping Data to the Public. 2008.

Vinci, B., Tonacci, A., Caudai, C., De Rosa, P., Nencini, L. y Pratali, L. The SENSEable Pisa Project: Citizen-Participation in Monitoring Acoustic Climate of Mediterranean City Centers. Clean - Soil, Air, Water, vol. 45(7), 2017.

Vivanco, M. Muestreo estadístico. Diseño y aplicaciones. Editorial universitaria, 2005.

Wachsmuth, D. y Weisler, A. Airbnb and the rent gap: Gentrification through the sharing economy. Environment and Planning A: Economy and Space, 2018.

Wallsten, S. The competitive effects of the sharing economy: how is uber changing taxis. Technology Policy Institute, vol. 22, 2015.

Wang, Y., Huang, M., Xiaoyan Zhu y Zhao, L. Attention-based LSTM for Aspectlevel Sentiment Classification. En Proceedings of the 2016 Conference on Empirical Methods in Natural Language Processing, páginas 606-615. Association for Computational Linguistics, 2016.

WeI, W. W. Time Series Analysis. Oxford University Press, 2013. ISBN 9780199934898.

WHO Regional Office For Europe. Night noise guidelines for Europe. World Health Organization, 2009. ISBN 9789289041737.

WhO Regional Office For Europe. Burden of disease from environmental noise. Quantification of healthy life years lost in Europe. World Health Organization, 2011. ISBN 9789289002295.

Wilson, A. Final Report of the Committee on the Problem of Noise. Informe técnico, Her Majesty's Stationery Office, 1963.

Winkel, P. y Fan Zhang, N. Theory of Statistical Process Control. En Statistical Development of Quality in Medicine, capítulo 1, páginas 9-36. Wiley-Blackwell, 2007. ISBN 9780470515884. 
Woodward, J. M., Briscoe, L. L., Dunholter, P. y Board, T. R. ACRP report 15. Aircraft Noise: A Toolkit for managing community expectations. Informe técnico, Transportation Research Board, 2009.

Working Group on the Assessment of Exposure. Presenting Noise Mapping Information to the Public - A Position Paper from the European Environment Agency Working Group on the Assessment of Exposure to Noise. Informe técnico, European Environment Agency, 2008.

World Health Organization. Guidelines for community noise. World Health Organization, Geneva, Switzerland, 1999. ISBN 9789971887704.

World Health Organization. Environmental Noise Guidelines for the European Region. World Health Organization Europe Copenhagen, Denmark, 2018. ISBN 9789289053563.

Zambon, G., Benocci, R., Bisceglie, A., Roman, H. E. y Bellucci, P. The life dynamap project: Towards a procedure for dynamic noise mapping in urban areas. Applied Acoustics, vol. 124, páginas 52-60, 2017.

Zigbee Alliance. Zigbee Alliance website. https://www.zigbee.org/, 2018. Accessed: 2018-12-21.

Zimbra, D. y AbBasi, A. The State-of-the-Art in Twitter Sentiment Analysis : A Review and Benchmark Evaluation The State-of-the-Art in Twitter Sentiment Analysis : A Review and. ACM Transactions on Management Information Systems, vol. March, página 29, 2018. 



\section{Lista de acrónimos}

ACI .......... Airport Council International

API.......... Application Programming Interface, Interfaz de programación de aplicaciones

ARIMA...... AutoRegressive Integrated Moving Average, Modelo Autorregresivo Integrado de Media Móvil

AUROC ...... Area Under the Receiver Operating Characteristic, Area Bajo la curva de la Característica Operativa del Receptor

BoW ......... Bag of Words, Bolsa de Palabras

FAA $\ldots . . . \ldots$ Federal Aviation Administration

HL .......... Hamming Loss score

ICAO ........ International Civil Aviation Organization

IoT $\ldots . . . \ldots$ Internet of Things, Internet de las Cosas

ISO ......... International Organization for Standardization, Organización Internacional de Normalización

LSOAs....... Lower Layer Super Output Areas

MSOAs....... Middle Layer Super Output Areas

NHS ........ National Health Service, Servicio Nacional de Salud Británica

NLP ........ Natural Language Processing, Procesado de Lenguaje Natural

NU $\ldots . . . . . .$. Naciones Unidas

OAs.......... Output Areas

OMS ......... Organización Mundial de la Salud

ONS .......... Office for National Statistics

PM $3.0 \ldots . .$. Policy Making 3.0, Creación de políticas 3.0

PoS ......... Part of Speech, Categoría morfosintáctica

RFP ........ Razón de Falsos Positivos, False Positive Rate

ROC ......... Receiver Operating Characteristic, Característica Operativa del Receptor 
RSO ........ Redes Sociales Online, Online Social Networks

RVP ........ Razón de Verdaderos Positivos, True Positive Rate

TF-IDF ...... Term Frequency-Inverse Document Frequency,Frecuencia de término-frecuencia inversa de documento

TICs......... Tecnologías de la Información y las Comunicaciones

UE ......... Unión Europea 
Apéndices 



\section{Apéndice A: Encuesta inicial}

Encuesta de investigación sobre el Ruido Urbano

\section{DATOS SOCIO-DEMOGRÁFICOS}

Género:

1. Hombre

2. Mujer

Edad

1. $18-19$

2. $20-24$

3. $25-34$

4. $35-44$

5. $45-54$

6. $55-64$

6. $55-6$

7. $65-74$

8. \&gt;75

9. Prefiero no contestar

Nacionalidad

1. Español/a

2. Europeo/a

3. Otra

4. Prefiero no contestar

\section{DATOS SOCIO-DEMOGRÁFICOS}

Nivel de estudios:

1. Sin estudios

2. Educación primaria

3. Educación secundaria

4. Bachillerato/Formación profesional

5. Estudios superiores no universitarios

6. Estudios superiores universitarios

7. Prefiero no contestar

¿Cuál de las siguientes opciones describe mejor su situación actual?

1. Estoy trabajando a tiempo completo

2. Estoy trabajando a tiempo parcial

3. Estoy desempleado/a y buscando trabajo

4. Estoy retirado/a o jubilado/a

5. Estoy estudiando

6. Estoy dedicado/a a las labores del hogar

7. Prefiero no contestar

8. Otra (especificar)

¿Cuánto tiempo hace que reside en esta ciudad?

1. Menos de 6 meses

2. De 6 meses a 1 año

3. De 1 a 2 años

4. De 2 a 5 años

5. De 5 a 10 años

6. Más de 10 años

7. Desde siempre 
Encuesta de investigación sobre el Ruido Urbano RESPECTO A SU VIVIENDA

En relación a la vivienda dónde ha recibido la invitación..

¿Cuánto tiempo lleva residiendo en esta vivienda?
1. Menos de 6 meses
2. De 6 meses a 1 año
3. De 1 a 2 años
4. De 2 a 5 años
5. De 5 a 10 años
6. Más de 10 años
7. Desde siempre
8. Es mi segunda residencia
9. No es mi vivienda habitual

¿Cuánto tiempo lleva residiendo en esta vivienda?
1. Menos de 6 meses
2. de 6 meses a 1 año
3. de 1 a 2 años
4. de 2 a 5 años
5. de 5 a 10 años
6. más de 10 años
7. Es una segunda residencia
8. No es mi residencia habitual

¿Cuentan las ventanas de su vivienda con doble acristalamiento?
1. Sí, todas
2. Sí, algunas
3. No, ninguna
4. No lo sé

SU RELACIÓN CON EL RUIDO

En relación a usted y el ruido en su barrio...

¿Cómo de sensible se considera usted con respecto al ruido?

\begin{tabular}{|l|c|c|c|c|c|c|c|c|c|c|c|c|}
\hline & 0 & 1 & 2 & 3 & 4 & 5 & 6 & 7 & 8 & 9 & $\begin{array}{c}\text { No lo } \\
\text { sé }\end{array}$ \\
\hline & $\square$ & $\square$ & $\square$ & $\square$ & $\square$ & $\square$ & $\square$ & $\square$ & $\square$ & $\square$ & $\square$ & $\square$ \\
\hline
\end{tabular}

¿Cómo de ruidoso considera que es este barrio?

\begin{tabular}{|l|c|c|c|c|c|c|c|c|c|c|c|c|}
\hline & 0 & 1 & 2 & 3 & 4 & 5 & 6 & 7 & 8 & 9 & 10 & $\begin{array}{c}\text { No lo } \\
\text { sé }\end{array}$ \\
\hline & $\square$ & $\square$ & $\square$ & $\square$ & $\square$ & $\square$ & $\square$ & $\square$ & $\square$ & $\square$ & $\square$ & $\square$ \\
\hline
\end{tabular}

¿Pertenece usted, o alguno de los residentes en esta vivienda a alguna asociación o agrupación que tenga entre sus objetivos la lucha contra el ruido?

1. Sí

SU RELACIÓN CON EL RUIDO

I2A2 - Universidad Politécnica de Madrid 
Encuesta de investigación sobre el Ruido Urbano

Pensando en los últimos 12 meses, cuando está en el interior de su vivienda...

¿Hasta que punto diría que le molesta, incomoda o afecta el ruido que procede de la calle?

1. Extremadamente

2. Mucho

3. Medianamente

4. Ligeramente

5. Absolutamente nada

¿Podría indicar cuánto le molesta o incomoda el ruido producido por las siguientes fuentes sonoras?

\begin{tabular}{|c|c|c|c|c|c|c|c|c|c|c|c|c|}
\hline & 0 & 1 & 2 & 3 & 4 & 5 & 6 & 7 & 8 & 9 & 10 & $\begin{array}{c}\text { Nunca } \\
\text { lo oigo }\end{array}$ \\
\hline Tráfico rodado & $\square$ & $\square$ & $\square$ & $\square$ & $\square$ & $\square$ & $\square$ & $\square$ & $\square$ & $\square$ & $\square$ & $\square$ \\
\hline $\begin{array}{c}\text { Construcción, obras, } \\
\text { reformas\&hellip; }\end{array}$ & $\square$ & $\square$ & $\square$ & $\square$ & $\square$ & $\square$ & $\square$ & $\square$ & $\square$ & $\square$ & $\square$ & $\square$ \\
\hline Actividades comerciales & $\square$ & $\square$ & $\square$ & $\square$ & $\square$ & $\square$ & $\square$ & $\square$ & $\square$ & $\square$ & $\square$ & $\square$ \\
\hline $\begin{array}{c}\text { Actividades de ocio (bares, } \\
\text { espectáculos, deportes...) }\end{array}$ & $\square$ & $\square$ & $\square$ & $\square$ & $\square$ & $\square$ & $\square$ & $\square$ & $\square$ & $\square$ & $\square$ & $\square$ \\
\hline Servicios & $\square$ & $\square$ & $\square$ & $\square$ & $\square$ & $\square$ & $\square$ & $\square$ & $\square$ & $\square$ & $\square$ & $\square$ \\
\hline Vecinos & $\square$ & $\square$ & $\square$ & $\square$ & $\square$ & $\square$ & $\square$ & $\square$ & $\square$ & $\square$ & $\square$ & $\square$ \\
\hline Otros ruidos & $\square$ & $\square$ & $\square$ & $\square$ & $\square$ & $\square$ & $\square$ & $\square$ & $\square$ & $\square$ & $\square$ & $\square$ \\
\hline
\end{tabular}

Utilice este espacio para escribir cualquier comentario acerca de ruidos que le molesten:

TODAS LAS FUENTES DE RUIDO EN SU ZONA DE RESIDENCIA

Teniendo en cuenta los ruidos y sonidos de esta zona...

Considera que el ruido es un problema en su vida?

1. $\mathrm{Si}$

2. No

¿Podría valorar en qué medida el ruido existente en esta zona deteriora su calidad de vida?

\begin{tabular}{|l|c|c|c|c|c|c|c|c|c|c|c|c|}
\hline & 0 & 1 & 2 & 3 & 4 & 5 & 6 & 7 & 8 & 9 & 10 & $\begin{array}{c}\text { No lo } \\
\text { sé }\end{array}$ \\
\hline & $\square$ & $\square$ & $\square$ & $\square$ & $\square$ & $\square$ & $\square$ & $\square$ & $\square$ & $\square$ & $\square$ & $\square$ \\
\hline
\end{tabular}

¿Considera que la situación respecto al ruido en esta vivienda es mejor o peor que hace 5 años?

\begin{tabular}{|l|c|c|c|c|c|c|c|c|}
\hline & $\begin{array}{c}\text { Ha } \\
\text { mejorado } \\
\text { mucho }\end{array}$ & $\begin{array}{c}\text { Ha } \\
\text { mejorado } \\
\text { poco }\end{array}$ & $\begin{array}{c}\text { No ha } \\
\text { mejorado } \\
\text { ni } \\
\text { empeorad } \\
\text { o }\end{array}$ & $\begin{array}{c}\text { Ha } \\
\text { empeorad } \\
\text { o algo }\end{array}$ & $\begin{array}{c}\text { Ha } \\
\text { empeorad } \\
\text { o mucho }\end{array}$ & $\begin{array}{c}\text { No soy } \\
\text { capaz de } \\
\text { valorarlo }\end{array}$ & No lo sé \\
\hline & $\square$ & $\square$ & $\square$ & $\square$ & $\square$ & $\square$ & $\square$ \\
\hline
\end{tabular}

I2A2 - Universidad Politécnica de Madrid 
Encuesta de investigación sobre el Ruido Urbano

TODAS LAS FUENTES DE RUIDO EN SU ZONA DE RESIDENCIA

Pensando aproximadamente en los últimos 5 años..

¿Usted o alguien de su familia ha emprendido alguna acción para solucionar un problema relacionado con el ruido existente en su zona o su vivienda? ¿Fue dicha acción efectiva?

¿A cuáles de las siguientes fuentes de ruido estaban ligadas las acciones que ha mencionado en la pregunta anterior?

1. Tráfico rodado

2. Construcción, obras, reformas\&hellip

3. Actividades comerciales

4. Actividades de ocio (bares, espectáculos, deportes...)

5. Servicios

6. Vecinos

7. Otros ruidos

Utilice este espacio para detallar o comentar su experiencia relacionada con las acciones emprendidas:

\section{FUENTES DE RUIDO ESPECÍFICAS}

Pensando aproximadamente en los últimos 12 meses..

¿Podría indicar cuál de las siguientes fuentes de ruido le afecta más cuando está en su vivienda? Elija sólo una respuesta, por favor:

1. Tráfico rodado

2. Construcción, obras, reformas\&hellip;

3. Actividades comerciales

4. Actividades de ocio (bares, espectáculos, deportes...)

5. Servicios

6. Vecinos

7. Otros ruidos

8. No me molesta ninguna fuente de ruido

\section{VECINOS}

Refiriéndose al ruido producido por vecinosy pensando en los últimos 12 meses aproximadamente...

¿Podría indicar la molestia que le ocasiona el ruido producido por las distintas actividades mostradas cuando está en el interior de su vivienda?

\begin{tabular}{|c|c|c|c|c|c|c|c|c|c|c|c|c|}
\hline $\begin{array}{c}\text { Fiestas en zonas comunes o } \\
\text { terrazas }\end{array}$ & $\square$ & $\square$ & $\square$ & $\square$ & $\square$ & $\square$ & $\square$ & $\square$ & $\square$ & $\square$ & $\square$ & $\square$ \\
\hline $\begin{array}{c}\text { Piscina, actividades } \\
\text { deportivas }\end{array}$ & $\square$ & $\square$ & $\square$ & $\square$ & $\square$ & $\square$ & $\square$ & $\square$ & $\square$ & $\square$ & $\square$ & $\square$ \\
\hline $\begin{array}{c}\text { Juegos infantiles } \\
\text { oigo }\end{array}$ & $\square$ & $\square$ & $\square$ & $\square$ & $\square$ & $\square$ & $\square$ & $\square$ & $\square$ & $\square$ & $\square$ & $\square$ \\
\hline $\begin{array}{c}\text { Conversaciones en zonas } \\
\text { comunes o terrazas }\end{array}$ & $\square$ & $\square$ & $\square$ & $\square$ & $\square$ & $\square$ & $\square$ & $\square$ & $\square$ & $\square$ & $\square$ & $\square$ \\
\hline $\begin{array}{c}\text { Maquinaria de jardinería, } \\
\text { bricolaje... }\end{array}$ & $\square$ & $\square$ & $\square$ & $\square$ & $\square$ & $\square$ & $\square$ & $\square$ & $\square$ & $\square$ & $\square$ & $\square$ \\
\hline $\begin{array}{c}\text { Televisión, radio, música, } \\
\text { dispositivos electrónicos... }\end{array}$ & $\square$ & $\square$ & $\square$ & $\square$ & $\square$ & $\square$ & $\square$ & $\square$ & $\square$ & $\square$ & $\square$ & $\square$ \\
\hline $\begin{array}{c}\text { Electrodomésticos } \\
\text { Instalaciones (tuberías, } \\
\text { ascensores, aire } \\
\text { acondicionado...) }\end{array}$ & $\square$ & $\square$ & $\square$ & $\square$ & $\square$ & $\square$ & $\square$ & $\square$ & $\square$ & $\square$ & $\square$ & $\square$ \\
\hline $\begin{array}{c}\text { Perros y otros animales } \\
\text { domésticos }\end{array}$ & $\square$ & $\square$ & $\square$ & $\square$ & $\square$ & $\square$ & $\square$ & $\square$ & $\square$ & $\square$ & $\square$ & $\square$ \\
\hline \begin{tabular}{c} 
Pisadas y pasos \\
\hline
\end{tabular} & $\square$ & $\square$ & $\square$ & $\square$ & $\square$ & $\square$ & $\square$ & $\square$ & $\square$ & $\square$ & $\square$ & $\square$ \\
\hline
\end{tabular}

I2A2 - Universidad Politécnica de Madrid 
Encuesta de investigación sobre el Ruido Urbano

Encuesta de investigación sobre el Ruido Urbano
\begin{tabular}{|c|c|c|c|c|c|c|c|c|c|c|c|c|}
\hline Otros & $\square$ & $\square$ & $\square$ & $\square$ & $\square$ & $\square$ & $\square$ & $\square$ & $\square$ & $\square$ & $\square$ & $\square$ \\
\hline
\end{tabular}

Escriba, si lo desea, algún comentario o especifique el tipo de ruidos que le molestan y que no hayan sido contemplados:

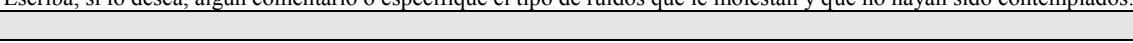

\section{TRAFICO RODADO}

Refiriéndose al ruido producido por el tráfico rodado y pensando en los últimos 12 meses aproximadamente...

¿Podría indicarnos la molestia que le ocasiona el ruido que producen los diferentes tipos de vehículos cuando está en el interior de su vivienda?

\begin{tabular}{|l|c|c|c|c|c|c|c|c|c|c|c|c|}
\hline & 0 & 1 & 2 & 3 & 4 & 5 & 6 & 7 & 8 & 9 & $\begin{array}{c}\text { 10 } \\
\text { oigo }\end{array}$ \\
\hline Furgonetas de reparto & $\square$ & $\square$ & $\square$ & $\square$ & $\square$ & $\square$ & $\square$ & $\square$ & $\square$ & $\square$ & $\square$ & $\square$ \\
\hline Autobuses & $\square$ & $\square$ & $\square$ & $\square$ & $\square$ & $\square$ & $\square$ & $\square$ & $\square$ & $\square$ & $\square$ & $\square$ \\
\hline Coches / taxis & $\square$ & $\square$ & $\square$ & $\square$ & $\square$ & $\square$ & $\square$ & $\square$ & $\square$ & $\square$ & $\square$ & $\square$ \\
\hline Motos & $\square$ & $\square$ & $\square$ & $\square$ & $\square$ & $\square$ & $\square$ & $\square$ & $\square$ & $\square$ & $\square$ & $\square$ \\
\hline $\begin{array}{c}\text { Vehículos de recogida de } \\
\text { residuos }\end{array}$ & $\square$ & $\square$ & $\square$ & $\square$ & $\square$ & $\square$ & $\square$ & $\square$ & $\square$ & $\square$ & $\square$ & $\square$ \\
\hline Otros & $\square$ & $\square$ & $\square$ & $\square$ & $\square$ & $\square$ & $\square$ & $\square$ & $\square$ & $\square$ & $\square$ & $\square$ \\
\hline
\end{tabular}

Escriba, si lo desea, algún comentario o especifique el tipo de ruidos que le molestan y que no hayan sido contemplados:

\section{RUIDO DE CONSTRUCCIÓN, OBRAS Y REFORMAS}

Refiriéndose al ruido de construcción, obras y reformas, y pensando aproximadamente en los últimos 12 meses...

¿Podría indicar la molestia que le ocasiona el ruido producido por las distintas actividades mostradas cuando está en el interior de su vivienda?

\begin{tabular}{|c|c|c|c|c|c|c|c|c|c|c|c|c|}
\hline & 0 & 1 & 2 & 3 & 4 & 5 & 6 & 7 & 8 & 9 & 10 & $\begin{array}{c}\text { No lo } \\
\text { oigo }\end{array}$ \\
\hline Edificación & $\square$ & $\square$ & $\square$ & $\square$ & $\square$ & $\square$ & $\square$ & $\square$ & $\square$ & $\square$ & $\square$ & D \\
\hline $\begin{array}{l}\text { Otras construcciones } \\
\text { (parques, campos de fútbol, } \\
\text { infraestructuras\&hellip;) }\end{array}$ & $\square$ & $\square$ & $\square$ & $\square$ & $\square$ & $\square$ & $\square$ & $\square$ & $\square$ & $\square$ & $\square$ & $\square$ \\
\hline Demolición & $\square$ & $\square$ & $\square$ & $\square$ & $\square$ & $\square$ & $\square$ & $\square$ & $\square$ & $\square$ & $\square$ & $\square$ \\
\hline
\end{tabular}

I2A2 - Universidad Politécnica de Madrid 


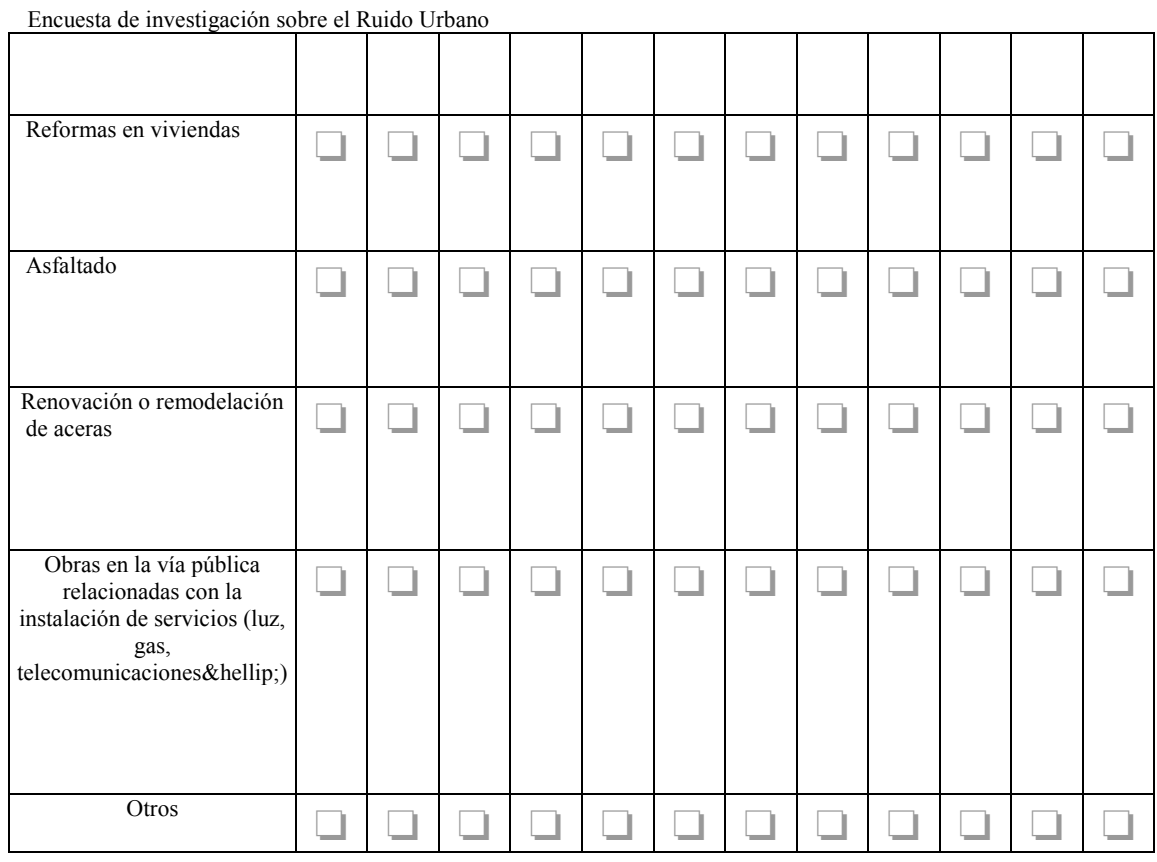

Escriba, si lo desea, algún comentario o especifique el tipo de ruidos que le molestan y que no hayan sido contemplados:

\section{RUIDO DE ACTIVIDADES COMERCIALES}

Refiriéndose al ruido de actividades comerciales y pensando aproximadamente en los últimos 12 meses..

¿Podría indicar la molestia que le ocasiona el ruido producido por las distintas actividades mostradas cuando está en el interior de su vivienda?

\begin{tabular}{|c|c|c|c|c|c|c|c|c|c|c|c|c|}
\hline & 0 & 1 & 2 & 3 & 4 & 5 & 6 & 7 & 8 & 9 & 10 & $\begin{array}{c}\text { No lo } \\
\text { oigo }\end{array}$ \\
\hline Centros comerciales & $\square$ & $\square$ & $\square$ & $\square$ & $\square$ & $\square$ & $\square$ & $\square$ & $\square$ & $\square$ & $\square$ & $\square$ \\
\hline Gasolineras & $\square$ & $\square$ & $\square$ & $\square$ & $\square$ & $\square$ & $\square$ & $\square$ & $\square$ & $\square$ & $\square$ & $\square$ \\
\hline Supermercados & $\square$ & $\square$ & $\square$ & $\square$ & $\square$ & $\square$ & $\square$ & $\square$ & $\square$ & $\square$ & $\square$ & $\square$ \\
\hline Tiendas & $\square$ & $\square$ & $\square$ & $\square$ & $\square$ & $\square$ & $\square$ & $\square$ & $\square$ & $\square$ & $\square$ & $\square$ \\
\hline Rastrillos o mercadillos & $\square$ & $\square$ & $\square$ & $\square$ & $\square$ & $\square$ & $\square$ & $\square$ & $\square$ & $\square$ & $\square$ & $\square$ \\
\hline Puntos limpios & $\square$ & $\square$ & $\square$ & $\square$ & $\square$ & $\square$ & $\square$ & $\square$ & $\square$ & $\square$ & $\square$ & $\square$ \\
\hline Aglomeración de gente en \\
calles & $\square$ & $\square$ & $\square$ & $\square$ & $\square$ & $\square$ & $\square$ & $\square$ & $\square$ & $\square$ & $\square$ & $\square$ \\
\hline Instalaciones de climatización & $\square$ & $\square$ & $\square$ & $\square$ & $\square$ & $\square$ & $\square$ & $\square$ & $\square$ & $\square$ & $\square$ & $\square$ \\
\hline
\end{tabular}

I2A2 - Universidad Politécnica de Madrid 
Encuesta de investigación sobre el Ruido Urbano

Encuesta de investigación sobre el Ruido Urbano
\begin{tabular}{|c|c|c|c|c|c|c|c|c|c|c|c|c|}
\hline $\begin{array}{c}\text { Operaciones de } \\
\text { mantenimiento }\end{array}$ & $\square$ & $\square$ & $\square$ & $\square$ & $\square$ & $\square$ & $\square$ & $\square$ & $\square$ & $\square$ & $\square$ & $\square$ \\
\hline Carga y descarga & $\square$ & $\square$ & $\square$ & $\square$ & $\square$ & $\square$ & $\square$ & $\square$ & $\square$ & $\square$ & $\square$ & $\square$ \\
\hline Otros & $\square$ & $\square$ & $\square$ & $\square$ & $\square$ & $\square$ & $\square$ & $\square$ & $\square$ & $\square$ & $\square$ & $\square$ \\
\hline
\end{tabular}

Escriba, si lo desea, algún comentario o especifique el tipo de ruidos que le molestan y que no hayan sido contemplados: -

\section{RUIDO DEL OCIO}

Refiriéndose al ruido del ocioy pensando aproximadamente en los últimos 12 meses.

¿Podría indicar la molestia que le ocasiona el ruido producido por las distintas actividades mostradas cuando está en el interior de su vivienda?

\begin{tabular}{|c|c|c|c|c|c|c|c|c|c|c|c|c|}
\hline & 0 & 1 & 2 & 3 & 4 & 5 & 6 & 7 & 8 & 9 & $\begin{array}{c}\text { No lo } \\
\text { oigo }\end{array}$ \\
\hline Espectáculos al aire libre & $\square$ & $\square$ & $\square$ & $\square$ & $\square$ & $\square$ & $\square$ & $\square$ & $\square$ & $\square$ & $\square$ & $\square$ \\
\hline Discotecas & $\square$ & $\square$ & $\square$ & $\square$ & $\square$ & $\square$ & $\square$ & $\square$ & $\square$ & $\square$ & $\square$ & $\square$ \\
\hline Pubs & $\square$ & $\square$ & $\square$ & $\square$ & $\square$ & $\square$ & $\square$ & $\square$ & $\square$ & $\square$ & $\square$ & $\square$ \\
\hline $\begin{array}{c}\text { Prácticas deportivas } \\
\text { Afluencia de gente a eventos } \\
\text { deportivos }\end{array}$ & $\square$ & $\square$ & $\square$ & $\square$ & $\square$ & $\square$ & $\square$ & $\square$ & $\square$ & $\square$ & $\square$ & $\square$ \\
\hline $\begin{array}{c}\text { Salones de juego } \\
\text { Recintos feriales }\end{array}$ & $\square$ & $\square$ & $\square$ & $\square$ & $\square$ & $\square$ & $\square$ & $\square$ & $\square$ & $\square$ & $\square$ & $\square$ \\
\hline $\begin{array}{c}\text { Bares, restaurantes, terrazas } \\
\text { Acumulación de gente }\end{array}$ & $\square$ & $\square$ & $\square$ & $\square$ & $\square$ & $\square$ & $\square$ & $\square$ & $\square$ & $\square$ & $\square$ & $\square$ \\
\hline $\begin{array}{c}\text { asociada a bares, restaurantes } \\
\text { y terrazas }\end{array}$ & $\square$ & $\square$ & $\square$ & $\square$ & $\square$ & $\square$ & $\square$ & $\square$ & $\square$ & $\square$ & $\square$ & $\square$ \\
\hline $\begin{array}{c}\text { Botellón } \\
\text { Parques infantiles }\end{array}$ & $\square$ & $\square$ & $\square$ & $\square$ & $\square$ & $\square$ & $\square$ & $\square$ & $\square$ & $\square$ & $\square$ & $\square$ \\
\hline $\begin{array}{c}\text { Otras aglomeraciones de } \\
\text { gente }\end{array}$ & $\square$ & $\square$ & $\square$ & $\square$ & $\square$ & $\square$ & $\square$ & $\square$ & $\square$ & $\square$ & $\square$ & $\square$ \\
\hline $\begin{array}{c}\text { Otras actividades lúdicas } \\
\text { Ontros }\end{array}$ & $\square$ & $\square$ & $\square$ & $\square$ & $\square$ & $\square$ & $\square$ & $\square$ & $\square$ & $\square$ & $\square$ & $\square$ \\
\hline$\square$ & $\square$ & $\square$ & $\square$ & $\square$ & $\square$ & $\square$ & $\square$ & $\square$ & $\square$ & $\square$ & $\square$ \\
\hline
\end{tabular}

\section{RUIDO DEL OCIO}

Refiriéndose al ruido del ocio y pensando aproximadamente en los últimos 12 meses...

¿Podría indicar la molestia que le ocasionan los distintos tipos de ruido mostrados cuando está en el interior de su vivienda?

\begin{tabular}{|c|c|c|c|c|c|c|c|c|c|c|c|c|}
\hline & 0 & 1 & 2 & 3 & 4 & 5 & 6 & 7 & 8 & 9 & 10 & $\begin{array}{c}\text { No lo } \\
\text { oigo }\end{array}$ \\
\hline $\begin{array}{c}\text { Fumadores en la puerta de un } \\
\text { bar, restaurante, discoteca... }\end{array}$ & $\square$ & $\square$ & $\square$ & $\square$ & $\square$ & $\square$ & $\square$ & $\square$ & $\square$ & $\square$ & $\square$ & $\square$ \\
\hline
\end{tabular}

I2A2 - Universidad Politécnica de Madrid 


Encuesta de investigación sobre el Ruido Urbano
\begin{tabular}{|c|c|c|c|c|c|c|c|c|c|c|c|c|}
\hline Conversaciones & $\square$ & $\square$ & $\square$ & $\square$ & $\square$ & $\square$ & $\square$ & $\square$ & $\square$ & $\square$ & $\square$ & $\square$ \\
\hline Bullicio, cánticos, gritos... & $\square$ & $\square$ & $\square$ & $\square$ & $\square$ & $\square$ & $\square$ & $\square$ & $\square$ & $\square$ & $\square$ & $\square$ \\
\hline Riñas, peleas & $\square$ & $\square$ & $\square$ & $\square$ & $\square$ & $\square$ & $\square$ & $\square$ & $\square$ & $\square$ & $\square$ & $\square$ \\
\hline Música & $\square$ & $\square$ & $\square$ & $\square$ & $\square$ & $\square$ & $\square$ & $\square$ & $\square$ & $\square$ & $\square$ & $\square$ \\
\hline Arrastre de sillas & $\square$ & $\square$ & $\square$ & $\square$ & $\square$ & $\square$ & $\square$ & $\square$ & $\square$ & $\square$ & $\square$ & $\square$ \\
\hline Niños jugando & $\square$ & $\square$ & $\square$ & $\square$ & $\square$ & $\square$ & $\square$ & $\square$ & $\square$ & $\square$ & $\square$ & $\square$ \\
\hline Golpes, balonazos... & $\square$ & $\square$ & $\square$ & $\square$ & $\square$ & $\square$ & $\square$ & $\square$ & $\square$ & $\square$ & $\square$ & $\square$ \\
\hline Otras actividades cotidianas & $\square$ & $\square$ & $\square$ & $\square$ & $\square$ & $\square$ & $\square$ & $\square$ & $\square$ & $\square$ & $\square$ & $\square$ \\
\hline Otros actos incívicos & $\square$ & $\square$ & $\square$ & $\square$ & $\square$ & $\square$ & $\square$ & $\square$ & $\square$ & $\square$ & $\square$ & $\square$ \\
\hline Otros & $\square$ & $\square$ & $\square$ & $\square$ & $\square$ & $\square$ & $\square$ & $\square$ & $\square$ & $\square$ & $\square$ & $\square$ \\
\hline
\end{tabular}

Escriba, si lo desea, algún comentario o especifique el tipo de ruidos que le molestan y que no hayan sido contemplados:

\section{RUIDO DEL OCIO}

Refiriéndose al ruido del ocio y pensando aproximadamente en los últimos 12 meses...

¿Con qué frecuencia participa usted en las siguientes actividades?

\begin{tabular}{|c|c|c|c|}
\hline & Muy a menudo & Alguna vez & $\begin{array}{c}\text { Nunca o casi } \\
\text { nunca }\end{array}$ \\
\hline Parques infantiles & $\square$ & $\square$ & $\square$ \\
\hline Espectáculos al aire libre & $\square$ & $\square$ & $\square$ \\
\hline Bares, restaurantes y terrazas & $\square$ & $\square$ & $\square$ \\
\hline Pubs, discotecas & $\square$ & $\square$ & $\square$ \\
\hline Práctica de deportes colectivos & $\square$ & $\square$ & $\square$ \\
\hline Cine, teatro... & $\square$ & $\square$ & $\square$ \\
\hline
\end{tabular}

\section{RUIDO DE SERVICIOS PÚBLICOS}

Refiriéndose al ruido de servicios públicos y pensando aproximadamente en los últimos 12 meses...

¿Podría indicarnos el grado de molestia que le ocasiona el ruido que producen los diferentes tipos de actividad enumeradas cuando se encuentra en el interior de esta vivienda?

\begin{tabular}{|c|c|c|c|c|c|c|c|c|c|c|c|c|}
\hline & 0 & 1 & 2 & 3 & 4 & 5 & 6 & 7 & 8 & 9 & 10 & $\begin{array}{c}\text { No lo } \\
\text { oigo }\end{array}$ \\
\hline $\begin{array}{c}\text { Barredoras y otros vehículos } \\
\text { de limpieza }\end{array}$ & $\square$ & $\square$ & $\square$ & $\square$ & $\square$ & $\square$ & $\square$ & $\square$ & $\square$ & $\square$ & $\square$ & $\square$ \\
\hline $\begin{array}{c}\text { Recogida de residuos urbanos } \\
\text { (basura, reciclaje) }\end{array}$ & $\square$ & $\square$ & $\square$ & $\square$ & $\square$ & $\square$ & $\square$ & $\square$ & $\square$ & $\square$ & $\square$ & $\square$ \\
\hline
\end{tabular}

I2A2 - Universidad Politécnica de Madrid 
Encuesta de investigación sobre el Ruido Urbano

Encuesta de investigación sobre el Ruido Urbano
\begin{tabular}{|c|c|c|c|c|c|c|c|c|c|c|c|c|}
\hline Otros servicios de limpieza & $\square$ & $\square$ & $\square$ & $\square$ & $\square$ & $\square$ & $\square$ & $\square$ & $\square$ & $\square$ & $\square$ & $\square$ \\
\hline Jardinería & $\square$ & $\square$ & $\square$ & $\square$ & $\square$ & $\square$ & $\square$ & $\square$ & $\square$ & $\square$ & $\square$ & $\square$ \\
\hline $\begin{array}{c}\text { Centros educativos (timbres, } \\
\text { patio...) }\end{array}$ & $\square$ & $\square$ & $\square$ & $\square$ & $\square$ & $\square$ & $\square$ & $\square$ & $\square$ & $\square$ & $\square$ & $\square$ \\
\hline $\begin{array}{c}\text { Centros sanitarios } \\
\text { Estaciones de bomberos }\end{array}$ & $\square$ & $\square$ & $\square$ & $\square$ & $\square$ & $\square$ & $\square$ & $\square$ & $\square$ & $\square$ & $\square$ & $\square$ \\
\hline Comisarias & $\square$ & $\square$ & $\square$ & $\square$ & $\square$ & $\square$ & $\square$ & $\square$ & $\square$ & $\square$ & $\square$ & $\square$ \\
\hline Edificios religiosos & $\square$ & $\square$ & $\square$ & $\square$ & $\square$ & $\square$ & $\square$ & $\square$ & $\square$ & $\square$ & $\square$ & $\square$ \\
\hline Otros & $\square$ & $\square$ & $\square$ & $\square$ & $\square$ & $\square$ & $\square$ & $\square$ & $\square$ & $\square$ & $\square$ & $\square$ \\
\hline
\end{tabular}

Escriba, si lo desea, algún comentario o especifique el tipo de ruidos que le molestan y que no hayan sido contemplados:

\section{OTROS RUIDOS}

Refiriéndose otros ruidos y pensando aproximadamente en los últimos 12 meses..

¿Podría precisar a qué tipo de ruidos se refiere?

¿Podría indicarnos la molestia que le ocasiona el ruido que producen cuando se encuentra en el interior de su vivienda?

\begin{tabular}{|c|c|c|c|c|c|c|c|c|c|c|c|c|}
\hline & 0 & 1 & 2 & 3 & 4 & 5 & 6 & 7 & 8 & 9 & 10 & $\begin{array}{c}\text { No lo } \\
\text { oigo }\end{array}$ \\
\hline Ruido 1 & $\square$ & $\square$ & $\square$ & $\square$ & $\square$ & $\square$ & $\square$ & $\square$ & $\square$ & $\square$ & $\square$ & $\square$ \\
\hline Ruido 2 & $\square$ & $\square$ & $\square$ & $\square$ & $\square$ & $\square$ & $\square$ & $\square$ & $\square$ & $\square$ & $\square$ & $\square$ \\
\hline
\end{tabular}

\section{TIPO DE RUIDO: \$ custom1\}}

En referencia al $\$\{$ custom 1$\}$..

Seleccione un máximo de CINCO palabras que mejor describan su sentimiento cuando escucha ese tipo de ruido:
1. Irritado
2. Ansioso
3. Molesto
4. Cómodo
5. Asustado
6. Preocupado
7. Bien
8. Tenso
9. Sorprendido
10. Estresado
11. Cansado
12. Animado
13. Deprimido
14. Harto
15. Seguro
16. Relajado
17. Furioso
18. Excitado

I2A2 - Universidad Politécnica de Madrid 
Encuesta de investigación sobre el Ruido Urbano

19. Triste

20. Indispuesto

¿Interfiere ese tipo de ruido a alguna de las actividades que realiza en su casa durante su vida cotidiana?

\begin{tabular}{|c|c|c|}
\hline & Si & No \\
\hline Ver/escuchar TV, radio o música & $\square$ & $\square$ \\
\hline Tener una conversación (incluyendo telefónica) & $\square$ & $\square$ \\
\hline Ceer, escribir o cualquier actividad que requiera un ambiente tranquilo & $\square$ & $\square$ \\
\hline Concentrarme & $\square$ & $\square$ \\
\hline Dormir & $\square$ & $\square$ \\
\hline Utilizar la casa en general & $\square$ & $\square$ \\
\hline Pasar tiempo en el jardín, balcón o terraza & $\square$ & $\square$ \\
\hline Tener las ventanas o puertas abiertas & $\square$ & $\square$ \\
\hline Estar tiempo en casa & $\square$ & $\square$ \\
\hline
\end{tabular}

TIPO DE RUIDO: \$ custom1\}

En referencia al $\$\{$ custom 1$\} \ldots$

¿En qué periodos del día le molesta o incomoda esta fuente de ruido?

Días laborables[,]

\begin{tabular}{|c|c|c|c|c|}
\hline & Si & No & A veces & No lo sé \\
\hline Periodo diurno (7 - 19h) & $\square$ & $\square$ & $\square$ & $\square$ \\
\hline Periodo tarde (19-23h) & $\square$ & $\square$ & $\square$ & $\square$ \\
\hline Periodo noche (23- 7h) & $\square$ & $\square$ & $\square$ & $\square$ \\
\hline
\end{tabular}

Fines de semana y/o festivos[,]

\begin{tabular}{|c|c|c|c|c|}
\hline & Si & No & A veces & No lo sé \\
\hline Periodo diurno (7 - 19h) & $\square$ & $\square$ & $\square$ & \\
\hline Periodo tarde (19-23h) & $\square$ & $\square$ & $\square$ & $\square$ \\
\hline Periodo noche (23- 7h) & $\square$ & $\square$ & $\square$ & $\square$ \\
\hline
\end{tabular}

I2A2 - Universidad Politécnica de Madrid 
Encuesta de investigación sobre el Ruido Urbano

TIPO DE RUIDO: $\$\{$ custom1 $\}$

Refiriéndose al $\$\{$ custom 1$\}$ y pensando aproximadamente en los últimos 12 meses..

¿Con qué frecuencia se produce el ruido que le molesta?
1. Todos o casi todos los dias
2. Alguna vez a la semana
3. Alguna vez al mes
4. Alguna vez a lo largo del año

¿En qué época le molesta más ese tipo de ruido?

1. Primavera-Verano

2. Otoño-Invierno

3. No hay diferencias

4. Varía

5. No lo sé

¿Diría que el ruido procedente de esa fuente en concreto ha mejorado o empeorado a lo largo de los últimos 5 años?

1. Ha mejorado mucho

2. Ha mejorado algo

3. Ni ha mejorado ni empeorado

4. Ha empeorado algo

5. Ha empeorado mucho

6. No soy capaz de valorarlo

7. No lo sé

¿Hay alguna cuestión en concreto que le gustaría exponer o expresar respecto al ruido procedente de la fuente elegida?

PARA FINALIZAR

A lo largo de la investigación es posible que volvamos a necesitar su ayuda. ¿Nos da su consentimiento para contactar nuevamente con usted en relación a esta Investigación sobre el Ruido?

1. Si, sólo con este fin

2. No

1. Málaga 2015 DEFINITIVA

I2A2 - Universidad Politécnica de Madrid 



\title{
Apéndice B: Invitación a la encuesta
}

\author{
Encuesta de investigación sobre el Ruido \\ Urbano en Málaga
}

POLITÉCNICA

"Ingeniamos el futuro"

Código de Invitación: 4 gv84dno

Número para el sorteo: 668

\author{
Sr/Sra. Residente \\ Calle MONTAÑO 2 Escalera: $1^{\circ}-1$ \\ 29012 Malaga (Málaga)
}

La Universidad Politécnica de Madrid (UPM) está realizando una Investigación en distintas ciudades españolas en relación al Ruido Urbano, con el fin último de reducir la contaminación acústica en las ciudades y mejorar la calidad de vida de los ciudadanos.

Su vivienda ha sido seleccionada por la UPM, de manera aleatoria, entre un conjunto de más de 2000 viviendas de Málaga cuyas características se ajustan a los objetivos del estudio, y es por esto que quisiéramos invitarle a colaborar con este proyecto participando en una sencilla encuesta en la que se le dará la posibilidad de manifestar su opinión respecto a aspectos básicos de su ciudad.

La realización de esta encuesta tan sólo le llevará 10 minutos, y, en agradecimiento a su colaboración, podrá ser agraciado con uno de los 5 premios que sorteamos, a elegir por los ganadores:

- Cofre VIP "Experiencias a la Carta", cuyas condiciones son las determinadas en la página www.cofrevip.com.

- Tablet Android 7" Airis Onepad 740 - Tab740

- Tarjeta regalo El Corte Inglés (con un importe de 50€).

Para la realización de la encuesta es necesario ser mayor de 18 años y ser residente en la vivienda. Si usted no cumpliera esos requerimientos, le agradeceríamos enormemente que hiciera llegar esta invitación a un mayor de edad que resida en la vivienda.

Para cumplimentar la encuesta, hemos habilitado dos posibilidades alternativas:

- Encuesta web: Conéctese a https://ruidourbanoupm.questionpro.com, y rellene la encuesta cuando prefiera. Para acceder a la cumplimentación, deberá introducir el código de invitación escrito en la parte superior de esta carta.

- Cómo medida de seguridad y para evitar respuestas múltiples, sólo se puede acceder a la encuesta una única vez, por eso le pedimos que cuando la rellene disponga del tiempo suficiente para finalizarla al completo.

- Encuesta telefónica: Para ello, es necesario que nos facilite un teléfono de contacto. Llámenos al número 913364696, y concertaremos con usted una cita, para realizarle la encuesta por teléfono'.

El plazo para cumplimentar la encuesta finaliza el próximo: 22 de abril de 2015.

Agradeciendo de antemano su colaboración con este proyecto de investigación, reciba un cordial saludo del Equipo de Investigación de la UPM.

Grupo de Investigación en Instrumentación y Acústica Aplicada (I2A2)

Nota: GUARDE ESTA INVITACIÓN, ya que le será necesaria para participar en la encuesta y el sorteo.

1 La alternativa de encuesta telefónica, podrá quedar restringida o cancelada unilateralmente por la UPM por motivos logisticos.

2 En la página web www.i2a2.upm.es, puede encontrar la politica de privacidad de la encuesta y las bases del sorteo 


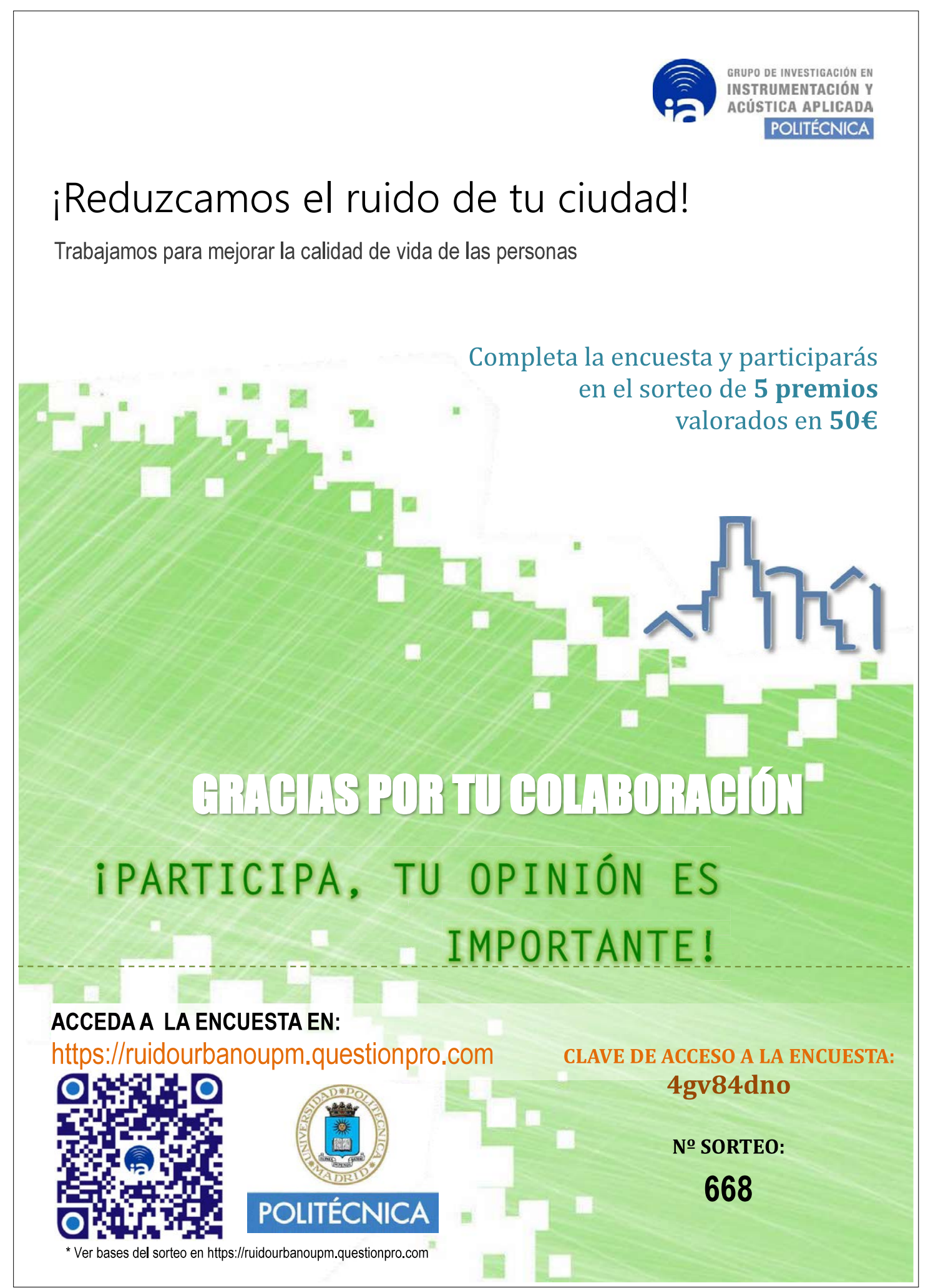




\section{Apéndice C: Encuesta final}

Encuesta de investigación sobre el Ruido Urbano DATOS SOCIO-DEMOGRÁFICOS

Género:

1. Hombre

2. Mujer

Edad

1. $18-19$

2. $20-24$

3. $25-34$

4. $35-44$

5. $45-54$

6. $55-64$

7. $65-74$

8. \&gt;75

9. Prefiero no contestar

Nacionalidad

1. Español/a

2. Europeo/a

3. Otra

4. Prefiero no contestar

\section{DATOS SOCIO-DEMOGRÁFICOS}

Nivel de estudios:

1. Sin estudios

2. Educación primaria

3. Educación secundaria

4. Bachillerato/ Formación profesional

5. Estudios superiores no universitarios

6. Estudios superiores universitarios

7. Prefiero no contestar

¿Cuál de las siguientes opciones describe mejor su situación actual?

1. Estoy trabajando a tiempo completo

2. Estoy trabajando a tiempo parcial

3. Estoy desempleado/a y buscando trabajo

4. Estoy retirado/a o jubilado/a

5. Estoy estudiando

6. Estoy dedicado/a a las labores del hogar

7. Prefiero no contestar

8. Otra (especificar)

Escriba aquí el nombre de su municipio:

DATOS SOCIO-DEMOGRÁFICOS

¿En qué distrito de Málaga reside?

1. Centro

2. Este

3. Ciudad Jardín

4. Bailén-Miraflores

5. Palma-Palmilla

6. Cruz de Humilladero

7. Carretera de Cádiz

8. Churriana

9. Campanillas

10. Puerto de la Torre

11. Teatinos-Universidad

12. No lo sé

I2A2 - Universidad Politécnica de Madrid 


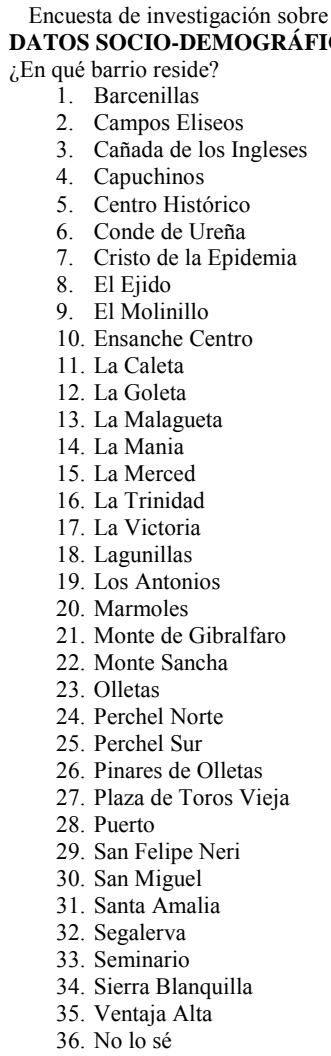

\section{DATOS SOCIO-DEMOGRÁFICOS}

¿En qué barrio reside?

1. Cañada de los Cardos

2. Ciudad Santa Inés

3. Ciudad Universitaria

4. Colonia Santa Inés

5. Cortijo Alto

6. El Cónsul

7. El Cónsul 2

8. El Romeral

9. El Tejar

10. Finca La Palma

11. Hacienda Bizcochero

12. Hacienda Capitán

13. Hacienda Roldán

14. Las Morillas

15. Los Molinos

16. Quinta Alegre

17. Teatinos

18. Torre Atalaya

19. No lo sé

I2A2 - Universidad Politécnica de Madrid 
Encuesta de investigación sobre el Ruido Urbano

DATOS SOCIO-DEMOGRÁFICOS

¿En qué barrio reside?

\section{DATOS SOCIO-DEMOGRÁFICOS}

¿Cuánto tiempo hace que reside en esta ciudad?

1. Menos de 6 meses

2. De 6 meses a 1 año

3. De 1 a 2 años

4. De 2 a 5 años

5. De 5 a 10 años

6. Más de 10 año

7. Desde siempre

\section{RESPECTO A SU VIVIENDA}

En relación a la vivienda dónde reside...

¿Cuánto tiempo lleva residiendo en esta vivienda?
1. Menos de 6 meses
2. De 6 meses a 1 año
3. De 1 a 2 años
4. De 2 a 5 años
5. De 5 a 10 años
6. Más de 10 años
7. Desde siempre

¿Cómo valora el aislamiento acústico de esta vivienda?
1. Muy bueno
2. Bueno
3. Regular
4. Malo
5. Muy malo
6. No lo sé

¿Cuentan las ventanas de su vivienda con doble acristalamiento?
1. Sí, todas
2. Sí, algunas
3. No, ninguna
4. No lo sé

\section{SU RELACIÓN CON EL RUIDO}

En relación a usted y el ruido en su barrio...

¿Cómo de sensible se considera usted con respecto al ruido?

\begin{tabular}{|l|c|c|c|c|c|c|c|c|c|c|c|c|}
\hline & 0 & 1 & 2 & 3 & 4 & 5 & 6 & 7 & 8 & 9 & 10 & $\begin{array}{c}\text { No lo } \\
\text { sé }\end{array}$ \\
\hline & $\square$ & $\square$ & $\square$ & $\square$ & $\square$ & $\square$ & $\square$ & $\square$ & $\square$ & $\square$ & $\square$ & $\square$ \\
\hline
\end{tabular}

¿Cómo de ruidoso considera que es su barrio?

¿Cómo de ruidoso considera que es su barrio?
\begin{tabular}{|c|c|c|c|c|c|c|c|c|c|c|c|c|}
\hline & 0 & 1 & 2 & 3 & 4 & 5 & 6 & 7 & 8 & 9 & 10 & $\begin{array}{c}\text { No lo } \\
\text { sé }\end{array}$ \\
\hline & $\square$ & $\square$ & $\square$ & $\square$ & $\square$ & $\square$ & $\square$ & $\square$ & $\square$ & $\square$ & $\square$ & $\square$ \\
\hline
\end{tabular}

I2A2 - Universidad Politécnica de Madrid 
Encuesta de investigación sobre el Ruido Urbano

¿Pertenece usted, o alguno de los residentes en su vivienda a alguna asociación o agrupación que tenga entre sus objetivos la lucha contra el ruido?

1. Sí

2. No

SU RELACIÓN CON EL RUIDO

Pensando en los últimos 12 meses, cuando está en el interior de su vivienda...

¿Hasta que punto diría que le molesta, incomoda o afecta el ruido que procede de la calle?

1. Extremadamente

2. Mucho

3. Medianamente

4. Ligeramente

5. Absolutamente nada

¿Podría indicar cuánto le molesta o incomoda el ruido producido por las siguientes fuentes sonoras?

\begin{tabular}{|c|c|c|c|c|c|c|c|c|c|c|c|c|}
\hline & 0 & 1 & 2 & 3 & 4 & 5 & 6 & 7 & 8 & 9 & 10 & $\begin{array}{c}\text { Nunca } \\
\text { lo oigo }\end{array}$ \\
\hline Tráfico rodado & $\square$ & $\square$ & $\square$ & $\square$ & $\square$ & $\square$ & $\square$ & $\square$ & $\square$ & $\square$ & $\square$ & $\square$ \\
\hline Tráfico aéreo & $\square$ & $\square$ & $\square$ & $\square$ & $\square$ & $\square$ & $\square$ & $\square$ & $\square$ & $\square$ & $\square$ & $\square$ \\
\hline Tráfico ferroviario & $\square$ & $\square$ & $\square$ & $\square$ & $\square$ & $\square$ & $\square$ & $\square$ & $\square$ & $\square$ & $\square$ & $\square$ \\
\hline $\begin{array}{c}\text { Construcción, obras, } \\
\text { reformas\&hellip; }\end{array}$ & $\square$ & $\square$ & $\square$ & $\square$ & $\square$ & $\square$ & $\square$ & $\square$ & $\square$ & $\square$ & $\square$ & $\square$ \\
\hline \begin{tabular}{c} 
Actividades comerciales \\
\hline $\begin{array}{c}\text { Actividades de ocio (bares, } \\
\text { espectáculos, deportes...) }\end{array}$
\end{tabular}$\quad \square$ & $\square$ & $\square$ & $\square$ & $\square$ & $\square$ & $\square$ & $\square$ & $\square$ & $\square$ & $\square$ & $\square$ & $\square$ \\
\hline Servicios & $\square$ & $\square$ & $\square$ & $\square$ & $\square$ & $\square$ & $\square$ & $\square$ & $\square$ & $\square$ & $\square$ & $\square$ \\
\hline Vecinos & $\square$ & $\square$ & $\square$ & $\square$ & $\square$ & $\square$ & $\square$ & $\square$ & $\square$ & $\square$ & $\square$ & $\square$ \\
\hline Otros ruidos & $\square$ & $\square$ & $\square$ & $\square$ & $\square$ & $\square$ & $\square$ & $\square$ & $\square$ & $\square$ & $\square$ & $\square$ \\
\hline
\end{tabular}

Utilice este espacio para escribir cualquier comentario acerca de ruidos que le molesten:

TODAS LAS FUENTES DE RUIDO EN SU ZONA DE RESIDENCIA

Teniendo en cuenta los ruidos y sonidos de esta zona..

¿Considera que el ruido es un problema en su vida?

1. $\mathrm{Si}$

2. No

¿Podría valorar en qué medida el ruido existente en esta zona deteriora su calidad de vida?

\begin{tabular}{|l|c|c|c|c|c|c|c|c|c|c|c|c|}
\hline & 0 & 1 & 2 & 3 & 4 & 5 & 6 & 7 & 8 & 9 & 10 & $\begin{array}{c}\text { No lo } \\
\text { sé }\end{array}$ \\
\hline & $\square$ & $\square$ & $\square$ & $\square$ & $\square$ & $\square$ & $\square$ & $\square$ & $\square$ & $\square$ & $\square$ & $\square$ \\
\hline
\end{tabular}

I2A2 - Universidad Politécnica de Madrid 
Encuesta de investigación sobre el Ruido Urbano

¿Considera que la situación respecto al ruido en esta vivienda es mejor o peor que hace 5 años?

\begin{tabular}{|l|c|c|c|c|c|c|c|}
\hline & $\begin{array}{c}\text { Ha } \\
\text { mejorado } \\
\text { mucho }\end{array}$ & $\begin{array}{c}\text { Ha } \\
\text { mejorado } \\
\text { poco }\end{array}$ & $\begin{array}{c}\text { No ha } \\
\text { mejorado } \\
\text { ni } \\
\text { empeorad } \\
\text { o }\end{array}$ & $\begin{array}{c}\text { Ha } \\
\text { empeorad } \\
\text { o algo }\end{array}$ & $\begin{array}{c}\text { Ha } \\
\text { empeorad } \\
\text { o mucho }\end{array}$ & $\begin{array}{c}\text { No soy } \\
\text { capaz de } \\
\text { valorarlo }\end{array}$ & No lo sé \\
\hline & $\square$ & $\square$ & $\square$ & $\square$ & $\square$ & $\square$ & $\square$ \\
\hline
\end{tabular}

TODAS LAS FUENTES DE RUIDO EN SU ZONA DE RESIDENCIA

Pensando aproximadamente en los últimos 5 años...

¿Usted o alguien de su familia ha emprendido alguna acción para solucionar un problema relacionado con el ruido existente en su zona o su vivienda? ¿Fue dicha acción efectiva?

¿A cuáles de las siguientes fuentes de ruido estaban ligadas las acciones que ha mencionado en la pregunta anterior?
1. Tráfico rodado
2. Tráfico aéreo
3. Tráfico ferroviario
4. Construcción, obras, reformas\&hellip;
5. Actividades comerciales
6. Actividades de ocio (bares, espectáculos, deportes...)
7. Servicios
8. Vecinos
9. Otros ruidos

Utilice este espacio para detallar o comentar su experiencia relacionada con las acciones emprendidas:

\section{FUENTES DE RUIDO ESPECÍFICAS}

Pensando aproximadamente en los últimos 12 meses...

¿Podría indicar cuál de las siguientes fuentes de ruido le afecta más cuando está en su vivienda? Elija sólo una respuesta, por favor:
1. Tráfico rodado
2. Tráfico aéreo
3. Tráfico ferroviario
4. Construcción, obras, reformas\&hellip;
5. Actividades comerciales
6. Actividades de ocio (bares, espectáculos, deportes...)
7. Servicios
8. Vecinos
9. Otros ruidos
10. No me molesta ninguna fuente de ruido 
Encuesta de investigación sobre el Ruido Urbano

TRÁFICO FERROVIARIO

Refiriéndose al ruido producido por el tráfico ferroviarioy pensando en los últimos 12 meses aproximadamente...

¿Podría indicar la molestia que le ocasiona el ruido producido por las distintas actividades mostradas cuando está en el interior de su vivienda?

\begin{tabular}{|c|c|c|c|c|c|c|c|c|c|c|c|c|}
\hline & 0 & 1 & 2 & 3 & 4 & 5 & 6 & 7 & 8 & 9 & $\begin{array}{c}\text { No lo } \\
\text { oigo }\end{array}$ \\
\hline \begin{tabular}{c} 
Cercanías, metro \\
\hline $\begin{array}{c}\text { Larga distancia, alta } \\
\text { velocidad }\end{array}$
\end{tabular} & $\square$ & $\square$ & $\square$ & $\square$ & $\square$ & $\square$ & $\square$ & $\square$ & $\square$ & $\square$ & $\square$ & $\square$ \\
\hline $\begin{array}{c}\text { Tren ligero, metro ligero, } \\
\text { tranvía }\end{array}$ & $\square$ & $\square$ & $\square$ & $\square$ & $\square$ & $\square$ & $\square$ & $\square$ & $\square$ & $\square$ & $\square$ & $\square$ \\
\hline $\begin{array}{c}\text { Mercancías } \\
\text { Estaciones }\end{array}$ & $\square$ & $\square$ & $\square$ & $\square$ & $\square$ & $\square$ & $\square$ & $\square$ & $\square$ & $\square$ & $\square$ & $\square$ \\
\hline Otros & $\square$ & $\square$ & $\square$ & $\square$ & $\square$ & $\square$ & $\square$ & $\square$ & $\square$ & $\square$ & $\square$ & $\square$ \\
\hline$\square$ & $\square$ & $\square$ & $\square$ & $\square$ & $\square$ & $\square$ & $\square$ & $\square$ & $\square$ & $\square$ & $\square$ \\
\hline
\end{tabular}

Escriba, si lo desea, algún comentario o especifique el tipo de ruidos que le molestan y que no hayan sido contemplados:

\section{TRÁFICO AÉREO}

Refiriéndose al ruido producido por el tráfico aéreoy pensando en los últimos 12 meses aproximadamente...

¿Podría indicar la molestia que le ocasiona el ruido producido por las distintas fuentes mostradas cuando está en el interior de su vivienda?

\begin{tabular}{|c|c|c|c|c|c|c|c|c|c|c|c|c|}
\hline & 0 & 1 & 2 & 3 & 4 & 5 & 6 & 7 & 8 & 9 & 10 & $\begin{array}{c}\text { No lo } \\
\text { oigo }\end{array}$ \\
\hline Vuelos comerciales & $\square$ & $\square$ & $\square$ & $\square$ & $\square$ & $\square$ & $\square$ & $\square$ & $\square$ & $\square$ & $\square$ & $\square$ \\
\hline Helicópteros civiles & $\square$ & $\square$ & $\square$ & $\square$ & $\square$ & $\square$ & $\square$ & $\square$ & $\square$ & $\square$ & $\square$ & $\square$ \\
\hline Aeronaves militares & $\square$ & $\square$ & $\square$ & $\square$ & $\square$ & $\square$ & $\square$ & $\square$ & $\square$ & $\square$ & $\square$ & $\square$ \\
\hline Avionetas, ultraligeros... & $\square$ & $\square$ & $\square$ & $\square$ & $\square$ & $\square$ & $\square$ & $\square$ & $\square$ & $\square$ & $\square$ & $\square$ \\
\hline Otros & $\square$ & $\square$ & $\square$ & $\square$ & $\square$ & $\square$ & $\square$ & $\square$ & $\square$ & $\square$ & $\square$ & $\square$ \\
\hline
\end{tabular}

Escriba, si lo desea, algún comentario o especifique el tipo de ruidos que le molestan y que no hayan sido contemplados:

\section{VECINOS}

Refiriéndose al ruido producido por vecinosy pensando en los últimos 12 meses aproximadamente...

¿Podría indicar la molestia que le ocasiona el ruido producido por las distintas actividades mostradas cuando está en el interior de su vivienda?

\begin{tabular}{|c|c|c|c|c|c|c|c|c|c|c|c|c|}
\hline & 0 & 1 & 2 & 3 & 4 & 5 & 6 & 7 & 8 & 9 & 10 & $\begin{array}{c}\text { No lo } \\
\text { oigo }\end{array}$ \\
\hline $\begin{array}{c}\text { Fiestas en zonas comunes o } \\
\text { terrazas }\end{array}$ & $\square$ & $\square$ & $\square$ & $\square$ & $\square$ & $\square$ & $\square$ & $\square$ & $\square$ & $\square$ & $\square$ & $\square$ \\
\hline
\end{tabular}

I2A2 - Universidad Politécnica de Madrid 


\begin{tabular}{|c|c|c|c|c|c|c|c|c|c|c|c|c|}
\hline \multicolumn{13}{|c|}{ ncuesta de investigación sobre el Ruido Urbano } \\
\hline $\begin{array}{c}\text { Piscina, actividades } \\
\text { deportivas }\end{array}$ & $\square$ & $\square$ & $\square$ & $\square$ & $\square$ & $\square$ & $\square$ & $\square$ & $\square$ & $\square$ & $\square$ & $\square$ \\
\hline Juegos infantiles & $\square$ & $\square$ & $\square$ & $\square$ & $\square$ & $\square$ & $\square$ & $\square$ & $\square$ & $\square$ & $\square$ & $\square$ \\
\hline $\begin{array}{l}\text { Conversaciones en zonas } \\
\text { comunes o terrazas }\end{array}$ & $\square$ & $\square$ & $\square$ & $\square$ & $\square$ & $\square$ & $\square$ & $\square$ & $\square$ & $\square$ & $\square$ & $\square$ \\
\hline $\begin{array}{c}\text { Maquinaria de jardinería, } \\
\text { bricolaje... }\end{array}$ & $\square$ & $\square$ & $\square$ & $\square$ & $\square$ & $\square$ & $\square$ & $\square$ & $\square$ & $\square$ & $\square$ & $\square$ \\
\hline $\begin{array}{l}\text { Televisión, radio, música, } \\
\text { dispositivos electrónicos... }\end{array}$ & $\square$ & $\square$ & $\square$ & $\square$ & $\square$ & $\square$ & $\square$ & $\square$ & $\square$ & $\square$ & $\square$ & $\square$ \\
\hline Electrodomésticos & $\square$ & $\square$ & $\square$ & $\square$ & $\square$ & $\square$ & $\square$ & $\square$ & $\square$ & $\square$ & $\square$ & $\square$ \\
\hline $\begin{array}{l}\text { Instalaciones (tuberías, } \\
\text { ascensores, aire } \\
\text { acondicionado...) }\end{array}$ & $\square$ & $\square$ & $\square$ & $\square$ & $\square$ & $\square$ & $\square$ & $\square$ & $\square$ & $\square$ & $\square$ & $\square$ \\
\hline $\begin{array}{c}\text { Perros y otros animales } \\
\text { domésticos }\end{array}$ & $\square$ & $\square$ & $\square$ & $\square$ & $\square$ & $\square$ & $\square$ & $\square$ & $\square$ & $\square$ & $\square$ & $\square$ \\
\hline Pisadas y pasos & $\square$ & $\square$ & $\square$ & $\square$ & $\square$ & $\square$ & ע & $\square$ & $\square$ & $\square$ & $\square$ & $\square$ \\
\hline Otros & $\square$ & $\square$ & $\square$ & $\square$ & $\square$ & $\square$ & $\square$ & $\square$ & $\square$ & $\square$ & $\square$ & $\square$ \\
\hline
\end{tabular}

Escriba, si lo desea, algún comentario o especifique el tipo de ruidos que le molestan y que no hayan sido contemplados:

\section{TRÁFICO RODADO}

Refiriéndose al ruido producido por el tráfico rodado y pensando en los últimos 12 meses aproximadamente...

¿Podría indicarnos la molestia que le ocasiona el ruido que producen los diferentes tipos de vehículos cuando está en el interior de su vivienda?

\begin{tabular}{|c|c|c|c|c|c|c|c|c|c|c|c|c|}
\hline & 0 & 1 & 2 & 3 & 4 & 5 & 6 & 7 & 8 & 9 & 10 & $\begin{array}{l}\text { No lo } \\
\text { oigo }\end{array}$ \\
\hline Furgonetas de reparto & $\square$ & $\square$ & $\square$ & $\square$ & $\square$ & $\square$ & $\square$ & $\square$ & $\square$ & $\square$ & $\square$ & $\square$ \\
\hline Autobuses & $\square$ & $\square$ & $\square$ & $\square$ & $\square$ & $\square$ & $\square$ & $\square$ & $\square$ & $\square$ & $\square$ & $\square$ \\
\hline Coches / taxis & $\square$ & $\square$ & $\square$ & $\square$ & $\square$ & $\square$ & $\square$ & $\square$ & $\square$ & $\square$ & $\square$ & $\square$ \\
\hline Motos & $\square$ & $\square$ & $\square$ & $\square$ & $\square$ & $\square$ & $\square$ & $\square$ & $\square$ & $\square$ & $\square$ & $\square$ \\
\hline $\begin{array}{l}\text { Vehículos de recogida de } \\
\text { residuos }\end{array}$ & $\square$ & $\square$ & $\square$ & $\square$ & $\square$ & $\square$ & $\square$ & $\square$ & $\square$ & $\square$ & $\square$ & $\square$ \\
\hline Otros & $\square$ & $\square$ & $\square$ & $\square$ & $\square$ & $\square$ & $\square$ & $\square$ & $\square$ & $\square$ & $\square$ & $\square$ \\
\hline
\end{tabular}

Escriba, si lo desea, algún comentario o especifique el tipo de ruidos que le molestan y que no hayan sido contemplados:

I2A2 - Universidad Politécnica de Madrid 
Encuesta de investigación sobre el Ruido Urbano RUIDO DE CONSTRUCCIÓN, OBRAS Y REFORMAS

Refiriéndose al ruido de construcción, obras y reformas, y pensando aproximadamente en los últimos 12 meses..

¿Podría indicar la molestia que le ocasiona el ruido producido por las distintas actividades mostradas cuando está en el interior de su vivienda?

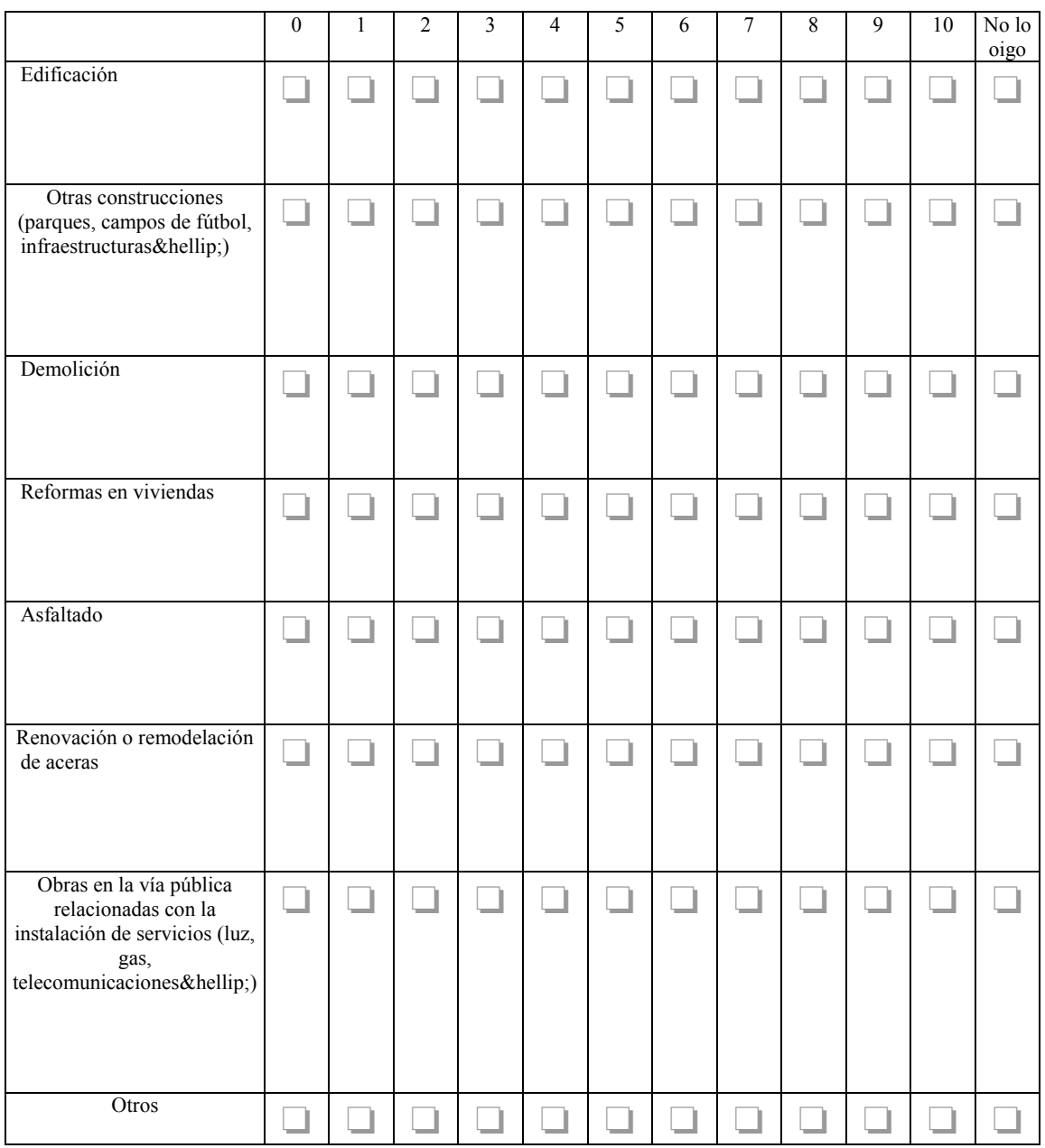

Escriba, si lo desea, algún comentario o especifique el tipo de ruidos que le molestan y que no hayan sido contemplados: 
Encuesta de investigación sobre el Ruido Urbano RUIDO DE ACTIVIDADES COMERCIALES

Refiriéndose al ruido de actividades comerciales y pensando aproximadamente en los últimos 12 meses..

¿Podría indicar la molestia que le ocasiona el ruido producido por las distintas actividades mostradas cuando está en el interior de su vivienda?

\begin{tabular}{|c|c|c|c|c|c|c|c|c|c|c|c|c|}
\hline & 0 & 1 & 2 & 3 & 4 & 5 & 6 & 7 & 8 & 9 & 10 & $\begin{array}{c}\text { No lo } \\
\text { oigo }\end{array}$ \\
\hline Centros comerciales & $\square$ & $\square$ & $\square$ & $\square$ & $\square$ & $\square$ & $\square$ & $\square$ & $\square$ & $\square$ & $\square$ & $\square$ \\
\hline Gasolineras & $\square$ & $\square$ & $\square$ & $\square$ & $\square$ & $\square$ & $\square$ & $\square$ & $\square$ & $\square$ & $\square$ & $\square$ \\
\hline Supermercados & $\square$ & $\square$ & $\square$ & $\square$ & $\square$ & $\square$ & $\square$ & $\square$ & $\square$ & $\square$ & $\square$ & $\square$ \\
\hline Tiendas & $\square$ & $\square$ & $\square$ & $\square$ & $\square$ & $\square$ & $\square$ & $\square$ & $\square$ & $\square$ & $\square$ & $\square$ \\
\hline Rastrillos o mercadillos & $\square$ & $\square$ & $\square$ & $\square$ & $\square$ & $\square$ & $\square$ & $\square$ & $\square$ & $\square$ & $\square$ & $\square$ \\
\hline Puntos limpios & $\square$ & $\square$ & $\square$ & $\square$ & $\square$ & $\square$ & $\square$ & $\square$ & $\square$ & $\square$ & $\square$ & $\square$ \\
\hline Aglomeración de gente en & $\square$ & $\square$ & $\square$ & $\square$ & $\square$ & $\square$ & $\square$ & $\square$ & $\square$ & $\square$ & $\square$ & $\square$ \\
\hline Installaciones de climatización & $\square$ & $\square$ & $\square$ & $\square$ & $\square$ & $\square$ & $\square$ & $\square$ & $\square$ & $\square$ & $\square$ & $\square$ \\
\hline $\begin{array}{c}\text { Operaciones de } \\
\text { mantenimiento }\end{array}$ & $\square$ & $\square$ & $\square$ & $\square$ & $\square$ & $\square$ & $\square$ & $\square$ & $\square$ & $\square$ & $\square$ & $\square$ \\
\hline Carga y descarga & $\square$ & $\square$ & $\square$ & $\square$ & $\square$ & $\square$ & $\square$ & $\square$ & $\square$ & $\square$ & $\square$ & $\square$ \\
\hline Otros & $\square$ & $\square$ & $\square$ & $\square$ & $\square$ & $\square$ & $\square$ & $\square$ & $\square$ & $\square$ & $\square$ & $\square$ \\
\hline
\end{tabular}

Escriba, si lo desea, algún comentario o especifique el tipo de ruidos que le molestan y que no hayan sido contemplados:

\section{RUIDO DEL OCIO}

Refiriéndose al ruido del ocioy pensando aproximadamente en los últimos 12 meses.

¿Podría indicar la molestia que le ocasiona el ruido producido por las distintas actividades mostradas cuando está en el interior de su vivienda?

\begin{tabular}{|c|c|c|c|c|c|c|c|c|c|c|c|c|}
\hline & 0 & 1 & 2 & 3 & 4 & 5 & 6 & 7 & 8 & 9 & 10 & $\begin{array}{c}\text { No lo } \\
\text { oigo }\end{array}$ \\
\hline Espectáculos al aire libre & $\square$ & $\square$ & $\square$ & $\square$ & $\square$ & $\square$ & $\square$ & $\square$ & $\square$ & $\square$ & $\square$ & $\square$ \\
\hline Discotecas & $\square$ & $\square$ & $\square$ & $\square$ & $\square$ & $\square$ & $\square$ & $\square$ & $\square$ & $\square$ & $\square$ & $\square$ \\
\hline Pubs & $\square$ & $\square$ & $\square$ & $\square$ & $\square$ & $\square$ & $\square$ & $\square$ & $\square$ & $\square$ & $\square$ & $\square$ \\
\hline $\begin{array}{c}\text { Prácticas deportivas } \\
\text { Afluencia de gente a eventos } \\
\text { deportivos }\end{array}$ & $\square$ & $\square$ & $\square$ & $\square$ & $\square$ & $\square$ & $\square$ & $\square$ & $\square$ & $\square$ & $\square$ & $\square$ \\
\hline \begin{tabular}{c} 
Salones de juego \\
\hline \begin{tabular}{c} 
Recintos feriales \\
\hline
\end{tabular}
\end{tabular}$\square$ & $\square$ & $\square$ & $\square$ & $\square$ & $\square$ & $\square$ & $\square$ & $\square$ & $\square$ & $\square$ & $\square$ \\
\hline
\end{tabular}

I2A2 - Universidad Politécnica de Madrid 


Encuesta de investigación sobre el Ruido Urbano
\begin{tabular}{|c|c|c|c|c|c|c|c|c|c|c|c|c|}
\hline Bares, restaurantes, terrazas & $\square$ & $\square$ & $\square$ & $\square$ & $\square$ & $\square$ & $\square$ & $\square$ & $\square$ & $\square$ & $\square$ & $\square$ \\
\hline $\begin{array}{c}\text { Acumulación de gente } \\
\text { asociada a bares, restaurantes } \\
\text { y terrazas }\end{array}$ & $\square$ & $\square$ & $\square$ & $\square$ & $\square$ & $\square$ & $\square$ & $\square$ & $\square$ & $\square$ & $\square$ & $\square$ \\
\hline Botellón & $\square$ & $\square$ & $\square$ & $\square$ & $\square$ & $\square$ & $\square$ & $\square$ & $\square$ & $\square$ & $\square$ & $\square$ \\
\hline Parques infantiles & $\square$ & $\square$ & $\square$ & $\square$ & $\square$ & $\square$ & $\square$ & $\square$ & $\square$ & $\square$ & $\square$ & $\square$ \\
\hline $\begin{array}{c}\text { Otras aglomeraciones de } \\
\text { gente }\end{array}$ & $\square$ & $\square$ & $\square$ & $\square$ & $\square$ & $\square$ & $\square$ & $\square$ & $\square$ & $\square$ & $\square$ & $\square$ \\
\hline Otras actividades lúdicas & $\square$ & $\square$ & $\square$ & $\square$ & $\square$ & $\square$ & $\square$ & $\square$ & $\square$ & $\square$ & $\square$ & $\square$ \\
\hline Otros & $\square$ & $\square$ & $\square$ & $\square$ & $\square$ & $\square$ & $\square$ & $\square$ & $\square$ & $\square$ & $\square$ & $\square$ \\
\hline
\end{tabular}

\section{RUIDO DEL OCIO}

Refiriéndose al ruido del ocio y pensando aproximadamente en los últimos 12 meses..

¿Podría indicar la molestia que le ocasionan los distintos tipos de ruido mostrados cuando está en el interior de su vivienda?

\begin{tabular}{|c|c|c|c|c|c|c|c|c|c|c|c|c|}
\hline & 0 & 1 & 2 & 3 & 4 & 5 & 6 & 7 & 8 & 9 & $\begin{array}{l}10 \\
\text { No lo } \\
\text { oigo }\end{array}$ \\
\hline $\begin{array}{c}\text { Fumadores en la puerta de un } \\
\text { bar, restaurante, discoteca... }\end{array}$ & $\square$ & $\square$ & $\square$ & $\square$ & $\square$ & $\square$ & $\square$ & $\square$ & $\square$ & $\square$ & $\square$ & $\square$ \\
\hline Conversaciones & $\square$ & $\square$ & $\square$ & $\square$ & $\square$ & $\square$ & $\square$ & $\square$ & $\square$ & $\square$ & $\square$ & $\square$ \\
\hline Bullicio, cánticos, gritos... & $\square$ & $\square$ & $\square$ & $\square$ & $\square$ & $\square$ & $\square$ & $\square$ & $\square$ & $\square$ & $\square$ & $\square$ \\
\hline Riñas, peleas & $\square$ & $\square$ & $\square$ & $\square$ & $\square$ & $\square$ & $\square$ & $\square$ & $\square$ & $\square$ & $\square$ & $\square$ \\
\hline Música & $\square$ & $\square$ & $\square$ & $\square$ & $\square$ & $\square$ & $\square$ & $\square$ & $\square$ & $\square$ & $\square$ & $\square$ \\
\hline Arrastre de sillas & $\square$ & $\square$ & $\square$ & $\square$ & $\square$ & $\square$ & $\square$ & $\square$ & $\square$ & $\square$ & $\square$ & $\square$ \\
\hline Niños jugando & $\square$ & $\square$ & $\square$ & $\square$ & $\square$ & $\square$ & $\square$ & $\square$ & $\square$ & $\square$ & $\square$ & $\square$ \\
\hline Golpes, balonazos... & $\square$ & $\square$ & $\square$ & $\square$ & $\square$ & $\square$ & $\square$ & $\square$ & $\square$ & $\square$ & $\square$ & $\square$ \\
\hline Otras actividades cotidianas & $\square$ & $\square$ & $\square$ & $\square$ & $\square$ & $\square$ & $\square$ & $\square$ & $\square$ & $\square$ & $\square$ & $\square$ \\
\hline Otros actos incívicos & $\square$ & $\square$ & $\square$ & $\square$ & $\square$ & $\square$ & $\square$ & $\square$ & $\square$ & $\square$ & $\square$ & $\square$ \\
\hline Otros & $\square$ & $\square$ & $\square$ & $\square$ & $\square$ & $\square$ & $\square$ & $\square$ & $\square$ & $\square$ & $\square$ & $\square$ \\
\hline
\end{tabular}

Escriba, si lo desea, algún comentario o especifique el tipo de ruidos que le molestan y que no hayan sido contemplados: 
Encuesta de investigación sobre el Ruido Urbano RUIDO DEL OCIO

Refiriéndose al ruido del ocio y pensando aproximadamente en los últimos 12 meses...

¿Con qué frecuencia participa usted en las siguientes actividades?

\begin{tabular}{|c|c|c|c|}
\hline & Muy a menudo & Alguna vez & $\begin{array}{c}\text { Nunca o casi } \\
\text { nunca }\end{array}$ \\
\hline Parques infantiles & $\square$ & $\square$ & $\square$ \\
\hline Espectáculos al aire libre & $\square$ & $\square$ & $\square$ \\
\hline Bares, restaurantes y terrazas & $\square$ & $\square$ & $\square$ \\
\hline Pubs, discotecas & $\square$ & $\square$ & $\square$ \\
\hline Práctica de deportes colectivos & $\square$ & $\square$ & $\square$ \\
\hline Cine, teatro... & $\square$ & $\square$ & $\square$ \\
\hline
\end{tabular}

\section{RUIDO DE SERVICIOS PÚBLICOS}

Refiriéndose al ruido de servicios públicos y pensando aproximadamente en los últimos 12 meses..

¿Podría indicarnos el grado de molestia que le ocasiona el ruido que producen los diferentes tipos de actividad enumeradas cuando se encuentra en el interior de su vivienda?

\begin{tabular}{|c|c|c|c|c|c|c|c|c|c|c|c|c|}
\hline $\begin{array}{c}\text { Barredoras y otros vehículos } \\
\text { de limpieza }\end{array}$ & $\square$ & 1 & 2 & 3 & 4 & 5 & 6 & 7 & 8 & 9 & 10 & $\begin{array}{c}\text { No lo } \\
\text { oigo }\end{array}$ \\
\hline $\begin{array}{c}\text { Recogida de residuos urbanos } \\
\text { (basura, reciclaje) }\end{array}$ & $\square$ & $\square$ & $\square$ & $\square$ & $\square$ & $\square$ & $\square$ & $\square$ & $\square$ & $\square$ & $\square$ & $\square$ \\
\hline \begin{tabular}{c} 
Otros servicios de limpieza \\
\hline Jardinería
\end{tabular} & $\square$ & $\square$ & $\square$ & $\square$ & $\square$ & $\square$ & $\square$ & $\square$ & $\square$ & $\square$ & $\square$ & $\square$ \\
\hline $\begin{array}{c}\text { Centros educativos (timbres, } \\
\text { patio..) }\end{array}$ & $\square$ & $\square$ & $\square$ & $\square$ & $\square$ & $\square$ & $\square$ & $\square$ & $\square$ & $\square$ & $\square$ & $\square$ \\
\hline $\begin{array}{c}\text { Centros sanitarios } \\
\text { Estaciones de bomberos }\end{array}$ & $\square$ & $\square$ & $\square$ & $\square$ & $\square$ & $\square$ & $\square$ & $\square$ & $\square$ & $\square$ & $\square$ & $\square$ \\
\hline \begin{tabular}{c} 
Comisarias \\
\hline Edificios religiosos
\end{tabular} & $\square$ & $\square$ & $\square$ & $\square$ & $\square$ & $\square$ & $\square$ & $\square$ & $\square$ & $\square$ & $\square$ & $\square$ \\
\hline Otros & $\square$ & $\square$ & $\square$ & $\square$ & $\square$ & $\square$ & $\square$ & $\square$ & $\square$ & $\square$ & $\square$ \\
\hline
\end{tabular}

Escriba, si lo desea, algún comentario o especifique el tipo de ruidos que le molestan y que no hayan sido contemplados: 
Encuesta de investigación sobre el Ruido Urbano OTROS RUIDOS

Refiriéndose otros ruidos y pensando aproximadamente en los últimos 12 meses...

¿Podría precisar a qué tipo de ruidos se refiere?

¿Podría indicarnos la molestia que le ocasiona el ruido que producen cuando se encuentra en el interior de su vivienda?

\begin{tabular}{|c|c|c|c|c|c|c|c|c|c|c|c|c|}
\hline & 0 & 1 & 2 & 3 & 4 & 5 & 6 & 7 & 8 & 9 & 10 & $\begin{array}{c}\text { No lo } \\
\text { oigo }\end{array}$ \\
\hline Ruido 1 & $\square$ & $\square$ & $\square$ & $\square$ & $\square$ & $\square$ & $\square$ & $\square$ & $\square$ & $\square$ & $\square$ & $\square$ \\
\hline Ruido 2 & $\square$ & $\square$ & $\square$ & $\square$ & $\square$ & $\square$ & $\square$ & $\square$ & $\square$ & $\square$ & $\square$ & $\square$ \\
\hline
\end{tabular}

TIPO DE RUIDO: \$ custom1\}

En referencia al $\$\{$ custom 1$\} ..$

Seleccione un máximo de CINCO palabras que mejor describan su sentimiento cuando escucha ese tipo de ruido:

1. Irritado

2. Ansioso

3. Molesto

4. Cómodo

5. Asustado

6. Preocupado

7. Bien

8. Tenso

9. Sorprendido

10. Estresado

11. Cansado

12. Animado

13. Deprimido

14. Harto

5. Seguro

16. Relajado

17. Furioso

18. Excitado

19. Triste

20. Indispuesto

¿Interfiere ese tipo de ruido a alguna de las actividades que realiza en su casa durante su vida cotidiana?

\begin{tabular}{|c|c|c|}
\hline Ver/escuchar TV, radio o música & Si & No \\
\hline Tener una conversación (incluyendo telefónica) & $\square$ & \\
\hline Leer, escribir o cualquier actividad que requiera un ambiente tranquilo & $\square$ & $\square$ \\
\hline Concentrarme & $\square$ & $\square$ \\
\hline Dormir & $\square$ & $\square$ \\
\hline Descansar & $\square$ & $\square$ \\
\hline Utilizar la casa en general & $\square$ & $\square$ \\
\hline
\end{tabular}

I2A2 - Universidad Politécnica de Madrid 
Encuesta de investigación sobre el Ruido Urbano

\begin{tabular}{|c|c|c|}
\hline Pasar tiempo en el jardín, balcón o terraza & $\square$ & $\square$ \\
\hline Tener las ventanas o puertas abiertas & $\square$ & $\square$ \\
\hline Tener visitas & $\square$ & $\square$ \\
\hline Estar tiempo en casa & $\square$ & $\square$ \\
\hline
\end{tabular}

TIPO DE RUIDO: \$ custom1\}

En referencia al $\$\{$ custom 1$\} \ldots$

¿En qué periodos del día le molesta o incomoda esta fuente de ruido?

Días laborables[,]

\begin{tabular}{|c|c|c|c|c|}
\hline Periodo diurno (7 - 19h) & Si & No & A veces & No lo sé \\
\hline Periodo tarde (19-23h) & $\square$ & $\square$ & $\square$ & \\
\hline Periodo noche (23- 7h) & $\square$ & $\square$ & $\square$ & $\square$ \\
\hline
\end{tabular}

Fines de semana y/o festivos[,]

\begin{tabular}{|c|c|c|c|c|}
\hline & Si & No & A veces & No lo sé \\
\hline Periodo diurno (7 - 19h) & $\square$ & $\square$ & $\square$ & $\square$ \\
\hline Periodo tarde (19-23h) & $\square$ & $\square$ & $\square$ & $\square$ \\
\hline Periodo noche (23- 7h) & $\square$ & $\square$ & $\square$ & $\square$ \\
\hline
\end{tabular}

TIPO DE RUIDO: \$ custom1\}

Refiriéndose al \$\{custom 1$\}$ y pensando aproximadamente en los últimos 12 meses..

¿Con qué frecuencia se produce el ruido que le molesta?

1. Todos o casi todos los dias

2. Alguna vez a la semana

3. Alguna vez al mes

4. Alguna vez a lo largo del año

¿En qué época le molesta más ese tipo de ruido?

1. Primavera-Verano

2. Otoño-Invierno

3. No hay diferencias

4. Varía

5. No lo sé

¿Diría que el ruido procedente de esa fuente en concreto ha mejorado o empeorado a lo largo de los últimos 5 años?

1. Ha mejorado mucho

2. Ha mejorado algo

3. Ni ha mejorado ni empeorado

4. Ha empeorado algo

5. Ha empeorado mucho

6. No soy capaz de valorarlo

7. No lo sé

¿Hay alguna cuestión en concreto que le gustaría exponer o expresar respecto al ruido procedente de la fuente elegida?

I2A2 - Universidad Politécnica de Madrid 
Encuesta de investigación sobre el Ruido Urbano

¿Considera que su ciudad es tranquila?

1. Sí

2. No

\section{RED DE MONITORADO DE RUIDO}

El Ayuntamiento ha instalado recientemente un sistema de monitorado de ruido en Málaga, ¿conocía usted su existencia?

1. $\mathrm{Si}$

2. No

\section{RED DE MONITORADO DE RUIDO}

En relación al sistema de monitorado instalado en Málaga...

¿Se ha conectado a la aplicación web/móvil?

1. Sí, me he conectado más de una vez

2. Sí, me he conectado una vez y me volveré a conectar en el futuro

3. Sí, me he conectado únicamente para conocer la iniciativa

4. No, pero me conectaré en el futuro

5. No, porque no conocía la aplicación

6. No, porque no me resulta interesante

\section{RED DE MONITORADO DE RUIDO}

En relación al sistema de monitorado instalado en Málaga...

¿Cuáles de los siguientes objetivos considera que cubre esta iniciativa?

1. Informar a la población sobre los niveles de ruido a que está expuesta

2. Concienciar a las personas o actividades que generan ruido

3. Remitir quejas sobre el ruido

4. Concienciar a la administración sobre los niveles de ruido a los que está expuesta la población

5. Otros (especificar)

¿Que carencias encuentra en la aplicación que deberían ser incluidas en el futuro?

\section{PARA FINALIZAR}

Su perfil se ajusta perfectamente a los objetivos de la investigación, y es por este motivo por el que necesitaríamos conocer su dirección postal (calle y número). Sólo la UPM accederá a dicha información, y únicamente con fines científicos. ¿Desea facilitarnos su dirección postal para mejorar los resultados del estudio?

$$
\text { 1. } \mathrm{Si}
$$

PARA FINALIZAR

A continuación se muestra un mapa en el que se muestran las posiciones donde está previsto ubicar los monitores de ruido en Málaga.¿Podría indicarnos el número de monitor más cercano a su vivienda?

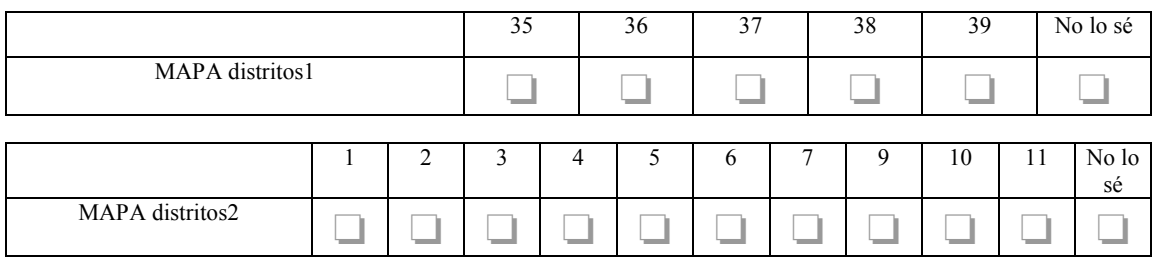

I2A2 - Universidad Politécnica de Madrid 
Encuesta de investigación sobre el Ruido Urbano

\begin{tabular}{|c|c|c|c|c|c|c|c|c|c|c|c|c|c|c|c|c|c|c|c|c|c|c|c|c|c|c|}
\hline & 2 & 3 & 4 & 5 & 6 & & 7 & 9 & 10 & 11 & 12 & 14 & 15 & 16 & 18 & 19 & 22 & 25 & 28 & 29 & 30 & 31 & 32 & 33 & 34 & $\begin{array}{c}\text { No } \\
\text { lo } \\
\text { sé }\end{array}$ \\
\hline $\begin{array}{c}\text { MAPA } \\
\text { distritos3 }\end{array}$ & $\square$ & $\square$ & $\square$ & $\square$ & $\square$ & & $\square$ & $\square$ & $\square$ & $\square$ & $\square$ & $\square$ & $\square$ & $\square$ & $\square$ & $\square$ & $\square$ & $\square$ & $\square$ & $\square$ & $\square$ & $\square$ & $\square$ & $\square$ & $\square$ & $\square$ \\
\hline
\end{tabular}

PARA FINALIZAR

¿Podría valorar la encuesta?

\begin{tabular}{l} 
¿Podría valorar la encuesta? \\
\hline Valoración: \\
\hline
\end{tabular}

A lo largo de la investigación es posible que volvamos a necesitar su ayuda. ¿Nos da su consentimiento para contactar nuevamente con usted en relación a esta Investigación sobre el Ruido?

1. Si, sólo con este fin

2. No

1. Encuesta sobre Ruido Urbano - UPM

I2A2 - Universidad Politécnica de Madrid

$\cdots$ 



\section{Apéndice D: Descriptivos de las encuestas}

\begin{tabular}{|c|c|c|c|}
\hline Variable & Categorías & PRE & POST \\
\hline \multirow{2}{*}{ SD1 } & hombre & $15(44.1 \%)$ & $44(66.7 \%)$ \\
\hline & mujer & $19(55.9 \%)$ & $22(33.3 \%)$ \\
\hline \multirow{9}{*}{ SD2 } & $18-19$ & $0(0.0 \%)$ & $0(0.0 \%)$ \\
\hline & $20-24$ & $5(14.3 \%)$ & $1(1.5 \%)$ \\
\hline & $25-34$ & $10(28.6 \%)$ & $9(13.4 \%)$ \\
\hline & $35-44$ & $9(25.7 \%)$ & $26(38.8 \%)$ \\
\hline & $45-54$ & $6(17.1 \%)$ & $20(29.8 \%)$ \\
\hline & $55-64$ & $3(8.6 \%)$ & $10(14.9 \%)$ \\
\hline & $65-74$ & $0(0.0 \%)$ & $1(1.5 \%)$ \\
\hline & 75 o más & $1(2.9 \%)$ & $0(0.0 \%)$ \\
\hline & prefiero no contestar & $1(2.9 \%)$ & $0(0.0 \%)$ \\
\hline \multirow{4}{*}{ SD3 } & Español & $35(100.0 \%)$ & $66(98.5 \%)$ \\
\hline & Europeo & $0(0.0 \%)$ & $0(0.0 \%)$ \\
\hline & Otra & $0(0.0 \%)$ & $0(0.0 \%)$ \\
\hline & Prefiero no contestar & $0(0.0 \%)$ & $1(1.5 \%)$ \\
\hline \multirow{7}{*}{ SD4 } & Sin estudios & $0(0.0 \%)$ & $0(0.0 \%)$ \\
\hline & Educacion primaria & $0(0.0 \%)$ & $0(0.0 \%)$ \\
\hline & Educacion secundaria & $2(6.1 \%)$ & $2(3.0 \%)$ \\
\hline & Bachillerato-Formacion profesional & $6(18.2 \%)$ & $18(26.9 \%)$ \\
\hline & Estudios superiores no universitarios & $1(3.0 \%)$ & $5(7.5 \%)$ \\
\hline & Estudios superiores universitarios & $21(63.6 \%)$ & $42(62.7 \%)$ \\
\hline & Prefiero no contestar & $3(9.1 \%)$ & $0(0.0 \%)$ \\
\hline \multirow{8}{*}{ SD5 } & Trabajo a tiempo completo & $16(48.5 \%)$ & $51(76.1 \%)$ \\
\hline & Trabajo a tiempo parcial & $0(0.0 \%)$ & $2(3.0 \%)$ \\
\hline & Desempleado o buscando empleo & $4(12.1 \%)$ & $11(16.4 \%)$ \\
\hline & Retirado o jubilado & $1(3.0 \%)$ & $1(1.5 \%)$ \\
\hline & Estudiante & $7(21.2 \%)$ & $1(1.5 \%)$ \\
\hline & Labores del hogar & $3(9.1 \%)$ & $1(1.5 \%)$ \\
\hline & Prefiero no contestar & $1(3.0 \%)$ & $0(0.0 \%)$ \\
\hline & Otra & $1(3.0 \%)$ & $0(0.0 \%)$ \\
\hline \multirow{7}{*}{ SD7 } & Menos de 6 meses & $0(0.0 \%)$ & $0(0.0 \%)$ \\
\hline & De 6 meses a 1 año & $3(8.8 \%)$ & $1(1.5 \%)$ \\
\hline & De 1 a 2 años & $1(2.9 \%)$ & $1(1.5 \%)$ \\
\hline & De 2 a 5 años & $8(23.5 \%)$ & $2(3.0 \%)$ \\
\hline & De 5 a 10 años & $3(8.8 \%)$ & $4(6.0 \%)$ \\
\hline & Mas de 10 años & $8(23.5 \%)$ & $27(40.3 \%)$ \\
\hline & Desde siempre & $11(32.4 \%)$ & $32(47.8 \%)$ \\
\hline \multirow{12}{*}{ RR1 } & 0 & $0(0.0 \%)$ & $0(0.0 \%)$ \\
\hline & 1 & $0(0.0 \%)$ & $1(1.5 \%)$ \\
\hline & 2 & $0(0.0 \%)$ & $2(3.0 \%)$ \\
\hline & 3 & $4(11.4 \%)$ & $4(6.0 \%)$ \\
\hline & 4 & $3(8.6 \%)$ & $3(4.5 \%)$ \\
\hline & 5 & $7(20.0 \%)$ & $18(26.9 \%)$ \\
\hline & 6 & $5(14.3 \%)$ & $6(9.0 \%)$ \\
\hline & 7 & $8(22.9 \%)$ & $10(14.9 \%)$ \\
\hline & 8 & $2(5.7 \%)$ & $5(7.5 \%)$ \\
\hline & 9 & $4(11.4 \%)$ & $2(3.0 \%)$ \\
\hline & 10 & $2(5.7 \%)$ & $16(23.9 \%)$ \\
\hline & No lo se & $0(0.0 \%)$ & $0(0.0 \%)$ \\
\hline \multirow{7}{*}{ RR2 } & 0 & $0(0.0 \%)$ & $0(0.0 \%)$ \\
\hline & 1 & $0(0.0 \%)$ & $0(0.0 \%)$ \\
\hline & 2 & $0(0.0 \%)$ & $0(0.0 \%)$ \\
\hline & 3 & $0(0.0 \%)$ & $0(0.0 \%)$ \\
\hline & 4 & $1(2.9 \%)$ & $0(0.0 \%)$ \\
\hline & 5 & $4(11.4 \%)$ & $1(1.5 \%)$ \\
\hline & 6 & $0(0.0 \%)$ & $1(1.5 \%)$ \\
\hline
\end{tabular}




\begin{tabular}{|c|c|c|c|}
\hline Variable & Categorías & PRE & POST \\
\hline & 7 & $6(17.1 \%)$ & $0(0.0 \%)$ \\
\hline & 8 & $9(25.7 \%)$ & $8(11.9 \%)$ \\
\hline & 9 & $3(8.6 \%)$ & $13(19.4 \%)$ \\
\hline & 10 & $12(34.3 \%)$ & $44(65.7 \%)$ \\
\hline & No lo se & $0(0.0 \%)$ & $0(0.0 \%)$ \\
\hline \multirow{2}{*}{ RR3 } & $\mathrm{Si}$ & $1(2.9 \%)$ & $23(34.3 \%)$ \\
\hline & No & $34(97.1 \%)$ & $44(65.7 \%)$ \\
\hline \multirow{5}{*}{ RR4 } & Extremadamente & $6(17.1 \%)$ & $29(43.3 \%)$ \\
\hline & Mucho & $9(25.7 \%)$ & $36(53.7 \%)$ \\
\hline & Medianamente & $13(37.1 \%)$ & $2(3.0 \%)$ \\
\hline & Ligeramente & $4(11.4 \%)$ & $0(0.0 \%)$ \\
\hline & Absolutamente nada & $3(8.6 \%)$ & $0(0.0 \%)$ \\
\hline \multirow{12}{*}{$R R 5_{\text {trodado }}$} & 0 & $4(11.4 \%)$ & $7(10.4 \%)$ \\
\hline & 1 & $1(2.9 \%)$ & $5(7.5 \%)$ \\
\hline & 2 & $6(17.1 \%)$ & $4(6.0 \%)$ \\
\hline & 3 & $6(17.1 \%)$ & $13(19.4 \%)$ \\
\hline & 4 & $4(11.4 \%)$ & $2(3.0 \%)$ \\
\hline & 5 & $2(5.7 \%)$ & $11(16.4 \%)$ \\
\hline & 6 & $4(11.4 \%)$ & $4(6.0 \%)$ \\
\hline & 7 & $4(11.4 \%)$ & $6(9.0 \%)$ \\
\hline & 8 & $2(5.7 \%)$ & $5(7.5 \%)$ \\
\hline & 9 & $0(0.0 \%)$ & $2(3.0 \%)$ \\
\hline & 10 & $0(0.0 \%)$ & $7(10.4 \%)$ \\
\hline & Nunca lo oigo & $2(5.7 \%)$ & $1(1.5 \%)$ \\
\hline \multirow{12}{*}{$R R 5_{\text {obras }}$} & 0 & $6(17.1 \%)$ & $16(23.9 \%)$ \\
\hline & 1 & $4(11.4 \%)$ & $6(9.0 \%)$ \\
\hline & 2 & $3(8.6 \%)$ & $10(14.9 \%)$ \\
\hline & 3 & $3(8.6 \%)$ & $3(4.5 \%)$ \\
\hline & 4 & $3(8.6 \%)$ & $5(7.5 \%)$ \\
\hline & 5 & $3(8.6 \%)$ & $6(9.0 \%)$ \\
\hline & 6 & $3(8.6 \%)$ & $7(10.4 \%)$ \\
\hline & 7 & $2(5.7 \%)$ & $5(7.5 \%)$ \\
\hline & 8 & $2(5.7 \%)$ & $5(7.5 \%)$ \\
\hline & 9 & $3(8.6 \%)$ & $0(0.0 \%)$ \\
\hline & 10 & $3(8.6 \%)$ & $4(6.0 \%)$ \\
\hline & Nunca lo oigo & $0(0.0 \%)$ & $0(0.0 \%)$ \\
\hline \multirow{12}{*}{$R R 5_{\text {actcomerciales }}$} & 0 & $13(37.1 \%)$ & $17(25.4 \%)$ \\
\hline & 1 & $3(8.6 \%)$ & $5(7.5 \%)$ \\
\hline & 2 & $3(8.6 \%)$ & $3(4.5 \%)$ \\
\hline & 3 & $3(8.6 \%)$ & $3(4.5 \%)$ \\
\hline & 4 & $3(8.6 \%)$ & $3(4.5 \%)$ \\
\hline & 5 & $2(5.7 \%)$ & $10(14.9 \%)$ \\
\hline & 6 & $3(8.6 \%)$ & $5(7.5 \%)$ \\
\hline & 7 & $1(2.9 \%)$ & $3(4.5 \%)$ \\
\hline & 8 & $0(0.0 \%)$ & $2(3.0 \%)$ \\
\hline & 9 & $1(2.9 \%)$ & $0(0.0 \%)$ \\
\hline & 10 & $2(5.7 \%)$ & $12(17.9 \%)$ \\
\hline & Nunca lo oigo & $1(2.9 \%)$ & $4(6.0 \%)$ \\
\hline \multirow{8}{*}{$R R 5_{\text {ocio }}$} & 0 & $1(2.9 \%)$ & $4(6.0 \%)$ \\
\hline & 1 & $0(0.0 \%)$ & $0(0.0 \%)$ \\
\hline & 2 & $0(0.0 \%)$ & $0(0.0 \%)$ \\
\hline & 3 & $1(2.9 \%)$ & $1(1.5 \%)$ \\
\hline & 4 & $0(0.0 \%)$ & $0(0.0 \%)$ \\
\hline & 5 & $2(5.7 \%)$ & $1(1.5 \%)$ \\
\hline & 6 & $3(8.6 \%)$ & $1(1.5 \%)$ \\
\hline & 7 & $4(11.4 \%)$ & $1(1.5 \%)$ \\
\hline
\end{tabular}




\begin{tabular}{|c|c|c|c|}
\hline Variable & Categorías & PRE & POST \\
\hline & 8 & $3(8.6 \%)$ & $5(7.5 \%)$ \\
\hline & 9 & $4(11.4 \%)$ & $8(11.9 \%)$ \\
\hline & 10 & $17(48.6 \%)$ & $46(68.7 \%)$ \\
\hline & Nunca lo oigo & $0(0.0 \%)$ & $0(0.0 \%)$ \\
\hline \multirow{12}{*}{$R R 5_{\text {servicios }}$} & 0 & $10(28.6 \%)$ & $6(9.0 \%)$ \\
\hline & 1 & $3(8.6 \%)$ & $6(9.0 \%)$ \\
\hline & 2 & $6(17.1 \%)$ & $4(6.0 \%)$ \\
\hline & 3 & $3(8.6 \%)$ & $5(7.5 \%)$ \\
\hline & 4 & $0(0.0 \%)$ & $2(3.0 \%)$ \\
\hline & 5 & $5(14.3 \%)$ & $5(7.5 \%)$ \\
\hline & 6 & $0(0.0 \%)$ & $3(4.5 \%)$ \\
\hline & 7 & $2(5.7 \%)$ & $5(7.5 \%)$ \\
\hline & 8 & $1(2.9 \%)$ & $12(17.9 \%)$ \\
\hline & 9 & $3(8.6 \%)$ & $2(3.0 \%)$ \\
\hline & 10 & $1(2.9 \%)$ & $16(23.9 \%)$ \\
\hline & Nunca lo oigo & $1(2.9 \%)$ & $1(1.5 \%)$ \\
\hline \multirow{12}{*}{$R R 5_{\text {vecinos }}$} & 0 & $8(22.9 \%)$ & $18(26.9 \%)$ \\
\hline & 1 & $5(14.3 \%)$ & $5(7.5 \%)$ \\
\hline & 2 & $2(5.7 \%)$ & $10(14.9 \%)$ \\
\hline & 3 & $3(8.6 \%)$ & $8(11.9 \%)$ \\
\hline & 4 & $1(2.9 \%)$ & $3(4.5 \%)$ \\
\hline & 5 & $4(11.4 \%)$ & $9(13.4 \%)$ \\
\hline & 6 & $3(8.6 \%)$ & $5(7.5 \%)$ \\
\hline & 7 & $2(5.7 \%)$ & $2(3.0 \%)$ \\
\hline & 8 & $3(8.6 \%)$ & $3(4.5 \%)$ \\
\hline & 9 & $1(2.9 \%)$ & $3(4.5 \%)$ \\
\hline & 10 & $2(5.7 \%)$ & $1(1.5 \%)$ \\
\hline & Nunca lo oigo & $1(2.9 \%)$ & $0(0.0 \%)$ \\
\hline \multirow{12}{*}{$R R 5_{\text {otros }}$} & 0 & $11(31.4 \%)$ & $17(25.4 \%)$ \\
\hline & 1 & $0(0.0 \%)$ & $5(7.5 \%)$ \\
\hline & 2 & $0(0.0 \%)$ & $2(3.0 \%)$ \\
\hline & 3 & $3(8.6 \%)$ & $5(7.5 \%)$ \\
\hline & 4 & $2(5.7 \%)$ & $6(9.0 \%)$ \\
\hline & 5 & $8(22.9 \%)$ & $7(10.4 \%)$ \\
\hline & 6 & $0(0.0 \%)$ & $2(3.0 \%)$ \\
\hline & 7 & $2(5.7 \%)$ & $3(4.5 \%)$ \\
\hline & 8 & $0(0.0 \%)$ & $3(4.5 \%)$ \\
\hline & 9 & $0(0.0 \%)$ & $0(0.0 \%)$ \\
\hline & 10 & $6(17.1 \%)$ & $14(20.9 \%)$ \\
\hline & Nunca lo oigo & $3(8.6 \%)$ & $3(4.5 \%)$ \\
\hline \multirow{2}{*}{ TFR1 } & $\mathrm{Si}$ & $19(54.3 \%)$ & $61(91.0 \%)$ \\
\hline & No & $16(45.7 \%)$ & $6(9.0 \%)$ \\
\hline \multirow{14}{*}{ TFR2 } & 0 & $2(5.7 \%)$ & $1(1.5 \%)$ \\
\hline & 1 & $2(5.7 \%)$ & $0(0.0 \%)$ \\
\hline & 2 & $3(8.6 \%)$ & $0(0.0 \%)$ \\
\hline & 3 & $7(20.0 \%)$ & $2(3.0 \%)$ \\
\hline & 4 & $1(2.9 \%)$ & $0(0.0 \%)$ \\
\hline & 5 & $3(8.6 \%)$ & $2(3.0 \%)$ \\
\hline & 6 & $6(17.1 \%)$ & $3(4.5 \%)$ \\
\hline & 7 & $2(5.7 \%)$ & $7(10.4 \%)$ \\
\hline & 8 & $3(8.6 \%)$ & $10(14.9 \%)$ \\
\hline & 9 & $2(5.7 \%)$ & $12(17.9 \%)$ \\
\hline & 10 & $4(11.4 \%)$ & $30(44.8 \%)$ \\
\hline & No lo se & $0(0.0 \%)$ & $0(0.0 \%)$ \\
\hline & Ha mejorado mucho & $2(5.7 \%)$ & $0(0.0 \%)$ \\
\hline & Ha mejorado poco & $0(0.0 \%)$ & $0(0.0 \%)$ \\
\hline
\end{tabular}




\begin{tabular}{|c|c|c|c|}
\hline Variable & Categorías & PRE & POST \\
\hline & No ha mejorado ni empeorado & $6(17.1 \%)$ & $5(7.5 \%)$ \\
\hline & Ha empeorado algo & $9(25.7 \%)$ & $3(4.5 \%)$ \\
\hline & Ha empeorado mucho & $9(25.7 \%)$ & $52(77.6 \%)$ \\
\hline & No soy capaz de valorarlo & $2(5.7 \%)$ & $4(6.0 \%)$ \\
\hline & No lo se & $7(20.0 \%)$ & $3(4.5 \%)$ \\
\hline \multirow{10}{*}{ RE1 } & Trafico rodado & $4(11.4 \%)$ & $4(6.1 \%)$ \\
\hline & Construccion, obras, reformas & $2(5.7 \%)$ & $1(1.5 \%)$ \\
\hline & Actividades comerciales & $0(0.0 \%)$ & $1(1.5 \%)$ \\
\hline & Actividades de ocio & $21(60.0 \%)$ & $47(71.2 \%)$ \\
\hline & Servicios & $0(0.0 \%)$ & $6(9.1 \%)$ \\
\hline & Vecinos & $4(11.4 \%)$ & $3(4.5 \%)$ \\
\hline & Otros ruidos & $2(5.7 \%)$ & $4(6.1 \%)$ \\
\hline & No me molesta ninguna fuente de ruido & $2(5.7 \%)$ & $0(0.0 \%)$ \\
\hline & Trafico aereo & $0(0.0 \%)$ & $0(0.0 \%)$ \\
\hline & Trafico ferroviario & $0(0.0 \%)$ & $0(0.0 \%)$ \\
\hline \multirow{2}{*}{ TMR1 } & $\mathrm{Si}$ & \multirow{2}{*}{ Sin valores } & $47(73.4 \%)$ \\
\hline & No & & $17(26.6 \%)$ \\
\hline \multirow{6}{*}{ TMR2 } & Si me he conectado mas de una vez & \multirow{6}{*}{ Sin valores } & $11(22.0 \%)$ \\
\hline & $\begin{array}{l}\text { Si me he conectado una vez y me vol- } \\
\text { vere a conectar }\end{array}$ & & $7(14.0 \%)$ \\
\hline & $\begin{array}{l}\text { Si me he conectado solo para conocer la } \\
\text { iniciativa }\end{array}$ & & $6(12.0 \%)$ \\
\hline & No pero me conectare en el futuro & & $9(18.0 \%)$ \\
\hline & No porque no conocia la aplicacion & & $13(26.0 \%)$ \\
\hline & No porque no me resulta interesante & & $4(8.0 \%)$ \\
\hline
\end{tabular}


The end is just another beginning 
